\title{
A STUDY OF SOME ISSUES RELATED TO SEISMIC DESIGN PROVISIONS OF NATIONAL BUILDING CODE OF CANADA
}

by

\author{
Mohamed Ahmed Mahgoub \\ B. Sc., Al-Azhar University, Cairo, Egypt \\ M. Sc., McMaster University, Hamilton, Ontario, Canada
}

\begin{abstract}
A thesis submitted to the
Faculty of Graduate Studies and Research

In partial fulfilment of the requirements

For the degree of
\end{abstract}

DOCTOR OF PHILOSOPHY

in

Engineering*

Carleton University

Ottawa, Ontario, Canada

September, 2004

CCopyright, Mohamed Ahmed Mahgoub, 2004

*The Doctor of Philosophy in Civil Engineering

is a joint program with University of Ottawa,

administrated by the Ottawa-Carleton Institute for Civil Engineering 


$\begin{array}{ll}\begin{array}{l}\text { Library and } \\ \text { Archives Canada }\end{array} & \begin{array}{l}\text { Bibliothèque et } \\ \text { Archives Canada }\end{array} \\ \begin{array}{l}\text { Published Heritage } \\ \text { Branch }\end{array} & \begin{array}{l}\text { Direction du } \\ \text { Patrimoine de l'édition }\end{array} \\ \begin{array}{l}\text { 395 Wellington Street } \\ \text { Ottawa ON K1A ON4 }\end{array} & \begin{array}{l}\text { 395, rue Wellington } \\ \text { Ottawa ON K1A ON4 } \\ \text { Canada }\end{array}\end{array}$

Your file Votre référence

ISBN: 0-494-00804-0

Ourfile Notre référence

ISBN: 0-494-00804-0

NOTICE:

The author has granted a nonexclusive license allowing Library and Archives Canada to reproduce, publish, archive, preserve, conserve, communicate to the public by telecommunication or on the Internet, loan, distribute and sell theses worldwide, for commercial or noncommercial purposes, in microform, paper, electronic and/or any other formats.

The author retains copyright ownership and moral rights in this thesis. Neither the thesis nor substantial extracts from it may be printed or otherwise reproduced without the author's permission.
AVIS:

L'auteur a accordé une licence non exclusive permettant à la Bibliothèque et Archives Canada de reproduire, publier, archiver, sauvegarder, conserver, transmettre au public par télécommunication ou par l'Internet, prêter, distribuer et vendre des thèses partout dans le monde, à des fins commerciales ou autres, sur support microforme, papier, électronique et/ou autres formats.

L'auteur conserve la propriété du droit d'auteur et des droits moraux qui protège cette thèse. $\mathrm{Ni}$ la thèse ni des extraits substantiels de celle-ci ne doivent être imprimés ou autrement reproduits sans son autorisation.
In compliance with the Canadian

Privacy Act some supporting forms may have been removed from this thesis.

While these forms may be included in the document page count, their removal does not represent any loss of content from the thesis.
Conformément à la loi canadienne sur la protection de la vie privée, quelques formulaires secondaires ont été enlevés de cette thèse.

Bien que ces formulaires aient inclus dans la pagination, il n'y aura aucun contenu manquant.

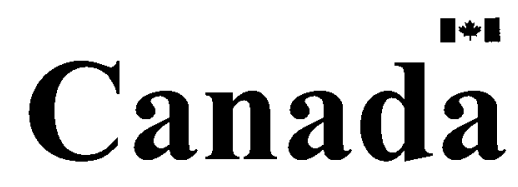




\begin{abstract}
For the design of an earthquake-resistant structure one needs to know the characteristics of the structure under consideration and the seismicity of the region in which the structure is located. New knowledge on the seismicity of Canada and understanding of the structural behaviour under earthquakes have provided the motivation for significant changes in the existing provisions of the National Building Code of Canada (NBCC). This study is related to some of the new seismic design provisions being considered for the next revision of NBCC to be published in 2005 . The study focuses on four different issues associated with the new provisions. The main objectives of the study are: (a) Development of representative values of the higher mode factor for different structural configurations, (b) Review of the NBCC 1995 code provisions procedure for distributing the base shear across the height, (c) Development of adjustment factors to be applied to the overturning moments obtained from the lateral forces determined by the NBCC 1995 distribution, (d) Study of the torsional behavior of single storey and multistorey building models of general class for a range of parameters and investigation of the applicability of single storey results to multistorey buildings, (e) Evaluation of the validity and limitations of the design eccentricity expressions proposed by Humar and Kumar (1998a, and 1998b) to general class of multistorey buildings and to suggest necessary modifications, if any, and (f) Assessment of the significance of P- $\Delta$ effect in a building subjected to earthquakes and development of a method to account for this effect.

A comprehensive study is performed to assess the higher mode effect on multistorey buildings. The equivalent static procedure included in the NBCC is used to obtain the elastic base shear from an elastic Uniform Hazard Spectrum (UHS) and the first mode period of the structure under consideration. Adjustment factors that must be applied to the base shear and overturning moments determined from the first mode period
\end{abstract}


to account for higher mode effects are derived for several different structural types including moment-resisting frames, braced frames, flexural walls, coupled flexural walls and hybrid systems.

A detailed study is performed on the ductility and strength demands in inelastic multistorey buildings, having two types of structural systems: moment-resisting frames, and flexural walls. The models used in this study are subjected to UHS-compatible acceleration time histories corresponding to earthquakes with a return period of 2500 years developed for cities in western and eastern Canada. Modification factors that should be applied to demand parameters derived from SDOF models are derived to account for higher mode effects.

This research also presents the results obtained from analytical studies conducted to study the elastic torsional response of a variety of asymmetric multistorey buildings of general class in which the ratios of torsional to translational stiffness vary significantly along the height of the building. Response spectrum dynamic analysis is carried out to obtain the exact response of the buildings. The results obtained from dynamic analysis are then compared to the results obtained according to design provisions proposed by Humar and Kumar (1998a). The dynamic analysis results are also compared to those of single storey buildings.

Finally, nonlinear static and dynamic analyses are carried out on single and multistorey frames subjected to five different earthquake ground motions to assess the effect of P- $\Delta$. A single storey and a typical 10 -storey moment-resisting steel frames are studied to assess the P- $\Delta$ effect on the seismic response. The effect of strain hardening, ductility and ground motion duration on P- $\Delta$ is also investigated. Proposed equations for calculating amplification factors that must be applied to account for P- $\Delta$ effect in single and multistorey buildings are presented. 
Dedicated to:

my teacher, with gratitude,

my parents, with affection,

my wife and my daughter, with love 


\section{ACKNOWLEDGEMENT}

I have found the preparation of this thesis an enjoyable and rewarding experience. I indeed thank Allah almighty who guided and aided me to bring forth to light the knowledge presented in this thesis. Thanks are due to several people for their involvement during my research.

I am deeply indebted to my supervisor Dr. Jagmohan L. Humar, Professor Emeritus, Department of Civil and Environmental Engineering, Carleton University, for his advice, guidance and support throughout the course of this research. It has been a great honor to work with such a world-class professor. No words can sufficiently express my thanks for his invaluable assistance, comments, and suggestions which were very inspiring. I would like also to thank him for arranging financial support for me through his research grant which enabled me to carry out this research.

Appreciation and sincere thanks are extended to Dr. Mohammad Ali Rahgozar, Dr. Praveen Kumar, and Dr. Ashutosh Bagchi for their help and support in the course of this research. Special thanks are due to Dr. Gail Atkinson for supplying the ground motion time histories. I wish to express my gratitude to the Department of Civil and Environmental Engineering, Carleton University for the award of a teaching assistantship and scholarships, and for providing the needed facilities during the term of my studies. Many thanks are due to faculty, staff, and students whose work at the Department has directly or indirectly contributed to this thesis. I would like to express my profound gratitude to my employer, Alfred Benesch and Company, for providing me with limitless facilities, encouragement and support in the completion of this thesis. Thanks are due to Mr. Albert Kaltenthaler and Mrs. Marianne Smith of Alfred Benesch for their great help and support.

Last but not least, I would like to thank my parents for their encouragement and continuous support. I wish to extend my sincere thanks to my wife, Karen, and my daughter, Nora, for their support, patience, understanding and inspiration. 


\section{TABLE OF CONTENTS}

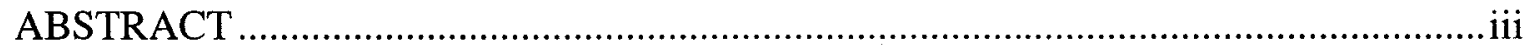

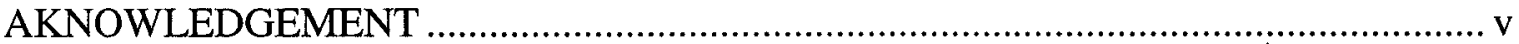

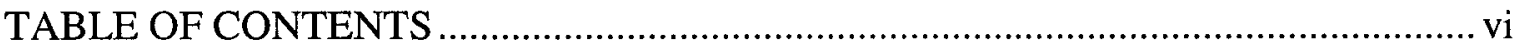

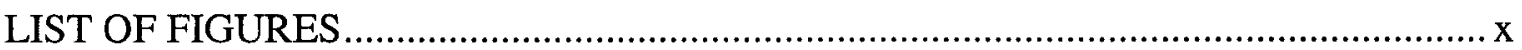

LIST OF TABLES .......................................................................................

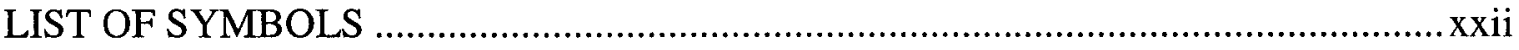

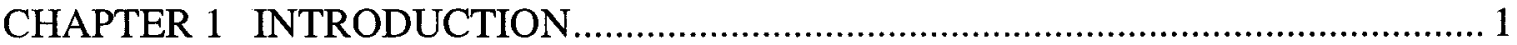

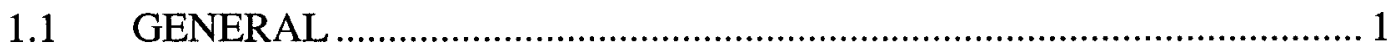

1.2 ISSUES TO BE ADDRESSED IN THE PRESENT STUDY .................. 2

1.2.1 Uniform Hazard Spectrum ................................................... 3

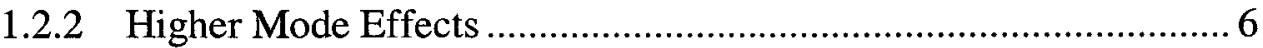

1.2.3 Torsional Response ............................................................... 7

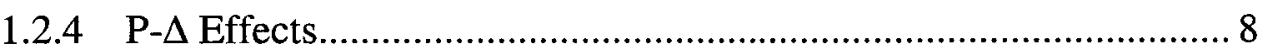

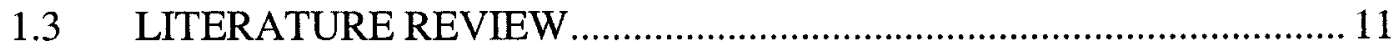

1.3.1 Higher Mode Effects ............................................................. 11

1.3.2 Torsional Response ........................................................... 12

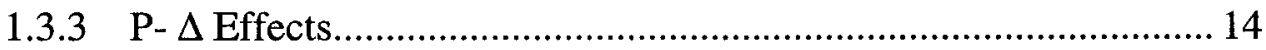

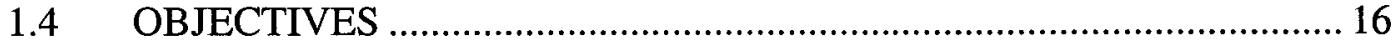

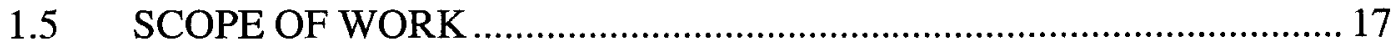

1.6 ORGANIZATION OF THESIS ........................................................ 18

CHAPTER 2 HIGHER MODE EFFECT IN UHS-BASED DESIGN …...................... 26

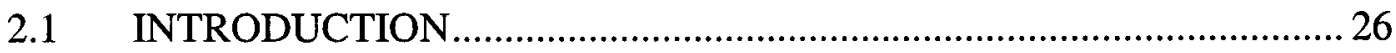

2.2 EFFECT OF HIGHER MODE PARTICIPATION ON BASE SHEAR .. 29

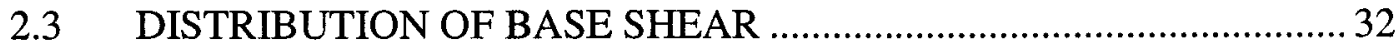

2.4 METHODOLOGY FOR ESTIMATING $M_{v}$ AND $J$ FACTORS............. 33 
2.5 DESCRIPTION OF THE BUILDING MODEL ................................. 35

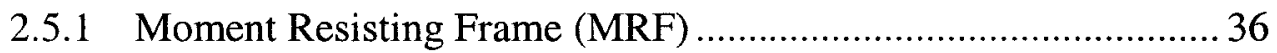

2.5.2 Concentrically Braced Frame................................................ 37

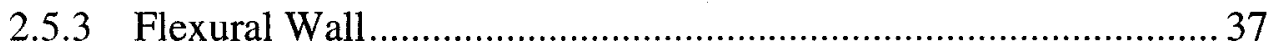

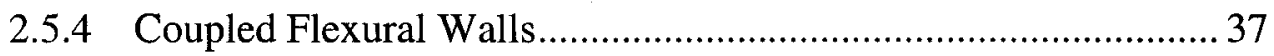

2.5.5 Hybrid Frame-Wall System ................................................... 38

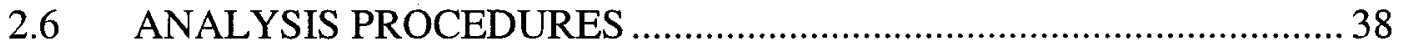

2.7 ANALYTICAL RESULTS AND DISCUSSION .................................. 40

2.7.1 Modal Periods and Modal Masses ........................................... 40

2.7.2 Moment Resisting Frame, Braced Frame, and Flexural Wall...... 41

Base Shear and Base Overturning Moment .............................. 41

Distribution of Shear and Overturning Moment ........................4 45

2.7.3 Coupled Flexural Walls........................................................ 47

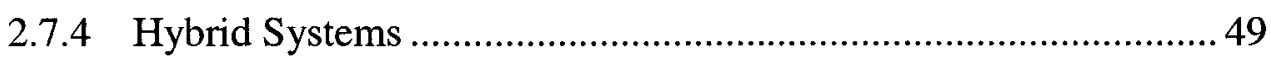

2.8 SUMMARY AND CONCLUSIONS ............................................ 51

CHAPTER 3 ELASTIC TORSIONAL RESPONSE OF ASYMMETRIC

MULTISTOREY BUILDINGS ...................................................... 86

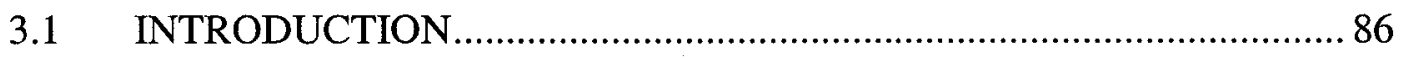

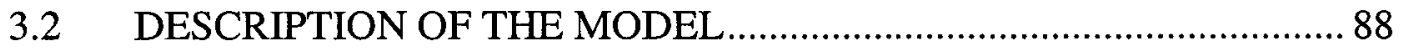

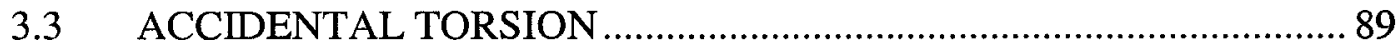

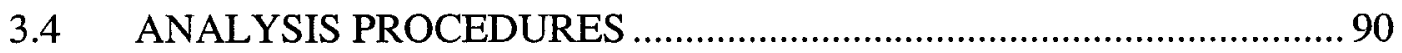

3.4.1 Single Storey Building Model ............................................... 90

3.4.2 Multistorey Building Models of General Class .......................... 96

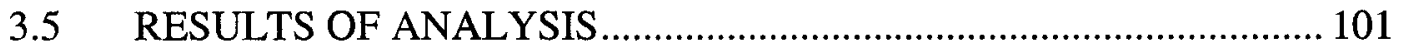

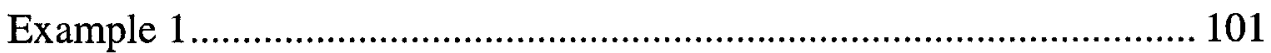

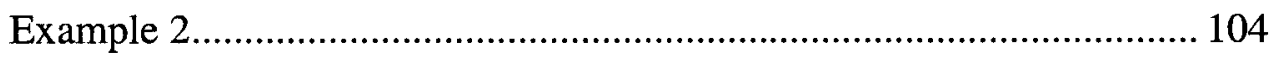

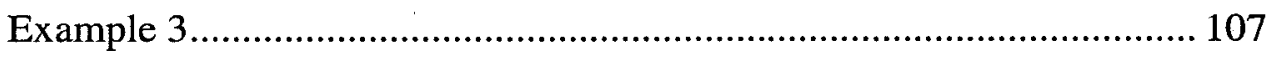

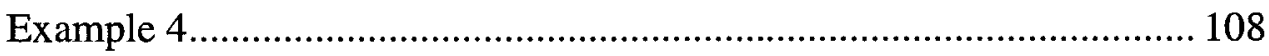

Example 5........................................................................... 109

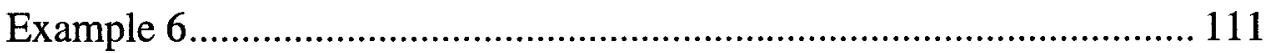


3.6 ALTERNATIVE PROVISIONS TO ACCOUNT FOR TORSIONAL

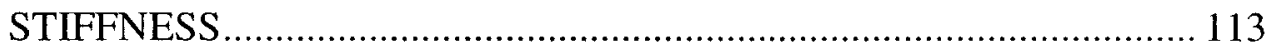

3.7 SUMMARY AND CONCLUSIONS ………………......................... 117

CHAPTER 4 INELASTIC ANALYSIS OF HIGHER MODE EFFECT ................... 152

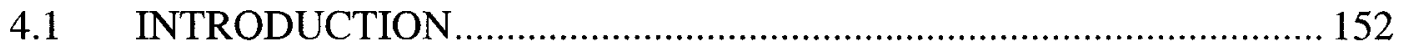

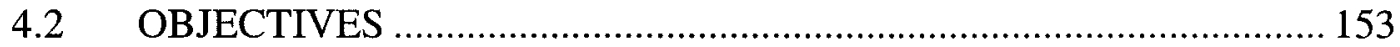

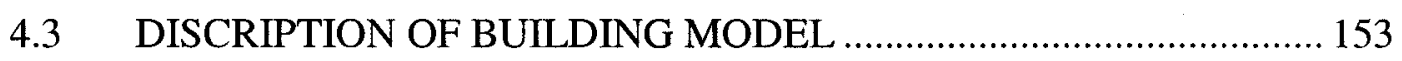

4.3.1 Moment Resisting Frame (MRF) …………………………..... 154

4.3.2 Flexural Wall ........................................................................... 155

4.4 SPECTRUM-COMPATIBLE TIME HISTORIES .................................. 156

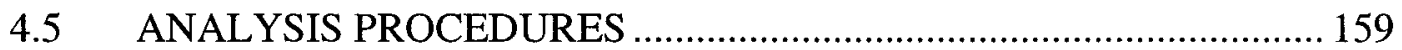

4.5.1 Storey Ductility Ratio................................................................ 159

4.5.2 Storey Ductility Demand .............................................................. 161

4.6 CALCULATION OF THE STRENGTH MODIFICATION FACTOR. 163

4.6.1 Strength Modified for Each Storey ……………………………... 164

4.6.2 Strength Modified for First Storey Only ...................................... 165

4.7 ANALYTICAL RESULTS AND DISCUSSION..................................... 165

4.8 SUMMARY AND CONCLUSIONS ………………………………....... 168

CHAPTER 5 P- $\triangle$ EFFECT ON SEISMIC RESPONSE............................................... 185

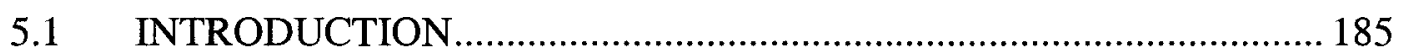

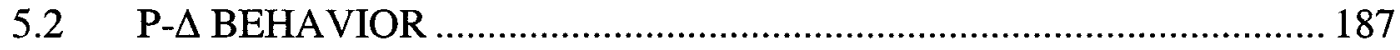

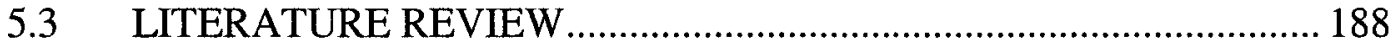

5.4 NBCC CODE PROVISIONS FOR DESIGN AGAINST P- $\triangle$ EFFECT 190

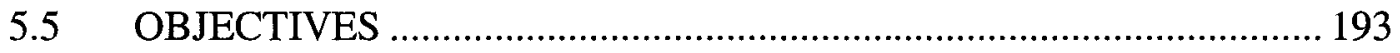

5.6 MODEL AND ANALYSIS PROCEDURES …………………………... 193

5.7 EFFECT OF STRAIN HARDENING ................................................... 198

5.8 COMPENSATING FOR P-A EFFECT, EXAMPLES ……………….... 201

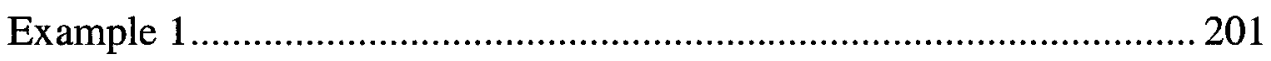

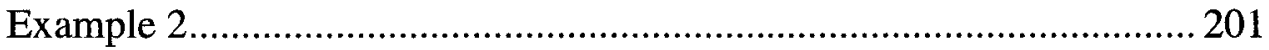




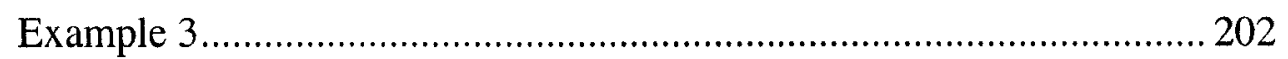

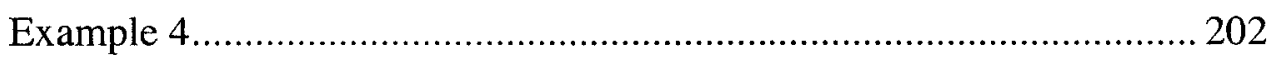

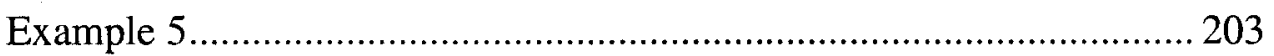

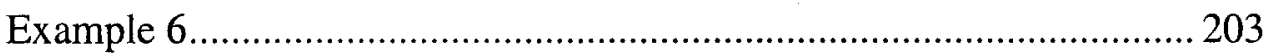

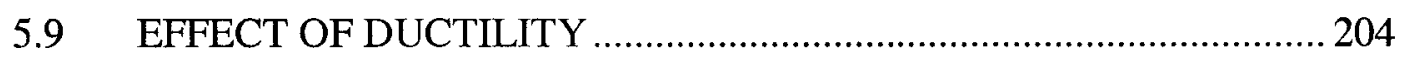

5.10 EFFECT OF GROUND MOTION DURATION ..............................207

5.11 EFFECT OF STRAIN HARDENINIG WITH DIFFERENT GROUND

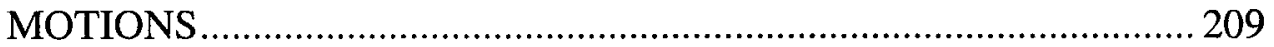

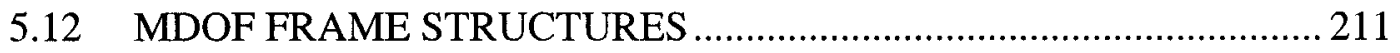

5.13 SUMMARY AND CONCLUSIONS ............................................. 219

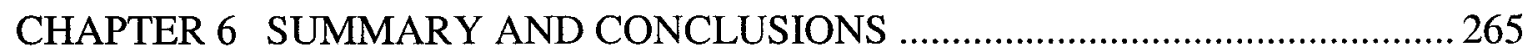

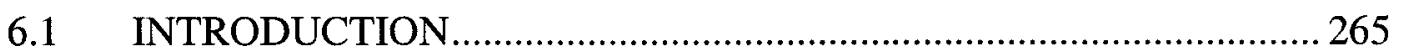

6.1.1 Uniform Hazard Spectrum ................................................266

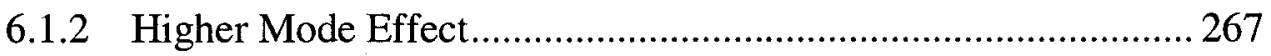

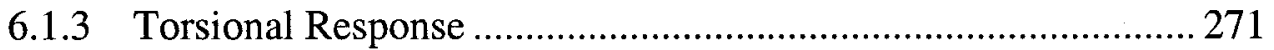

6.1.4 P- $\Delta$ Effect ...................................................................... 272

6.2 RECOMMENDATIONS FOR FUTURE WORK............................ 274

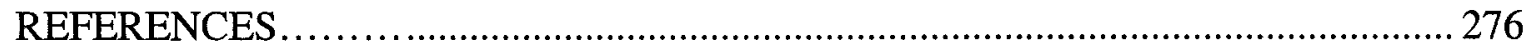




\section{LIST OF FIGURES}

1.1 Construction of an Elastic Uniform Hazard Spectra (UHS) ............................. 23

1.2 Elastic Uniform Hazard Spectra (UHS) for Montreal (East) and Vancouver

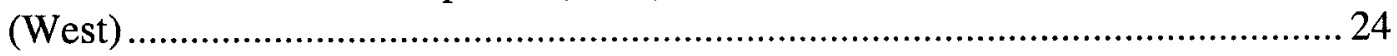

1.3 Lateral force-displacement relationship ................................................ 25

2.1 Modal weights and effective moment arms for

(a) Shear cantilever beam, and (b) Flexural cantilever beam

2.2 Plan view of the structure model

2.3 Elevation of selected structure models

(a) moment-resisting frame, (b) braced frame with cross bracing,

(c) braced frame with Chevron bracing, and (d) flexural wall.

2.4 Elevation of selected structure models

(a) coupled flexural walls (b) hybrid frame-wall system

2.5 Variation of $\mathrm{Mv}$ factor with period for MRF structures

(a) Cities in the west (b) Cities in the east 66

2.6 Variation of Mv factor with period for braced frame structures

(a) Cities in the west (b) Cities in the east

2.7 Variation of Mv factor with period for wall structures

(a) Cities in the west (b) Cities in the east 68

2.8 Variation of $\mathrm{J}$ factor with period for MRF structures

(a) Cities in the west (b) Cities in the east

2.9 Variation of $\mathrm{J}$ factor with period for braced frame structures

(a) Cities in the west (b) Cities in the east 70

2.10 Variation of $\mathbf{J}$ factor with period for wall structures

(a) Cities in the west (b) Cities in the east. 
2.11 Absolute acceleration response spectra for Montreal (5\% damping) 72

2.12 Height wise normalized shear distribution for MRF system,
(a) City of Vancouver
(b) City of Montreal
$(\mathrm{T} 1=2.0 \mathrm{~s})$

2.13 Height wise normalized shear distribution for braced frame system,
(a) City of Vancouver
(b) City of Montreal
$(\mathrm{T} 1=2.0 \mathrm{~s})$ 74

2.14 Height wise normalized shear distribution for flexural wall system,
(a) City of Vancouver
(b) City of Montreal
$(\mathrm{T} 1=2.0 \mathrm{~s})$ 75

2.15 Height wise normalized overturning moment distribution for MRF system,
(a) City of Vancouver
(b) City of Montreal
$(\mathrm{T} 1=2.0 \mathrm{~s})$ 76

2.16 Height wise normalized overturning moment distribution for braced frame system, (a) City of Vancouver $\quad$ (b) City of Montreal $\quad(\mathrm{T} 1=2.0 \mathrm{~s})$

2.17 Height wise normalized overturning moment distribution for flexural wall system, (a) City of Vancouver $\quad$ (b) City of Montreal $\quad(\mathrm{T} 1=2.0 \mathrm{~s}) \ldots \ldots \ldots \ldots \ldots . . . . .78$

2.18 Height wise distribution of storey moment modification factor, $\mathrm{Jx}$,
(a) Cities in the West
(b) Cities in the East
(Flexural wall, $\mathrm{T} 1=2.0 \mathrm{~s}$ ) 79

2.19 Variation of $\mathrm{Mv}$ factor with period for coupled walls structures,

(a) City of Vancouver (b) City of Montreal 80

2.20 Variation of $\mathrm{J}$ factor with period for coupled walls structures,

(a) City of Vancouver (b) City of Montreal 81

2.21 Shear distribution across the height for a coupled wall system,
(a) Beam depth $=0.20 \mathrm{~m}$
(b) Beam depth $=1.2 \mathrm{~m}$ (Montreal, $\mathrm{T} 1=2.0 \mathrm{~s}$ )

2.22 Variation of $\mathrm{Mv}$ factor with period for hybrid structures,

(a) City of Vancouver (b) City of Montreal 83

2.23 Variation of $\mathrm{J}$ factor with period for hybrid structures,

(a) City of Vancouver (b) City of Montreal

2.24 Shear distribution across the height for a hybrid system,

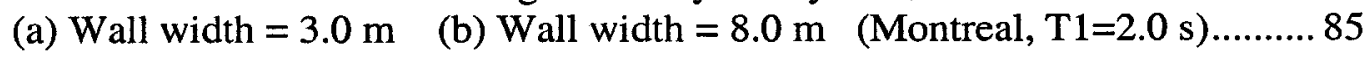

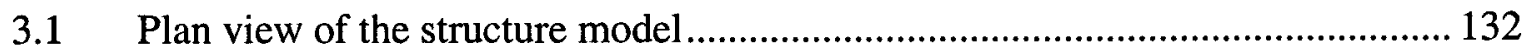

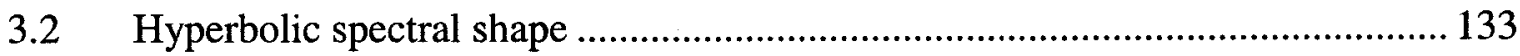


3.3 Five storey shear frame, (a) plan view (b) elevation 134

3.4 Interstorey displacement at flexible edge of a building of example 1,

(a) $\Omega_{R}=1.00$ (floors 1,2 and 3), $=0.75$ (floors 4 and 5)

(b) $\Omega_{R}=0.75$ (floors 1,2 and 3 ), $=1.00$ (floors 4 and 5)

3.5 Interstorey displacement at stiff edge of a building of example 1,

(a) $\Omega_{R}=1.00$ (floors 1,2 and 3), $=0.75$ (floors 4 and 5)

(b) $\Omega_{R}=0.75$ (floors 1,2 and 3), $=1.00$ (floors 4 and 5)

3.6 Ten storey shear frame, (a) plan view (b) elevation

3.7 Interstorey displacement at flexible edge of a building of example 2,

(a) $\Omega_{R}=1.00$ (floors 1 to 5 ), $=0.75$ (floors 6 to 10 )

(b) $\Omega_{R}=0.75$ (floors 1 to 5 ), $=1.00$ (floors 6 to 10 )

3.8 Interstorey displacement at stiff edge of a building of example 2,

(a) $\Omega_{R}=1.00$ (floors 1 to 5 ), $=0.75$ (floors 6 to 10 )

(b) $\Omega_{R}=0.75$ (floors 1 to 5 ), $=1.00$ (floors 6 to 10 )

3.9 Interstorey displacement at flexible edge of a building of example 3,

(a) $\Omega_{R}=1.25$ (floors 1 to 5 ), $=1.00$ (floors 6 to 10 )

(b) $\Omega_{R}=1.00$ (floors 1 to 5 ), $=1.25$ (floors 6 to 10 ) 140

3.10 Interstorey displacement at stiff edge of a building of example 3,

(a) $\Omega_{R}=1.25$ (floors 1 to 5 ), $=1.00$ (floors 6 to 10 )

(b) $\Omega_{R}=1.00$ (floors 1 to 5 ), $=1.25$ (floors 6 to 10 )

3.11 Interstorey displacement at flexible edge of a building of example 4,

(a) $\Omega_{R}=1.25$ (floors 1 to 5 ), $=0.75$ (floors 6 to 10 )

(b) $\Omega_{R}=0.75$ (floors 1 to 5 ), $=1.25$ (floors 6 to 10 ) 142

3.12 Interstorey displacement at stiff edge of a building of example 4,

(a) $\Omega_{R}=1.25$ (floors 1 to 5 ), $=0.75$ (floors 6 to 10 )

(b) $\Omega_{R}=0.75$ (floors 1 to 5 ), $=1.25$ (floors 6 to 10 )

3.13 Interstorey displacement at flexible edge of a building of example 5,

(a) $\Omega_{R}=1.00$ (floors 1 to 4 ), 1.25 (floors 5 to 7 ), 0.75 (floors 8 to 10 )

(b) $\Omega_{R}=0.75$ (floors 1 to 4 ), 1.25 (floors 5 to 7 ), 1.00 (floors 8 to 10 ) 144

3.14 Interstorey displacement at stiff edge of a building of example 5,

(a) $\Omega_{R}=1.00$ (floors 1 to 4 ), 1.25 (floors 5 to 7 ), 0.75 (floors 8 to 10 )

(b) $\Omega_{R}=0.75$ (floors 1 to 4 ), 1.25 (floors 5 to 7 ), 1.00 (floors 8 to 10 ) 145 
3.15 Interstorey displacement at flexible edge of a building of example 6,

(a) $\Omega_{R}=1.00$ (floors 1 to 4 ), 0.75 (floors 5 to 7 ), 1.25 (floors 8 to 10 )

(b) $\Omega_{R}=1.25$ (floors 1 to 4 ), 0.75 (floors 5 to 7 ), 1.00 (floors 8 to 10 ). 146

3.16 Interstorey displacement at stiff edge of a building of example 6 ,

(a) $\Omega_{R}=1.00$ (floors 1 to 4 ), 0.75 (floors 5 to 7 ), 1.25 (floors 8 to 10)

(b) $\Omega_{R}=1.25$ (floors 1 to 4 ), 0.75 (floors 5 to 7 ), 1.00 (floors 8 to 10) 147

3.17 Torsional sensitivity of single storey buildings, aspect ratio $=0.33 \ldots \ldots \ldots \ldots \ldots \ldots . .148$

3.18 Torsional sensitivity of single storey buildings, aspect ratio $=0.50 \ldots \ldots \ldots \ldots \ldots \ldots . .149$

3.19 Torsional sensitivity of single storey buildings, aspect ratio $=1.00 \ldots \ldots \ldots \ldots \ldots \ldots . .150$

3.20 Torsional sensitivity of single storey buildings, aspect ratio $=3.00 \ldots \ldots \ldots \ldots \ldots \ldots . .151$

4.1 The UHS compatible acceleration time histories used for Vancouver ................ 175

4.2 The UHS compatible acceleration time histories used for Montreal .................. 176

4.3 Elastic and inelastic spectra for city of Vancouver

$\begin{array}{ll}\text { (a) Short range records } & \text { (b) Long range record }\end{array}$

4.4 Elastic and inelastic spectra for city of Montreal

(a) Short range records (b) Long range record 178

4.5 Height wise storey ductility demands for a 20 -storey MRF subjected to long period record with associated SDOF target ductility, $\mu=4.0$

(a) Located in East Canada (b) Located in West Canada

4.6 Height wise storey ductility demands for a 20 -storey flexural wall subjected to long period record with associated SDOF target ductility, $\mu=4.0$

(a) Located in East Canada (b) Located in West Canada 180

4.7 Variation of first storey ductility demand with period for moment-resisting frame located in (a) Montreal (b) Vancouver

4.8 Variation of first storey ductility demand with period for flexural wall located in (a) Montreal (b) Vancouver.

4.9 Variation of $M_{v}, M_{v 0}$ and $M_{v m}$ factors with period for $\mu=2$ and 4 for a moment-resisting frame located in (a) Montreal (b) Vancouver.

4.10 Variation of $M_{v}, M_{v 0}$ and $M_{v m}$ factors with period for $\mu=2$ and 4 for a flexural wall located in (a) Montreal (b) Vancouver. 
5.1 A single storey shear frame model

5.2 Lateral load versus displacement relationship for a single storey frame

(a) elasto-plastic, no P- $\Delta$, (b) elasto-plastic, with P- $\Delta$

5.3 Load deflection relationship for the frame shown in Fig. 5.1, compensating for $\mathrm{P}-\Delta$ by increasing the strength, (a) no $\mathrm{P}-\Delta$, (b) with $\mathrm{P}-\Delta$, (c) increased strength and $P-\Delta$

5.4 Load deflection relationship for the frame shown in Fig. 5.1, compensating for P $-\Delta$ by increasing the stiffness, (a) no P- $\Delta$, (b) with P- $\Delta$, (c) increased stiffness and $P-\Delta$

5.5 Load deflection relationship for the frame shown in Fig. 5.1, compensating for P- $\Delta$ by increasing both the strength and the stiffness, (a) no P- $\Delta$, (b) with P- $\Delta$,

(c) increased strength and stiffness and P- $\Delta$.

5.6 History of lateral frame displacement caused by El-Centro 1940 ground motion,

(a) without $\mathrm{P}-\Delta$ effect, (b) with $\mathrm{P}-\Delta$ effect and no compensation,

(c) elastic response, no strain hardening in each case

5.7 Load displacement relationships for the frame of Fig. 5.1, with a strain hardening ratio of 0.2 , (a) no $\mathrm{P}-\Delta$, (b) with $\mathrm{P}-\Delta$, (c) increased strength and stiffness and $\mathrm{P}-\Delta,(\mathrm{d})$ increased strength and $\mathrm{P}-\Delta$

5.8 History of lateral frame displacement caused by El-Centro 1940 ground motion, (a) original frame without P- $\Delta$ effect, (b) original frame with P- $\Delta$ effect, (c) frame with a strength $\mathrm{V}_{\mathrm{y} 1}=\mathrm{V}_{\mathrm{y} 0} /(1-\theta)$ and $\mathrm{P}-\Delta$ effect,

no strain hardening in each case.

5.9 History of lateral frame displacement caused by El-Centro 1940 ground motion,

(a) original frame without $\mathrm{P}-\Delta$ effect, (b) original frame with $\mathrm{P}-\Delta$ effect,

(c) frame with a stiffness $k_{1}=k_{0}(1+\theta)$ and P- $\Delta$ effect,

no strain hardening in each case.

5.10 History of lateral frame displacement caused by El-Centro 1940 ground motion,

(a) original frame without P- $\Delta$ effect, (b) original frame with P- $\Delta$ effect,

(b) frame with a strength $V_{y 1}=V_{y 0}(1+\theta)$, stiffness $k_{1}=k_{0}(1+\theta)$ and $P-\Delta$ effect,

no strain hardening in each case.

5.11 History of lateral frame displacement caused by El-Centro 1940 ground motion,

(a) original frame without P- $\Delta$ effect, but with $10 \%$ strain hardening,

(b) original frame with P- $\Delta$ effect and $10 \%$ strain hardening 233 
5.12 History of lateral frame displacement caused by El-Centro 1940 ground motion, (a) original frame without P- $\Delta$ effect (b) original frame with P- $\Delta$ effect, both strength and stiffness enhanced by 1.3 , no strain hardening in each case.

5.13 History of lateral frame displacement caused by El-Centro 1940 ground motion, (a) frame with $5 \%$ strain hardening but without $\mathrm{P}-\Delta$ effect (b) frame with $5 \%$ strain hardening and with P- $\Delta$ effect, (c) frame with $5 \%$ strain hardening, with $\mathrm{P}-\Delta$ effect and with both strength and stiffness enhanced by 1.18

5.14 History of lateral frame displacement caused by El-Centro 1940 ground motion, (a) frame with no strain hardening and without $P-\Delta$ effect (b) frame with $5 \%$ strain hardening, with P- $\Delta$ effect and with both strength and stiffness enhanced by 1.18

5.15 History of lateral frame displacement caused by Montana 1935 ground motion (a) original frame without P- $\Delta$ effect, (b) original frame with P- $\Delta$ effect, (c) frame with a strength, $\mathrm{V}_{\mathrm{y} 1}=0.67 \mathrm{~V}_{\mathrm{y} 0}$ and $\mathrm{P}-\Delta$ effect, no strain hardening in each case

5.16 History of lateral frame displacement caused by Montana 1935 ground motion (a) original frame without P- $\Delta$ effect, (b) original frame with P- $\Delta$ effect, (c) frame with a strength, $\mathrm{V}_{\mathrm{y} 1}=0.78 \mathrm{~V}_{\mathrm{y} 0}$ and $\mathrm{P}-\Delta$ effect, no strain hardening in each case 238

5.17 History of lateral frame displacement caused by Montana 1935 ground motion (a) original frame without P- $\Delta$ effect, (b) original frame with P- $\Delta$ effect, (c) frame with a strength, $\mathrm{V}_{\mathrm{y} 1}=0.89 \mathrm{~V}_{\mathrm{y} 0}$ and $\mathrm{P}-\Delta$ effect, no strain hardening in each case 239

5.18 History of lateral frame displacement caused by Montana 1935 ground motion (a) original frame without P- $\Delta$ effect, (b) original frame with P- $\Delta$ effect, (c) frame with a strength, $\mathrm{V}_{\mathrm{y} 1}=1.11 \mathrm{~V}_{\mathrm{y} 0}$ and $\mathrm{P}-\Delta$ effect, no strain hardening in each case 240

5.19 History of lateral frame displacement caused by El-Centro 1940 ground motion (a) original frame without P- $\Delta$, (b) original frame with P- $\Delta$, (c) frame with $\mathrm{V}_{\mathrm{y} 1}=1.11 \mathrm{~V}_{\mathrm{yo}} \& \mathrm{P}-\Delta$, (d) frame with $\mathrm{V}_{\mathrm{yl}}=1.22 \mathrm{~V}_{\mathrm{yo}} \& \mathrm{P}-\Delta$, no strain hardening in each case 241

5.20 History of lateral frame displacement caused by El-Centro 1940 ground motion back to back, (a) original frame without P- $\Delta$, (b) original frame with P- $\Delta$,

(c) frame with a strength $V_{y 1}=V_{y 0} /(1-\theta)$ and P- $\Delta$ effect, no strain hardening in each case 
5.21 History of lateral frame displacement caused by El-Centro 1940 ground motion back to back, (a) original frame without $\mathrm{P}-\Delta$, (b) original frame with $\mathrm{P}-\Delta$,

(c) frame with a stiffness $K_{1}=K_{0}(1+\theta)$ and P- $\Delta$ effect, no strain hardening in each case.

5.22 History of lateral frame displacement caused by El-Centro 1940 ground motion back to back, (a) original frame without $\mathrm{P}-\Delta$, (b) original frame with $\mathrm{P}-\Delta$,

(c) frame with a strength $\mathrm{V}_{\mathrm{yl}}=\mathrm{V}_{\mathrm{y} 0}(1+\theta)$, stiffness $\mathrm{K}_{1}=\mathrm{K}_{0}(1+\theta)$ and $\mathrm{P}-\Delta$ effect, no strain hardening in each case

5.23 History of lateral frame displacement caused by El-Centro 1940 ground motion back to back, (a) frame without P- $\Delta$ effect, with $\alpha=10 \%$ (b) frame with P- $\Delta$ effect and $\alpha=10 \%$

5.24 History of lateral frame displacement caused by El-Centro 1940 ground motion back to back, (a) original frame without $\mathrm{P}-\Delta$ effect (b) original frame with $\mathrm{P}-\Delta$ effect, both strength and stiffness enhanced by 1.3 , no strain hardening in each case

5.25 History of lateral frame displacement caused by El-Centro ground motion back to back, (a) frame without P- $\Delta$ and $\alpha=5 \%$, (b) frame with P- $\Delta$ and $\alpha=5 \%$,

(c) frame with P- $\Delta, \alpha=5 \%$ and both strength and stiffness enhanced by $1.18 \ldots 247$

5.26 History of lateral frame displacement caused by El-Centro 1940 ground motion

(a) frame without P- $\Delta$ and $\alpha=10 \%$, (b) frame with P- $\Delta$ and $\alpha=10 \%$,

(c) enhanced frame with P- $\Delta$ and $\alpha=10 \%$ (Eq. 5.13),

(d) enhanced frame with P- $\Delta$ and $\alpha=10 \%$ (Eq. 5.16)

5.27 History of lateral frame displacement caused by Kern County 1952 ground motion (a) frame without P- $\Delta$ and $\alpha=10 \%$, (b) frame with P- $\Delta$ and $\alpha=10 \%$, (c) enhanced frame with P- $\Delta$ and $\alpha=10 \%$ (Eq. 5.13),

(d) enhanced frame with P- $\Delta$ and $\alpha=10 \%$ (Eq. 5.16)

5.28 History of lateral frame displacement caused by Montana 1935 ground motion (a) frame without P- $\Delta$ and $\alpha=10 \%$, (b) frame with P- $\Delta$ and $\alpha=10 \%$,

(c) enhanced frame with P- $\Delta$ and $\alpha=10 \%$ (Eq. 5.13),

(d) enhanced frame with P- $\Delta$ and $\alpha=10 \%$ (Eq. 5.16) 250

5.29 History of lateral frame displacement caused by Monte Negro 1979 ground motion (a) frame without P- $\Delta$ and $\alpha=10 \%$, (b) frame with P- $\Delta$ and $\alpha=10 \%$, (c) enhanced frame with P- $\Delta$ and $\alpha=10 \%$ (Eq. 5.13),

(d) enhanced frame with P- $\Delta$ and $\alpha=10 \%$ (Eq. 5.16). 
5.30 History of lateral frame displacement caused by Parkfield 1966 ground motion (a) frame without P- $\Delta$ and $\alpha=10 \%$, (b) frame with P- $\Delta$ and $\alpha=10 \%$,

(c) enhanced frame with P- $\Delta$ and $\alpha=10 \%$ (Eq. 5.13),

(d) enhanced frame with P- $\Delta$ and $\alpha=10 \%$ (Eq. 5.16) 252

5.31 History of lateral frame displacement caused by El-Centro 1940 ground motion

(a) frame without P- $\Delta$ and $\alpha=12 \%$, (b) frame with P- $\Delta$ and $\alpha=12 \%$,

(c) enhanced frame with P- $\Delta$ and $\alpha=12 \%$ (Eq. 5.16). 253

5.32 History of lateral frame displacement caused by Kern County 1952 ground motion (a) frame without P- $\Delta$ and $\alpha=12 \%$, (b) frame with P- $\Delta$ and $\alpha=12 \%$,

(c) enhanced frame with P- $\Delta$ and $\alpha=12 \%$ (Eq. 5.16)

5.33 History of lateral frame displacement caused by Montana 1935 ground motion (a) frame without P- $\Delta$ and $\alpha=12 \%$, (b) frame with P- $\Delta$ and $\alpha=12 \%$,

(c) enhanced frame with P- $\Delta$ and $\alpha=12 \%$ (Eq. 5.16) 255

5.34 History of lateral frame displacement caused by Monte Negro1979 ground motion

(a) frame without P- $\Delta$ and $\alpha=12 \%$, (b) frame with P- $\Delta$ and $\alpha=12 \%$,

(c) enhanced frame with P- $\Delta$ and $\alpha=12 \%$ (Eq. 5.16) 256

5.35 History of lateral frame displacement caused by Parkfield 1966 ground motion (a) frame without P- $\Delta$ and $\alpha=12 \%$, (b) frame with P- $\Delta$ and $\alpha=12 \%$,

(c) enhanced frame with P- $\Delta$ and $\alpha=12 \%$ (Eq. 5.16)

5.36 Elevation and a plan view for the 10 storey MRF model............................... 258

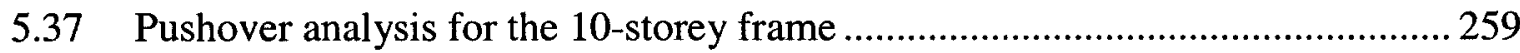

5.38 History of lateral top frame displacement caused by El-Centro 1940 ground motion (scale factor $=2.291$ ), (a) MRF inelastic response without P- $\Delta$,

(b) MRF inelastic response with P- $\Delta$, (c) MRF elastic response without P- $\Delta . . .260$

5.39 History of inelastic lateral top frame displacement caused by El-Centro 1940 ground motion (scale factor $=3.00$ ), (a) MRF without P- $\Delta$, (b) MRF with P- $\Delta$,

(c) enhanced MRF without P- $\Delta$ (d) enhanced MRF with P- $\Delta . . \ldots \ldots \ldots \ldots \ldots \ldots \ldots \ldots . . . . . . . . . . . .261$

5.40 Pushover analysis for the 10 -storey original and enhanced frame $\ldots \ldots \ldots \ldots \ldots \ldots \ldots . . . . . . . .262$

5.41 History of lateral top frame displacement caused by Kern County 1952 ground motion (scale factor $=5.070$ ), (a) MRF inelastic response without $\mathrm{P}-\Delta$,

(b) MRF inelastic response with P- $\Delta$, (c) MRF elastic response without P- $\Delta . . .263$ 
5.42 History of lateral top frame displacement caused by Kern County 1952 ground motion (scale factor $=6.00$ ), (a) MRF without $\mathrm{P}-\Delta$, (b) MRF with $\mathrm{P}-\Delta$,

(c) enhanced MRF without P- $\Delta$ (d) enhanced MRF with P- $\Delta$.......................... 264 


\section{LIST OF TABLES}

1.1 Uniform hazard spectral values, $2 \%$ in 50 years robust hazard (Canada east region), (Adams et al, 2003)

1.2 Uniform hazard spectral values, $2 \%$ in 50 years robust hazard (Canada west region), (Adams et al, 2003)

2.1 Design shears in a building of two different structural types located in Vancouver and Montreal

2.2 Modal periods for the five selected structural systems $\left(T_{1}=0.5 \mathrm{~s}\right) \ldots \ldots \ldots \ldots \ldots \ldots \ldots \ldots . . .55$

2.3 Modal masses in percent of total mass for the five selected structural systems ... 56

2.4 Base shear and overturning moment values for a moment-resisting frame .......... 57

2.5 Base shear and overturning moment values for a braced frame ........................... 58

2.6 Base shear and overturning moment values for a flexural wall ........................... 59

2.7 Proposed base shear and overturning moment adjustment Factors, $M_{\nu}$ and $J$ for different structural systems.

2.8 Degree of coupling of flexural wall system located in Montreal $\left(T_{I}=1.5 \mathrm{~s}\right) \ldots \ldots .61$

3.1 Storey lateral stifnesses of five-storey building models

$\Omega_{R}=1.0$ (floors 1,2 and 3) and 0.75 (floors 4 and 5), $e=0.1 b$ (all floors)

3.2 Storey shears and forces obtained from dynamic analysis of five-storey torsionally balanced building , $\Omega_{R}=1.0$ (floors 1,2 and 3) and 0.75 (floors 4 and 5)

3.3 Shear in edge frames obtained from static analysis for five-storey building $\Omega_{R}=1.0$ (floors 1,2 and 3 ) and 0.75 (floors 4 and 5), $e=0.1 b$ (all floors). 
3.4 Shear in edge frames obtained from dynamic analysis for five-storey building $\Omega_{R}=1.0$ (floors 1,2 and 3 ) and 0.75 (floors 4 and 5), $e=0.1 b$ (all floors)....... 120

3.5 Normalized edge displacement ratios obtained from response spectrum analysis for single storey, $\Omega_{R}=1.0$

3.6 Storey lateral stifnesses of ten-storey building models,

$\Omega_{R}=1.0$ (floors $1,2,3,4$ and 5) and 0.75 (floors 6, 7, 8, 9 and 10), $e=0.1 b$ (all floors)

3.7 Storey shears and forces obtained from dynamic analysis of torsionally balanced ten-storey building

$\Omega_{R}=1.0$ (floors $1,2,3,4$ and 5) and 0.75 (floors 6, 7, 8, 9 and 10).... 122

3.8 Shear in edge frames obtained from static analysis for ten-storey building $\Omega_{R}=1.0$ (floors $1,2,3,4$ and 5) and 0.75 (floors 6, 7, 8, 9 and 10), $e=0.1 b$ (all floors)

3.9 Shear in edge frames obtained from dynamic analysis for ten-storey building $\Omega_{R}=1.0$ (floors $1,2,3,4$ and 5) and 0.75 (floors 6, 7, 8, 9 and 10), $e=0.1 b$ (all floors)

3.10 Shear in edge frames obtained from static analysis for ten-storey building $\Omega_{R}=1.25$ (floors 1, 2, 3, 4 and 5) and 1.0 (floors 6, 7, 8, 9 and 10), $e=0.1 b$ (all floors).

3.11 Shear in edge frames obtained from dynamic analysis for ten-storey building $\Omega_{R}=1.25$ (floors $1,2,3,4$ and 5) and 1.0 (floors 6, 7, 8, 9 and 10), $e=0.1 b$ (all floors)

3.12 Shear in edge frames obtained from dynamic analysis for ten-storey building $\Omega_{R}=1.25$ (floors $1,2,3,4$ and 5) and 0.75 (floors 6, 7, 8, 9 and 10), $e=0.1 b$ (all floors)

3.13 Shear in edge frames obtained from dynamic analysis for ten-storey building $\Omega_{R}=1.0$ (floors $1,2,3$ and 4), 1.25 (floors 5, 6 and 7) and 0.75 (floors 8,9 and 10$), e=0.1 b$ (all floors)

3.14 Shear in edge frames obtained from dynamic analysis for ten-storey building $\Omega_{R}=1.0$ (floors $1,2,3$ and 4), 0.75 (floors 5, 6 and 7) and 1.25 (floors 8,9 and 10 ), $e=0.1 b$ (all floors)

3.15 Torsional sensitivity factor, $B_{x}$ obtained from static analysis for five-storey torsionally unbalanced building $\Omega_{R}=1.0$ (floors 1,2 and 3) and 0.75 (floors 4 and 5), $e=0.1 b$ (all floors) 
3.16 Torsional sensitivity factor, $B_{x}$ obtained from static analysis for ten-storey torsionally unbalanced building

$\Omega_{R}=1.0$ (floors $1,2,3,4$ and 5) and 0.75 (floors 6, 7, 8, 9 and 10),

$e=0.1 b$ (all floors)

4.1 Table 4.1 Modal period and modal mass (\% of total mass) for MDOF models,

(a) Moment-resisting frames, and (b) Flexural walls

(Humar and Rahgozar 2000)

4.2 Cross sectional moment of inertia for the structural types studied

(a) Five storey models

(b) Ten storey models

(c) Twenty storey models

(d) Thirty storey models

4.3 Magnitude, distance and fine tune factors (FTF) for UHS compatible motions, (Atkinson et al, 1998)

5.1 Values of ductility factor, $\mu$ for different earthquake arrangements

5.2 Modal period and modal mass (\% of total mass) for the 10 -storey moment-resisting frame model (no P- $\Delta$ ) 


\section{LIST OF SYMBOLES}

"The symbols used in the text are listed below. Most symbols are again defined at appropriate places in the text. Occasionally, the same symbol may be used to represent more than one parameter, but the meaning should be clear when read in context."

$a$

plan dimension of the building parallel to the direction of earthquake

$a / v \quad$ ratio of peak ground acceleration expressed in terms of $g$ to peak ground velocity expressed in the units of $\mathrm{m} / \mathrm{s}$

$b$ plan dimension of the building perpendicular to the direction of earthquake

$B \quad$ torsional sensitivity ratio

$B_{x} \quad$ torsional sensitivity ratio at level $x$

$C_{d} \quad$ deflection amplification factor

digid beam depth

$D \quad$ dead load

$D_{n x} \quad$ the plan dimension of the building at level $x$ perpendicular to the direction of earthquake forces

$e$

static eccentricity

$e_{d} \quad$ effective dynamic eccentricity

$e_{d 1}, e_{d 2} \quad$ design eccentricities

$e_{d n} \quad$ effective dynamic eccentricity in mode $n$

$\overline{e_{d n}} \quad$ normalized effective dynamic eccentricity in mode $n\left(=e_{d n} / r\right)$

$e_{f} \quad$ effective flexible edge eccentricity 


\begin{tabular}{|c|c|}
\hline$e_{s}$ & effective stiff edge eccentricity \\
\hline$e_{x}$ & static eccentricity at level $x$ \\
\hline$E$ & earthquake load \\
\hline$F$ & foundation factor \\
\hline$F_{i}$ & lateral force at storey $i$ \\
\hline$F_{t}$ & top floor force \\
\hline$F_{x}$ & earthquake force at level $x$ \\
\hline$g$ & ground acceleration \\
\hline$h_{i}$ & height of $i$ th storey \\
\hline$h_{s x}$ & height of storey $x$ \\
\hline$h_{x}, H_{x}$ & height of storey $x$ relative to the base of the structure \\
\hline$H$ & total height of the structure \\
\hline$H_{x}$ & storey height below level $x$ \\
\hline$I$ & importance factor \\
\hline$I_{x}$ & cross sectional moment of inertia \\
\hline$J$ & overturning moment factor that accounts for higher mode effect \\
\hline$J_{x}$ & overturning moment factor at level $x$ \\
\hline$k_{x i}$ & lateral stiffness of the $i$ th plane parallel to the $x$ axis \\
\hline$k_{y i}$ & lateral stiffness of the $i$ th plane parallel to the $y$ axis \\
\hline$K_{0}$ & lateral stiffness of the original frame \\
\hline$K_{1}$ & modified lateral stiffness \\
\hline$K_{y}$ & total lateral stiffness parallel to the $y$ axis \\
\hline$K_{\theta}$ & rotational stiffness of a storey about centre of mass \\
\hline
\end{tabular}




\begin{tabular}{|c|c|}
\hline$K_{\theta R}$ & rotational stiffness of a storey about centre of rigidity \\
\hline$L$ & live load \\
\hline$m$ & total mass of the floor \\
\hline$M$ & number of resisting planes in the $x$ direction \\
\hline$M_{b c}$ & code base overturning moment \\
\hline$M_{b e}$ & exact base overturning moment \\
\hline$M_{n b}$ & sum of the nominal moment resistances of the beams meeting at the joint \\
\hline$M_{p}$ & plastic moment capacity \\
\hline$M_{r c}$ & $\begin{array}{l}\text { sum of the factored moment resistances of the columns meeting at the } \\
\text { joint }\end{array}$ \\
\hline$M_{v}$ & base shear factor that accounts for higher mode effect \\
\hline$M_{v o}$ & strength modification factor (strength modified for first storey only) \\
\hline$M_{v m}$ & strength modification factor (strength modified for each storey) \\
\hline$M_{x c}$ & code overturning moment at storey $x$ \\
\hline$M_{x e}$ & exact overturning moment at storey $x$ \\
\hline$N$ & number of resisting planes in the $y$ direction; number of storeys \\
\hline$P$ & gravity load \\
\hline$P_{x}$ & total vertical design load above level $x$ \\
\hline$P_{y}$ & axial strength \\
\hline$r$ & radius of gyration of the floor about centre of mass \\
\hline$R$ & strength reduction factor \\
\hline$R_{d}$ & ductility capacity factor \\
\hline$R_{m e c h}$ & $\begin{array}{l}\text { mechanism factor that accounts for overstrength resulted from the } \\
\text { redistribution of the internal forces in the inelastic range }\end{array}$ \\
\hline
\end{tabular}




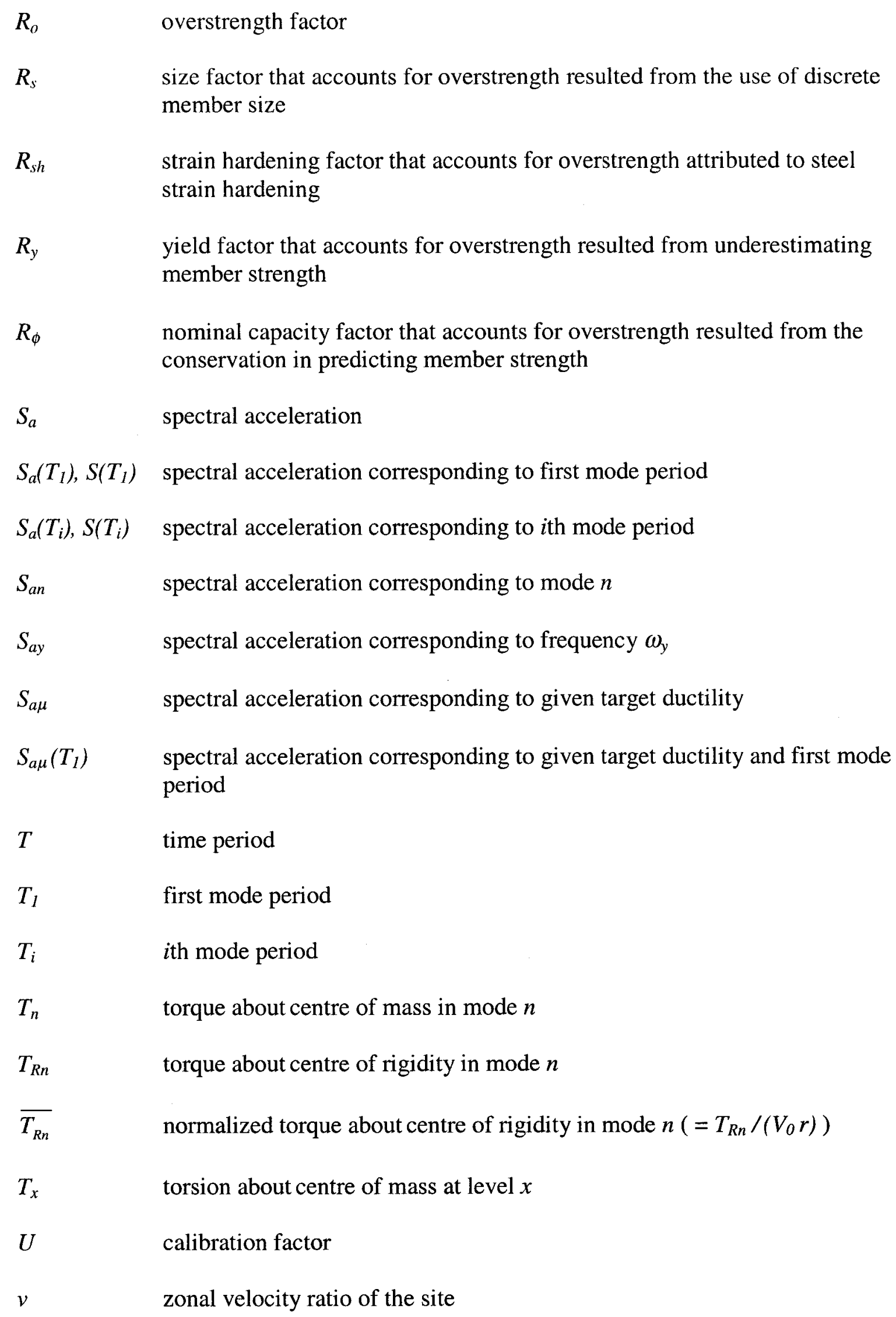




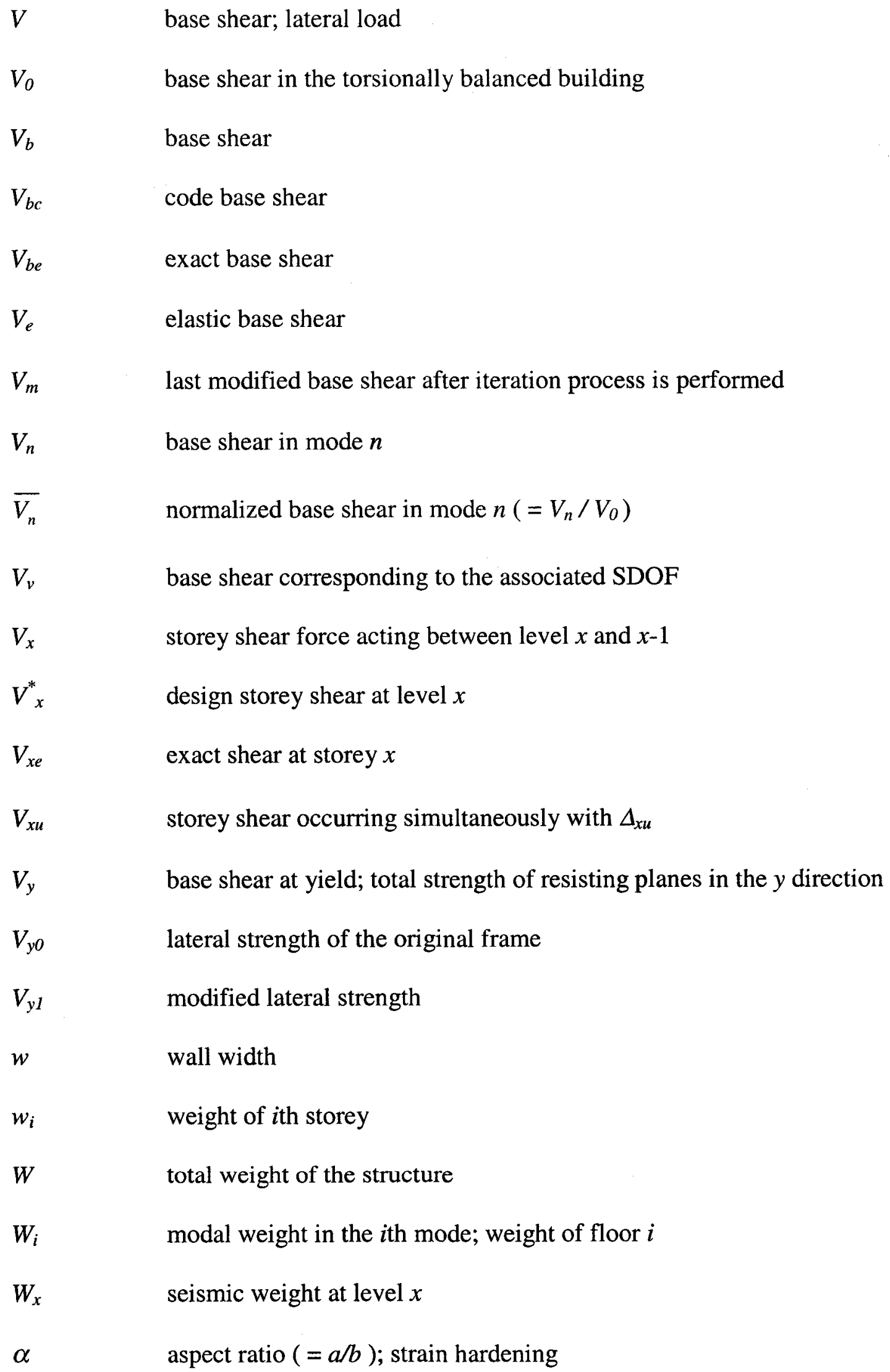


$\delta_{\text {ave }}$

$\delta_{\max }$

$\delta_{\text {min }}$

$\Delta_{0}$

$\Delta_{e}$

$\Delta_{e x}$

$\Delta_{f}$

$\overline{\Delta_{f}}$

$\Delta_{f c}$

$\overline{\Delta_{f c}}$

$\Delta_{f n}$

$\overline{\Delta_{f n}}$

$\Delta_{i}, \Delta_{m x}$

$\Delta_{p}$

$\Delta_{s}$

$\overline{\Delta_{s}}$

$\Delta_{s c}$ average displacement of $\delta_{\max }$ and $\delta_{\min }$

maximum displacement of the structure at level $x$ in the direction of the earthquake induced by equivalent static force acting at distance $\pm 0.1 D_{n x}$

minimum displacement of the structure at level $x$ in the direction of the earthquake induced by equivalent static force acting at distance $\pm 0.1 D_{n x}$

displacement or interstorey displacement of the torsionally balanced building

elastic displacement corresponding to elastic base shear

elastic drift of storey $x$ occurring simultaneously with $V_{x}$

displacement or interstorey displacement of the flexible edge in the torsionally unbalanced building

normalized displacement of the flexible edge $\left(=\Delta_{f} / \Delta_{0}\right)$

displacement of the flexible edge corresponding to proposed design eccentricities

normalized displacement of the flexible edge corresponding to proposed design eccentricities

displacement of the flexible edge in mode $n$

normalized displacement of the flexible edge in mode $n\left(=\Delta_{f n} / \Delta_{0}\right)$

maximum expected inelastic storey drift

plastic displacement

displacement or interstorey displacement of the stiff edge in the torsionally unbalanced building

normalized displacement of the stiff edge $\left(=\Delta_{s} / \Delta_{0}\right)$

displacement of the stiff edge corresponding to proposed design eccentricities 


\begin{tabular}{|c|c|}
\hline$\Delta_{s c}$ & $\begin{array}{l}\text { normalized displacement of the stiff edge corresponding to proposed } \\
\text { design eccentricities }\end{array}$ \\
\hline$\Delta_{s n}$ & displacement of the stiff edge in mode $n$ \\
\hline$\overline{\Delta_{s n}}$ & normalized displacement of the stiff edge in mode $n\left(=\Delta_{s n} / \Delta_{0}\right)$ \\
\hline$\Delta_{x u}$ & ultimate or design storey drift \\
\hline$\Delta y$ & yield displacement \\
\hline$\Delta_{y 0}$ & yield displacement of the original frame \\
\hline$\Delta_{y l}$ & modified yield displacement \\
\hline$\phi_{N B C C}$ & lateral load amplification factor corresponding to the $\mathrm{NBCC}$ code \\
\hline$\phi_{y n}, \phi_{\theta n}$ & mass orthonormalised mode shapes of a single storey \\
\hline$\mu$ & ductility ratio \\
\hline$\theta$ & stability factor \\
\hline$\theta_{1}$ & modified stability factor \\
\hline$\theta_{N B C C}$ & $\begin{array}{l}\text { stability factor that corresponds to the ratio of the second-order storey } \\
\text { shear force to the seismic storey shear prescribed in NBCC code }\end{array}$ \\
\hline$\theta_{x}$ & stability factor at storey $x$ \\
\hline$\omega_{1}, \omega_{2}$ & coupled frequencies of single storey model \\
\hline$\omega_{y}$ & uncoupled translational frequency \\
\hline$\omega_{\theta}$ & uncoupled rotational frequency \\
\hline$\Omega_{R}$ & $\begin{array}{l}\text { ratio of uncoupled rotational frequency to uncoupled translational } \\
\text { frequency }\end{array}$ \\
\hline
\end{tabular}




\section{CHAPTER 1 \\ INTRODUCTION}

\subsection{GENERAL}

Earthquake resistant design of structures is a challenging task on account of the many uncertainties involved. A major source of uncertainty is in the assessment of seismic hazard at a site and its representation in a form that it is suitable for engineering design. Another challenge is in understanding the behavior of structures subjected to seismic ground motion, particularly because a majority of the structures are expected to be strained into the inelastic range during a severe design earthquake. In dealing with these uncertainties, while keeping the design procedure simple enough to be of practical use in the routine design of buildings, seismic codes specify simplified design procedures and many empirical expressions for calculating seismic design forces. As greater insight is obtained into the assessment of seismic hazard and the response of structure to seismic motion, the code provisions are refined. This is also true of the National Building Code of Canada (NBCC 1995).

The current version of NBCC was issued in 1995. The level of seismic hazard in different regions of the country that formed the basis of 1995 NBCC was itself based on the catalogue of earthquakes until 1985. Since then, many more earthquakes have been recorded. Also, new relationships for calculating the attenuation of ground motion as it travels from 
the source to the site have been developed. These factors combined with improved knowledge of the tectonics of the country have led to a significant change in the manner in which the seismic hazard is represented, providing the main impetus for the revisions to the seismic provisions of NBCC. Other factors that have motivated the changes are: improved understanding of structural response based on observed behavior during earthquakes, new experimental results, and refinements in seismic codes of other countries with history of earthquakes. Work by the Canadian National Committee for Earthquake Engineering, which is an advisory committee on seismic design provisions of $\mathrm{NBCC}$, has led to significant revisions in the current provisions. After a period of public consultation and appropriate amendments to address the comments received, the Canadian Commission on Fire and Building Code has approved the new provisions. These provisions will come into effect with the publication of new code in 2005 .

The main motivation of the present work is to carry out background study for some important issues related to the proposals being developed for NBCC 2005. Some of the results reported in this study have been incorporated in the provisions, others, while not directly included in the code, are expected to provide useful tools for future developments.

\subsection{ISSUES TO BE ADDRESSED IN THE PRESENT STUDY}

A number of issues related to the provisions in NBCC 2005 are discussed in the current study. The present work identifies the problems related to such issues, and attempts to develop solutions that are both rational and simple. The following issues are addressed:

(a) Application of Uniform Hazard Spectra (UHS) in obtaining the seismic 
design forces.

(b) Accounting for higher mode effects on the base shear.

(c) Development of adjustment factors for calculating the overturning moments.

(d) Code provisions for designing against torsion.

(e) Accounting for $\mathrm{P}-\Delta$ effect.

A brief introduction to each of these issues is presented in the following sections.

\subsubsection{Uniform Hazard Spectrum}

The seismic design provisions of the current National Building Code of Canada, NBCC 1995 require that buildings be designed to resist without collapse a base shear obtained from an idealised response spectrum for a single-degree-of-freedom system with $5 \%$ damping. This idealized spectrum is derived from two ground motion parameters: the peak ground acceleration and the peak ground velocity for the seismic region in which the building is located. The spectral shape is obtained by applying suitable amplification factors to these ground motion bounds.

It has been pointed out that this method of obtaining the design response spectra may involve significant errors, which can be as large as 300\% (Atkinson, 1991). The factors most commonly used to amplify the ground motion bounds are based on the experience of spectral curves for some California earthquakes. However, the spectral shapes differ from region to region. For a given site this shape is governed by the magnitudes and source distances of earthquakes that contribute most significantly to the hazard. Obviously, spectral shapes derived from California earthquakes cannot be applied to different regions of the country and 
more rational procedures for determining the design response spectra are desired.

Since mid 1970's, methodologies have become available for deriving linear elastic spectra for a given site and for a given hazard level, for example, $10 \%$ probability of exceedance in 50 years. This is based on the knowledge of the seismicity of the area and ground motion attenuation relationships. Such spectra are called elastic Uniform Hazard Spectra (UHS). They provide spectral accelerations at specified values of the period of an elastic single-degree-of-freedom system. It is important to note the difference between a standard (idealized) spectrum and UHS. The standard spectrum provides the maximum spectral acceleration of a single-degree-of-freedom system with varying value of the period when excited by a single earthquake. On the other hand, a UHS represents the composite of spectral acceleration responses produced by several different earthquakes that contribute to the seismicity of the site and have varying magnitudes and source distances. Thus the maximum short-period spectral values in a UHS may result from short-distance earthquakes, while the long-period values may be contributed by more distant earthquakes. As an illustration of this point consider Fig. 1.1, which shows the response spectra for two different earthquakes: a short-distance lower magnitude earthquake, and a long-distance higher magnitude earthquake. The envelop of the two represents the uniform hazard spectrum. The short-distance earthquake contributes to the short period range of UHS, while the longdistance earthquake dominates the long period range. In reality a number of different earthquakes will contribute to different regions of the UHS. It is clear from the foregoing discussion that UHS should be the preferred basis for seismic mapping when compared to the spectra derived indirectly from peak ground motion bounds, because the former provide 
response parameters that can be used directly in estimating the design earthquake forces.

The Geological Survey of Canada, GSC, has produced preliminary seismic hazard spectra for different locations in Canada (Adams et al, 2003) for use with NBCC 2005. These spectra provide the median values of spectral acceleration for a 5\% damped elastic singledegree-of-freedom system with varying values of the period. The spectral values are derived for a uniform probability of exceedance of $2 \%$ in 50 years, corresponding to an average return period of 2500 years. Tables 1.1 and 1.2 give the uniform hazard spectral acceleration values provided by GSC in units of $g$ for 22 cities of Canada, 10 in the west and 12 in the east. It should be noted that spectral accelerations are also dependent on the ground condition. The spectral values given in Tables 1.1 and 1.2 correspond to class $\mathrm{C}$ ground condition, representing very dense soil and soft rock.

Figure 1.2 shows the UHS for two cities, Vancouver in the west, and Montreal in the east. It will be noted that in comparison to Vancouver the spectral acceleration values fall more rapidly with the period in Montreal. This is a typical feature of the seismicity of the two regions of Canada, west and east. In the eastern region, the major frequency content of the earthquakes is in the short period range. As a result, the long period spectral accelerations are significantly smaller than those in the short period range.

The revised picture of the seismicity of the country and the fact that it is best expressed in terms of UHS rather than peak ground motion values provide the main impetus for revisions proposed for NBCC 2005. 


\subsubsection{Higher Mode Effects}

Seismic building codes require that a building should be designed to resist the base shear and overturning moment obtained from a design response spectrum which is representative of the seismicity of the site. Most seismic building code provisions, including NBCC 1995, specify formulas for calculating the structural response to the design earthquakes that are based primarily on the vibration of the structure in its fundamental mode. These formulas include expressions for determining the base shear and the distribution of lateral forces over the height of the building.

For the design of regular buildings, NBCC 1995 specifies an equivalent static load approach in which the elastic base shear is obtained from an idealized response spectrum using the first mode period of the structure under consideration. The elastic base shear is then reduced by a factor that reflects the capacity of the structure to undergo inelastic deformation without collapse. The design base shear is distributed across the height of the building, primarily according to the first mode, although some adjustment is made for higher mode effects. Strictly speaking, the approach of obtaining the design shear from spectral acceleration corresponding to the first mode period is sufficient only for SDOF systems. In multi-degree-of-freedom systems, the higher modes contribute significantly to the structure response and cannot be ignored. In NBCC 1995, the contribution of higher modes was accounted for indirectly by artificially raising the design spectrum in the long period range. It was reasoned that multistorey buildings, for which the higher mode effects are most pronounced, will fall in the long period range, and by raising the design spectrum in that range, the contribution of higher modes will be taken care of, at least approximately. 
However, the higher mode effects depend both on the type of the structure and the shape of the response spectrum, and the use of a single spectral shape cannot account for such variation. The NBCC 1995 provisions for higher mode effects need to be reviewed in light of the proposed use of UHS.

To obtain a better estimate of structure's response, analytical studies are needed to obtain adjustment factors to be applied to the base shear and overturning moment determined from the first mode period. These factors are expected to be dependent on the spectral shape and the type of the structure. A comprehensive study is also needed to develop a height wise lateral load distribution that accounts for the effect of higher modes, and to examine where the top load $F_{t}$ provided for in the current NBCC adequately reflects the effect of higher modes in the distribution of lateral forces.

\subsubsection{Torsional Response}

The need for providing sufficient torsional resistance in building systems has been emphasised following damage studies of some recent earthquakes. Various researchers have carried out analytical studies on the elastic and inelastic torsional behavior of single and multistorey building models. There is still a need to provide a better understanding of the torsional behavior and to develop design guidelines that are both rational and simple to implement. Several issues related to seismic torsional response have not been studied and further research is required. Some of the issues that are addressed in this study are:

(1) How does the torsional stiffness, $K_{\theta}$, influence torsional response? In this study, the effect of torsional stiffness is represented by a frequency ratio, $\Omega_{R}$ defined as the ratio of uncoupled 
torsional frequency, $\omega_{\theta}$ to the uncoupled lateral frequency, $\omega_{y}$.

(2) Do the existing static design provisions of building codes correctly account for the elastic torsional behavior for the full practical range of governing parameters?

(3) Can the results obtained from single storey elastic models be applied to multistorey models of general class and if so, what are the limitations? (A general class of multistorey building is one in which the frequency ratio, $\Omega_{R}$ and/or the eccentricity between the centre of mass and the centre of stiffness vary from floor to floor).

(4) How does the variation of storey-wise frequency ratio, $\Omega_{R}$ along the height of the building affect the torsional response?

(5) What is the nature of the edge element displacements and how do they vary with the frequency ratio, $\Omega_{R}$ ?

Both elastic and inelastic dynamic analyses need to be carried out to study the effect of the various parameters on torsional response of single and multistorey building models. In addition, the existing code provisions for torsion should be studied and if necessary appropriate modifications developed.

\subsubsection{P- $\Delta$ Effects}

When a flexible building structure is subjected to lateral seismic force, the gravity loads acting through the lateral displacements lead to additional shears and moments throughout the entire structure. These additional shears and moments are caused by what is referred to as " the P- $\Delta$ effect " and they tend to reduce the capacity of the structure to resist the seismic lateral forces. 
A factor that governs the magnitude of P- $\Delta$ effect is the lateral displacements induced in the structure by earthquake forces. Most buildings are designed to have a strength that is a fraction of the strength required to resist the forces derived from an elastic response spectrum. This implies that a building structure is expected to undergo inelastic deformation during the design earthquakes. For a given structure and earthquake motion, the amount of inelastic deformation depends on the ratio of the strength of the structure to the strength required to keep its response within elastic limit. If the structure is considered elastic, the maximum value of the lateral force or base shear is $V_{e}$ and the corresponding displacement is $\Delta_{e}$. The minimum strength required to keep the structure elastic is thus $V_{e}$. Assume that the lateral force displacement relationship for the structure is elasto-plastic in nature, as shown in Fig.1.3. Then if the structural strength provided is $V_{y}$ with $V_{y}<V_{e}$, the structure will yield at a base shear of $V_{y}$ and will undergo further displacement at a constant value of shear equal to $V_{y}$. Let the maximum displacement of the elasto-plastic system be denoted by $\Delta_{i}$. This displacement is comprised of two parts: yield displacement, $\Delta_{y}$ and plastic displacement, $\Delta_{p}$. Previous studies have shown that, in general, inelastic displacement, $\Delta_{i}$ is close to the elastic displacement, $\Delta_{e}$.

Inelastic deformation causes damage to the structure. The level of damage should be kept within the capacity of the structure to sustain such damage without collapse. Various measures have been adopted to assess the damage level and the damage capacity. The simplest of these measures is the so called ductility, $\mu$ which is defined as the ratio of the total deformation, $\Delta_{i}$ to the yield deformation, $\Delta_{y}\left(\mu=\Delta_{i} / \Delta_{y}\right)$. The objective of the earthquake design is to determine the value of $V_{y}$ that will limit the ductility demand to 
within the ductility capacity. In NBCC 1995 , strength $V_{y}$ is determined from the elastic base shear, $V_{e}$, by applying a reduction factor to the latter. This reduction factor $R$ is taken as being equal to the ductility ( $R=V_{e} / V_{y}$ ). This approach permits the use of elastic response spectra for determining the design strength of an inelastic structure. The P- $\Delta$ effect may have a bearing on the value of $R$. This needs to be studied.

The stability of members under elastic and inelastic deformations caused by earthquakes is a direct function of both axial loading and bending of members. Stability considerations dictate that drift be controlled. As stated by several seismic code provisions including NBCC 1995, certain limitations should be applied on calculated drifts. A stability problem is resolved by limiting the drift of vertical load carrying elements and the resulting secondary moments and shears produced by the axial loads and deflections ( $\mathrm{P}-\Delta$ effects ). Under small lateral deformations, secondary stresses are normally within tolerable limits. However, buildings with heavy vertical loads and larger deformations can lead to significant secondary forces arising from P- $\Delta$ effect. The drift limitation provides an upper bound for such effects. Most procedures for calculating the P- $\Delta$ effect check the static stability of structure based on its initial stiffness. These methods are not accurate since they are not based on the structure's secant stiffness which is the parameter that must be used in the calculation of P- $\Delta$ effects.

Most recent studies on P- $\Delta$ effect are based on the inelastic response of single storey buildings (Bernal 1987). In accounting for P- $\Delta$ effect in multistorey buildings, significant uncertainties exist and should be addressed and resolved.

Some of the issues addressed in this study are: 
(1) Assess the significance of P- $\Delta$ effect in building subjected to earthquakes.

(2) Investigate the effect of strength and stiffness on P- $\Delta$.

(3) Investigate the effect of strain hardening, ductility and ground motion duration and frequency content on $\mathrm{P}-\Delta$.

(4) Develop methods to account for P- $\Delta$ effect in buildings.

\subsection{LITERATURE REVIEW}

\subsubsection{Higher Mode Effects}

A multistorey building has several different modes of vibration. Hence, to find a more exact value for the response of a multistorey building structure to a specified earthquake excitation, all natural modes that contribute to the response should be considered. Previous research has shown that sufficient accuracy is obtained even when the first few modes of vibration are taken into account (Chopra, 1995 and Humar, 2002).

Only a limited amount of work has been carried out in relation to the effect of higher modes when the design is based on a uniform hazard spectrum. Humar and Rahgozar (2000) have studied the higher mode effect in a design based on UHS. In their study they used two identical structural systems: a shear cantilever, and a flexural cantilever and the uniform hazard spectra for two cities; Vancouver and Montreal. They also carried out time history analyses on simple frame and shear wall models using spectrum compatible ground motion histories. Both elastic and inelastic structural responses were considered. Based on these studies they proposed representative values of adjustment factors to account for higher mode effect on base shear and base overturning moment. 
Prior to the work presented by Humar and Rahgozar, Nasser and Krawinkler (1991) studied the variation of higher mode factor for moment-resisting frames subjected to selected records from California Whittier Narrows Earthquake of 1987. Results from that study have also been summarized by Humar and Rahgozar (1996).

\subsubsection{Torsional Response}

Analyses have been carried out by many researchers to investigate the elastic torsional response of single storey buildings and multistorey buildings of special class in which the static eccentricity, $e$, between the centre of rigidity and centre of mass and frequency ratio, $\Omega_{R}$, do not vary from floor to floor (Kan and Chopra, 1976; Tso and Dempsey, 1980; Dela Llera and Chopra, 1994a and 1994b). These studies investigated the torsional behavior of different building types with varying values of the governing parameters. The studies helped in creating a general understanding of the nature of torsional response.

Most existing building codes, such as the National Building Code of Canada, NBCC, Uniform Building Code, UBC (1997), and New Zealand Standard (1992), include an equivalent static force method of design that also accounts for both natural and accidental torsion. The seismic codes specify that in order to determine the design load in a lateral load resisting element, the calculated storey shear should be applied at a distance $e_{d}$, referred to as the design eccentricity, from the centre of rigidity, CR. The design eccentricity values are given by:

$$
e_{d 1}=\alpha e+\beta b \quad(\text { for flexible edge })
$$




$$
e_{d 2}=\gamma e-\beta b \quad \text { (for stiff edge) }
$$

where $e$ is the distance between the centre of mass and the centre of rigidity, and $b$ is the plan dimension of the building perpendicular to the ground motion. The first term of each equation represents the natural torsion while the second term represents the accidental torsion. The NBCC 1995 specifies that $\alpha=1.5, \beta=0.1$, and $\gamma=0.5$. Parameters $\alpha$ and $\gamma$ are meant to account for the dynamic amplification of the static torsion. However, the NBCC 1995 does not take explicit account of two important issues: (1) the reduction of base shear caused by torsional coupling, and (2) the influence of torsional stiffness on the response.

In a series of recent studies, Humar and Kumar (1998 $a$ and 1998b) have carried out elastic and inelastic dynamic analyses on single and multistorey building models for a range of governing parameters. They have suggested simple expressions that can reasonably be used for the torsional design of both flexible and stiff edge lateral load resisting elements of multistorey buildings that are asymmetric in plan but otherwise fairly regular. They have concluded that the proposed expressions can be applied to multistorey buildings in which the frequency ratio, $\Omega_{R}$ defined at the storey level, does not vary appreciably along the height. Humar and Kumar have proposed the following expressions for design eccentricities:

$$
\begin{array}{rlrl}
e_{f} & =e+0.1 b & \\
e_{s}=e-0.1 b & & \text { for } \Omega_{R} \geq 1.0 \\
& =-0.1 b & & \text { for } \Omega_{R}<1.0
\end{array}
$$

where $e_{f}$ and $e_{s}$ are the design eccentricities for flexible and stiff edges respectively measured 
from the centre of rigidity, $\mathrm{CR}$. These provisions are easier to apply than the provisions in NBCC 1995 because they do not include a multiplier on the static eccentricity, $e$, which implies that there is no need to determine the locations of the centres of rigidity. It may be noted that the determination of centres of rigidity often requires the use of complicated analytical procedures.

Humar and Kumar have also shown that the provisions of NBCC for the design of resisting elements on the flexible side are overly conservative. On the other hand, they have shown that the NBCC provisions for the design of elements on the stiff side are conservative in some situations and inadequate in others. They verified their findings by carrying out time history dynamic analysis on single storey building models subjected to fifteen earthquake records of intermediate peak ground acceleration to peak ground velocity, $a / v$ ratio.

\subsubsection{P- $\Delta$ Effects}

Analyses have been carried out by many researchers to investigate the $P-\Delta$ effect on single storey and multistorey buildings. Paulay (1978) has examined the likely effects of secondary moments due to the gravity load in a building which is being laterally displaced during inelastic seismic storey drift, by studying the response of 18 -storey ductile reinforced concrete frames. He has suggested that if strength demand due to P- $\Delta$ effect exceeds $15 \%$ of the ideal lateral load carrying capacity of a subframe, this strength demand should be met. Recommendations have been made for the estimation of critical inelastic drifts in the lower half of the frame.

Montgomery (1981) has studied the influence of P- $\Delta$ effects on the elastic and 
inelastic response of buildings subjected to earthquake ground motion. The presented results, which were based on the stability factor approach for estimating P- $\Delta$ effect, suggest that the response of certain types of well-designed buildings is not significantly influenced by P- $\Delta$ effects.

Bernal (1987) has investigated the inelastic P- $\Delta$ effects. Amplification factors to account for gravity-induced effects in inelastic dynamic response were computed. Some of the currently used P- $\Delta$ amplification factors were discussed in the light of the results obtained.

Three different amplification factors that have been proposed to account for P- $\Delta$ effects in the seismic design of multistorey building structures have been described and compared by Tremblay et al, (1999). Nonlinear dynamic analyses of a typical 20 -storey steel moment resisting frame were carried out under earthquake ground motions typical of eastern and western Canada to evaluate the gravity load effects and to assess the effectiveness of each type of amplification factor in accounting for these effects. All three approaches maintained the ductility demand within the level computed without P- $\Delta$ effects, but lateral deformations were generally larger than those obtained neglecting the gravity loads. Nonlinear dynamic analyses were also performed on a shear beam model of the same building to examine the possibility of using such simple models for studying the dynamic stability of buildings subjected to ground motions. The shear beam model did not predict adequately the seismic behavior of steel moment frame for which P- $\Delta$ effects are significant. Gupta and Krawinkler (2000) have carried out 2D and 3D dynamic analyses on three storey, nine storey and twenty storey moment-resisting steel frame located in Boston, Seattle 
and Los Angeles to study the effect of P- $\Delta$. They concluded that the seismic response becomes very sensitive to modelling assumptions and ground motion characteristics if $\mathrm{P}-\Delta$ is large and the ground motion is severe. They figured out that the long motion duration and large pulse type input accentuate $\mathrm{P}-\Delta \mathrm{effect}$. They also concluded that elastic analysis will not be able to replicate the effects of $\mathrm{P}-\Delta$ on the inelastic system response and that the static push-over analysis is very useful in understanding the behavior of the structure and in identifying P- $\Delta$ sensitivity.

\subsection{OBJECTIVES}

The main objective of this study is to address some of the issues related to the existing and proposed seismic design provisions for building structures in Canada, and where appropriate to develop recommendations for new provisions or for modifications to those existing. In order to achieve this goal, the following studies have been carried out:

(1) Development of representative values of the higher mode factor for different structural configurations.

(2) Review of the NBCC 1995 code provisions procedure for distributing the base shear across the height.

(3) Development of adjustment factors to be applied to the overturning moments obtained from the lateral forces determined by the NBCC 1995 distribution.

(4) Study of the torsional behavior of single storey building models and multistorey building models of general class for a range of parameters and investigation of the applicability of single storey results to multistorey buildings. 
(5) Evaluation of the validity and limitations of the design eccentricity expressions proposed by Humar and Kumar (1998a, and 1998b) to general class of multistorey buildings and to suggest necessary modifications, if any.

(6) Assessment of the significance of P- $\Delta$ effect in buildings subjected to earthquakes and development of a method to account for this effect.

\subsection{SCOPE OF WORK}

The scope of the work carried out in the present study is summarized in the following:

(1) Elastic dynamic analysis of several different structural types, including moment-resisting frames, braced frames, flexural walls, coupled walls and hybrid systems, are carried out to evaluate the higher mode effects and recommendations are developed for higher mode factors to be used in association with the equivalent static load method being proposed for NBCC 2005. Recommendations are also developed for the overturning moment adjustment factors.

(2) Elastic dynamic analysis of single storey building models for a range of governing parameters are carried out to evaluate the effect of torsion. Elastic dynamic analysis of multistorey building models of a general type are carried out and the applicability of the single storey results and the newly proposed design eccentricity expressions (Humar and Kumar, $1998 a$ and $1998 b$ ) is verified.

(3) Inelastic dynamic analysis of same types of buildings as mentioned in (1) are carried out to study the effect of higher modes on ductility and strength demands. The results related to 
the contribution of higher mode effects are compared with those obtained from elastic analysis.

(4) Inelastic dynamic analyses are carried out to study the P- $\Delta$ effects on building structures during earthquakes. A new method to calculate P- $\Delta$ amplification factor is proposed.

\subsection{ORGANIZATION OF THESIS}

This thesis is organized into five chapters summarized as follows:

Chapter 1 presents an introduction to the present studies. It also presents a brief discussion of the topics discussed and the problems addressed in the present study. Relevant literature is briefly reviewed. The objectives and the scope of the current work are also presented.

Chapter 2 is related to the investigation of higher mode effects in multistorey buildings. A comprehensive analytical study is performed on five types of multistorey building models: moment-resisting frames, braced frames, flexural walls, coupled walls and hybrid systems. Elastic modal analysis are carried out using the computer program SUPERETABS (Maison and Neuss, 1983). The multi-degree-of-freedom models are subjected to UHS-compatible acceleration time histories corresponding to earthquakes with a return period of 2500 years developed for selected cities in western as well as eastern Canada. The dynamic analysis results are then compared with the results obtain according to NBCC 1995 code design provisions. Adjustment factors which must be applied to the value of base shear and overturning moments obtained according to NBCC 1995 are proposed.

Chapter 3 presents a study of the effect of some important parameters on torsion 
design. Elastic dynamic response of single storey buildings and multistorey buildings of general class is investigated. Results obtained from the elastic analysis of five and ten storey building are presented. Computer program SUPER-ETABS (Maison and Neuss, 1983) is used in carrying out the linear modal spectral analysis. A wide range of building models with different values of frequency ratios $\left(\Omega_{R}=0.75,1.00\right.$, and 1.25) varying from floor to floor are analyzed to investigate their response to idealized hyperbolic spectra. The response of the multistorey building models is then compared with the response results of single storey models obtained according to the torsional design provisions of NBCC 1995 and the response results obtained according to proposed design eccentricity expressions (Humar and Kumar, $1998 a$ and 1998b).

In Chapter 4, the results of inelastic analyses carried out to study the higher mode effect on buildings are presented. A comprehensive evaluation of ductility and strength demands in multi-storey building structures is carried out. The first three types of buildings presented in Chapter 2 are analyzed. Computer program DRAIN-2DX (Prakash and Powell, 1993 ) is used in performing the analysis.

Chapter 5 discusses the significance of P- $\Delta$ effect in buildings subjected to earthquakes. In order to analytically predict the nature of P- $\Delta$ effect, a simple and practical single storey model that would represent the behavior of ductile building structure is selected. An investigation is carried out to study the effect of strength, stiffness, strain hardening, ductility and ground motion duration and frequency content on P- $\Delta$. A method is developed to account for P- $\Delta$ effect in buildings and applied to a single storey as well as a 10-storey moment resisting frame designed according to NBCC 2005 provisions. Computer program 
DRAIN-2DX (Prakash and Powell, 1993) is used in performing the analysis.

Chapter 6 includes a summary of this work and provides an overview of the conclusions reached throughout the study. It also presents a list of recommendations for future work.

A list of references is included at the end of the thesis. 
Table 1.1 Uniform hazard spectral values, $2 \%$ in 50 years robust hazard (Canada east region), (Adams et al, 2003)

\begin{tabular}{|c|c|c|c|c|c|c|c|c|c|c|c|c|}
\hline $\begin{array}{c}\text { Period } \\
(\mathrm{s})\end{array}$ & $\begin{array}{c}\text { St. } \\
\text { John's }\end{array}$ & Halifax & Moncton & $\begin{array}{c}\text { Fredr- } \\
\text { icton }\end{array}$ & $\begin{array}{c}\text { La- } \\
\text { Malbaie }\end{array}$ & Quebec & $\begin{array}{c}\text { Trois- } \\
\text { Rivieres }\end{array}$ & Montreal & Ottawa & $\begin{array}{c}\text { Niagra } \\
\text { Falls }\end{array}$ & $\begin{array}{c}\text { woronto } \\
\text { Tor- } \\
\text { sor }\end{array}$ \\
\hline 0.10 & 0.13 & 0.19 & 0.31 & 0.38 & 1.90 & 0.56 & 0.61 & 0.65 & 0.64 & 0.46 & 0.28 & 0.17 \\
\hline 0.15 & 0.15 & 0.22 & 0.29 & 0.36 & 2.20 & 0.61 & 0.67 & 0.71 & 0.69 & 0.42 & 0.28 & 0.17 \\
\hline 0.20 & 0.18 & 0.23 & 0.30 & 0.39 & 2.30 & 0.59 & 0.64 & 0.69 & 0.67 & 0.41 & 0.28 & 0.18 \\
\hline 0.30 & 0.16 & 0.19 & 0.22 & 0.29 & 1.70 & 0.43 & 0.47 & 0.50 & 0.48 & 0.31 & 0.22 & 0.14 \\
\hline 0.40 & 0.13 & 0.16 & 0.19 & 0.24 & 1.40 & 0.34 & 0.35 & 0.39 & 0.38 & 0.26 & 0.17 & 0.11 \\
\hline 0.50 & 0.11 & 0.13 & 0.16 & 0.20 & 1.20 & 0.29 & 0.31 & 0.34 & 0.32 & 0.20 & 0.14 & 0.087 \\
\hline 1.00 & 0.060 & 0.070 & 0.068 & 0.086 & 0.60 & 0.14 & 0.12 & 0.14 & 0.14 & 0.073 & 0.055 & 0.040 \\
\hline 2.00 & 0.016 & 0.019 & 0.021 & 0.027 & 0.19 & 0.048 & 0.043 & 0.048 & 0.045 & 0.021 & 0.016 & 0.011 \\
\hline
\end{tabular}

The table presents median spectral values in units of $\mathrm{g}$ The reference ground is site class $C$ (firm ground) 
Table 1.2 Uniform hazard spectral values, $2 \%$ in 50 years robust hazard (Canada west region), (Adams et al, 2003)

\begin{tabular}{|c|c|c|c|c|c|c|c|c|c|c|}
\hline $\begin{array}{c}\text { Period } \\
(\mathrm{s})\end{array}$ & Calgary & Kelowna & Kamloops & $\begin{array}{c}\text { Prince } \\
\text { George }\end{array}$ & Vancouver & Victoria & Tofino & $\begin{array}{c}\text { Prince } \\
\text { Rupert }\end{array}$ & $\begin{array}{c}\text { Queen } \\
\text { Charlotte }\end{array}$ & \begin{tabular}{c} 
Inuvik \\
\hline 0.10
\end{tabular} \\
\hline 0.10 & 0.18 & 0.18 & 0.083 & 0.83 & 1.10 & 0.45 & 0.25 & 0.44 & 0.061 \\
\hline 0.15 & 0.14 & 0.26 & 0.26 & 0.12 & 0.97 & 1.20 & 0.61 & 0.35 & 0.61 & 0.091 \\
\hline 0.20 & 0.15 & 0.28 & 0.28 & 0.13 & 0.96 & 1.20 & 0.65 & 0.38 & 0.66 & 0.10 \\
\hline 0.30 & 0.13 & 0.24 & 0.24 & 0.12 & 0.84 & 1.10 & 0.61 & 0.34 & 0.67 & 0.092 \\
\hline 0.40 & 0.10 & 0.20 & 0.20 & 0.096 & 0.74 & 0.92 & 0.54 & 0.29 & 0.65 & 0.078 \\
\hline 0.50 & 0.084 & 0.17 & 0.17 & 0.080 & 0.66 & 0.83 & 0.47 & 0.25 & 0.63 & 0.067 \\
\hline 1.00 & 0.041 & 0.089 & 0.10 & 0.041 & 0.34 & 0.38 & 0.27 & 0.17 & 0.50 & 0.039 \\
\hline 2.00 & 0.023 & 0.053 & 0.060 & 0.026 & 0.18 & 0.19 & 0.15 & 0.096 & 0.26 & 0.025 \\
\hline
\end{tabular}

The table presents median spectral values in units of $\mathrm{g}$ The reference ground is site class $\mathrm{C}$ (firm ground). 


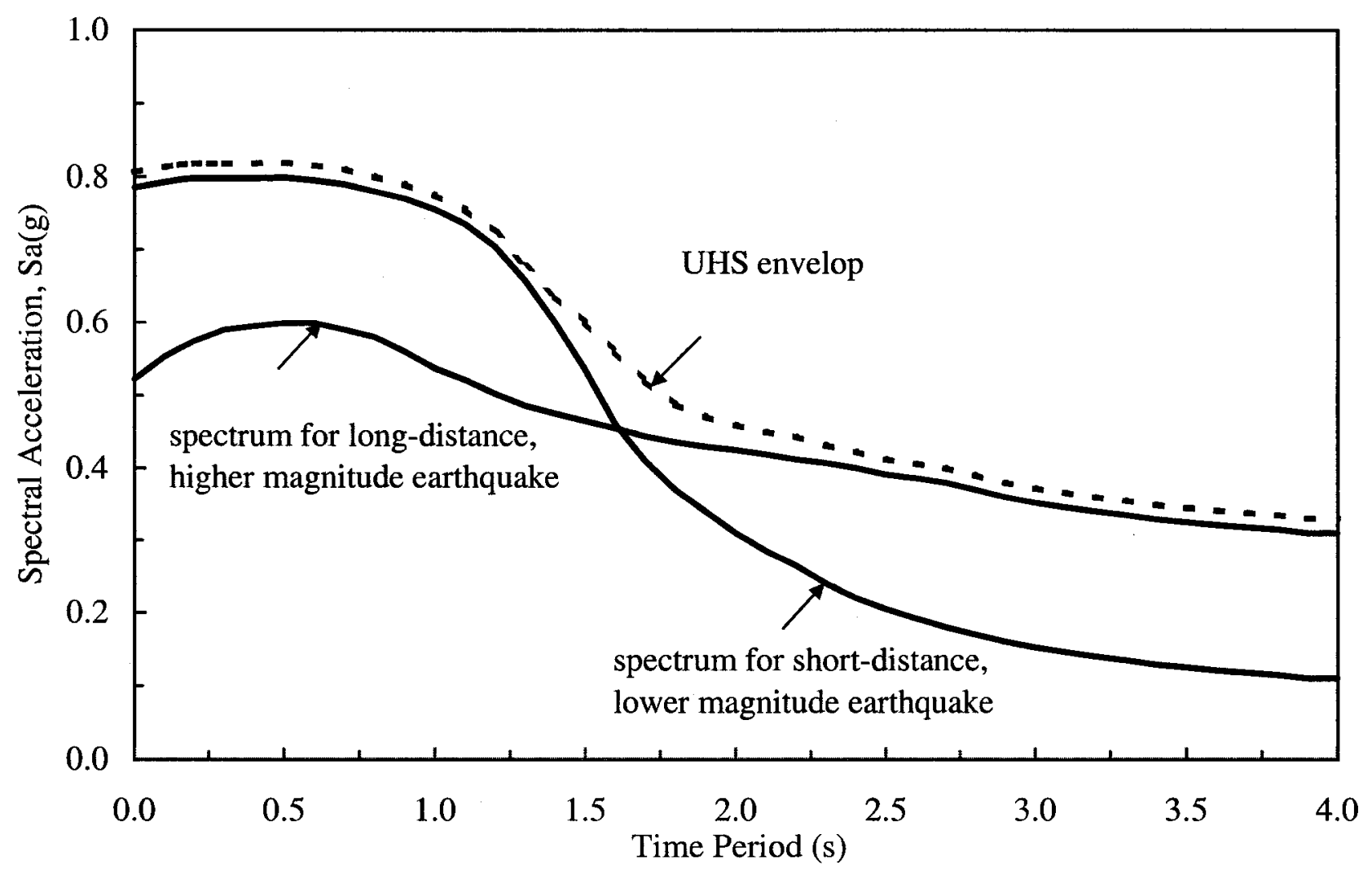

Fig. 1.1 Construction of an Elastic Uniform Hazard Spectra (UHS) 


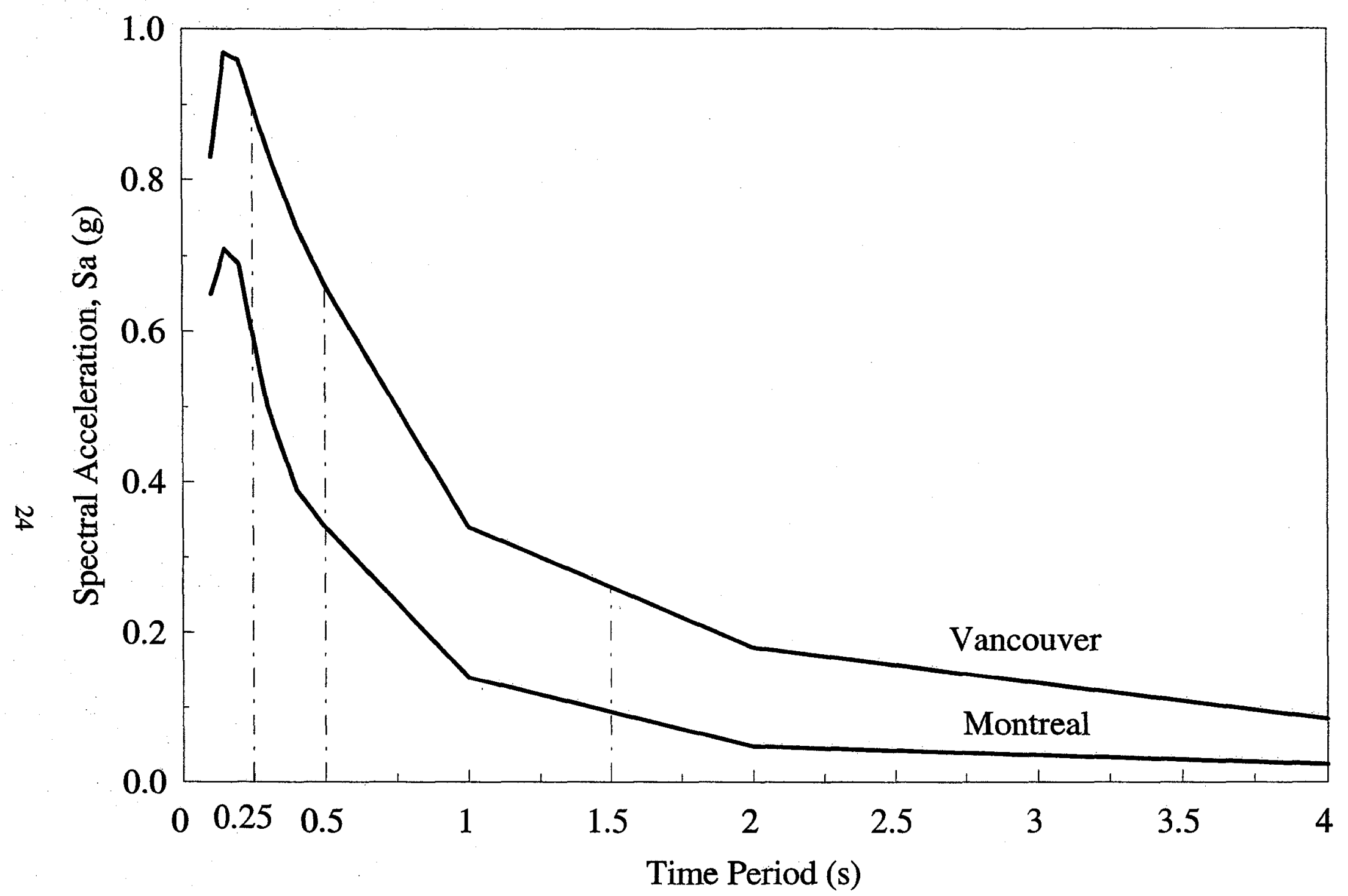

Fig. 1.2 Elastic Uniform Hazard Spectra (UHS) for Montreal (East) and Vancouver (West) 

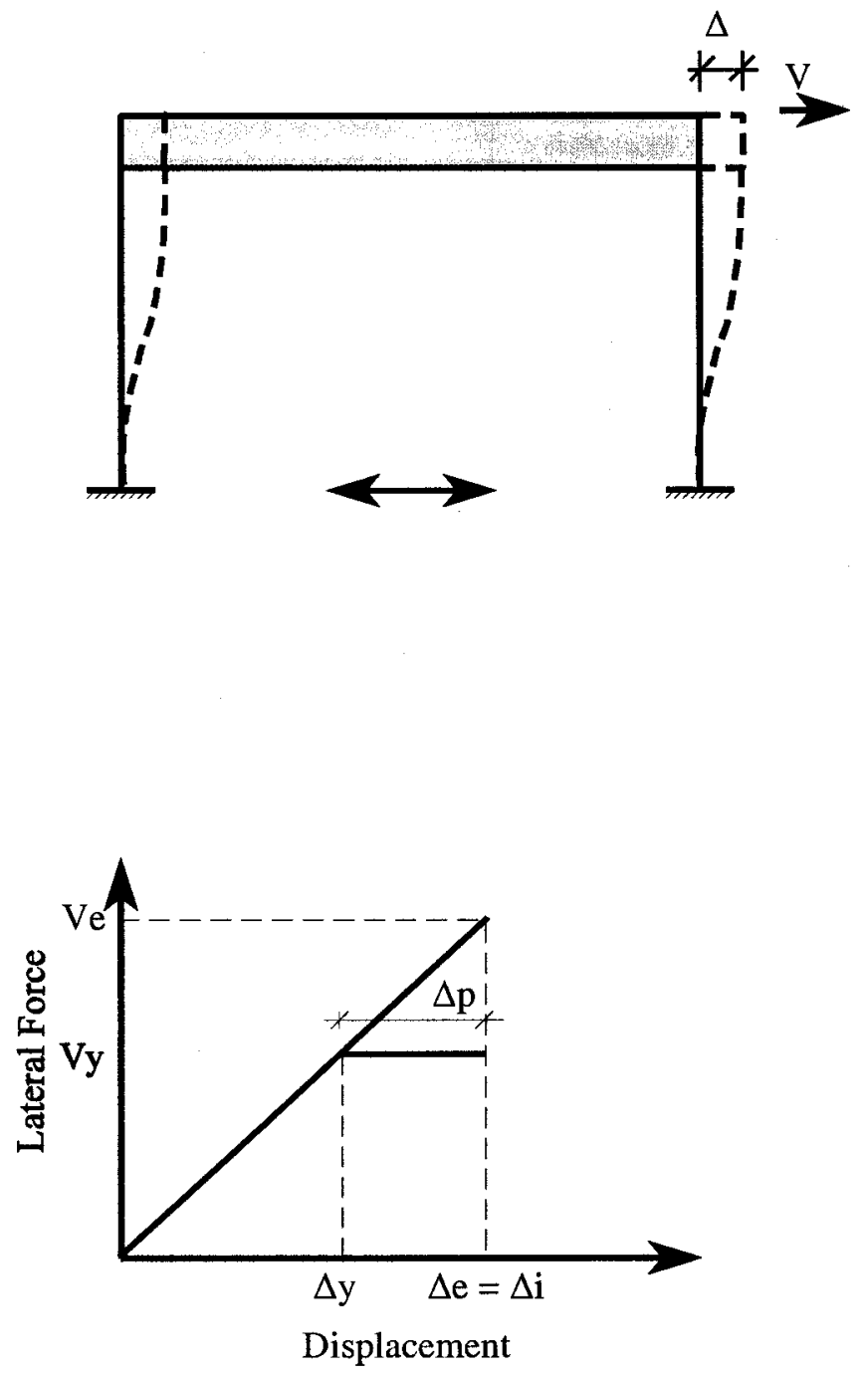

Fig. 1.3 Lateral force-displacement relationship 


\section{CHAPTER 2}

\section{HIGHER MODE EFFECT IN UHS-BASED DESIGN}

\section{$2.1 \quad$ INTRODUCTION}

For the seismic design of building structures that are regular in both plan and elevation, the National Building Code of Canada, 1995 (NBCC 1995) provides a simplified method known as the equivalent static load method. In this method, the design spectral acceleration is obtained from an idealized response spectrum that is itself derived from peak ground motion bounds for the site under consideration. The elastic base shear, $V_{e}$ is then calculated from the formula

$$
V_{e}=v I S F W
$$

where $v$ is the zonal velocity ratio for the site, $I$ is the seismic importance factor, $S$ is the seismic response factor which depends on the building fundamental period $T_{1}, F$ is the foundation factor to account for the effect of foundation soil on the spectral acceleration, and $W$ is the seismic weight of the structure at the time of earthquake.

In general, the structure is designed for only a fraction of the elastic base shear, in the expectation that during a design earthquake the structure will be strained into the inelastic range and that it possesses sufficient ductility capacity to withstand the resulting inelastic 
deformations without collapse. The design base shear is thus obtained from

$$
V=\frac{U V_{e}}{R}
$$

where $R \geq 1$ is a modification factor related to the ductility capacity of the structure and $U=0.6$ is a calibration factor. Factor $U$ is often justified on the grounds that structures designed according to the provisions of the code have been observed to have sufficient overstrength to be able to withstand forces that are significantly higher than those implied in such provisions.

The NBCC 1995 also provides empirical relationships to determine the first elastic mode period as well as the distribution of the design base shear across the height of the structure. It is evident from Eq. 2.1 that the code formula for determining the base shear is based primarily on the first mode response. In addition, the formula for distributing the base shear across the height also assumes that a major portion of the response would be in the first mode. However, in a multistorey building both the base shear and its distribution across the height are influenced by the higher elastic modes. The NBCC 1995 takes these factors into account in the following two ways; first the design response spectrum is artificially raised in the long period range to account for the effect of higher modes on the base shear, and second, in determining the seismic lateral forces at various storeys a part of the base shear is assigned as a lateral force on the top of the structure and only the remaining distributed according to the first mode.

In NBCC 2005, it is proposed that the idealized response spectrum of NBCC 1995 
be replaced by Uniform Hazard Spectra and that the effect of higher modes on the base shear be accounted for explicitly by including a higher mode factor in the base shear formula.

The base shear formula proposed in NBCC 2005 is:

$$
V=\frac{S\left(T_{1}\right) M_{v} I W}{R_{o} R_{d}}
$$

where $S\left(T_{l}\right)$ is the spectral acceleration corresponding to the fundamental period obtained from UHS and modified for the foundation effect, $R_{o}$ is a factor that accounts for dependable overstrength in the structure, factor $R_{d}$ is related to the ductility capacity of the structure, $I$ is the importance factor, and $W$ is the weight of the building contributing to the inertia forces during an earthquake. Factor $M_{v}$ in the base shear expression is meant to take account of the higher mode effect.

Because of the increased uncertainty associated with spectral acceleration values for periods greater than $2.0 \mathrm{~s}, \mathrm{NBCC} 2005$ specifies that the base shear, $V$ in Eq. 2.3 should not be less than $S(2.0) M_{v} I W /\left(R_{d} R_{o}\right)$. It is observed from Eq. 2.3 that the ductility factor $R$ of NBCC 1995 will be represented by the symbol $R_{d}$ in the new version. It is also noted that the overstrength factor $U$ of NBCC 1995 will be replaced by $1 / R_{o}$. The overstrength factor $R_{o}$ is composed of several other factors and is given by $R_{o}=R_{\varphi} R_{y} R_{s} R_{s h} R_{\text {mech }}$, where the component factors have the following meanings

(1) Nominal capacity factor, $R_{\varphi}$, which accounts for the conservatism in predicting member strength arising from the difference between the actual and nominal material strength properties. 
(2) Yield factor, $R_{y}$, which accounts for the effect of underestimating member strength capacities in the design process, because of the use of simplified and empirical expressions designed to err on the side of safety.

(3) Size factor, $R_{s}$, which accounts for the effect of overstrength resulting from the use of discrete member sizes, for example, selection of members from discrete list of available sections, and the use of limited bar sizes and arrangement in concrete structures.

(4) Strain hardening factor, $R_{s h}$, which accounts for the overstrength attributed to steel strain hardening, which is not taken into account in the design process.

(5) Mechanism factor, $R_{\text {mech }}$, which accounts for the overstrength resulting from the redistribution of internal forces in the inelastic range (e.g., strength difference between the formation of the first plastic hinge and a mechanism in frame structures).

The part of the present study reported on in this chapter deals with:

(1) development of representative values of the higher mode factor for different structural configurations.

(2) review of the NBCC 1995 procedure for distributing the base shear across the height.

(3) development of adjustment factors to be applied to the overturning moments obtained from the lateral forces determined by the NBCC 1995 distribution.

\subsection{EFFECT OF HIGHER MODE PARTICIPATION ON BASE SHEAR}

For an elastic structure, the relative contribution of higher modes depends on the spectral shape and on two dynamic characteristics of the system. These characteristics are: (1) the relative values of the modal periods $\left(T_{i} / T_{1}\right)$, and (2) the mass participation factors for 
different modes. The two sets of characteristics, in turn, depend on the structural type. For an illustration of these observations, consider two widely different structural types, a shear cantilever representing a shear frame and a flexural cantilever representing a flexural wall. In terms of the dynamic characteristics noted above, most structural types will fall between the two extremes. The relative modal periods and mass participation factors for the first five modes of the two structural types are shown in Fig. 2.1.

Consider a building structure with first mode period of $1.5 \mathrm{~s}$ and for simplicity assume that contributions from only the first two modes are significant. The design shears for the building for two different structural types and two different locations; Vancouver and Montreal, have been calculated in Table 2.1 assuming that contributions from only the first two modes are significant.

For the shear cantilever building in Vancouver, the first mode contributes a major portion of the base shear; the second mode contribution is only 0.28 times the first mode contribution. The base shear estimate obtained by taking the square root of the sum of the squares (SRSS) of the modal contributions is smaller than if the entire response is assumed to be in the first mode and an adjustment factor, $M_{v}=0.84$ must be applied to the latter to obtain a more precise value.

For a similar building located in Montreal, the first mode contribution would still be higher than that in the second mode, but in comparison to the building in Vancouver, the second mode makes a more significant contribution, as much as 0.41 times the first mode contribution. This difference is related to the spectral shape. In comparison to Vancouver, the spectral acceleration for Montreal drops more rapidly with period, so the spectral 
acceleration in the second mode is proportionally larger for Montreal. The adjustment factor, $M_{v}$ to be applied to the estimate based on the first mode alone now works out to 0.87 .

For a flexural wall building located in Vancouver the second mode contribution is larger than the first mode contribution. This is because in a wall structure the separation between the modal periods is comparatively large, the second mode period being only 0.167 times the first mode period, compared to 0.333 times the first mode period in shear frame structure. This, combined with the shape of the design spectrum, whereby the spectral acceleration drops fairly rapidly with the period, leads to a significantly higher spectral acceleration for the second and higher modes in comparison to that for the first mode. In addition, when compared to a shear frame, the modal weight for the second mode of a flexural wall constitutes a larger proportion of the total weight. A higher spectral acceleration and a higher modal weight together lead to a larger contribution from the second mode. The adjustment factor $M_{v}$ to be applied to the response based on first mode alone is still less than 1 .

When the flexural wall building is located in Montreal the second mode contribution is substantially higher than the first mode contribution. This is because of (1) the rapidly dropping spectral shape for Montreal, (2) the larger separation between modal periods, and (3) the larger modal weight for the second period. The combined effect of all these factors is such that the adjustment factor $M_{v}$ works out to 1.35 .

The foregoing discussion indicates quite clearly that the base shear obtained by using the spectral acceleration value in the UHS corresponding to the first mode period needs to be modified by a factor $M_{v}$ to get a more precise estimate of the elastic response. 


\subsection{DISTRIBUTION OF BASE SHEAR}

In the provisions of NBCC 1995, the base shear is distributed across the height of the structure according to a shape that is representative of the first mode of the structure. The force at floor level $i$ is thus given by

$$
F_{i}=\frac{w_{i} h_{i}}{\Sigma w_{i} h_{i}} V
$$

where $w_{i}$ is the weight assigned to the $i$ th storey and $h_{i}$ is the height of the $i$ th storey above the base.

For uniform floor masses and uniform storey heights the distribution shape given by Eq. 2.4 is an inverted triangle. This linear shape is a reasonably good approximation of the first mode. The code recognizes that the first mode distribution fails to account for the effect of higher modes, which tend to increase the shear in the upper storeys. Also, the higher mode effect becomes more significant as the fundamental period increases. These factors are taken into account in the code by specifying that a portion of the base shear, $F_{t}$, be assigned to top floor level and the remaining shear distributed according to Eq. 2.4 with $V$ replaced by $V-F_{t}$. The top force $F_{t}$ is given by

$$
F_{t}=\begin{array}{ll}
0 & T_{l} \leq 0.7 \\
0.07 T_{1} V & 0.7<T_{1}>3.6 \\
0.25 \mathrm{~V} & T_{l} \geq 3.6
\end{array}
$$


As pointed out earlier, the contribution of higher modes depends on both the characteristics of the structure and the shape of the response spectrum. Higher mode effects are more predominant in a flexural wall structures than in a shear frame structures. Similarly, the response of a structure located in the eastern region of Canada is affected more by contributions from higher modes when compared to a structure located in the western region. This is because of the different shapes of the spectra in the two regions. Obviously a single formula for distribution of base shear across the height cannot capture the variation caused by different structural characteristics and different spectral shapes.

The overturning moments produced by seismic forces depend both on the magnitude of the base shear and how it is distributed across the height of the structure. For a given base shear the largest overturning moments are produced when that shear is distributed according to the first mode. The moment becomes proportionally smaller when higher mode contributions are accounted for in the distribution of the base shear. Since code-prescribed distribution of shear is based predominantly on the first mode, the overturning moments calculated from such forces overestimate the true moments. The NBCC 1995 specifies correction factors to account for this phenomenon. A factor $J$ is applied to the base overturning moments while factor $J_{x}$ is applied to the overturning moment at level $x$. With a change to the UHS-based design, these factors need to be reviewed.

\subsection{METHODOLOGY FOR ESTIMATING $M_{v}$ AND $J$ FACTORS}

As pointed earlier in Chapter 1, Humar and Rahgozar (2000) have studied the variation of $M_{v}$ and $J$ factors for frame and wall models for two locations, Vancouver and 
Montreal. In their study they used the UHS for these two cities and carried out response spectrum analyses for determining $M_{\nu}$ and $J$ factors.

In the present work this study has been extended in the following manner. First, several different structural configurations, other than a frame and a wall, have been introduced. These are braced frames, coupled wall systems and hybrid systems comprising a moment frame and a wall. Second, studies have been carried out for 22 different cities, 10 located in the western region of Canada and 12 located in the eastern region.

In the present study the structure is assumed to remain elastic. Based on this assumption the adjustment factor to be applied to the base shear obtained by assuming that the entire response is in the first mode is given by

$$
M_{v}=\frac{\sqrt{\Sigma\left[S_{a}\left(T_{i}\right) W_{i}\right]^{2}}}{S_{a}\left(T_{1}\right) W}
$$

where $S_{a}\left(T_{i}\right)$ is the spectral acceleration corresponding to the ith mode having a period $T_{i}$, $W_{i}$ is the modal weight in the $i$ th mode, and $W$ is the total weight of the structure. In Eq. 2.6 the base shear obtained by taking the square root of the sum of the squares of modal base shears is assumed to be a reasonably close estimate of the true value. It is evident from Eq. 2.6 that for a given spectral shape the $M_{v}$ factor depends only on the modal periods and modal weights.

Although the shear distribution provisions of NBCC 1995 are not accurate, they may be considered as being adequate for the routine design of buildings as reasoned in a later section. The base shear obtained by modal analysis is therefore distributed according to the 
provisions of NBCC 1995 to yield storey level forces. The overturning moments calculated from these forces are compared with their values obtained directly from the response spectrum analyses to produce the overturning moment adjustment factors.

\subsection{DESCRIPTION OF THE BUILDING MODEL}

A simplified symmetric multistorey building model is selected for the present study. The building floors are assumed to be infinitely rigid in their own planes. The torsional effects are neglected so that the response of the building can be studied by analyzing a single planar frame. In fact, for facility in the use of computer program SUPER-ETABS (Maison and Neuss, 1983) employed in this study, two identical parallel single bay frames are specified in the input. The entire mass of the structure is assumed to be uniformally distributed at the floor levels. The storey height and floor mass are assumed to be uniform across the height of the building. The lateral force resisting planes are selected to be regular and simple. The resisting planes may comprise columns and beams, shear walls, or combination of these elements. Figure 2.2 shows a plan view of the building model under consideration.

The storey stiffnesses in the moment-resisting frame model are adjusted such that under a set of storey forces distributed in an inverted triangular shape the interstorey displacements are approximately the same. The displaced shape under the selected forces is thus linear. The fundamental period of the building model is now matched to a specific value by selecting an appropriate value for the modulus of elasticity. In other words the same frame configuration is used for the entire range of periods studied, but with different values of the 
modulus of elasticity. The gross moment of inertia is considered in the analysis for both concrete and steel structures. It should be noted that in the study of an elastic system such as this, the important consideration is to produce the relative modal periods and modal weights that are representative of the structural type. The shape of the individual element, the absolute values of the element stiffness, and the number of storeys are irrelevant.

The following five different types of lateral force resisting systems are considered. These systems cover most practical structural systems found in buildings:

1. Moment-resisting frame

2. Concentrically braced frame

3. Flexural wall

4. Coupled flexural wall

5. Hybrid frame-wall system

\subsubsection{Moment Resisting Frame (MRF)}

In this case, each of the lateral force-resisting planes is a single-bay 10-storey steel frame comprised of rigidly connected beams and columns. The frame width is taken to be $8.0 \mathrm{~m}$. The ratio of the beam stiffness to the sum of the column stiffnesses in each storey is taken as $1 / 4$. This is representative of a strong-column-weak-beam system which is the system preferred by most seismic codes. The mass tributary at each level of the frame is taken as $55.18 \mathrm{Mg}$. An elevation of the frame indicating the values of element stiffnesses is shown in Fig. 2.3a. The member moments of inertia are also shown. As stated earlier, the modulus of elasticity is varied to obtain a desired period. 


\subsubsection{Concentrically Braced Frame}

Two different single-bay braced steel frame structures are used for the study. Each frame is modelled as a simple vertical truss. The first braced frame, shown in Fig. 2.3b, consists of 2-storey cross bracing. The frame is 8 storeys high, has a width of $8.0 \mathrm{~m}$ and a storey height of $3.6 \mathrm{~m}$. The modulus of elasticity is assumed to vary. The section properties of the various elements of the frame are shown in the figure. The mass tributary to each level of the frame is taken as $55.18 \mathrm{Mg}$. The second braced frame, shown in Fig. 2.3c, employs Chevron bracing. The frame is 12 storeys high, has a bay width of $8.0 \mathrm{~m}$ and a storey height of $3.8 \mathrm{~m}$. The cross-section properties of the various members are shown in the figure. The storey tributary mass is taken as $55.18 \mathrm{Mg}$.

\subsubsection{Flexural Wall}

A 10-storey flexural concrete wall system is used. The wall has a uniform width of $8.0 \mathrm{~m}$ and a uniform thickness of $0.4 \mathrm{~m}$ across the height, as shown in Fig. 2.3d. The modulus of elasticity is assumed to vary. The mass tributary at each storey level is taken as $55.18 \mathrm{Mg}$.

\subsubsection{Coupled Flexural Walls}

This structural system consists of two 12-storey flexural concrete walls connected to each other with concrete beams. The connections between the beams and walls are considered to be rigid. Each wall is $0.4 \mathrm{~m}$ thick and $8.0 \mathrm{~m}$ wide. The width of the beams is 
taken as $0.4 \mathrm{~m}$. The modulus of elasticity is assumed to vary. Analyses are carried out with 6 different beam depths $200,400,600,800,1000$, and $1200 \mathrm{~mm}$. The geometry of the structure and the cross-section properties of individual elements are shown in Fig. 2.4a. The storey tributary mass is taken as $91.46 \mathrm{Mg}$.

\subsubsection{Hybrid Frame-Wall System}

This system consists of a 12-storey moment- resisting steel frame connected by axially rigid links to a flexural concrete wall. The geometry and cross-sectional dimensions are shown in Fig. 2.4b. The wall width is taken as a variable and analysis is repeated with 6 different wall widths $3.0,4.0,5.0,6.0,7.0$, and $8.0 \mathrm{~m}$. The moduli of elasticity are assumed to vary but the $\mathrm{E}$ for concrete is taken as $1 / 10$ the $\mathrm{E}$ for steel. The tributary mass at each storey is $91.46 \mathrm{Mg}$.

\subsection{ANALYSIS PROCEDURES}

Since most structures are expected to remain elastic during moderate earthquakes, their dynamic response in the elastic range should be assessed to verify that the structures meet the serviceability requirements. An elastic analysis also provides insight into the nature of inelastic behavior of the structure. With these considerations this part of the study focuses on elastic behavior of the structures.

As mentioned in the preceding section, multistorey building structures of five different types are selected for study. The buildings are assumed to be located in twenty two cities in Canada, ten in the western region and twelve in the eastern region. 
A step-by-step implementation of the spectral dynamic analysis can be summarized as follows:

(1) The geographic location of the structure is selected and the associated elastic UHS is identified. Studies are conducted for each of the twenty two Canadian cities considered.

(2) The four types of the structures: moment-resisting frames, two types of concentrically braced frames, and flexural wall systems are analyzed for 7 different values of the fundamental period and for the 22 locations. The coupled flexural wall and the hybrid systems are analyzed for 2 locations, Montreal in the east and Vancouver in the west; and 7 fundamental periods. For the coupled flexural wall model 6 different beam depths are used, while for the hybrid system 6 different wall widths are used. In all cases the seven fundamental periods selected are $T_{1}=0.5,0.7,1.0,1.5,2.0,2.5$, and $3.0 \mathrm{~s}$. Axial deformations in both beams and columns are neglected and P- $\Delta$ effect is not included in the analysis.

(3) For any given structural system, selected location, and fundamental period the code base shear $V_{b c}$ is obtained from the following equation:

$$
V_{b c}=S_{a}\left(T_{1}\right) W
$$

where $S_{a}\left(T_{1}\right)$ is the spectral acceleration corresponding to the fundamental period, obtained from UHS.

(4) A response spectrum analysis is carried out using computer program SUPER-ETABS (Maison and Neuss, 1983) and the UHS as the input response spectrum. A more precise estimate of the base shear, $V_{b e}$ is obtained by taking the square root of the sum of the squares 
of the modal responses. The base shear adjustment factor is then calculated from

$$
M_{v}=\frac{V_{b e}}{V_{b c}}
$$

(5) Base shear, $V_{b e}$ is distributed according to the NBCC 1995 provisions using Eqs. 2.4 and 2.5 to obtain the storey level forces. These forces are used to calculate the storey level overturning moments $M_{x c}$ and the base overturning moment $M_{b c}$. More precise estimates for these parameters are then obtained from the response spectrum analysis. These estimated values are designated as $M_{x e}$ and $M_{b e}$, respectively. The storey level overturning moment adjustment factor $J_{x}$ and the base overturning moment adjustment factor $J$ are now given by

$$
\begin{gathered}
J_{x}=\frac{M_{x e}}{M_{x c}} \\
J=\frac{M_{b e}}{M_{b c}}
\end{gathered}
$$

\subsection{ANALYTICAL RESULTS AND DISCUSSION}

Free vibration linear dynamic analyses are carried out for all structure models under consideration. This section presents the results of the analyses.

\subsubsection{Modal Periods and Modal Masses}

The analyses yield the modal periods as well as the effective modal masses. The 
relative modal periods are presented in Table 2.2 for the five selected systems and the first ten modes. The effective modal masses are shown in Table 2.3. Several observations can be made from the data presented. In comparison to the moment-resisting frame the flexural wall exhibits a larger spread between the first mode period and the higher mode periods. Also, the higher mode effective masses are relatively larger in flexural walls than in moment-resisting frames. Thus, in a flexural wall higher modes account for $35.50 \%$ of the total mass while in a moment-resisting frame they account for only $25.90 \%$ of the total mass. A braced system lies between a moment-resisting frame and a flexural wall system. The coupled wall system shown in Tables 2.2 and 2.3 behaves like a moment-resisting frame. The hybrid system shown is similar in its behavior to a flexural wall system.

\subsubsection{Moment Resisting Frame, Braced Frame, and Flexural Wall Base Shear and Base Overturning Moment}

Analytical results for base shear and base overturning moment for a moment-resisting frame, a concentrically braced frame with cross braces, and flexural wall having fundamental periods of $T_{I}=0.5,0.7,1.0,1.5,2.0,2.5$, and $3.0 \mathrm{~s}$ are presented in Tables $2.4,2.5$ and 2.6 for the cities of Montreal and Vancouver. Results for all 22 locations including Montreal and Vancouver are presented in the form of graphs in Figs. 2.5 through 2.10. The curves related to Montreal and Vancouver are shown in bold lines. The following observations can be made on the basis of results presented:

(1) Base shear and overturning moment adjustment factors $M_{v}$ and $J$ are both period dependent. Factor $M_{v}$ increases with period while factor $J$ decreases with period. The rate of 
increase of $M_{v}$ and the rate of decrease of $J$ with period are both higher for the eastern region than for the western region. For example, in the west $M_{v}$ factor varies between 0.687 and 1.197, while in the east it ranges from 0.748 to 3.701 . Factor $J$ varies from 1.026 to 0.611 in the west, while it varies from 0.950 to 0.304 in the east.

(2) Both $M_{v}$ and $J$, are strongly dependent on the characteristic of the ground motion. For the same fundamental period, structures subjected to records in the east usually have larger $M_{v}$ factor and lower $J$ factor values than their counterparts in the west. This can be attributed to the difference in the spectral shapes for the two regions. Thus, in the east the spectrum drops more rapidly with period in comparison to that in the west. A consequence of this is that the higher mode contribution is more predominant in the east than in the west.

(3) Based on the analytical results obtained for the 22 cities, empirical expressions suitable for simplified code provisions are derived for $M_{v}$ and $J$ values for use in design. These values are shown in Table 2.7 for three structural types: moment-resisting frame, braced frame, and wall. The values vary with period and differ for the western and eastern regions. A single straight line, rather than a series of straight lines joining the mean values at selected periods, is used to maintain simplicity. In a few cases where the calculated values for a large urban centre, such as Montreal, lie significantly above the mean, the straight line representing $M_{v}$ and $J$ factors is selected to be close to the values for urban centre under reference. In Table 2.7 , the two regions are identified by the spectral ratio $S_{a}(0.2) / S_{a}(2.0)$. This ratio is less than 8.0 for the western region and more than 8.0 for the eastern region where the spectrum drops more rapidly with the period. For the purpose of comparison the empirical design values of $M_{v}$ and $J$ are shown by dashed lines on Figs. 2.5 through 2.10 . 
(4) It will be noted that the design values of $M_{v}$ and $J$ are assumed to be constant for $T_{l} \geq 2.0 \mathrm{~s}$. The rational for this is as follows. The Geological Survey of Canada has supplied spectral acceleration values for periods greater than $2.0 \mathrm{~s}$. However, these values have been derived by an indirect procedure and there is considerable uncertainty associated with them. The code proposals specify that for the purpose of design the spectral accelerations for periods greater than $2.0 \mathrm{~s}$ should be taken as equal to that at $T_{I}=2.0 \mathrm{~s}$. With this assumption $M_{v}$ and $J$ can be taken as being constant for $T_{1}>2.0$.

The UHS values used in calculating $M_{v}$ and $J$ factors in this chapter have changed in the process of code development. However, the changes are not very large and, most importantly, they do not significantly change the shape of the curves between $T_{i}=0$ to $2 \mathrm{~s}$, used in developing the NBCC code provisions.

It should be noted that $M_{v}$ and $J$ values presented in Table 2.7 are expected to be somewhat conservative. These values were derived by response spectrum analyses in which the UHS was used as the input response spectrum. However, as illustrated in Fig. 1.1, UHS is not the spectrum obtained from a single earthquake, but the composite of the spectral values contributed by different earthquakes (equivalent to simultaneous occurrence of small local and large distant events).

Figure 2.11 shows the long period and the short period UHS for the city of Montreal. These spectra have been derived from spectrum compatible ground motion records developed by Atkinson and Beresnev, (2003). If modal superposition is used to obtain the response of a multistorey building located in Montreal, at least two sets of analyses would be required, one with each of the two simulated spectra shown in Fig. 2.11. The larger of the 
response values obtained from the two analyses would provide the design forces. For illustration, consider a 10 storey moment-resisting frame structure located in Montreal. The first two modal periods of the structure are $1.0 \mathrm{~s}$ and $0.388 \mathrm{~s}$, respectively, as indicated in Fig. 2.11. Considering only the first two modes, a modal superposition analysis in which the resultant response is obtained by taking the square root of the sum of the squares (SRSS) of modal responses gives a base shear equal to $0.433 \mathrm{~W}$ when the long-period spectrum shown by a dashed line is used, and $0.439 \mathrm{~W}$ when the short-period spectrum shown by solid line is used. The design shear can thus be taken as $0.439 \mathrm{~W}$. Now if the envelope of the two spectra, which is representative of UHS, is used in the mode superposition analysis the base shear works out to $0.458 \mathrm{~W}$. In the present example use of UHS in a mode superposition analysis overestimates the base shear by 4.34 percent.

It is apparent that the use of UHS in a mode superposition analysis would lead to conservative results. For the spectra shown in Fig. 2.11, this is so whenever the period is longer than that at the crossover point, that is, longer than about $0.40 \mathrm{~s}$. The degree of conservatism is not however large. A number of calculations, similar to the ones illustrated above, for different regions of the country have shown that the overestimate is no more than $5 \%$, and in most cases, significantly smaller. This degree of conservatism is for most practical purposes quite insignificant. It is therefore acceptable to use a UHS in carrying out a mode superposition analysis, and this assumption has been made in arriving at the results presented in the remaining parts of this thesis. 


\section{Distribution of Shear and Overturning Moment}

Figures 2.12, 2.13 and 2.14 show the variation of normalized shear $V_{x e} / V_{b e}$ across the height of the structure for the three structural types referred to earlier, where $V_{x e}$ represents the shear at level $x$ as obtained from the response spectrum analysis. For the purpose of comparison the normalized shears resulting from forces obtained by distributing the base shear according to the provisions of NBCC 1995 as well as in the shape of an inverted triangle are also shown. The only difference between an NBCC 1995 and a triangular distribution is that NBCC 1995 provides for a top force $F_{t}$ determined from Eq. 2.5 while the triangular distribution has no top force.

It is observed that the triangular distribution results in an underestimation of the shear in the upper storeys and an overestimation in the lower storeys. By providing a top force $F_{t}$ the NBCC 1995 distribution compensates partially for the underestimation of shear in the upper storeys, but the difference still persists. The discrepancy between the distribution obtained from a response spectrum analysis and that given by NBCC 1995 provisions is larger for structures in the east than in the west and is larger for flexural wall structures and smaller for moment-resisting frames. The nature of discrepancy between the response spectrum distribution and NBCC 1995 distribution can be explained on the basis of the relative contribution of higher modes for different structural types and spectral shapes. Although it is recognized that the NBCC 1995 method for the distribution of shear is not precise, it is considered as being reasonable for the purpose of the code design provisions. No alternative way is therefore proposed and the overturning moment adjustment factors 
derived in the subsequent paragraphs are based on the existing NBCC 1995 provisions for the distribution of shear.

Figures $2.15,2.16$ and 2.17 show the variation of normalized overturning moment $M_{x e} /\left(V_{b e} H\right)$ across the height of the structure where $M_{x e}$ is the overturning moment at level $x$ obtained from a response spectrum analysis, and $H$ is the total height of the structure. For the purpose of comparison the normalized overturning moments obtained when $V_{b e}$ is distributed across the height in an inverted triangle shape, and according to the provisions of NBCC 1995 are also shown. The triangular and the NBCC 1995 distribution both overestimate the overturning moment in the lower storeys. The difference is larger in the eastern region than in the western region, and is largest for a flexural wall and smallest for a moment-resisting frame. Again, the nature of discrepancy between the response spectrum distribution and the other two distributions can be explained on the basis of the relative contribution of higher modes. In almost all cases the overturning moment in the upper storeys obtained from response spectrum is slightly larger than that given by the inverted triangular distribution or the NBCC 1995 distribution. This can be attributed to the fact that the NBCC 1995 and triangular distributions both underestimate the shear in the upper storeys. When the shear is distributed across the height in an empirical manner, say according to the NBCC 1995 provisions, the overturning moment at level $x, M_{x}$ can be obtained from

$$
M_{x c}=\Sigma_{i=x}^{n} F_{i}\left(h_{i}-h_{x}\right)
$$

where $h_{x}=$ the height from the base to level $x$ and $F_{i}=$ the seismic force at level $i$. 
An adjustment factor $J_{x}$ must be applied to $M_{x c}$ to obtain a better estimate of the overturning moment. Theoretically $J_{x}$ is given by

$$
J_{x}=\frac{M_{x e}}{M_{x c}}
$$

where $M_{x e}$ is the overturning moment at level $x$ obtained from the response spectrum analysis.

The variation of $J_{x}$ across the height is shown in Fig. 2.18 for a flexural wall having a fundamental period of $2.0 \mathrm{~s}$, for both the western and the eastern regions. Factor $J_{x}$ is seen to be significantly greater than 1 in the upper storeys, however, the absolute values of overturning moments are not large in these storeys, hence from the point of view of design it is sufficient to take $J_{x}=1$ in these storeys. Based on the above consideration and the shape of the variation of $J_{x}$, the following simple expressions are proposed for $J_{x}$

$$
\begin{array}{ll}
J_{x}=1.0 & \text { for } h_{x} \geq 0.6 \mathrm{H} \\
J_{x}=J+(1-J)\left(h_{x} / h_{n}\right) & \text { for } h_{x}<0.6 \mathrm{H}
\end{array}
$$

where $H$ is the total height of the structure, and $J$ is the overturning reduction factor at the base of the structure, given by Eq. $2.9 \mathrm{~b}$.

\subsubsection{Coupled Flexural Walls}

Coupled flexural wall structures shown in Fig. 2.4a, are often used in buildings to resist the lateral loads. The model considered here is a 12-storey coupled walls system. The 
storey height is taken to be $3.65 \mathrm{~m}$. The structure consists of two flexural walls, $2.0 \mathrm{~m}$ apart, each is $8.0 \mathrm{~m}$ in width and $0.4 \mathrm{~m}$ in thickness. The two walls are connected to each other by a rigid beam of $0.4 \mathrm{~m}$ width at each floor level. Response spectrum analyses are carried out for different combinations of connecting beam depths $(d=0.2,0.4,0.6,0.8,1.0$, and $1.2 \mathrm{~m})$, and different fundamental time periods $\left(T_{1}=0.5,0.7,1.0,1.5,2.0,2.5\right.$, and $\left.3.0 \mathrm{~s}\right)$ for two Canadian cities: Vancouver (West), and Montreal (East).

Figures 2.19 and 2.20 show the variation of the $M_{v}$ and $J$ factors with period for six different coupled flexural walls systems. For the sake of comparison, the figures also show the values of $M_{v}$ and $J$ factors for a moment-resisting frame and an isolated flexural wall. It will be observed from Figs. 2.19 and 2.20 that, as expected, the response of the coupled wall system lies between that of a moment-resisting frame and an isolated flexural wall. When the beam is very flexible $(d=0.2 \mathrm{~m})$, the system behaves like an isolated wall; when the beam is stiff ( $d=1.2 \mathrm{~m}$ ), the system behaves like a moment-resisting frame. In most practical structures the beams in a truly coupled system would be stiff enough that the coupled wall system can be assumed to behave like a moment-resisting frame.

The foregoing observations can be further verified by referring to Fig. 2.21, which shows the variation of shear across the height for a coupled wall system having a fundamental period of $2.0 \mathrm{~s}$ and located in Montreal. The thick solid curves in the figure represent the shear distribution obtained from a response spectrum analyses. The thin solid curve shows the variation of shear distribution according to NBCC 1995 with the base shear obtained by using $M_{v}$ corresponding to a wall while the short-dashed curve shows NBCC 1995 distribution in which the base shear is determined using $M_{v}$ appropriate for a frame. 
When the beam depth is $0.2 \mathrm{~m}$, the response spectrum values are higher than those for a frame and closer to those for a wall. For beam depth of $1.2 \mathrm{~m}$, the distribution is similar to that for a frame. It is observed from the analysis that the dynamic behavior of the coupled flexural wall system is similar to that of the frame structure for beam depths $>0.4 \mathrm{~m}$ which would cover most realistic building models.

The Canadian Reinforced Concrete Code (CSA A23.3 1994) states that in order to qualify for treatment as a coupled wall system, a majority of the overturning moment in the system must be carried through axial loads in the wall elements. The code specifies that the degree of coupling provided by the wall system should be $\geq 66.67 \%$. The degree of coupling is defined as the ratio of the base overturning moment carried by axial tension and compression forces in the walls (caused by lateral forces), to the total overturning moment. Tables 2.8 presents the degree of coupling of a flexural wall system located in Montreal for different combinations of connecting beam depths $(d=0.2 \mathrm{~m}$ to $1.2 \mathrm{~m})$ for fundamental time period, $T_{I}=1.5 \mathrm{~s}$. It should be noted that the values presented in the table are obtained from first mode as implied by CSA A23.3 1994. It is observed from the values presented in the table that all models with beam depths greater than $0.4 \mathrm{~m}$ qualify as ductile coupled wall systems. Figures 2.19 and 2.20 show that for such system the response is close to that for a frame.

\subsubsection{Hybrid Systems}

A hybrid system is defined here as one in which the lateral forces are shared by moment-resisting frames and flexural walls. An idealized model of a hybrid system is shown 
in Fig. 2.4b. The selected model is a 12-storey structure with a storey height of $3.65 \mathrm{~m}$. It consists of a moment-resisting frame, $8.0 \mathrm{~m}$ in width, connected by rigid links to a flexural wall that is $0.4 \mathrm{~m}$ thick and has varying width.

Response spectrum analyses are carried out for different combinations of wall widths $(w=3.0,4.0,5.0,6.0,7.0$, and $8.0 \mathrm{~m})$, fundamental time periods $\left(T_{l}=0.5,0.7,1.0,1.5,2.0\right.$, 2.5, and $3.0 \mathrm{~s}$ ), and two Canadian locations: Vancouver (West), and Montreal (East).

Figures 2.22 and 2.23 show the variation of $M_{v}$ and $J$ with the fundamental period for different hybrid systems. For the purpose of comparison, the figures also show the values of $M_{v}$ and $J$ factors for moment-resisting frame and flexural wall systems. As would be expected the response of a hybrid system lies between those for a flexural wall and a moment-resisting frame. When the wall width is very small, $2.0 \mathrm{~m}$, the system behaves essentially like a moment-resisting frame. When the wall width is larger, 7.0 or $8.0 \mathrm{~m}$, the system behaves essentially like a wall. In most practical structures the flexural wall will be considerably stiffer than the frame, so that the hybrid system will behave more like a wall. The above observation will be confirmed by referring to Fig. 2.24 which shows the distribution of shear across the height of the building as obtained from a response spectrum analysis. For the purpose of comparison, the NBCC 1995 distributions of base shear obtained by using $M_{v}$ factor for flexural wall and moment-resisting frame are also shown. For a wall width of $2.0 \mathrm{~m}$ the distribution is closer to that for a frame; for a wall width of $8.0 \mathrm{~m}$ it is approaching that for a wall. Again, as noted earlier the NBCC 1995 distribution tends to underestimate the shear in the upper storeys and overestimate that in the lower storeys. 


\subsection{SUMMARY AND CONCLUSIONS}

The equivalent static procedures included in many seismic codes including NBCC 1995 specify that the elastic base shear be obtained from a design response spectrum using the first mode period of the structure under consideration. The elastic base shear is then reduced by a factor that reflects the capacity of the structure to undergo inelastic deformation without collapse. In NBCC 1995 the elastic response spectrum is obtained by applying appropriate amplification factors to the peak ground motion bounds. In recent years methodologies have been developed that allow the direct determination of maximum spectral accelerations for specified values of the period and for a given probability of exceedance. The maximum spectral accelerations for a $5 \%$ damped single-degree-of-freedom system can be represented by a uniform hazard spectrum. Since the spectral acceleration values for different periods may be contributed by different earthquakes, a UHS is not the same as the

response spectrum of a single earthquake. Consequently when used in a modal analysis a UHS will provide somewhat conservative values of the response of a multi-degree-offreedom system. However, this conservatism is not excessive and the results of such modal analysis can still be used for the purpose of design.

In an equivalent static procedure of design based on UHS, the elastic base shear will be determined by finding the spectral acceleration corresponding to the first mode period of the structure. This processes ignores the effect of higher modes on response. Adjustment factors that must be applied to the base shear determined from the first mode period to obtain a better estimate are derived in the present study for several different structural types 
including moment-resisting frames, braced frames, flexural walls, coupled flexural walls and hybrid systems.

The corrected base shear can be distributed across the height according to the NBCC 1995 procedures. However, because the NBCC 1995 distribution is primarily in the form of the first mode, the resulting overturning moments generally overestimate the true moments which arise from a combination of various modes. Adjustment factors to be applied to the overturning moments determined from NBCC 1995 distribution are also derived in this study for the various structural types.

The following conclusions can be drawn from the results presented here:

(1) The base shear adjustment factors $M_{v}$, and the overturning moment reduction factor $J$ are both dependent on the characteristics of the lateral force-resisting system. Factor $M_{v}$ is largest for a flexural wall system and smallest for a moment-resisting frame. On the other hand, factor $J$ is smallest for a flexural wall and largest for a moment-resisting frame.

(2) Factors $M_{v}$ and $J$ also depend on the first mode period $T_{1}$. Thus $M_{v}$ increases with $T_{l}$ while $J$ decreases with $T_{1}$.

(3) Factors $M_{v}$ and $J$ strongly depend on the shape of the response spectrum. In comparison to the western regions of Canada, the UHS for the eastern regions drop more rapidly with the period. Thus the higher mode contribution is more predominant in east; as a consequence $M_{v}$ factors are larger and $J$ factors are lower for the eastern region.

(4) The distribution of shear across the height as specified in the current provision of NBCC 1995 is reasonable, but still underestimates the shear in the upper storeys while overestimating it in the lower storeys. 
(5) The underestimation of shear in the upper storeys also leads to underestimation of the overturning moments in those storeys. It is therefore proposed that the expression for $J_{x}$ be revised. A new formula for $J_{x}$ that is simpler than the current version is proposed.

(6) The dynamic behavior of a practical coupled flexural wall system is expected to be similar to that of a frame so that $M_{\nu}$ and $J$ factors for a moment-resisting frame can be applied to a coupled wall structure as well.

(7) The dynamic behavior of a practical hybrid system comprising a flexural wall and a moment-resisting frame is expected to be closer to that of a flexural wall so that factors $M_{v}$ and $J$ for a wall can be applied to the hybrid system too. 
Table 2.1 Design shears in a building of two different structural types located in Vancouver and Montreal

\begin{tabular}{|c|c|c|c|c|c|c|c|c|c|c|c|}
\hline $\begin{array}{l}\text { Structure } \\
\text { Type }\end{array}$ & $\begin{array}{l}1^{\text {st mode }} \\
\text { period }\end{array}$ & $\begin{array}{l}2^{\text {nd }} \text { mode } \\
\text { period }\end{array}$ & $\begin{array}{c}\text { Modal } \\
\text { weight } \\
1^{\text {st mode }}\end{array}$ & $\begin{array}{c}\text { Modal } \\
\text { weight } \\
2^{\text {nd }} \text { mode }\end{array}$ & $\begin{array}{l}\text { Spectral } \\
\text { accelera- } \\
\text { tion (g) in } \\
1^{\text {st }} \text { mode }\end{array}$ & $\begin{array}{l}\text { Spectral } \\
\text { accelera- } \\
\text { tion }(\mathrm{g}) \text { in } \\
2^{\text {nd }} \text { mode }\end{array}$ & $\begin{array}{l}\text { Base } \\
\text { shear in } \\
1^{\text {st mode }}\end{array}$ & $\begin{array}{c}\text { Base } \\
\text { shear in } \\
2^{20} \text { mode }\end{array}$ & $\begin{array}{l}\text { SRSS } \\
\text { shear }\end{array}$ & $\begin{array}{l}\text { Base shear } \\
\text { assuming } \\
\text { entire response } \\
\text { in } 1^{1 t} \text { mode }\end{array}$ & $\mathbf{M}_{\mathbf{v}}$ \\
\hline \multicolumn{12}{|l|}{ Vancouver } \\
\hline $\begin{array}{l}\text { Shear. } \\
\text { Cantilever }\end{array}$ & 1.50 & 0.50 & $0.811 W$ & $0.090 \mathrm{~W}$ & 0.260 & 0.660 & $0.211 W$ & $0.059 \mathrm{~W}$ & $0.219 W$ & $0.260 \mathrm{~W}$ & 0.843 \\
\hline $\begin{array}{l}\text { Flexural } \\
\text { Cantilever }\end{array}$ & 1.50 & 0.25 & $0.616 \mathrm{~W}$ & $0.188 \mathrm{~W}$ & 0.260 & 0.900 & $0.160 \mathrm{~W}$ & $0.169 \mathrm{~W}$ & $0.233 W$ & $0.260 \mathrm{~W}$ & 0.896 \\
\hline \multicolumn{12}{|l|}{ Montreal } \\
\hline $\begin{array}{l}\text { Shear } \\
\text { Cantilever }\end{array}$ & 1.50 & 0.50 & $0.811 \mathrm{~W}$ & $0.090 \mathrm{~W}$ & 0.094 & 0.340 & $0.076 \mathrm{~W}$ & $0.031 \mathrm{~W}$ & $0.082 W$ & $0.094 \mathrm{~W}$ & 0.872 \\
\hline $\begin{array}{l}\text { Flexural } \\
\text { Cantilever }\end{array}$ & 1.50 & 0.25 & $0.616 \mathrm{~W}$ & $0.188 W$ & 0.094 & 0.600 & $0.058 \mathrm{~W}$ & $0.113 W$ & $0.127 \mathrm{~W}$ & $0.094 W$ & 1.351 \\
\hline
\end{tabular}


Table 2.2 Modal periods for the five selected structural systems $\left(T_{1}=0.5 \mathrm{~s}\right)$

\begin{tabular}{|c|c|c|c|c|c|}
\hline \multirow{2}{*}{$\begin{array}{c}\text { Mode } \\
\text { Number }\end{array}$} & MRF & $\begin{array}{c}\text { Braced } \\
\text { Frame II }\end{array}$ & Wall & $\begin{array}{c}\text { Coupled walls } \\
\left(b^{*}=0.6 \text { m }\right)\end{array}$ & \begin{tabular}{c} 
Hybrid \\
$\left(w^{*}=8.0 ~\right.$ \\
\cline { 2 - 6 } )
\end{tabular}
\end{tabular}

$* b=$ link beam depth and $w=$ wall width 
Table 2.3 Modal masses in percent of total mass for the five selected structural systems

\begin{tabular}{|c|c|c|c|c|c|}
\hline \multirow{2}{*}{$\begin{array}{c}\text { Mode } \\
\text { Number }\end{array}$} & \multicolumn{5}{|c|}{ Global effective modal mass (as percent of total mass) } \\
\cline { 2 - 6 } & MRF & $\begin{array}{c}\text { Braced } \\
\text { Frame } \boldsymbol{I I}\end{array}$ & Wall & $\begin{array}{c}\text { Coupled walls } \\
(\boldsymbol{b = 0 . 6} \boldsymbol{m})\end{array}$ & $\begin{array}{c}\text { Hybrid } \\
(\boldsymbol{w = 8 . 0} \boldsymbol{m})\end{array}$ \\
\hline $\mathbf{1}$ & 74.10 & 71.70 & 64.50 & 75.30 & 64.60 \\
\hline $\mathbf{2}$ & 11.80 & 19.10 & 19.80 & 11.30 & 19.00 \\
\hline $\mathbf{3}$ & 5.10 & 5.20 & 6.80 & 5.10 & 6.70 \\
\hline $\mathbf{4}$ & 3.00 & 1.70 & 3.50 & 2.90 & 3.40 \\
\hline $\mathbf{5}$ & 2.00 & 1.40 & 2.10 & 1.80 & 2.10 \\
\hline $\mathbf{6}$ & 1.40 & 0.60 & 1.40 & 1.20 & 1.40 \\
\hline $\mathbf{7}$ & 1.00 & 0.20 & 0.90 & 0.90 & 1.00 \\
\hline $\mathbf{8}$ & 0.80 & 0.10 & 0.60 & 0.60 & 0.70 \\
\hline $\mathbf{9}$ & 0.60 & 0.00 & 0.40 & 0.40 & 0.50 \\
\hline $\mathbf{1 0}$ & 0.20 & 0.00 & 0.00 & 0.30 & 0.40 \\
\hline Totals & 100 & 100 & 100 & 99.80 & 99.80 \\
\hline
\end{tabular}

$* b=$ link beam depth and $w=$ wall width 
Table 2.4 Base shear and overturning moment values for a moment-resisting frame

\begin{tabular}{|c|c|c|c|c|c|c|}
\hline \multicolumn{7}{|c|}{ Vancouver } \\
\hline $\begin{array}{l}T_{1} \\
(s)\end{array}$ & $\begin{array}{c}V_{b e} \\
(k N)\end{array}$ & $\begin{array}{c}V_{b \boldsymbol{c}} \\
(k N)\end{array}$ & $\begin{array}{c}M_{\nu}= \\
V_{b e} / V_{b c}\end{array}$ & $\begin{array}{c}M_{b e} \\
(k N . m)\end{array}$ & $\begin{array}{c}M_{b c} \\
(k N . m)\end{array}$ & $\begin{array}{c}J= \\
M_{b e} / M_{b c}\end{array}$ \\
\hline 0.5 & 1307.44 & 1705.15 & 0.767 & 31845.32 & 32032.19 & 0.994 \\
\hline 0.7 & 1078.06 & 1391.18 & 0.775 & 25984.31 & 26412.34 & 0.984 \\
\hline 1.0 & 737.32 & 920.24 & 0.801 & 17193.40 & 18606.26 & 0.924 \\
\hline 1.5 & 563.98 & 690.18 & 0.817 & 12897.17 & 14439.37 & 0.893 \\
\hline 2.0 & 396.15 & 460.12 & 0.861 & 8602.20 & 10287.89 & 0.836 \\
\hline 2.5 & 369.53 & 443.88 & 0.833 & 8295.09 & 9732.51 & 0.852 \\
\hline 3.0 & 351.34 & 427.64 & 0.822 & 7990.38 & 9382.61 & 0.852 \\
\hline \multicolumn{7}{|c|}{ Montreal } \\
\hline $\begin{array}{l}T_{1} \\
(s)\end{array}$ & $\begin{array}{c}V_{b e} \\
(k N)\end{array}$ & $\begin{array}{c}V_{b c} \\
(k N)\end{array}$ & $\begin{array}{c}M_{v}= \\
V_{b e} / V_{b c}\end{array}$ & $\begin{array}{c}M_{b e} \\
(k N . m)\end{array}$ & $\begin{array}{c}M_{b c} \\
(k N . m)\end{array}$ & $\begin{array}{c}J= \\
M_{b e} / M_{b c}\end{array}$ \\
\hline 0.5 & 724.41 & 920.24 & 0.787 & 17190.83 & 17747.93 & 0.969 \\
\hline 0.7 & 563.12 & 703.71 & 0.800 & 13147.93 & 13796.53 & 0.953 \\
\hline 1.0 & 629.56 & 378.92 & 0.870 & 7085.34 & 8316.44 & 0.852 \\
\hline 1.5 & 233.99 & 254.42 & 0.920 & 4759.78 & 5990.69 & 0.795 \\
\hline 2.0 & 147.41 & 129.92 & 1.135 & 2436.75 & 3828.11 & 0.637 \\
\hline 2.5 & 115.42 & 97.44 & 1.185 & 1852.49 & 3039.75 & 0.609 \\
\hline 3.0 & 92.58 & 64.96 & 1.425 & 1271.61 & 2472.36 & 0.514 \\
\hline
\end{tabular}


Table 2.5 Base shear and overturning moment values for a braced frame

\begin{tabular}{|c|c|c|c|c|c|c|}
\hline \multicolumn{7}{|c|}{ Vancouver } \\
\hline $\begin{array}{l}T_{1} \\
(s)\end{array}$ & $\begin{array}{c}V_{b e} \\
(k N)\end{array}$ & $\begin{array}{c}V_{b c} \\
(k N)\end{array}$ & $\begin{array}{c}M_{v}= \\
V_{b e} / V_{b c}\end{array}$ & $\begin{array}{c}M_{b e} \\
(k N . m)\end{array}$ & $\begin{array}{c}M_{b c} \\
(k N . m)\end{array}$ & $\begin{array}{c}J= \\
M_{b e} / M_{b c}\end{array}$ \\
\hline 0.5 & 1051.12 & 1364.12 & 0.771 & 20947.84 & 21442.85 & 0.977 \\
\hline 0.7 & 893.27 & 1112.95 & 0.803 & 17115.91 & 18222.77 & 0.939 \\
\hline 1.0 & 635.01 & 736.19 & 0.863 & 11352.92 & 13327.68 & 0.852 \\
\hline 1.5 & 490.52 & 552.14 & 0.888 & 8523.59 & 10439.18 & 0.817 \\
\hline 2.0 & 362.24 & 368.09 & 0.984 & 5709.40 & 7815.630 & 0.731 \\
\hline 2.5 & 329.43 & 355.10 & 0.928 & 5491.10 & 7204.67 & 0.762 \\
\hline 3.0 & 299.18 & 342.11 & 0.875 & 5275.54 & 6631.04 & 0.796 \\
\hline \multicolumn{7}{|c|}{ Montreal } \\
\hline $\begin{array}{l}T_{1} \\
(s)\end{array}$ & $\begin{array}{c}V_{b e} \\
(k N)\end{array}$ & $\begin{array}{c}V_{b c} \\
(k N)\end{array}$ & $\begin{array}{c}M_{v}= \\
V_{b e} / V_{b c}\end{array}$ & $\begin{array}{c}M_{b e} \\
(k N . m)\end{array}$ & $\begin{array}{c}M_{b c} \\
(k N . m)\end{array}$ & $\begin{array}{c}J= \\
M_{b e} / M_{b c}\end{array}$ \\
\hline 0.5 & 601.54 & 736.19 & 0.817 & 11329.30 & 12271.40 & 0.923 \\
\hline 0.7 & 490.02 & 562.97 & 0.870 & 8685.65 & 9996.47 & 0.869 \\
\hline 1.0 & 308.17 & 303.14 & 1.017 & 4710.63 & 6467.91 & 0.728 \\
\hline 1.5 & 218.34 & 203.53 & 1.073 & 3170.63 & 4646.62 & 0.682 \\
\hline 2.0 & 151.74 & 103.93 & 1.460 & 1658.97 & 3273.87 & 0.507 \\
\hline 2.5 & 118.83 & 77.95 & 1.524 & 1264.28 & 2598.85 & 0.486 \\
\hline 3.0 & 87.85 & 51.97 & 1.691 & 870.62 & 1947.21 & 0.447 \\
\hline
\end{tabular}


Table 2.6 Base shear and overturning moment values for a flexural wall

\begin{tabular}{|c|c|c|c|c|c|c|}
\hline \multicolumn{7}{|c|}{ Vancouver } \\
\hline $\begin{array}{l}T_{1} \\
(s)\end{array}$ & $\begin{array}{c}V_{b e} \\
(k N)\end{array}$ & $\begin{array}{c}V_{b c} \\
(k N)\end{array}$ & $\begin{array}{c}M_{\nu}= \\
V_{b e} / V_{b c}\end{array}$ & $\begin{array}{c}M_{b e} \\
(k N . m)\end{array}$ & $\begin{array}{c}M_{b c} \\
(k N . m)\end{array}$ & $\begin{array}{c}J= \\
M_{b e} / M_{b c}\end{array}$ \\
\hline 0.5 & 1172.25 & 1705.15 & 0.687 & 29456.11 & 28720.11 & 1.026 \\
\hline 0.7 & 1006.20 & 1391.18 & 0.728 & 24146.40 & 24652.41 & 0.779 \\
\hline 1.0 & 777.21 & 920.24 & 0.845 & 16251.68 & 19612.86 & 0.829 \\
\hline 1.5 & 679.61 & 690.18 & 0.985 & 12458.52 & 17399.66 & 0.716 \\
\hline 2.0 & 550.90 & 460.12 & 1.197 & 8605.32 & 14306.85 & 0.601 \\
\hline 2.5 & 509.49 & 443.88 & 1.148 & 8206.83 & 13418.58 & 0.612 \\
\hline 3.0 & 481.78 & 427.64 & 1.127 & 7858.83 & 12865.83 & 0.611 \\
\hline \multicolumn{7}{|c|}{ Montreal } \\
\hline $\begin{array}{l}T_{1} \\
(s) \\
\end{array}$ & $\begin{array}{r}V_{b e} \\
(k N)\end{array}$ & $\begin{array}{r}V_{b c} \\
(k N)\end{array}$ & $\begin{array}{c}M_{v}= \\
V_{b e} / V_{b c}\end{array}$ & $\begin{array}{c}M_{b e} \\
(k N . m)\end{array}$ & $\begin{array}{c}M_{b c} \\
(k N . m) \\
\end{array}$ & $\begin{array}{c}J= \\
M_{b e} / M_{b c}\end{array}$ \\
\hline 0.5 & 688.21 & 920.24 & 0.748 & 16022.59 & 16861.02 & 0.950 \\
\hline 0.7 & 588.86 & 703.71 & 0.837 & 12409.32 & 14427.07 & 0.860 \\
\hline 1.0 & 450.48 & 378.92 & 1.189 & 7087.98 & 11367.88 & 0.624 \\
\hline 1.5 & 390.48 & 254.42 & 1.535 & 5079.14 & 9997.24 & 0.508 \\
\hline 2.0 & 307.86 & 129.92 & 2.370 & 3060.77 & 7995.15 & 0.383 \\
\hline 2.5 & 261.20 & 97.44 & 2.681 & 2420.52 & 6879.32 & 0.352 \\
\hline 3.0 & 240.40 & 64.96 & 3.701 & 1952.78 & 6419.85 & 0.304 \\
\hline
\end{tabular}


Table 2.7 Proposed base shear and overturning moment adjustment Factors, $M_{v}$ and $J$ for different structural systems

\begin{tabular}{|c|l|c|c|c|c|}
\hline \multirow{3}{*}{$S_{a}(0.2) / S_{a}(2.0)$} & $\begin{array}{l}\text { Type of lateral } \\
\text { force resisting } \\
\text { system }\end{array}$ & $\begin{array}{c}\boldsymbol{M}_{\boldsymbol{v}} \text { for } \\
\boldsymbol{T} \leq \mathbf{1 . 0}\end{array}$ & $\begin{array}{c}\boldsymbol{M}_{v} \text { for } \\
\boldsymbol{T} \geq \mathbf{2 . 0}\end{array}$ & $\begin{array}{c}\boldsymbol{J} \text { for } \\
\boldsymbol{T} \leq \mathbf{0 . 5}\end{array}$ & $\begin{array}{c}\boldsymbol{J} \text { for } \\
\boldsymbol{T} \geq \mathbf{2 . 0}\end{array}$ \\
\hline \multirow{3}{*}{$\mathbf{1 . 0}$ but $<\mathbf{8 . 0}$} & $\begin{array}{l}\text { Moment } \\
\text { resisting frame }\end{array}$ & 1.0 & 1.0 & 1.0 & 1.0 \\
\cline { 2 - 6 } & Braced frame & 1.0 & 1.0 & 1.0 & 0.8 \\
\cline { 2 - 6 } & Wall & 1.0 & 1.2 & 1.0 & 0.7 \\
\hline \multirow{3}{*}{$\mathbf{8 . 0}$} & $\begin{array}{l}\text { Moment } \\
\text { resisting frame }\end{array}$ & 1.0 & 1.2 & 1.0 & 0.7 \\
\cline { 2 - 6 } & Braced frame & 1.0 & 1.5 & 1.0 & 0.5 \\
\cline { 2 - 6 } & Wall & 1.0 & 2.5 & 1.0 & 0.4 \\
\hline
\end{tabular}

Notes:

Values of $M_{v}$ between periods of 1.0 and $2.0 \mathrm{~s}$ are to be obtained by linear interpolation.

Values of $J$ between periods of 0.5 and $2.0 \mathrm{~s}$ are to be obtained by linear interpolation. 
Table 2.8 Degree of coupling of flexural wall system located in Montreal $\left(T_{I}=1.5 \mathrm{~s}\right)$

\begin{tabular}{|c|c|c|c|}
\hline $\begin{array}{c}\text { Connecting beam } \\
\text { depth (m) }\end{array}$ & $\begin{array}{c}\text { Axial force in } \\
\text { each wall (kN) }\end{array}$ & $\begin{array}{c}\text { Base Moment in } \\
\text { each wall (kN.m) }\end{array}$ & $\begin{array}{c}\text { Degree of coupling } \\
(\mathbf{\%})\end{array}$ \\
\hline 0.2 & 1597.43 & 29574.69 & 27.01 \\
\hline 0.4 & 3913.52 & 30973.49 & 63.18 \\
\hline 0.6 & 4960.73 & 31946.56 & 77.64 \\
\hline 0.8 & 5480.20 & 32401.87 & 84.57 \\
\hline 1.0 & 5764.19 & 32640.03 & 88.30 \\
\hline 1.2 & 5927.86 & 32759.44 & 90.48 \\
\hline
\end{tabular}




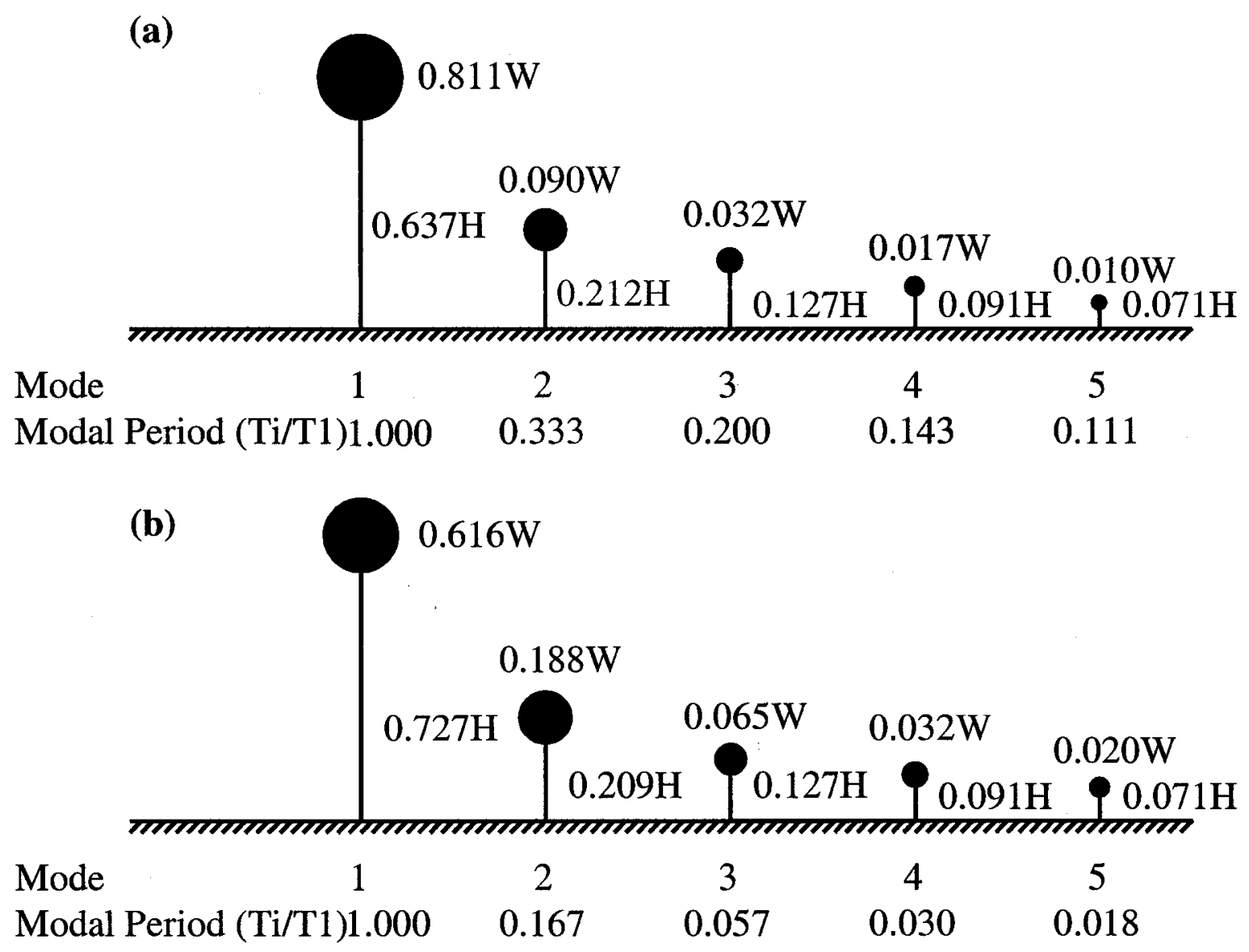

Fig. 2.1 Modal weights and effective moment arms for:

(a) Shear cantilever beam, and

(b) flexural cantilever beam 


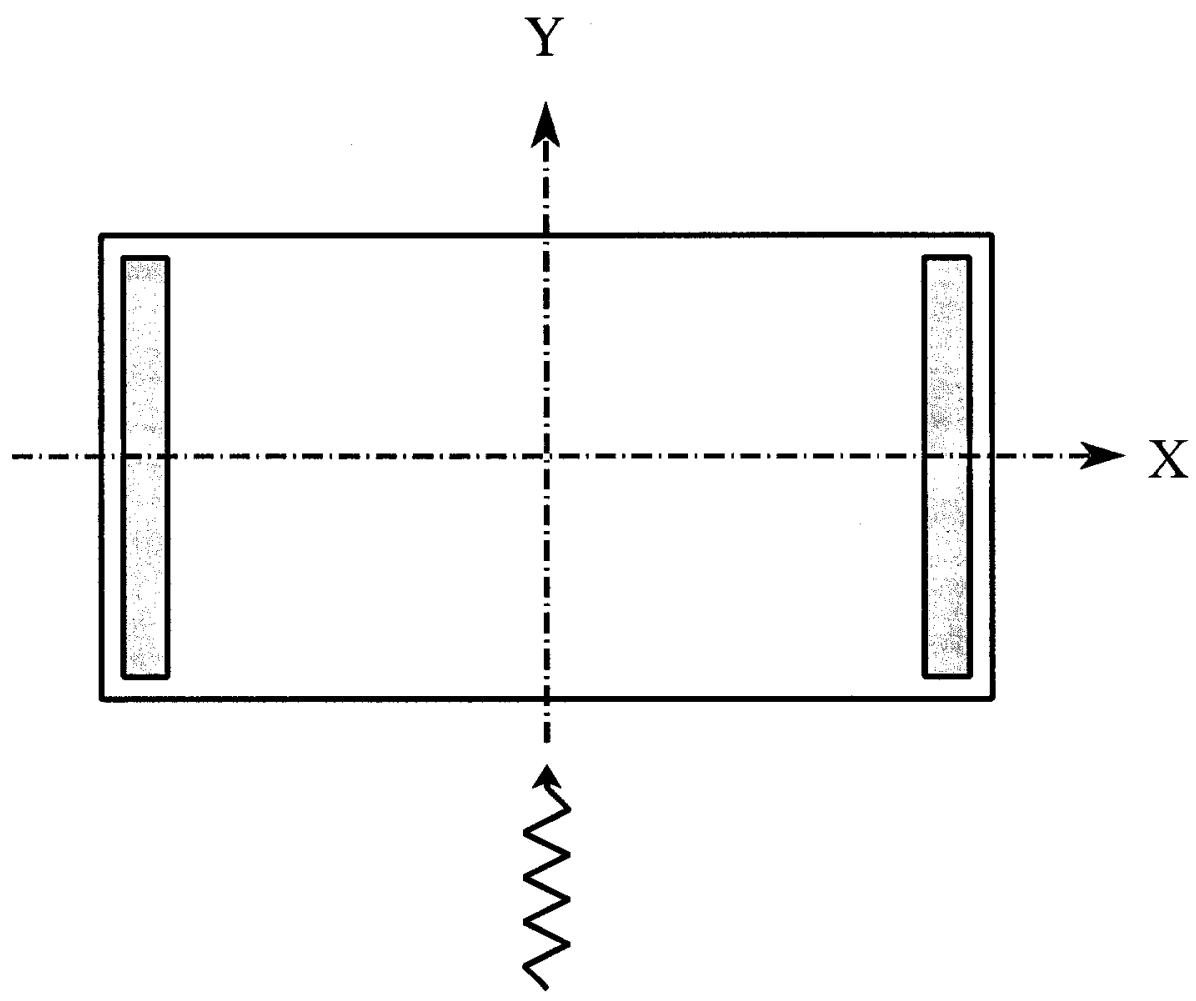

Earthquake direction

Fig. 2.2 Plan view of the structure model 


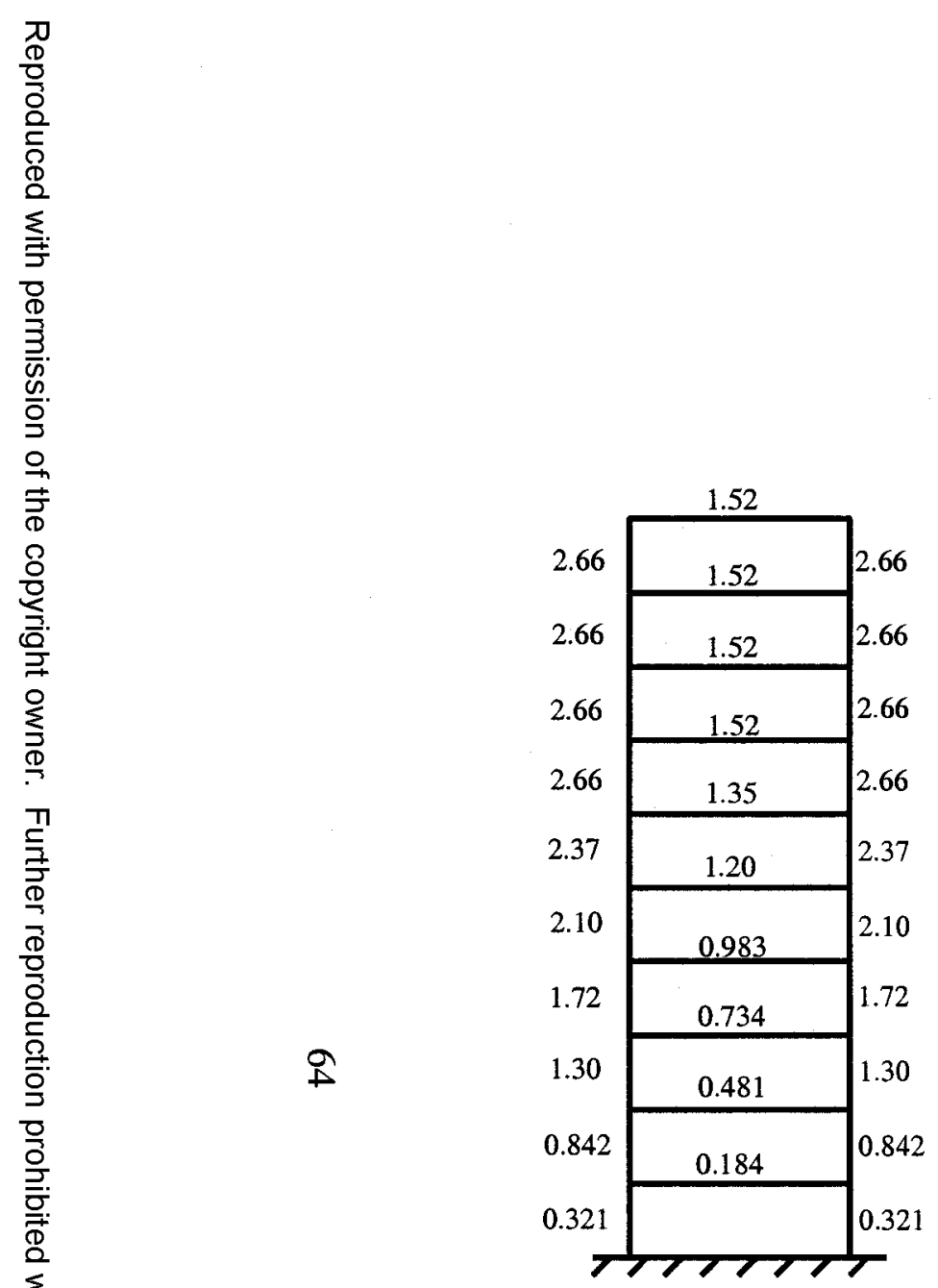

(a)

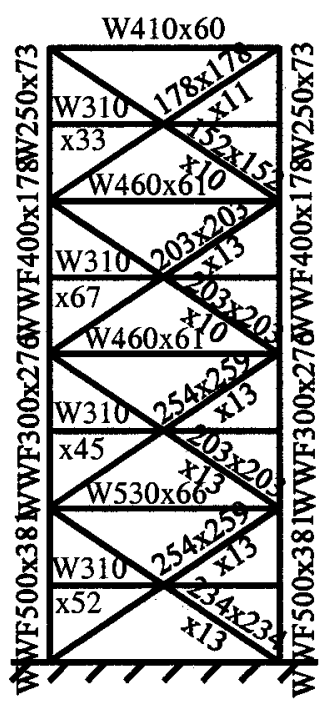

(b)

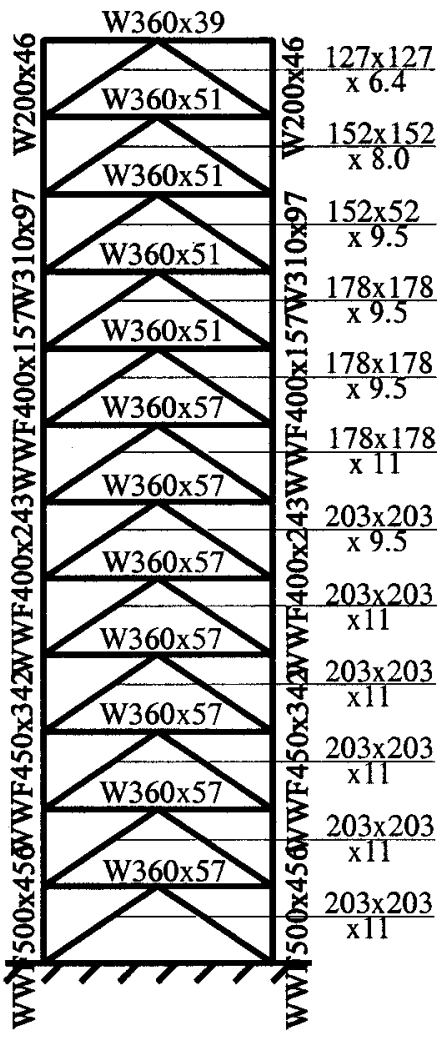

(c)

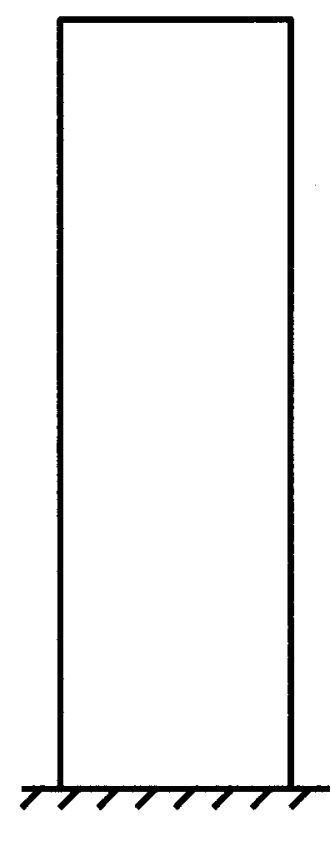

(d)

Fig. 2.3 Elevation of selected structural models, (a) moment-resisting frame, (b) braced frame with cross bracing, (c) braced frame with Chevron bracing, (d) flexural wall 

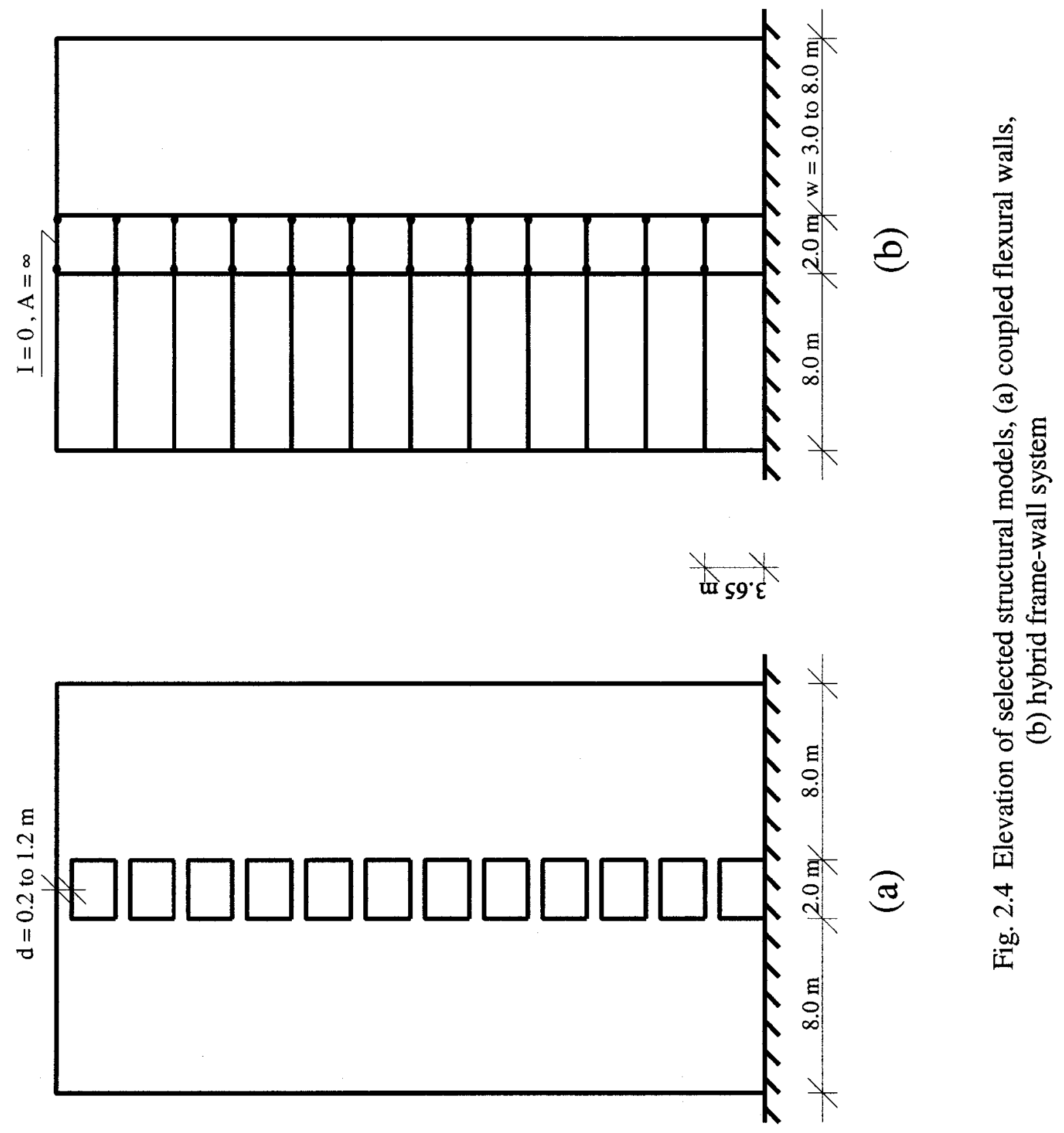


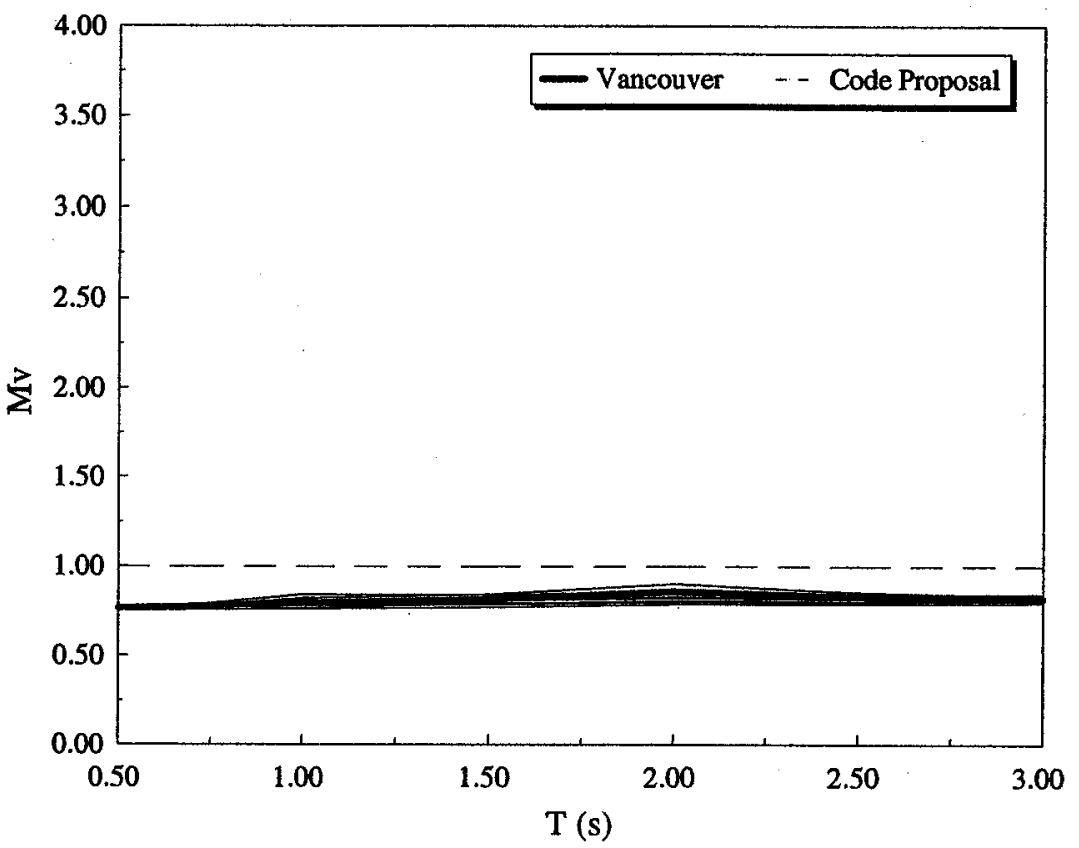

(a)

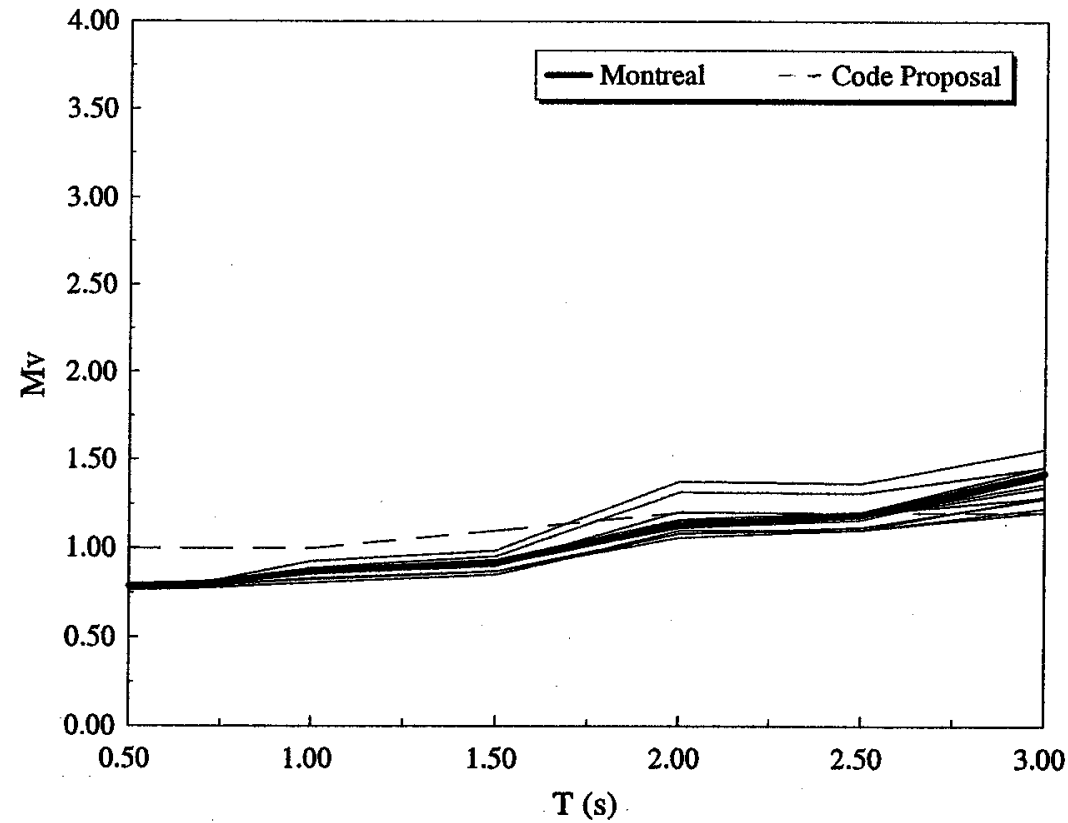

(b)

Fig. 2.5 Variation of Mv factor with period for MRF structures (a) Cities in the west (b) Cities in the east 


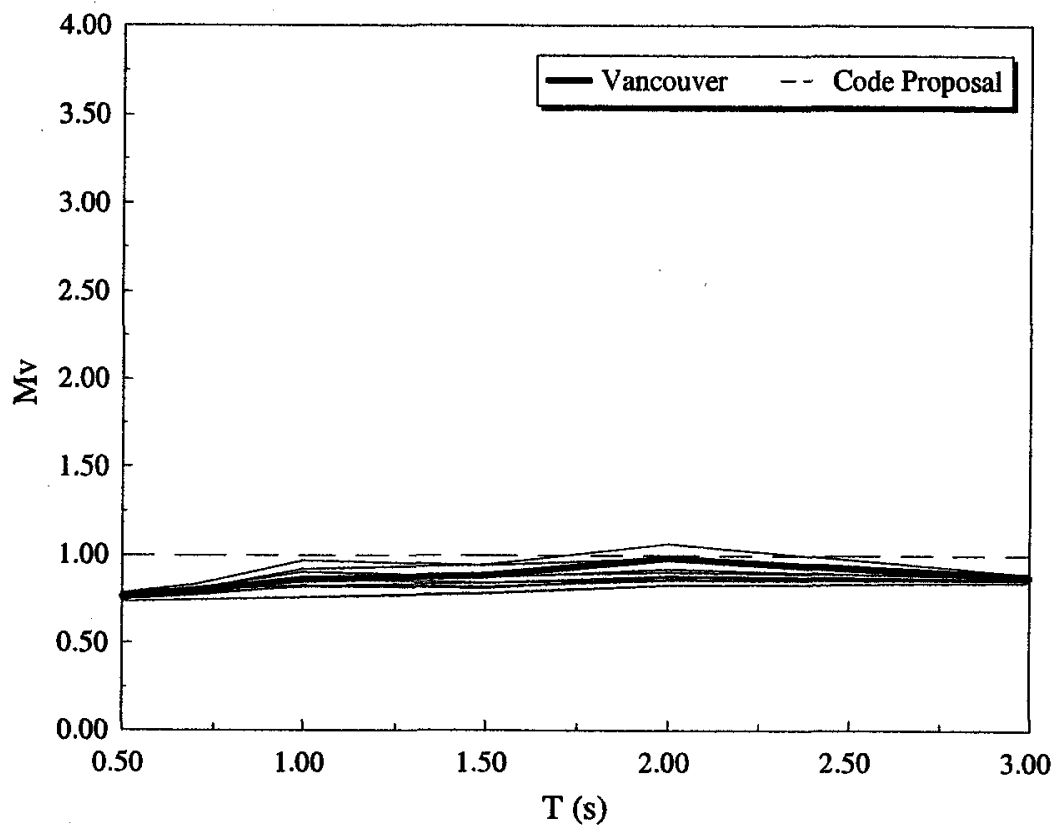

(a)

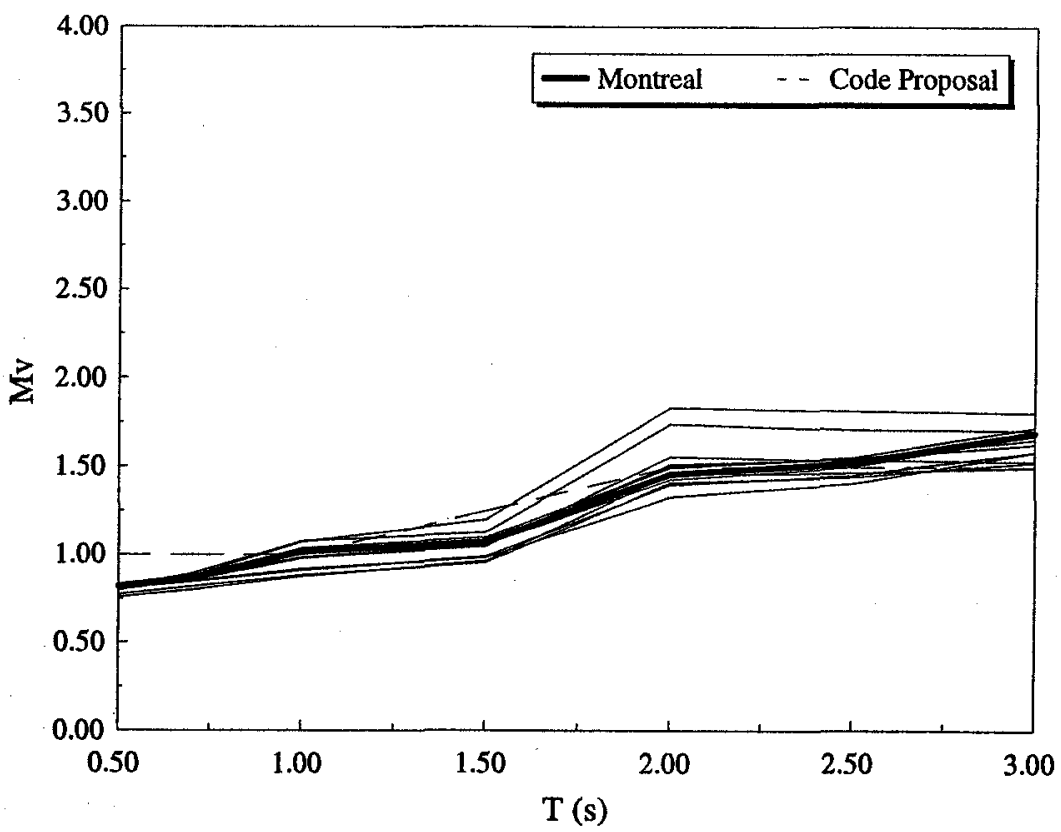

(b)

Fig. 2.6 Variation of $\mathrm{Mv}$ factor with period for braced frame structures (a) Cities in the west (b) Cities in the east 


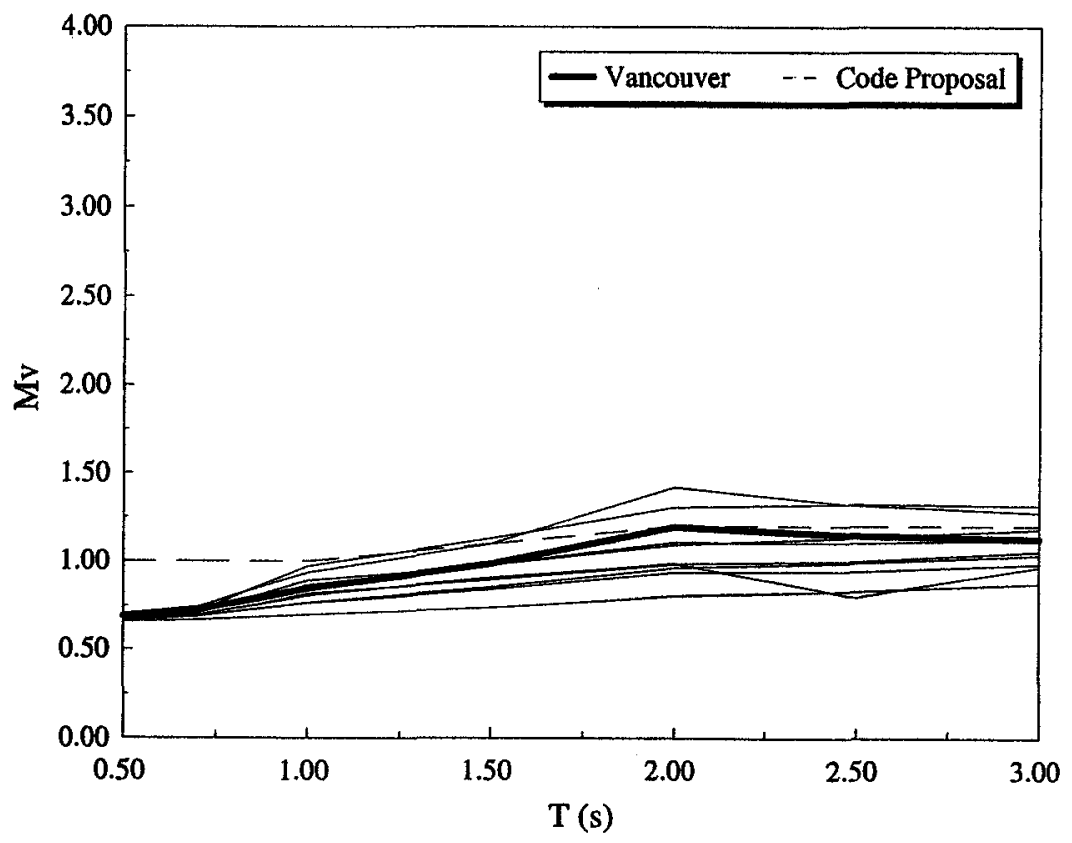

(a)

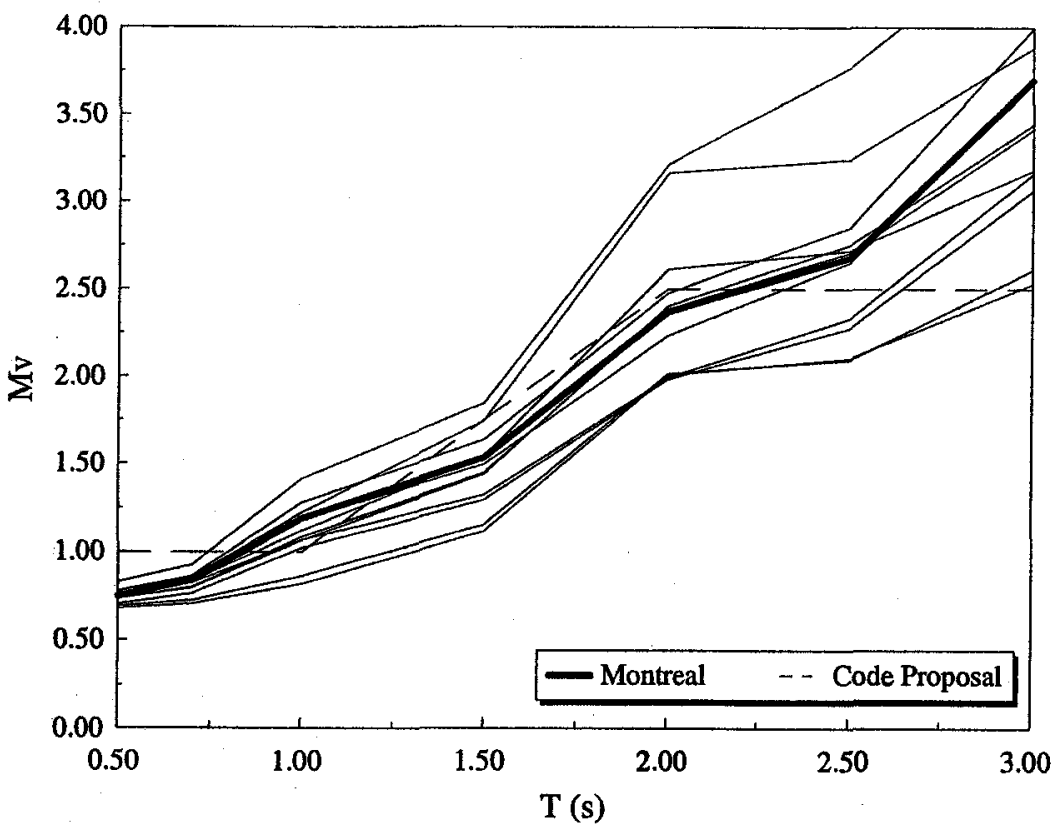

(b)

Fig. 2.7 Variation of Mv factor with period for wall structures (a) Cities in the west (b) Cities in the east 


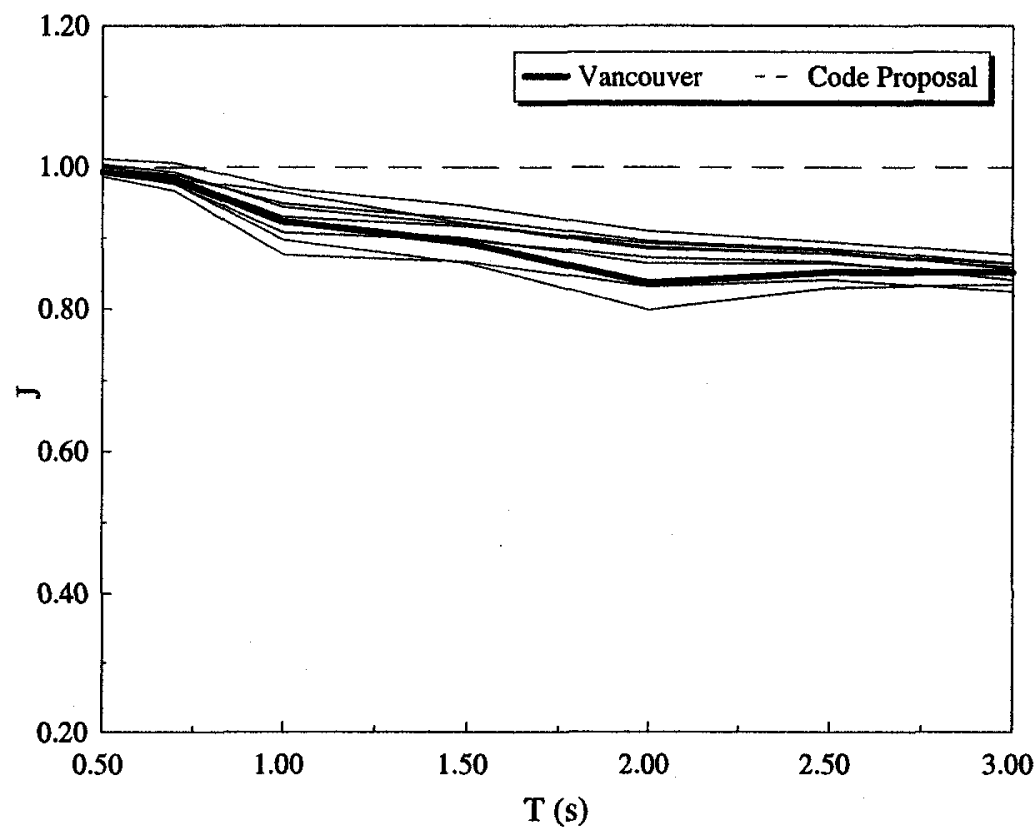

(a)

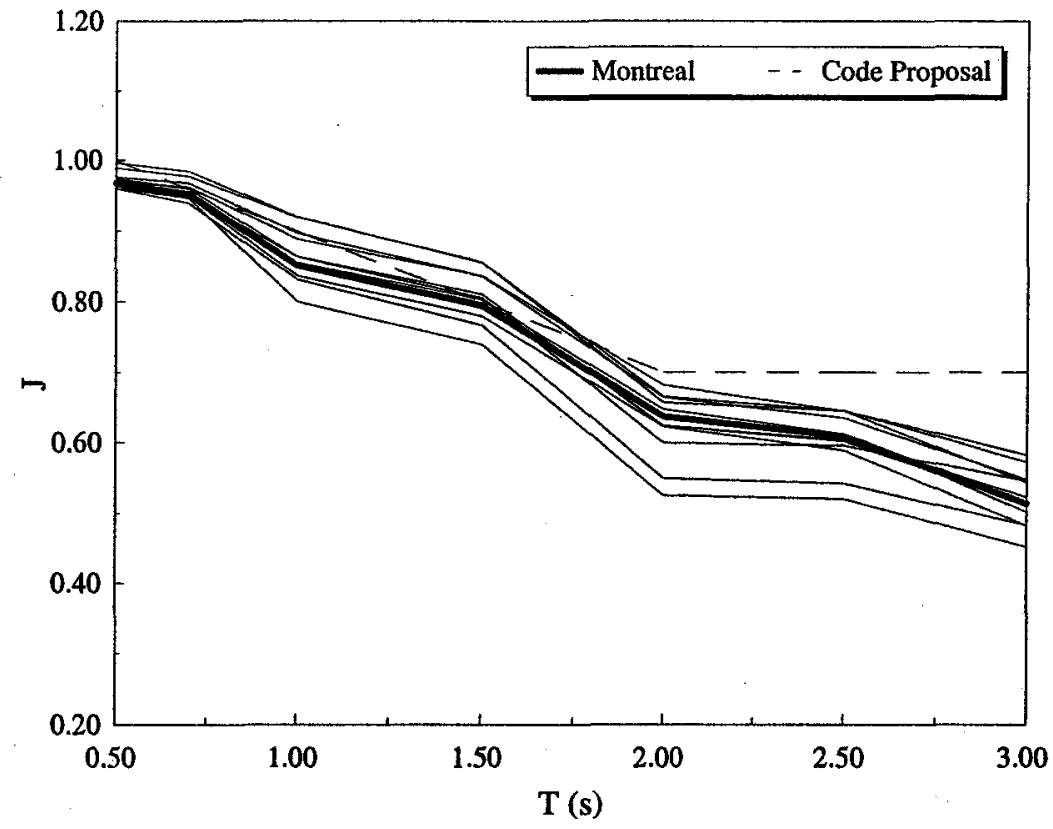

(b)

Fig. 2.8 Variation of $\mathrm{J}$ factor with period for MRF structures (a) Cities in the west (b) Cities in the east 


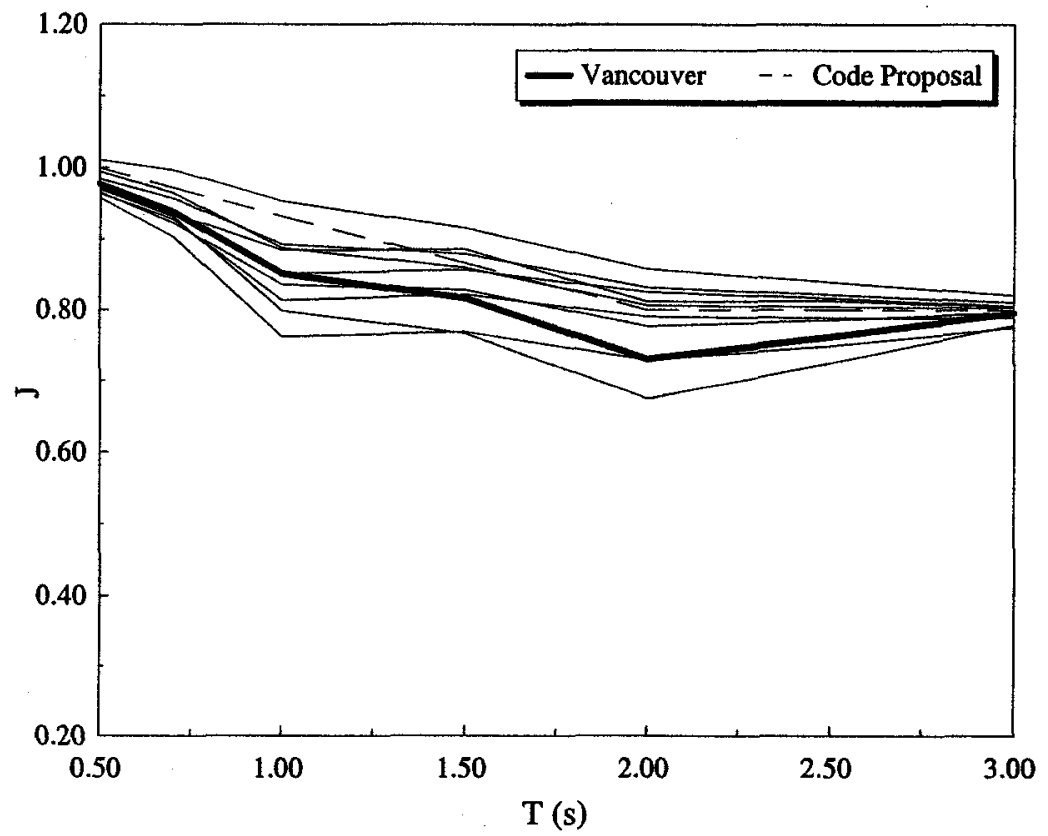

(a)

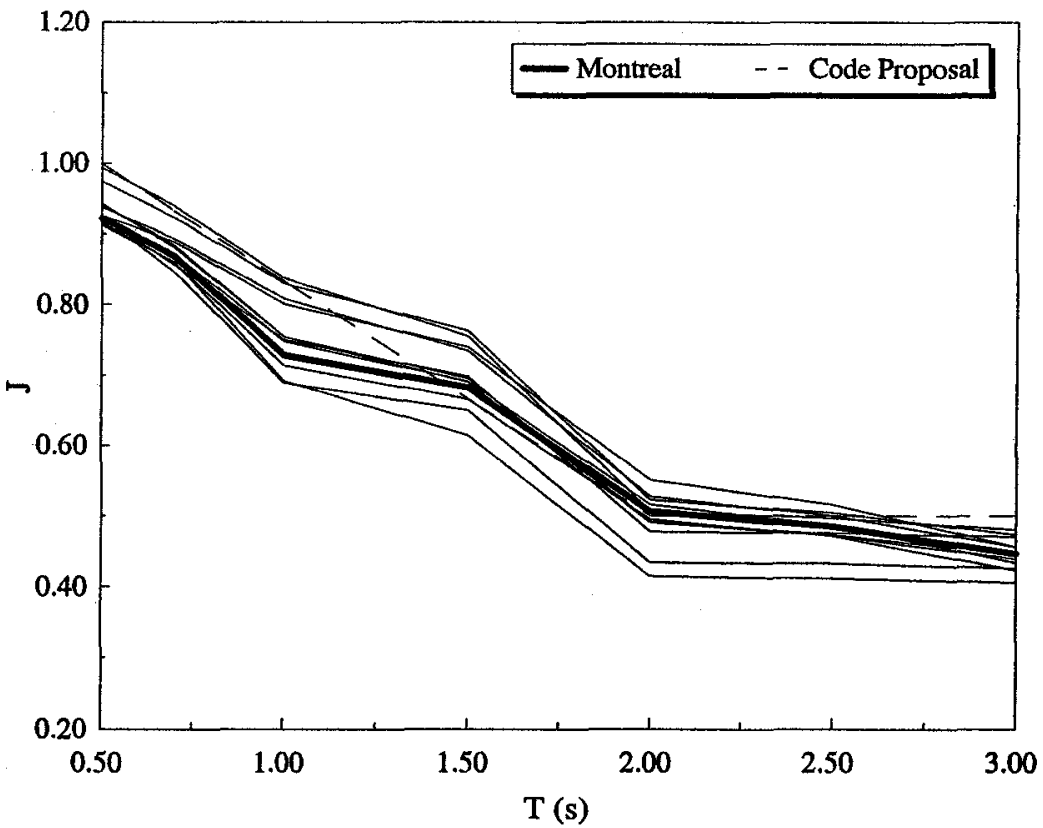

(b)

Fig. 2.9 Variation of $\mathrm{J}$ factor with period for braced frame structures (a) Cities in the west (b) Cities in the east 


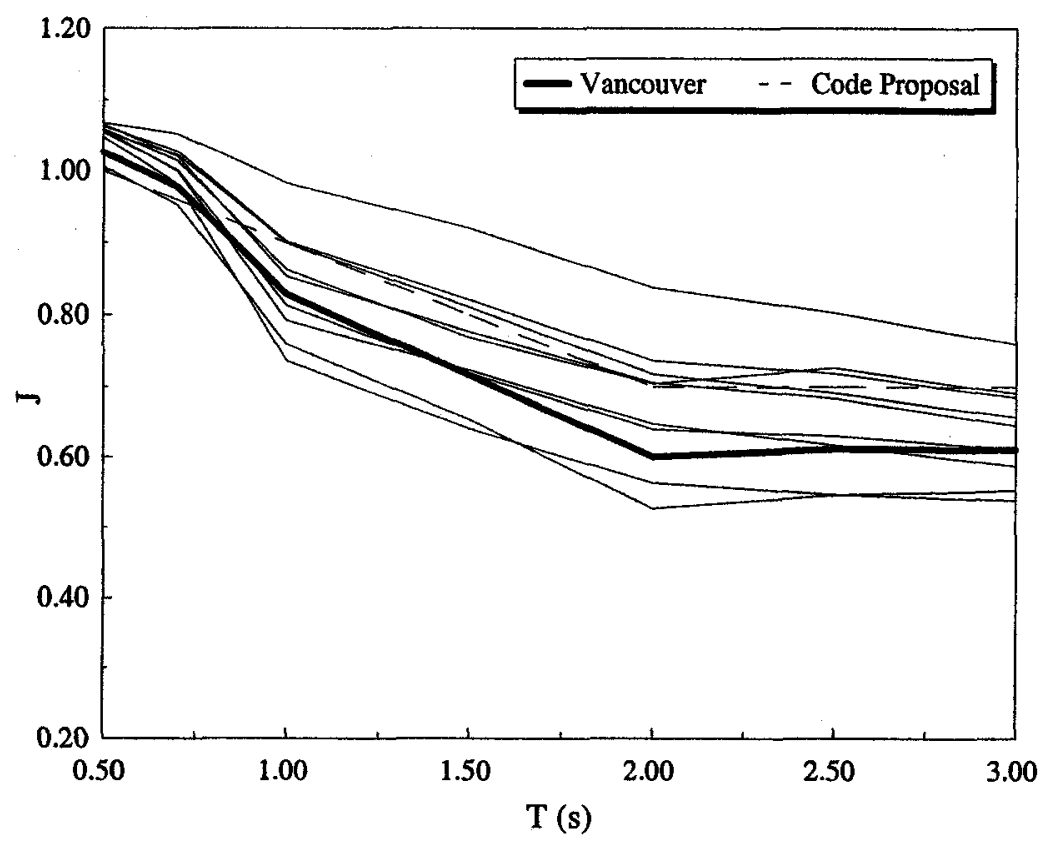

(a)

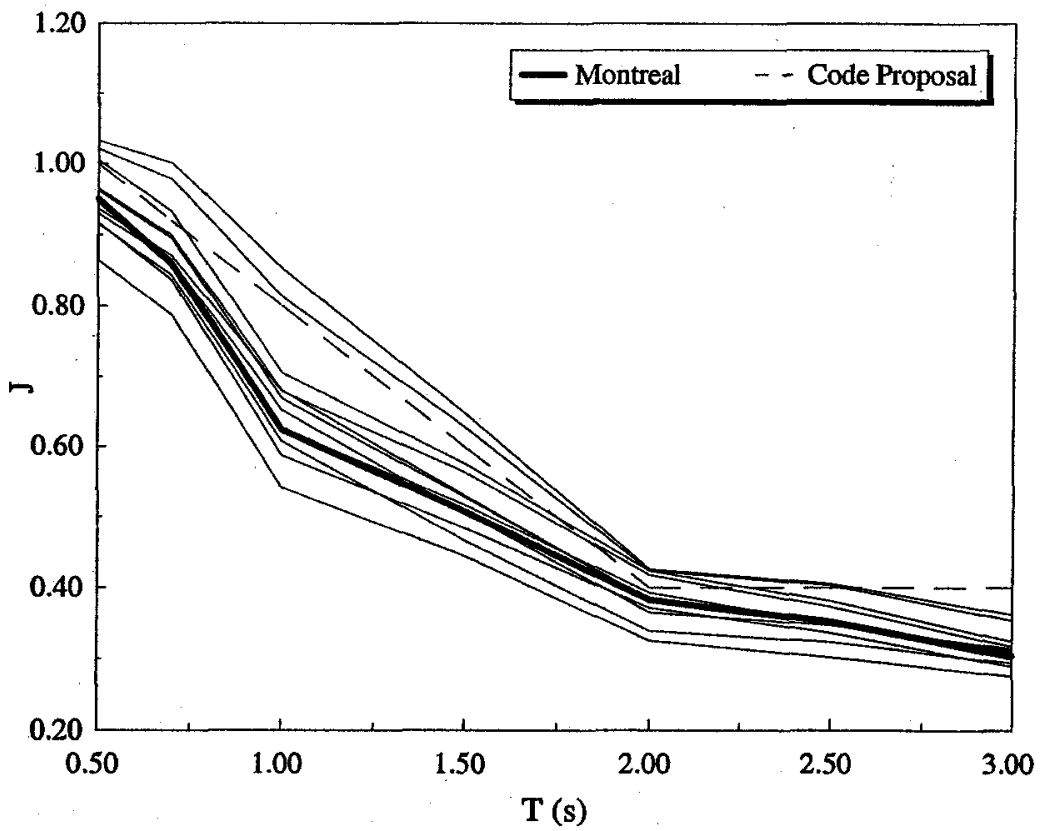

(b)

Fig. 2.10 Variation of $\mathrm{J}$ factor with period for wall structures (a) Cities in the west (b) Cities in the east 


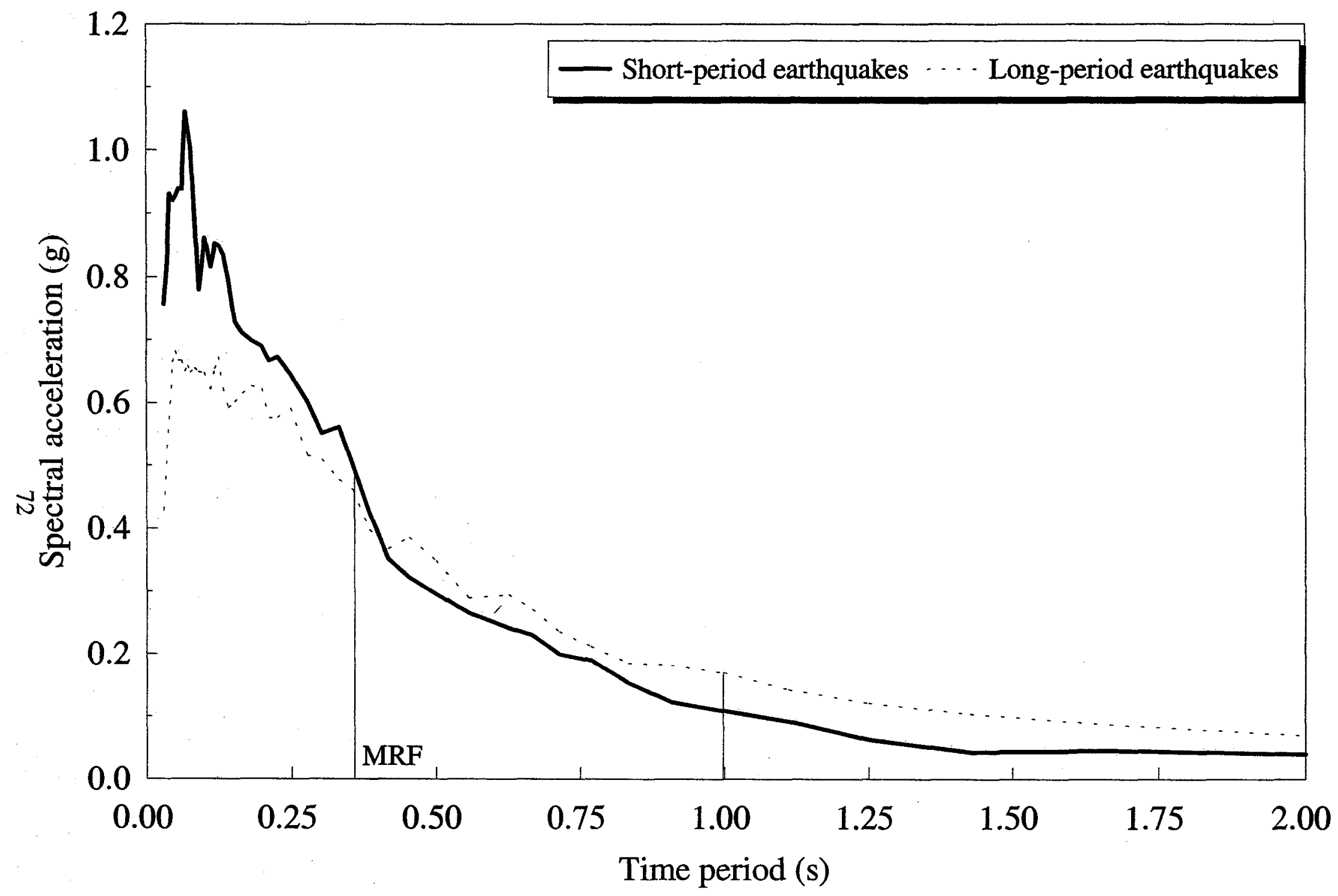

Fig. 2.11 Absolute acceleration response spectra for Montreal (5\% damping) 


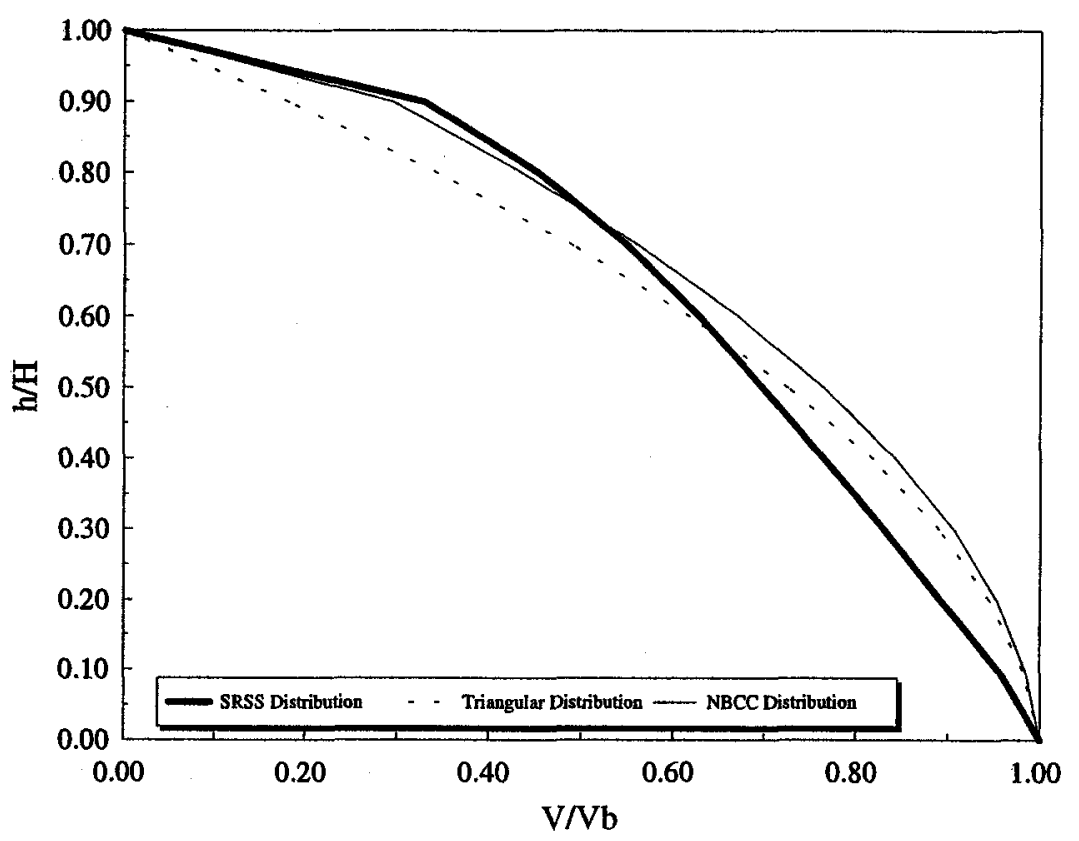

(a)

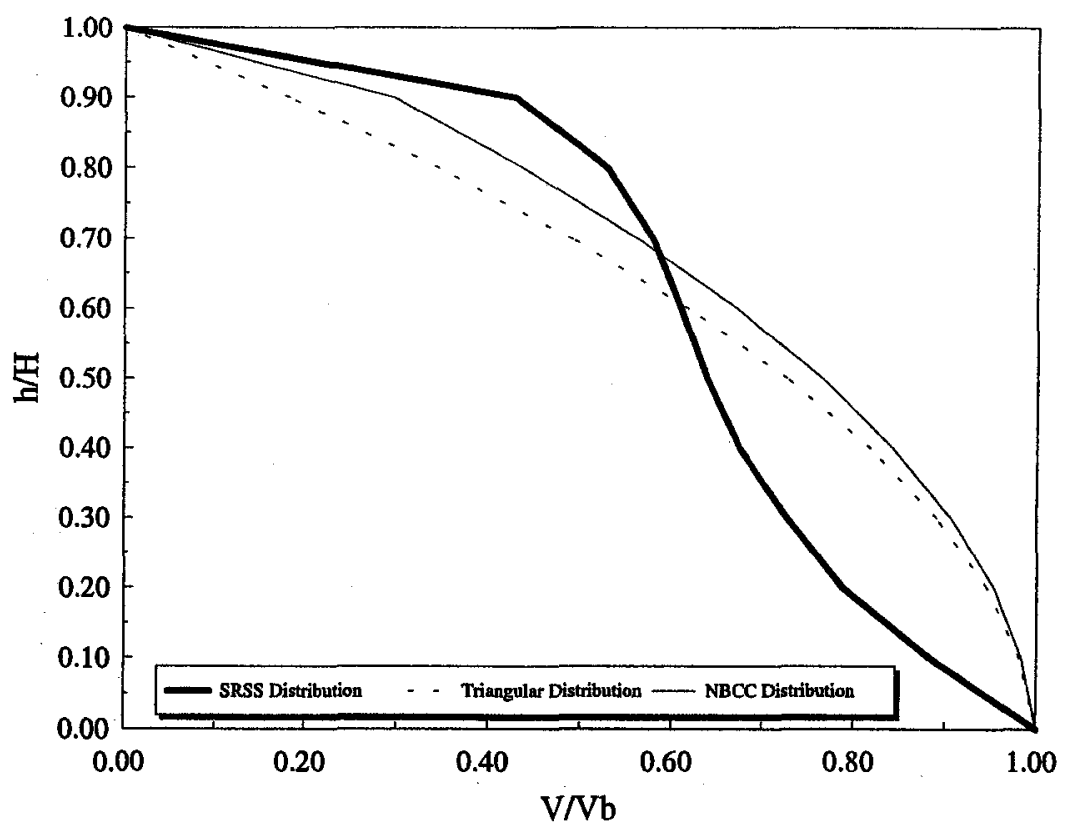

(b)

Fig. 2.12 Height wise normalized shear distribution for MRF system,
(a) City of Vancouver
(b) City of Montrea
$(\mathrm{T} 1=2.0 \mathrm{~s})$

73 


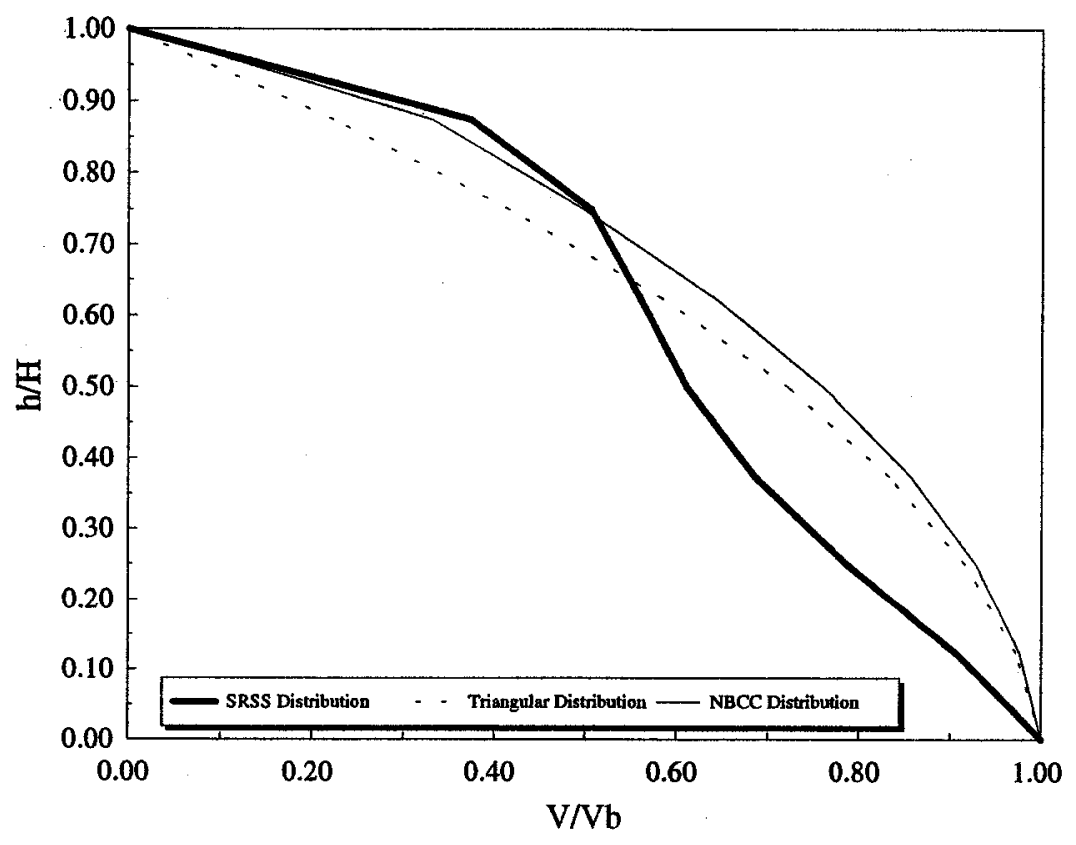

(a)

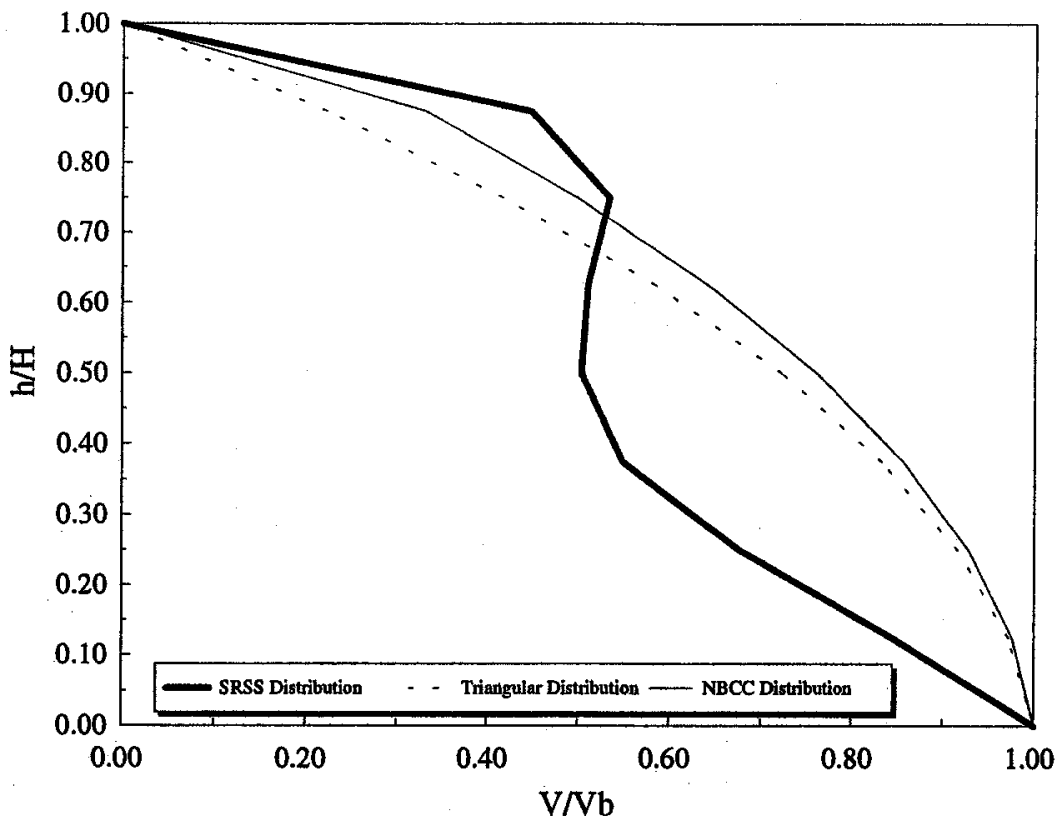

(b)

Fig. 2.13 Height wise normalized shear distribution for braced frame system, (a) City of Vancouver

(b) City of Montreal (T1=2.0 s) 


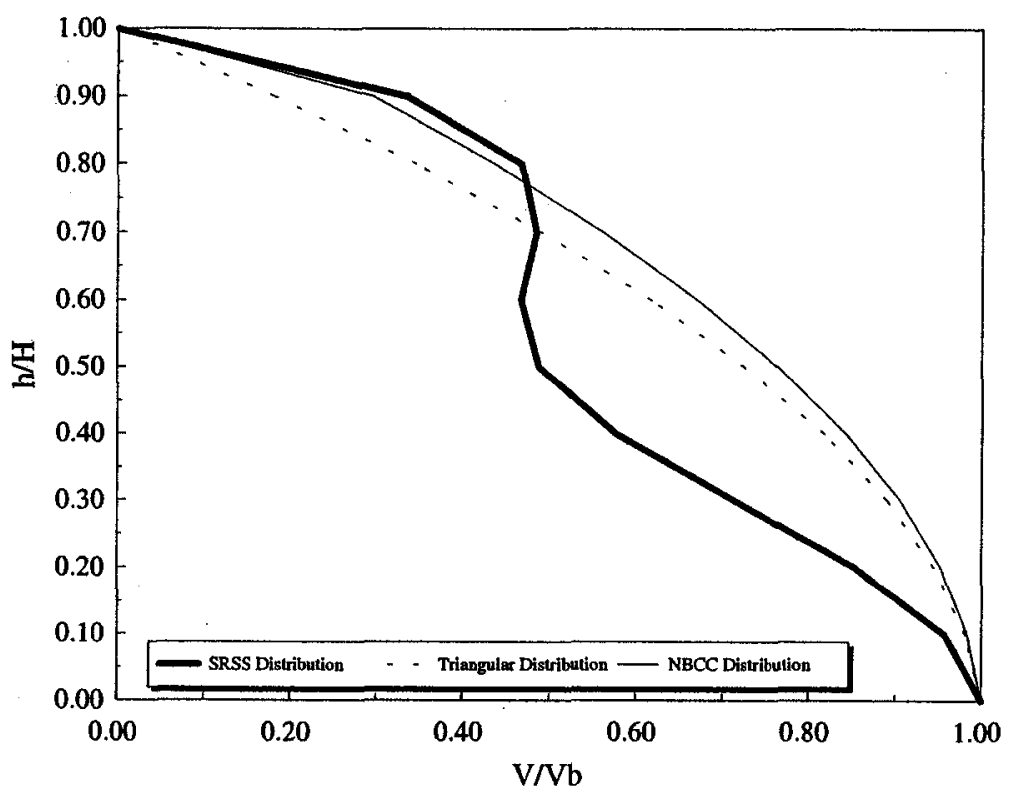

(a)

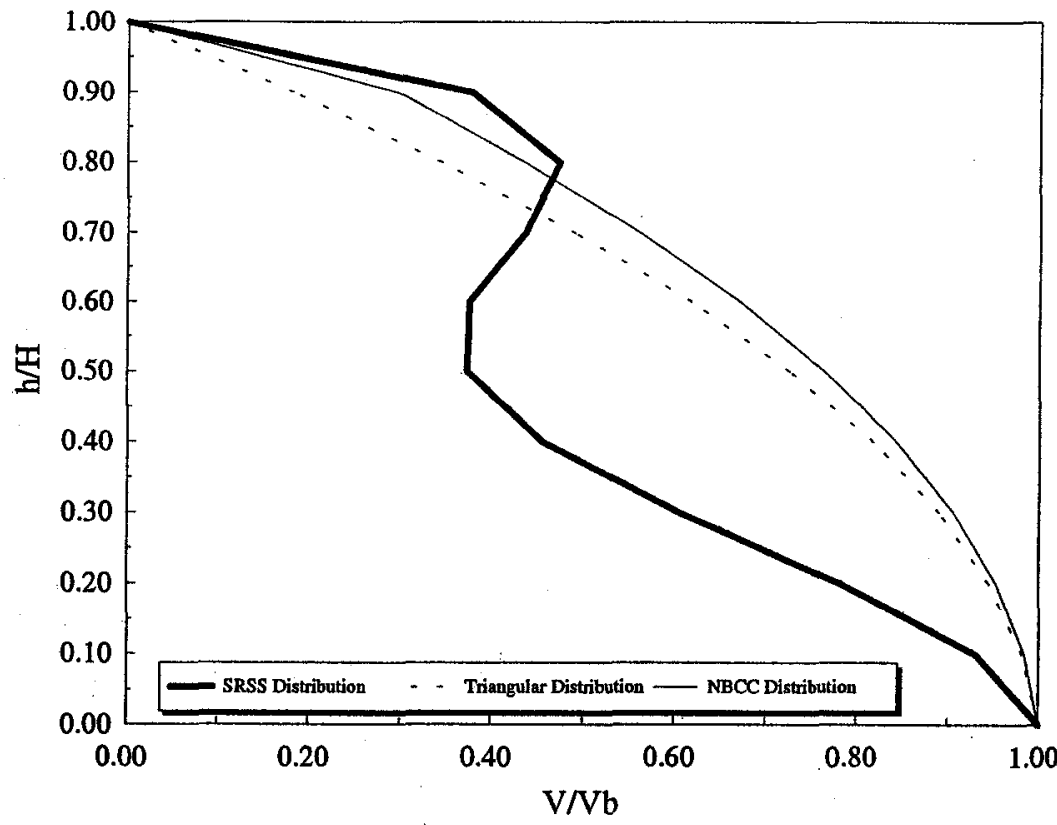

(b)

Fig. 2.14 Height wise normalized shear distribution for flexural wall system, (a) City of Vancouver

(b) City of Montreal (T1=2.0 s)

75 


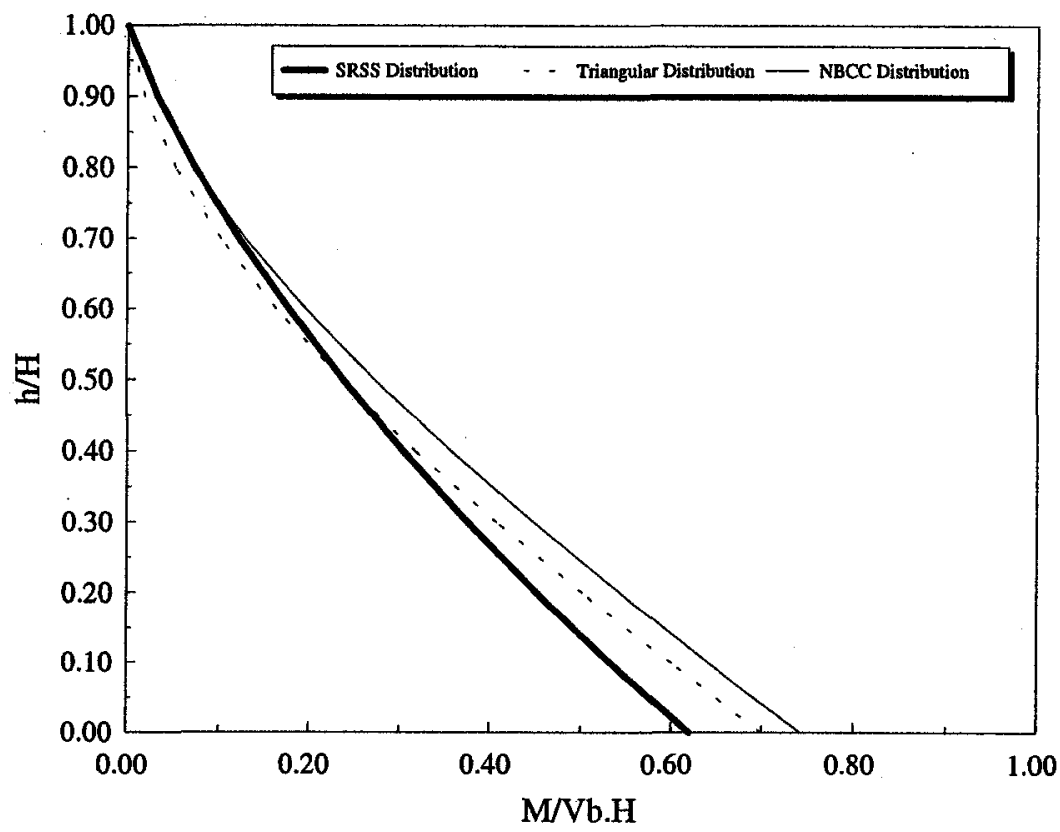

(a)

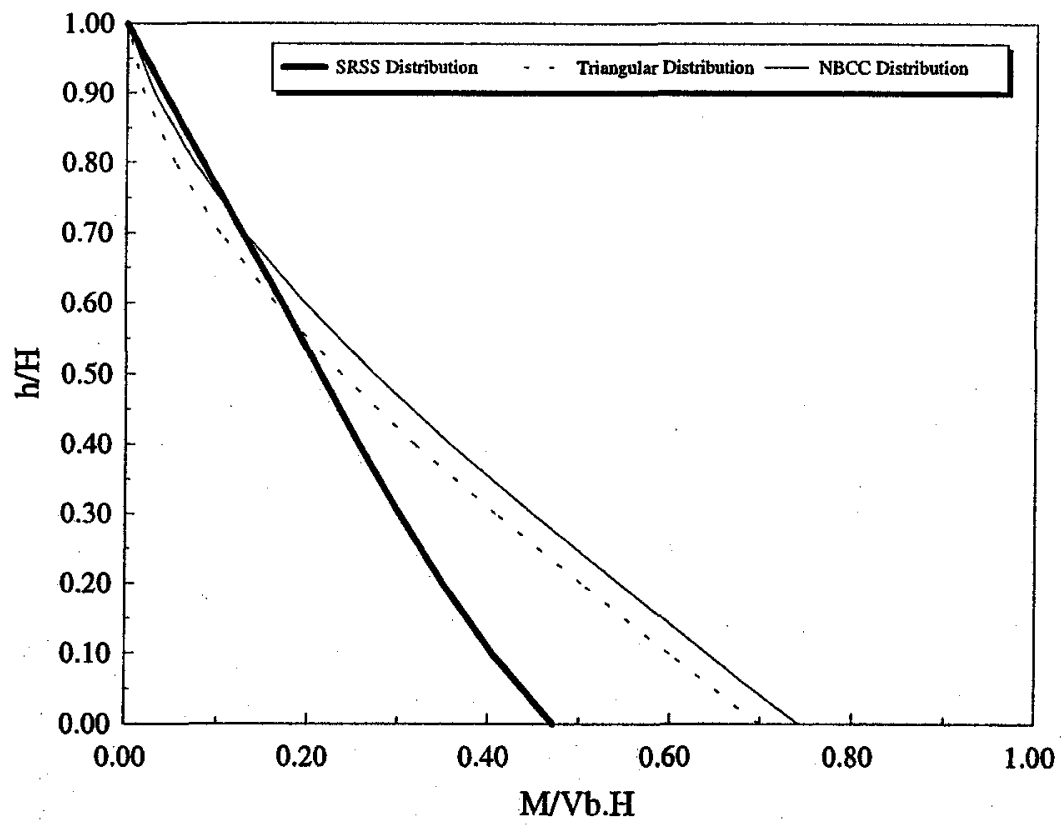

(b)

Fig. 2.15 Height wise normalized overturning moment distribution for MRF system, (a) City of Vancouver

(b) City of Montreal (T1=2.0 s) 


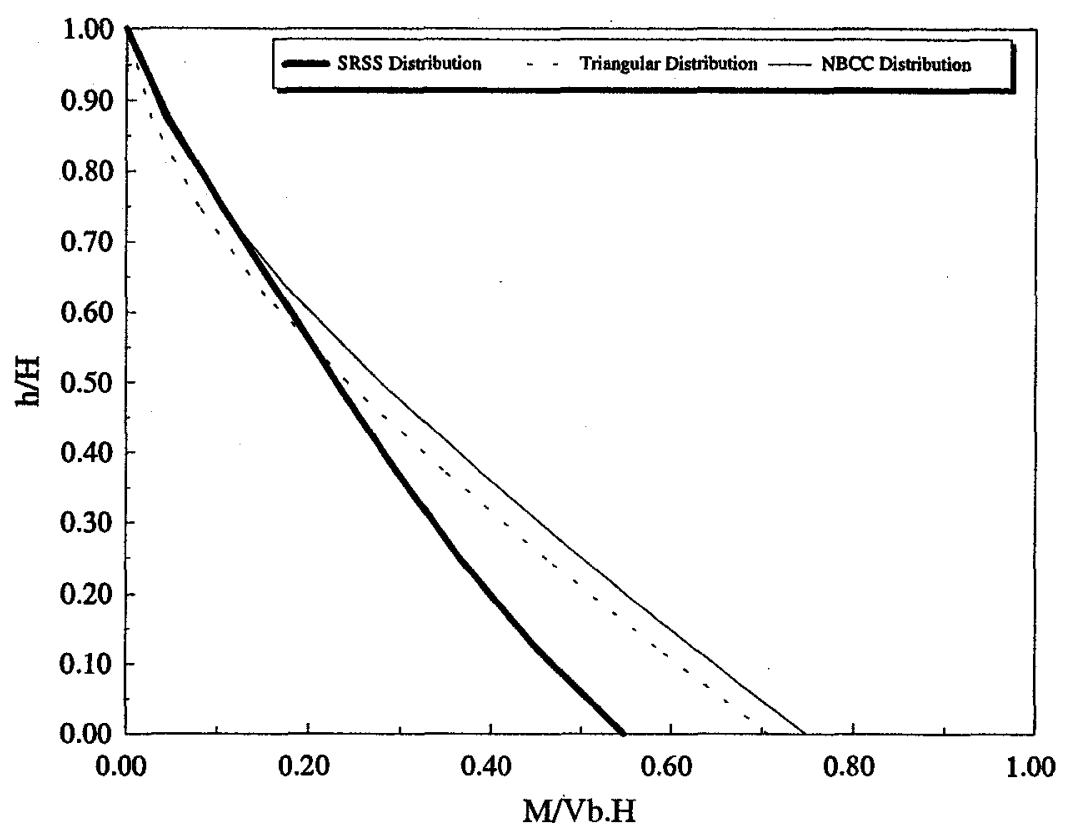

(a)

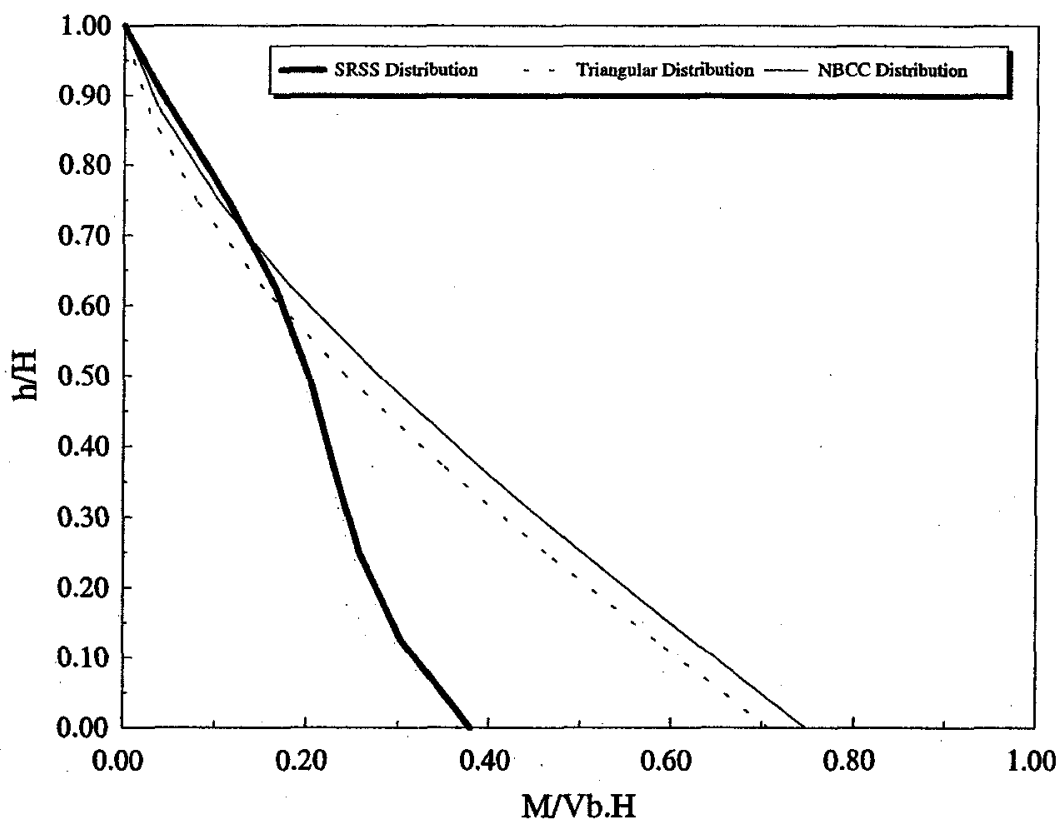

(b)

Fig. 2.16 Height wise normalized overturning moment distribution for braced frame system, (a) City of Vancouver

(b) City of Montreal $\quad(\mathrm{T} 1=2.0 \mathrm{~s})$ 


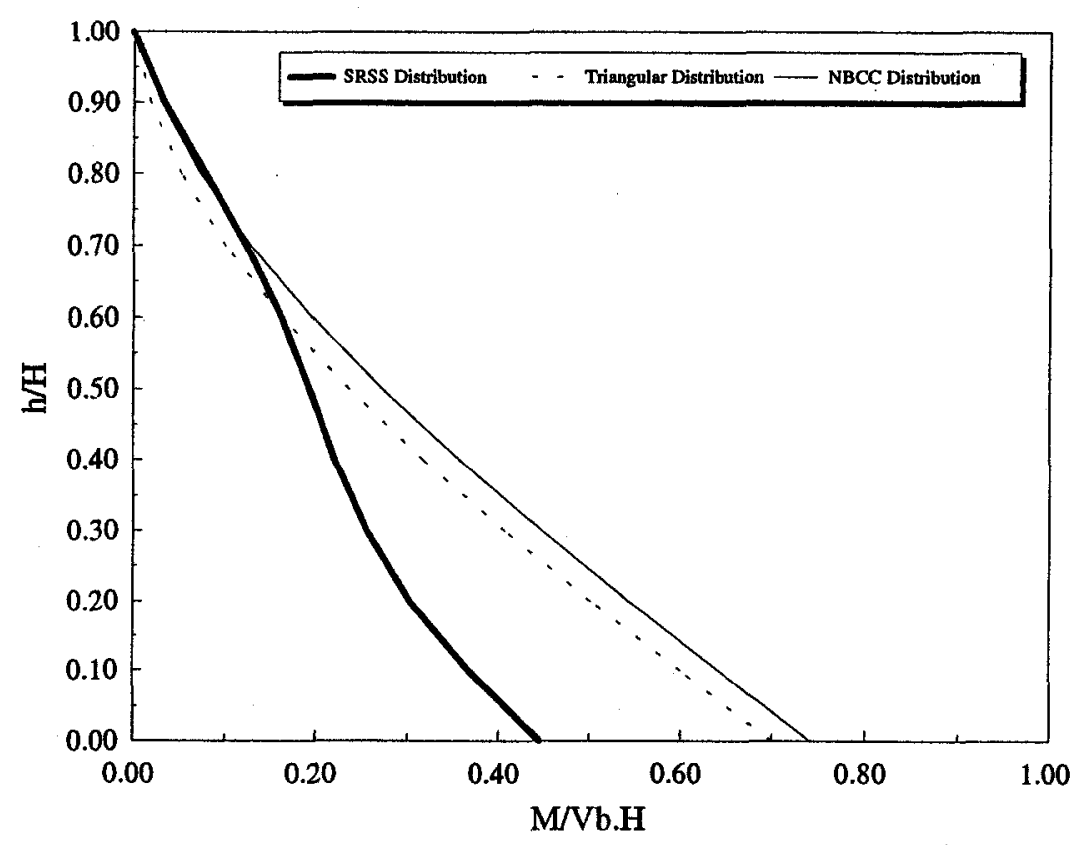

(a)

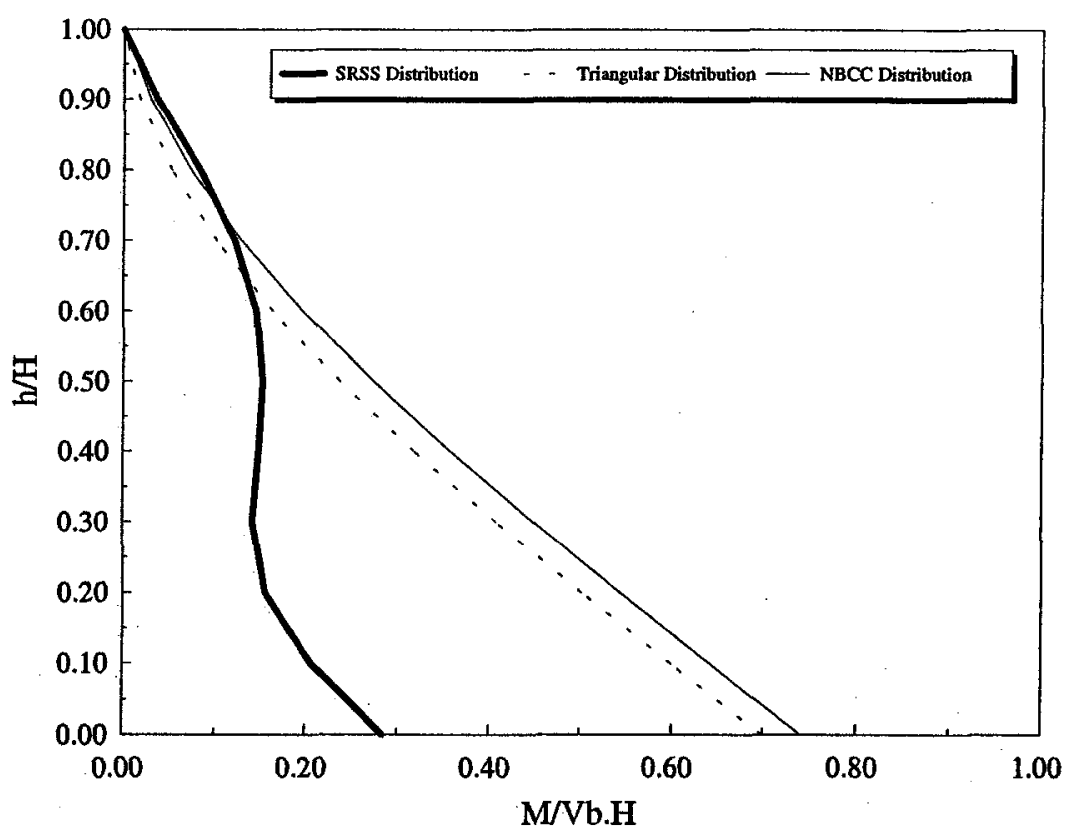

(b)

Fig. 2.17 Height wise normalized overturning moment distribution for flexural wall system, (a) City of Vancouver

(b) City of Montreal $\quad(\mathrm{T} 1=2.0 \mathrm{~s})$ 


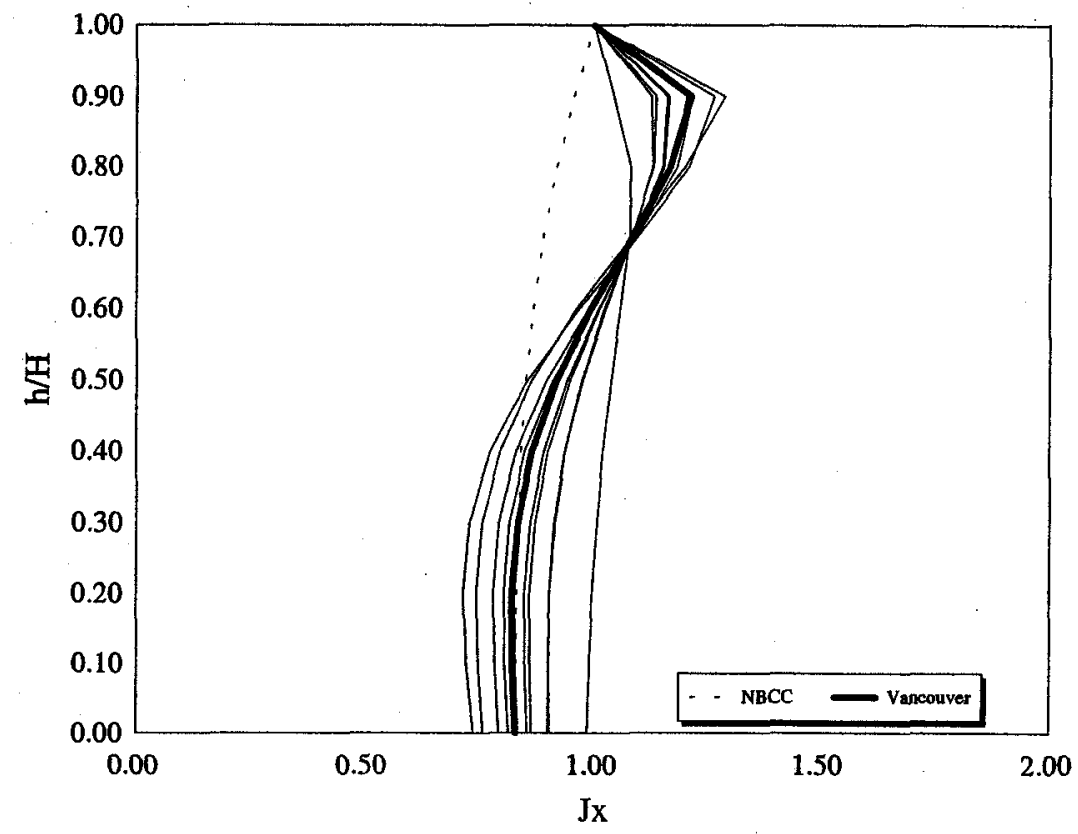

(a)

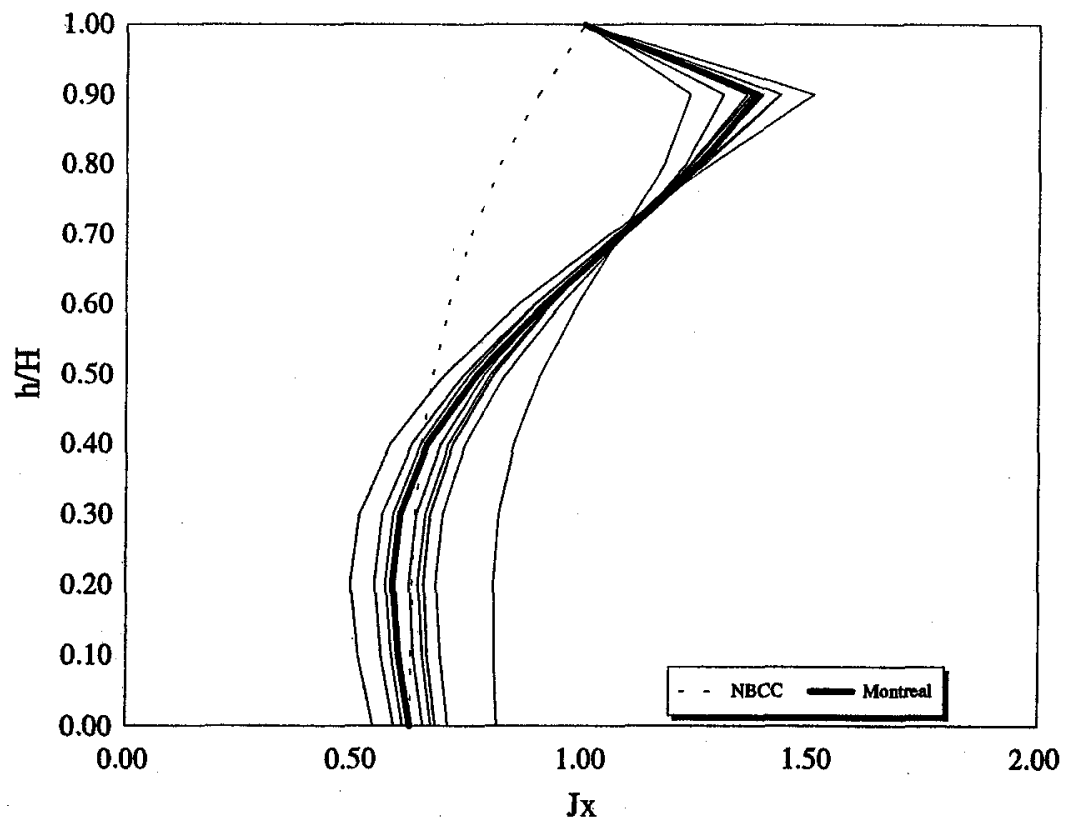

(b)

Fig. 2.18 Height wise distribution of storey moment modification factor, Jx,

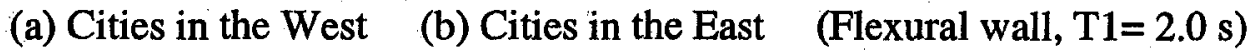




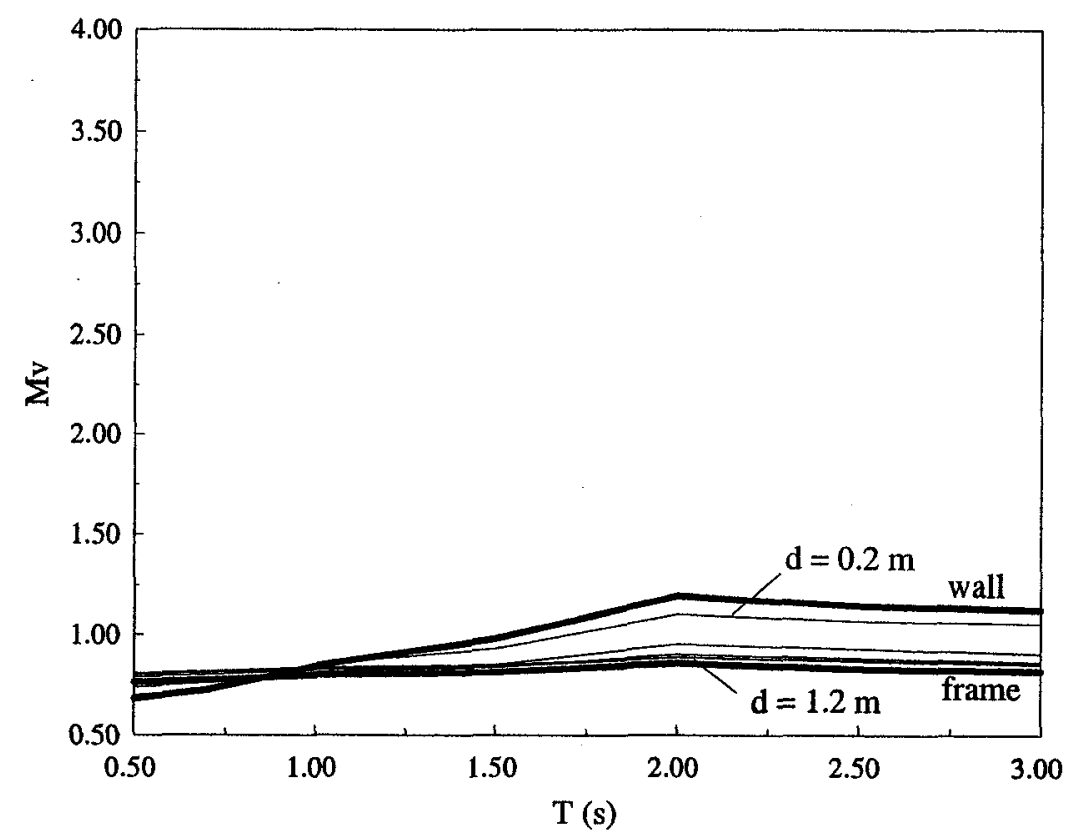

(a)

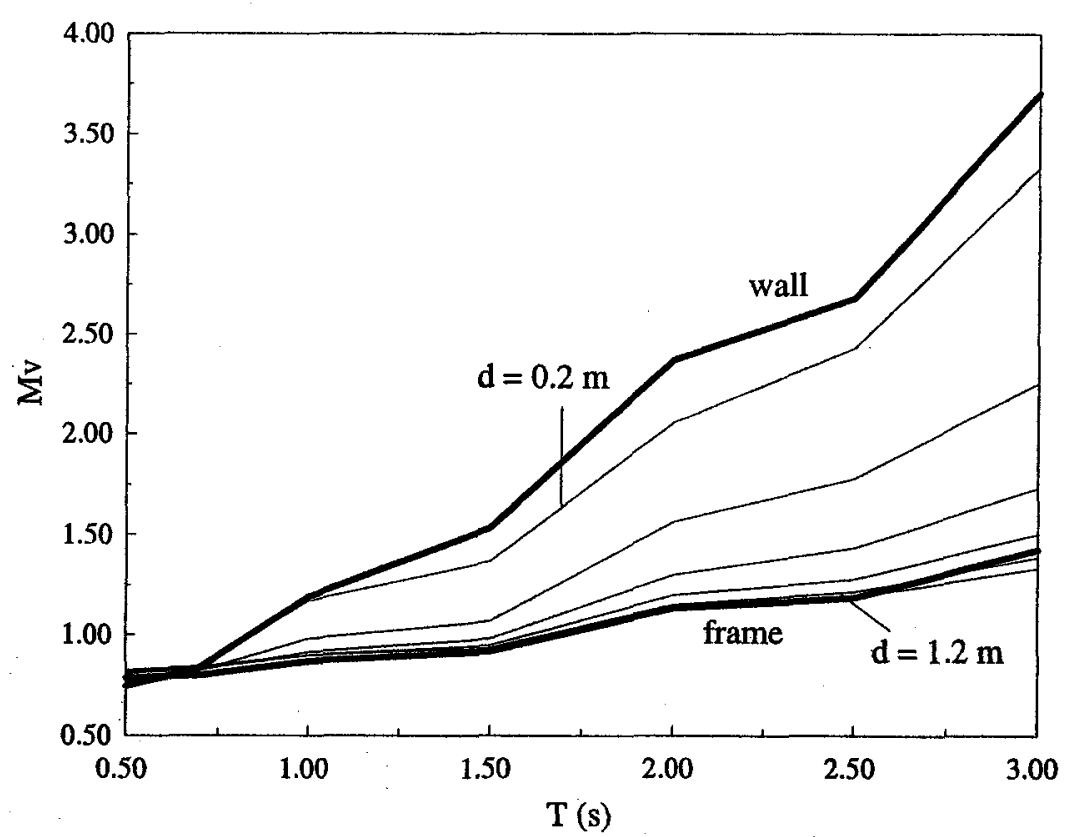

(b)

Fig. 2.19 Variation of Mv factor with period for coupled walls structures, (a) City of Vancouver (b) City of Montreal 


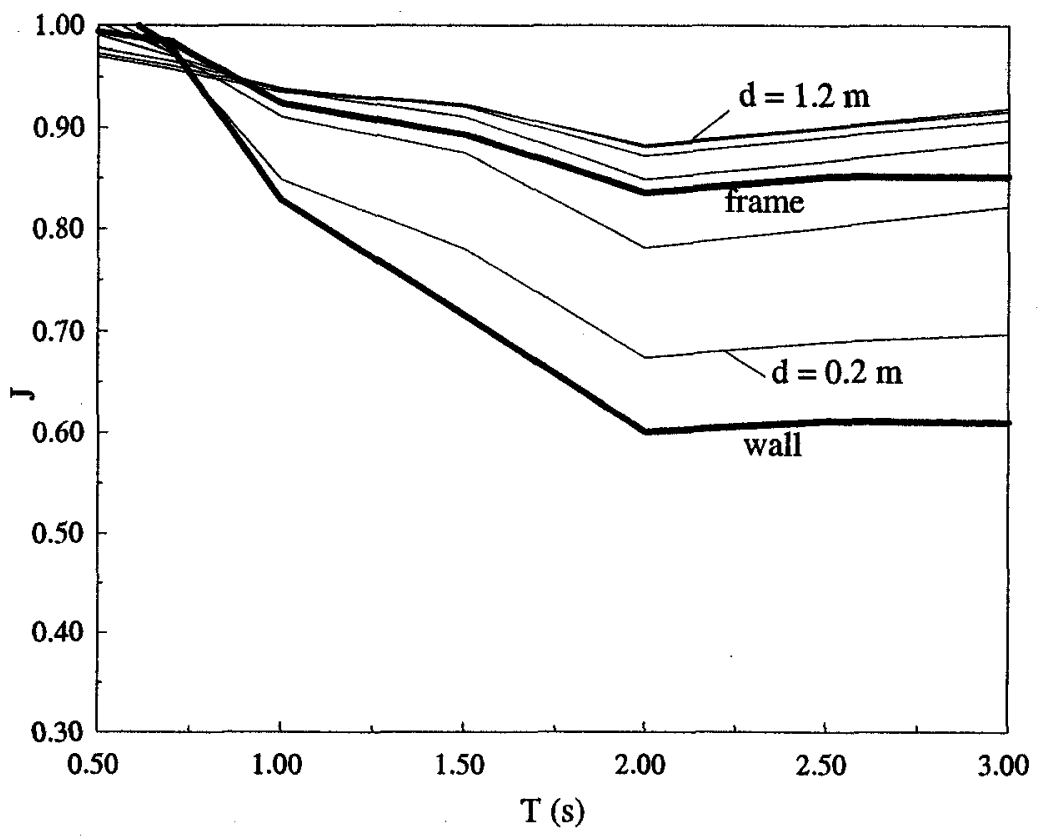

(a)

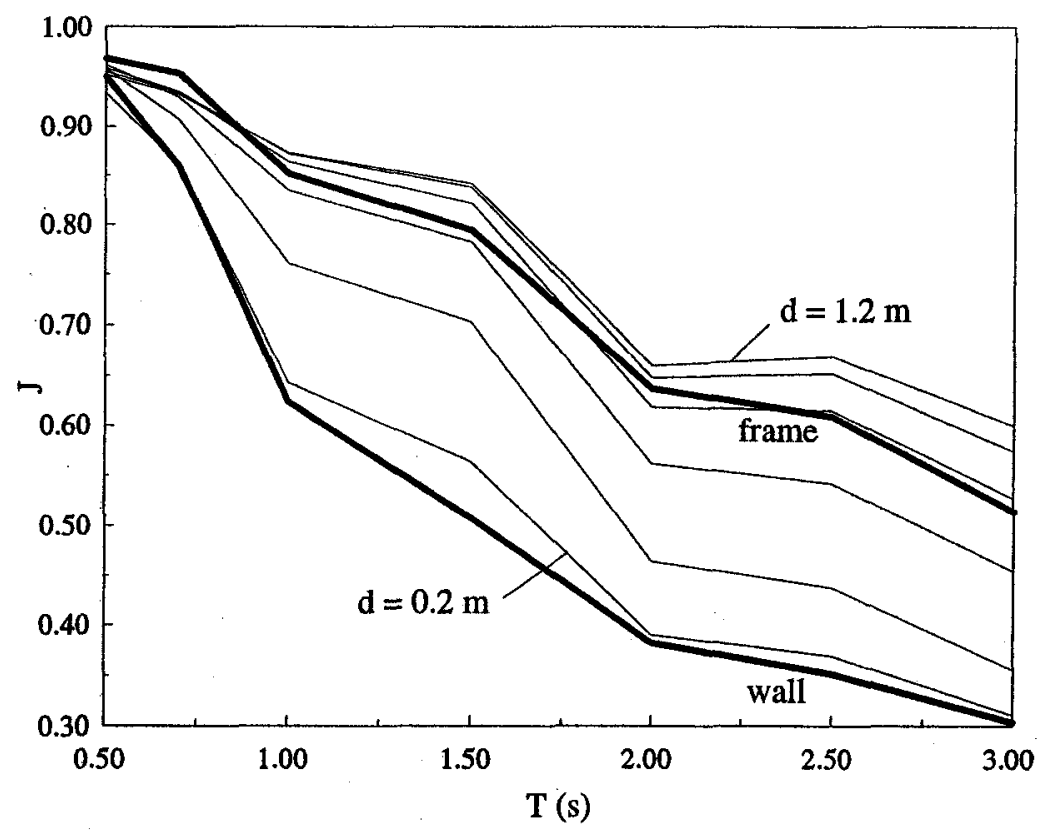

(b)

Fig. 2.20 Variation of $\mathbf{J}$ factor with period for coupled walls structures, (a) City of Vancouver (b) City of Montreal 


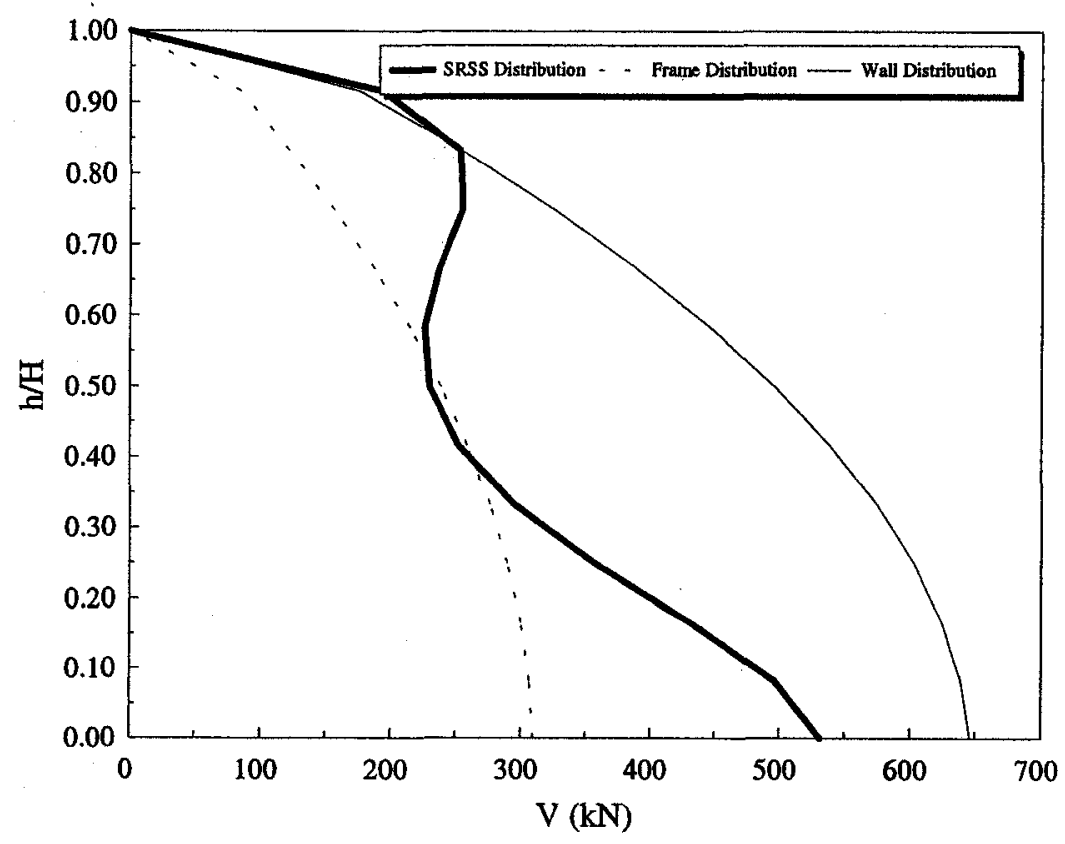

(a)

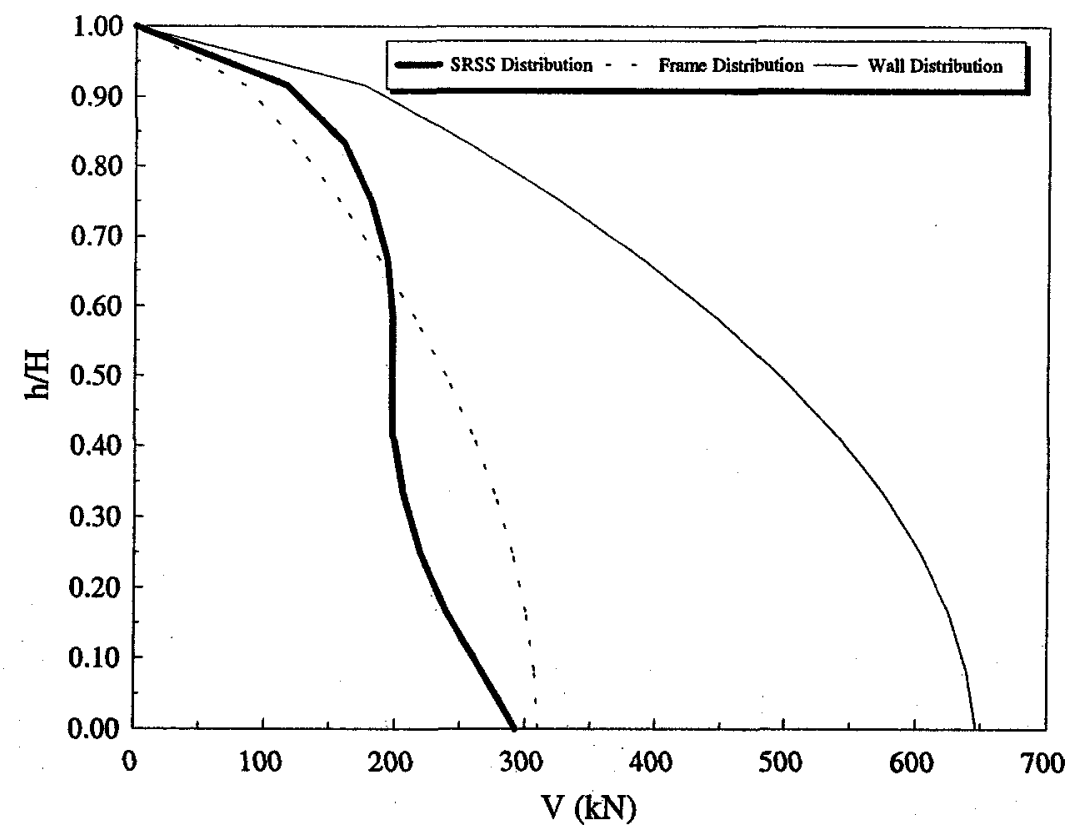

(b)

Fig. 2.21 Shear distribution across the height for a coupled wall system,

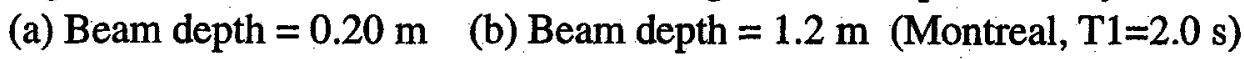




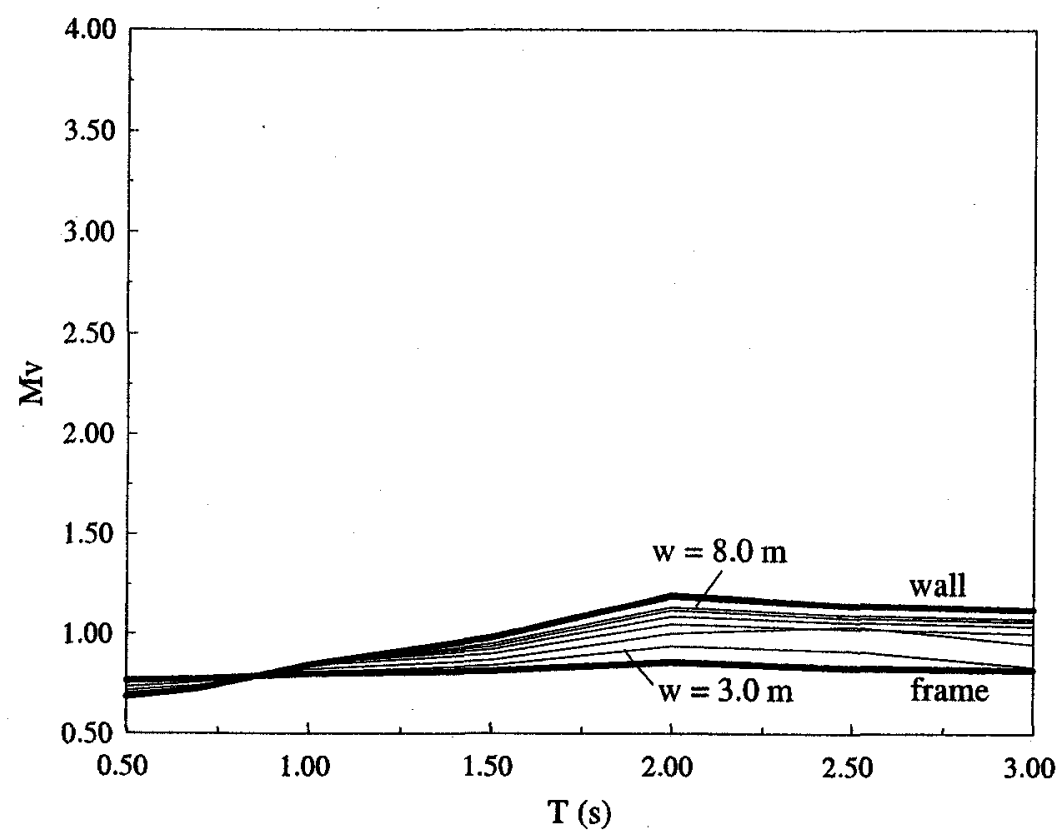

(a)

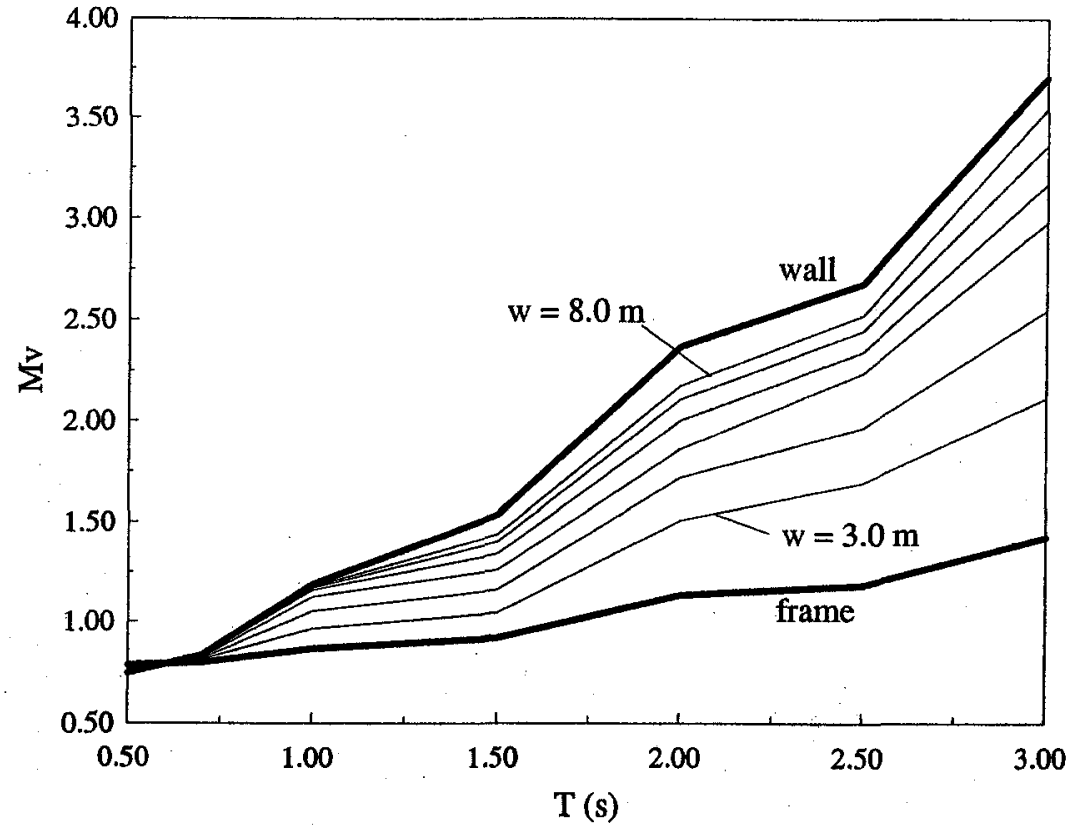

(b)

Fig. 2.22 Variation of Mv factor with period for hybrid structures, (a) City of Vancouver (b) City of Montreal 


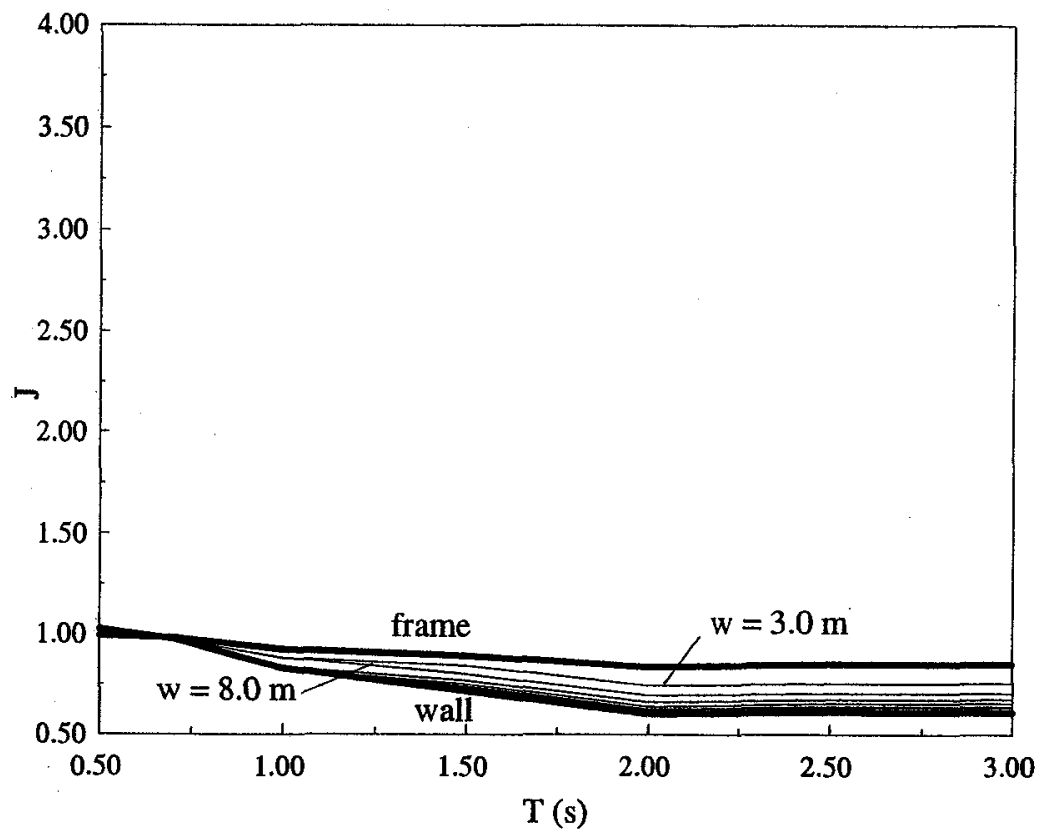

(a)

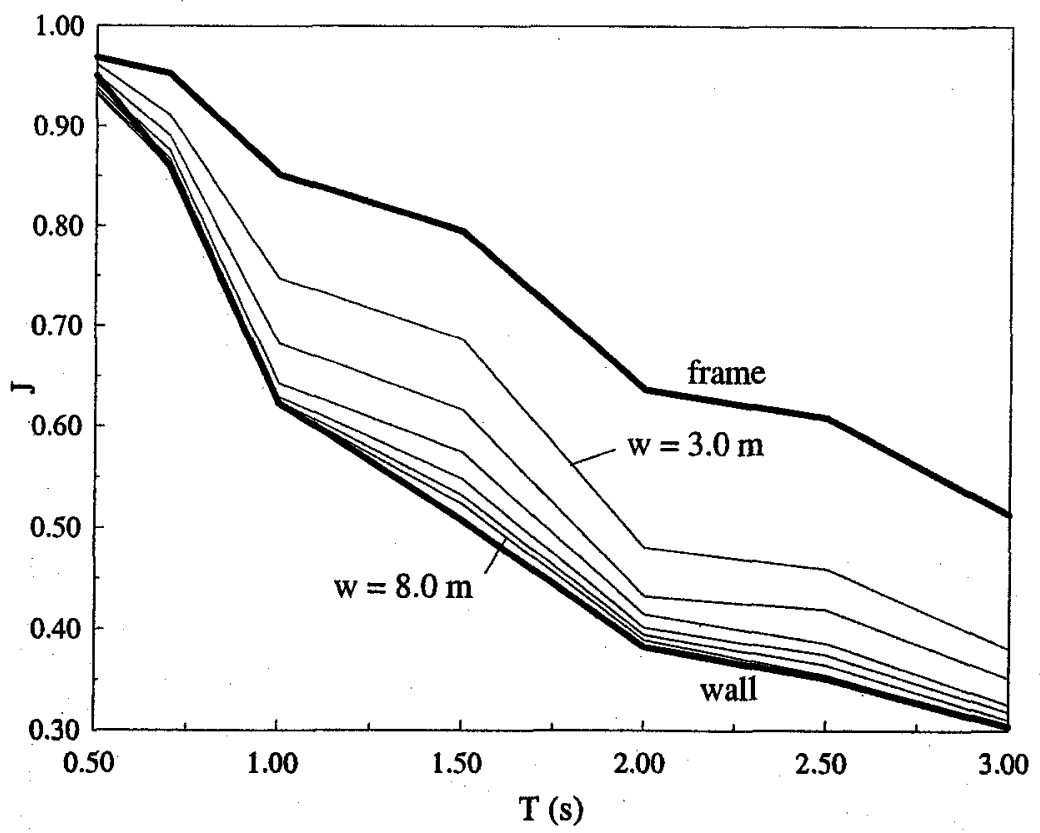

(b)

Fig. 2.23 Variation of $\mathrm{J}$ factor with period for hybrid structures, (a) City of Vancouver (b) City of Montreal 


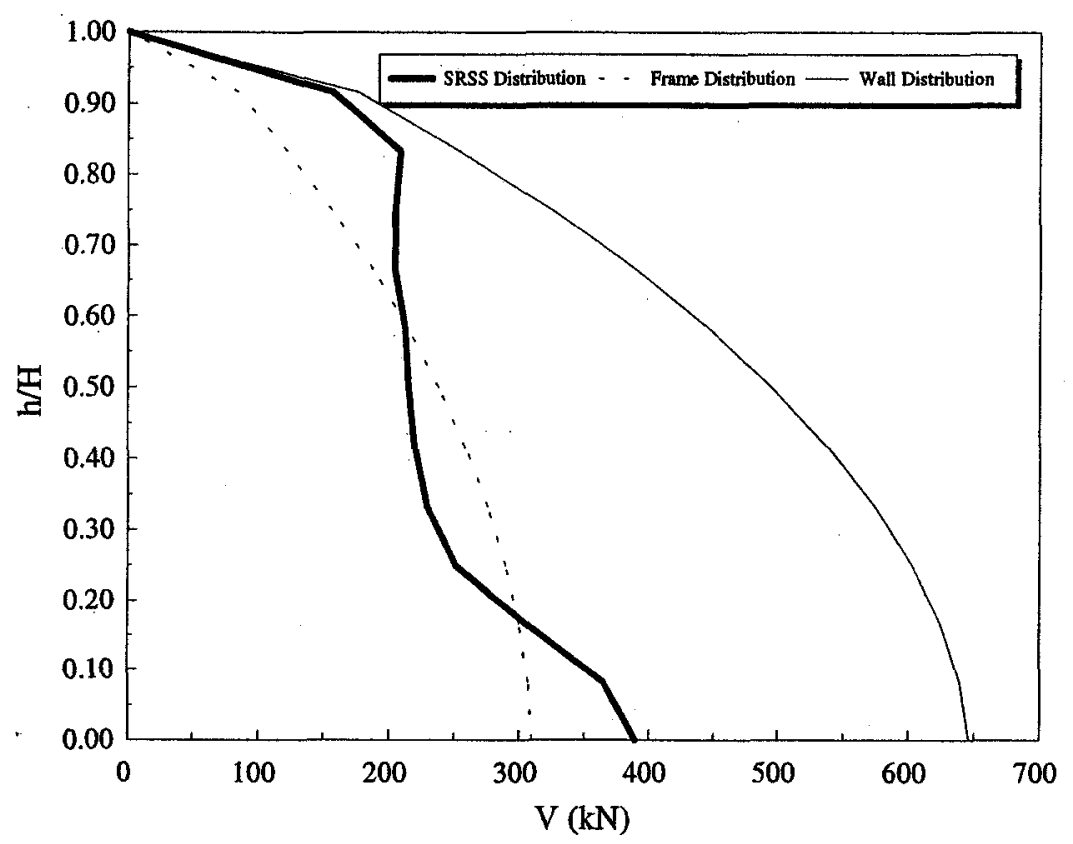

(a)

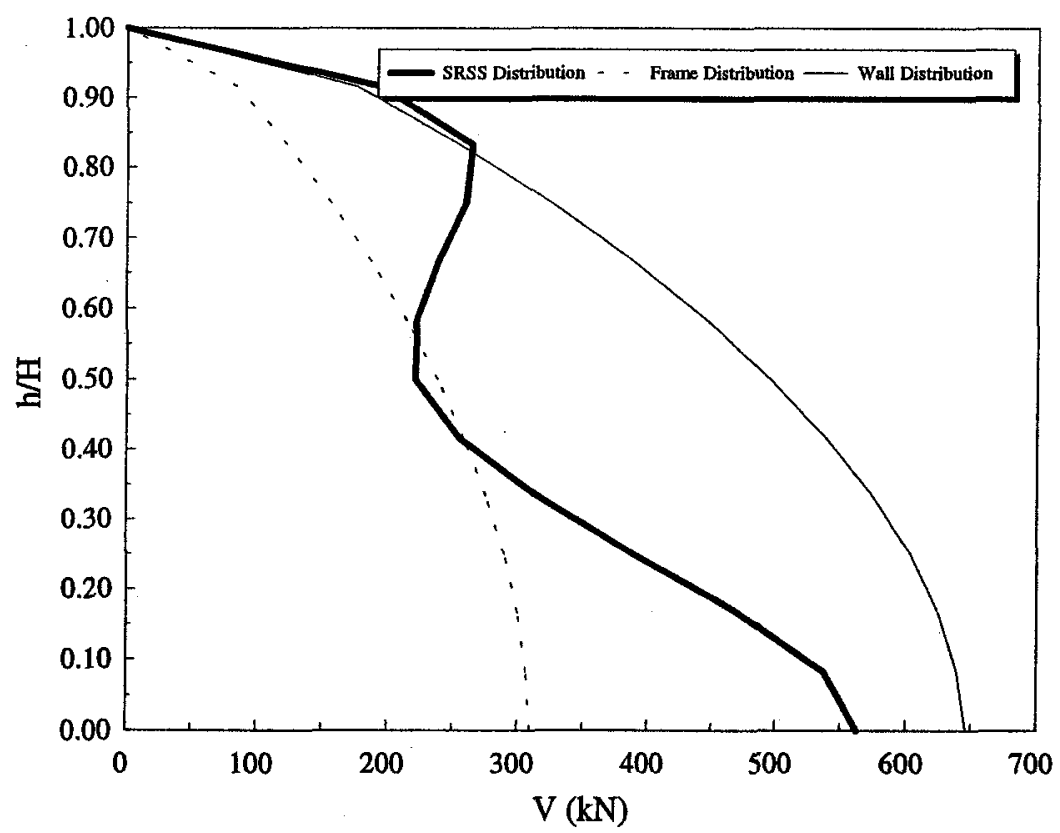

(b)

Fig. 2.24 Shear distribution across the height for a hybrid system,

$\begin{array}{ll}\text { (a) Wall width }=3.0 \mathrm{~m} & \text { (b) Wall width }=8.0 \mathrm{~m} \quad \text { (Montreal, } \mathrm{T} 1=2.0 \mathrm{~s} \text { ) }\end{array}$ 


\section{CHAPTER 3}

\section{ELASTIC TORSIONAL RESPONSE OF ASYMMETRIC MULTISTOREY BUILDINGS}

\subsection{INTRODUCTION}

Recent earthquakes have indicated that torsional motions often cause severe damage to buildings. Observation of damage has led to a renewed interest in the study of torsional response of building structures. Torsional motion results when the centre of rigidity, CR, does not coincide with the centre of mass, CM. Structures with noncoincident centres of mass and rigidity are referred to as "asymmetric structures" or "unbalanced structures". The torsional motion induced in such structures is called "natural torsion". Torsional motions may also result from factors other than known asymmetry. One factor is the uncertainty in the evaluation of the centres of mass and stiffness because of lack of precise data on modulus of elasticity or inaccuracy in measuring the element dimensions. Torsion may also result from ground rotational motion about vertical axis. Torsional motion due to above two factors is referred to as "accidental torsion". Researchers have found another mechanism that may cause torsional motion in both symmetric and asymmetric buildings. This mechanism is related to non-linear coupling between lateral and rotational motions, and is caused by the non-linear force-displacement characteristics of the lateral load resisting planes of the structure (Tso and Asmis, 1971). This type of torsion is referred to as "coupled torsion". 
It has been shown (Humar and Kumar, 1998a) that the parameter that most strongly influences torsional response is the rotational stiffness. This stiffness can be measured by the ratio of uncoupled torsional frequency, $\omega_{\theta}$, to the uncoupled lateral frequency, $\omega_{y}$, referred to as the frequency ratio, $\Omega_{R}$. Other parameters that influence torsional response are the forcedisplacement characteristics of the lateral load resisting elements and the characteristics of the ground motion.

Although most structures are designed to become inelastic during earthquakes, a study of elastic torsional response is of considerable interest in understanding the behavior of asymmetric buildings which are expected to deform into the inelastic range. When the building behaves elastically, torsional vibrations may cause significant additional displacements and forces in the lateral load resisting planes. A study of these effects is presented in this chapter.

As stated earlier, NBCC 2005 specifies that in order to determine the design load in a lateral load resisting element, the calculated storey shear should be applied at a distance $e_{d}$, referred to as the design eccentricity, from the centre of rigidity, $\mathrm{CR}$. The design eccentricity values are given by:

$$
\begin{array}{ll}
e_{d 1}=\alpha e+\beta b & (\text { for flexible edge }) \\
e_{d 2}=\gamma e-\beta b & (\text { for stiff edge })
\end{array}
$$

Also, Humar and Kumar (1998a) have proposed the following expressions for design eccentricities:

$$
e_{d l}=e+0.1 b
$$




$$
\begin{aligned}
e_{d 2} & =e-0.1 b & & \text { for } \Omega_{R} \geq 1.0 \\
& =-0.1 b & & \text { for } \Omega_{R}<1.0
\end{aligned}
$$

where $e_{d l}$ and $e_{d 2}$ are the design eccentricities for flexible and stiff edges, respectively measured from the centre of rigidity, $\mathrm{CR}$.

The main objective of this chapter is to provide a better understanding of the torsional behavior of multistorey buildings of a general class in which frequency ratio, $\Omega_{R}$, varies significantly from floor to floor. The objectives of this chapter can be summarized as follows:

(1) to study the elastic torsional behavior of multistorey building models of general class for a range of parameters not studied earlier and to investigate the applicability of single storey results.

(2) to evaluate the validity and limitations of the proposed design eccentricity expressions (Humar, and Kumar 1998a) in application to multistorey buildings of a general class and to suggest necessary modifications, if any.

\subsection{DESCRIPTION OF THE MODEL}

A simple and idealized asymmetric plan model, which has been studied by several researchers, is selected for carrying out the analyses of single storey buildings. Figure 3.1 shows a plan view of the selected building. The entire storey mass is assumed to be 
uniformly distributed at the floor level. The building floors are assumed to be infinitely rigid in their own planes. The origin of the coordinate axes is taken at the centre of mass, CM. The building model includes five resisting planes, three parallel to the $y$ axis and two parallel to the $x$ axis. The $i$ th plane parallel to the $x$ axis has a stiffness $k_{x i}$, while the $i$ th plane along the $y$ axis has a stiffness $k_{y i}$. The distribution of stiffness is symmetrical about the $x$ axis, but is asymmetrical about $y$ axis. The centre of rigidity, CR, lies on the $x$ axis at a distance $e$ from the centre of mass, $\mathrm{CM}$, where $e$ is given by

$$
e=\frac{\Sigma_{i=1}^{N} k_{y i} x_{i}}{\sum_{i=1}^{N} k_{y i}}
$$

and $N$ is the number of resisting planes in the $y$ direction.

It is assumed that earthquake ground motion is directed along the $y$ axis as shown in the figure. The dimension of the floor perpendicular to the direction of earthquake is $b$, and that parallel to the earthquake is $a$. During the earthquake, the torsional motion is opposed by the five vertical resisting planes which are selected to be regular and simple. They may comprise columns, beams, shear walls, or combinations of such elements. Because the system is assumed to behave elastically, elastic forces in the resisting planes are proportional to the stiffness of such planes. Thus, the centre of rigidity, $\mathrm{CR}$, coincides with the centre of stiffness.

\subsection{ACCIDENTAL TORSION}

The design eccentricities presented in the NBCC code provisions include an 
allowance for accidental torsion. For a proper comparison between the proposed design eccentricities and those specified by the code provisions, the effect of accidental torsion should be included. Recent studies carried out by De La Llera and Chopra (1994a, and 1994b) have shown that accidental torsion induced by various sources, including uncertainty in the distribution of mass and stiffness and ground rotational motion, can be accounted for by increasing or decreasing the eccentricity by $0.05 \mathrm{~b}$. Based on these observations, a portion of design eccentricity equal to $+0.05 b$ in Eq. 3.3 and $-0.05 b$ in Eq. $3.4 \mathrm{a}$ is assumed to account for accidental torsion. The design eccentricity that accounts for natural torsion is now taken as $e+0.05 b$ and $e-0.05 b$ for calculating the flexible and stiff edge displacements, respectively.

\subsection{ANALYSIS PROCEDURES}

Elastic dynamic and static analyses are carried out on single and multistorey building models. The results obtained from the analyses are then compared.

\subsubsection{Single Storey Building Model}

Linear dynamic analyses are carried out on torsionally unbalanced single storey structure, in which $\mathrm{CM}$ does not coincide with $\mathrm{CR}$. The uncoupled translational frequency, $\omega_{y}$, and the uncoupled rotational frequency, $\omega_{\theta}$, are obtained from the following expressions

$$
\omega_{y}=\sqrt{\frac{K_{y}}{m}}
$$




$$
\omega_{\theta}=\sqrt{\frac{K_{\theta R}}{m r^{2}}}
$$

where $K_{y}$ is the total lateral stiffness, and $K_{\theta R}$ is the torsional stiffness about the centre of rigidity, $\mathrm{CR}$. The latter is given by

$$
K_{\theta R}=\Sigma_{i=1}^{N} k_{y i}\left(x_{i}-e\right)^{2}+\Sigma_{i=1}^{M} k_{x i}\left(y_{i}\right)^{2}
$$

where $M$ is the number of resisting planes orthogonal to the direction of excitation. As mentioned earlier, the ratio of uncoupled torsional frequency, $\omega_{\theta}$, to the lateral frequency, $\omega_{y}$, is defined as

$$
\Omega_{R}=\frac{\omega_{\theta}}{\omega_{y}}
$$

The two frequencies of the system with a plan view as shown in Fig. 3.1 are then calculated from the following expressions (Humar, and Kumar 1998a)

$$
\begin{aligned}
& \frac{\omega_{1}}{\omega_{y}}=\sqrt{A-B} \\
& \frac{\omega_{2}}{\omega_{y}}=\sqrt{A+B}
\end{aligned}
$$

where $\mathrm{A}$ and $\mathrm{B}$ are given by 


$$
\begin{aligned}
& A=\frac{1}{2}\left[1+\Omega_{R}^{2}+\left(\frac{e}{r}\right)^{2}\right] \\
& B=\sqrt{A^{2}-\Omega_{R}^{2}}
\end{aligned}
$$

$r$ is the radius of gyration about the centre of mass given by the following expression

$$
r^{2}=\frac{a^{2}+b^{2}}{12}=\frac{b^{2}}{12}\left(1+\alpha^{2}\right)
$$

and $\alpha=a / b$ is the aspect ratio.

The mode shape components along coordinates $y$ and $\theta$ with origin at the centre of mass are then calculated from the following

$$
\begin{aligned}
& \varphi_{y n}=\frac{e / r}{\sqrt{(e / r)^{2}+\left(1-\left(\omega_{n} / \omega_{y}\right)^{2}\right)^{2}}} \\
& \varphi_{\theta n}=\frac{-\left(1-\left(\omega_{n} / \omega_{y}\right)^{2}\right)}{\sqrt{(e / r)^{2}+\left(1-\left(\omega_{n} / \omega_{y}\right)^{2}\right)^{2}}}
\end{aligned}
$$

where $n=1$, and 2

A response spectrum dynamic analysis is used in the present study. The maximum shear in the resisting planes is obtained by combining the modal values using the Complete Quadratic Combination (CQC) method. This is because the coupled torsional and translational frequencies, $\omega_{1}$ and $\omega_{2}$, may be close to each other and the Square Root of the Sum of the Squares (SRSS) method commonly used could lead to significant error. 
Before calculating the base shear and torque, we define a reference building which is not required to be symmetric but only to be torsionally balanced. This building has the same structural properties ( $K_{y}, K_{\theta R}, m$, and $r$ ) as the unbalanced building, but has coincident centres of mass and rigidity. The modal base shear and torque in the unbalanced building can be expressed in the following normalized forms (Humar, and Kumar 1998a)

$$
\begin{gathered}
V_{n}=m \varphi_{y n}^{2} S_{a n} \\
\bar{V}_{n}=\frac{V_{n}}{V_{o}}=\varphi_{y n}^{2} \frac{S_{a n}}{S_{a y}} \\
T_{n}=m r \varphi_{y n} \varphi_{\theta n} S_{a n} \\
T_{R n}=T_{n}-e V_{n}=m \varphi_{y n} S_{a n}\left(r \varphi_{\theta n}-e \varphi_{y n}\right) \\
\bar{T}_{R n}=\frac{T_{R n}}{V_{o} r}=\varphi_{y n}\left(\varphi_{\theta n}-\frac{e}{r} \varphi_{y n}\right) \frac{S_{a n}}{S_{a y}}=\frac{e_{d n}}{r}=\bar{e}_{d n}
\end{gathered}
$$

where $V_{n}$ is the base shear in the $n$th mode, $T_{n}$ is the torque about CM in the $n$th mode, $T_{R n}$ is the torque about $\mathrm{CR}$ in the $n$th mode, $S_{a n}$ is the spectral acceleration in the $n$th mode, $V_{o}$ is the base shear in the torsionally balanced building $\left(V_{o}=m S_{a y}\right)$, and $S_{a y}$ is the spectral acceleration corresponding to the frequency $\omega_{y}$. It is useful also to define a parameter $e_{d n}$ as the effective dynamic eccentricity, such that when the base shear, $V_{o}$, is applied at a distance $e_{d n}$ from CR it produces a torque $T_{R n}$ about CR.

In the elastic range, the lateral shears in the resisting planes are proportional to the displacements. We can therefore combine the modal displacements rather than modal shears. Modal displacements of the flexible and stiff edges of the building, $\Delta_{f n}$ and $\Delta_{s n}$, are given by 


$$
\begin{gathered}
\Delta_{f n}=\frac{V_{n}}{K_{y}}-\frac{T_{R n}}{K_{\theta R}}\left(e+\frac{b}{2}\right) \\
\Delta_{s n}=\frac{V_{n}}{K_{y}}+\frac{T_{R n}}{K_{\theta R}}\left(\frac{b}{2}-e\right)
\end{gathered}
$$

Both displacements are then normalized by the displacement of torsionally balanced building, $\Delta_{o}=V_{d} / K_{y}$. After substituting Eqs. 3.13 and 3.14 in Eqs. 3.15 and 3.16 and noting that $K_{\theta R} / K_{y}=\Omega_{R}{ }^{2} r^{2}$, we get

$$
\begin{aligned}
& \bar{\Delta}_{f n}=\frac{\Delta_{f n}}{\Delta_{o}}=\varphi_{y n}^{2} \frac{S_{a n}}{S_{a y}}-\frac{1}{\Omega_{R}^{2}} \varphi_{y n}\left(\varphi_{\theta n}-\frac{e}{r} \varphi_{y n}\right)\left(\frac{e}{r}+\frac{b}{2 r}\right) \frac{S_{a n}}{S_{a y}} \\
& \bar{\Delta}_{s n}=\frac{\Delta_{s n}}{\Delta_{o}}=\varphi_{y n}^{2} \frac{S_{a n}}{S_{a y}}+\frac{1}{\Omega_{R}^{2}} \varphi_{y n}\left(\varphi_{\theta n}-\frac{e}{r} \varphi_{y n}\right)\left(\frac{b}{2 r}-\frac{e}{r}\right) \frac{S_{a n}}{S_{a y}}
\end{aligned}
$$

The resultant normalized flexible and stiff edge displacements can be obtained by modal superposition.

The flexible and stiff edge effective eccentricities, $e_{f}$ and $e_{s}$, are also calculated. They are defined as the distances from $C R$ at which the application of base shear $V_{o}$ would produce flexible and stiff edge displacements of $\Delta_{f}$ and $\Delta_{s}$ respectively. The effective eccentricities are given by 


$$
\begin{aligned}
& \frac{e_{f}}{b}=\left(\bar{\Delta}_{f}-1\right) \frac{\Omega_{R}{ }^{2}}{\left(\frac{b}{r}\right)^{2}\left(\frac{1}{2}+\frac{e}{b}\right)} \\
& \frac{e_{s}}{b}=\left(1-\bar{\Delta}_{s}\right) \frac{\Omega_{R}{ }^{2}}{\left(\frac{b}{r}\right)^{2}\left(\frac{1}{2}-\frac{e}{b}\right)}
\end{aligned}
$$

An expression for normalized flexible edge displacement corresponding to the proposed design flexible edge eccentricity given by Eq. 3.3 can be obtained as follows

$$
\begin{aligned}
& \Delta_{f c}=\frac{V_{o}}{K_{y}}+\frac{V_{o} e_{d l}}{K_{0 R}}\left(e+\frac{b}{2}\right) \\
& \bar{\Delta}_{f c}=1+\frac{1}{\Omega_{R}^{2}}\left(\frac{e}{r}+0.1 \frac{b}{r}\right)\left(\frac{e}{r}+\frac{b}{2 r}\right)
\end{aligned}
$$

In a similar manner, the expression for the normalized stiff edge displacement corresponding to the proposed design stiff edge eccentricity given by Eq. $3.4 \mathrm{a}\left(\Omega_{R} \geq 1\right)$ is obtained from

$$
\begin{aligned}
& \Delta_{s c}=\frac{V_{o}}{K_{y}}-\frac{V_{o} e_{d 2}}{K_{\theta R}}\left(\frac{b}{2}-e\right) \\
& \bar{\Delta}_{s c}=1-\frac{1}{\Omega_{R}^{2}}\left(\frac{e}{r}-0.1 \frac{b}{r}\right)\left(\frac{b}{2 r}-\frac{e}{r}\right)
\end{aligned}
$$


The expression corresponding to the proposed design stiff edge eccentricity given by Eq. $3.4 \mathrm{~b}\left(\Omega_{R}<1\right)$ is

$$
\bar{\Delta}_{s c}=1+\frac{1}{\Omega_{R}^{2}}\left(0.1 \frac{b}{r}\right)\left(\frac{b}{2 r}-\frac{e}{r}\right)
$$

The normalized stiff edge displacement produced by the application of $V_{o}$ at a design flexible edge eccentricity, $e_{d l}$, should now be checked

$$
\bar{\Delta}_{s c}=1-\frac{1}{\Omega_{R}^{2}}\left(\frac{e}{r}+0.1 \frac{b}{r}\right)\left(\frac{b}{2 r}-\frac{e}{r}\right)
$$

The first term in Eq. 3.24 represents the normalized displacement produced by the translation of the building while the second term represents the normalized displacement produced by the rotation of the building about $\mathrm{CR}$. In a torsionally very flexible system, the rotational component of displacement may exceed the translational component leading the second term in the equation to be greater than 1 . In such cases, the absolute value of displacement obtained from Eq. 3.24 may exceed that obtained from Eqs. 3.22 and 3.23.

\subsubsection{Multistorey Building Models of General Class}

It has been pointed out by Humar and Kumar (1998a) that the response of multistorey buildings of special class, in which centres of mass and centres of rigidity lie on two vertical lines and the frequency ratio, $\Omega_{R}$, is the same for all floors, can be obtained by analyzing an associated torsionally coupled (unbalanced) single storey building and a torsionally 
uncoupled (balanced) multistorey building. They have observed that the results obtained from single storey building can apply also to multistorey buildings of such special class. Similar findings were obtained by Kumar (1998) after carrying out analyses of buildings in which the frequency ratio, $\Omega_{R}$, was the same for all floors but eccentricity, e, varied along the height.

The torsional response of multistorey buildings of general class is quite complex. It is therefor of considerable interest to examine the extent to which the results of single storey models can be used for such a class of multistorey buildings. A complete set of elastic static and dynamic analyses is carried out to investigate the torsional response of general class of multistorey building models, in which the eccentricity, $e$, is kept the same for all floors but the frequency ratio, $\Omega_{R}$ may vary from floor to floor. The main issues this study addresses are:

(1) How well do the edge displacements of the equivalent single storey building predict the interstorey edge displacement ratios of the multistorey building of a general class when it is subjected to the same earthquake motion as represented by an idealized response spectrum? (2) Do the proposed design eccentricity expressions, derived for a single storey building (Humar and Kumar 1998a), namely Eqs. 3.3, 3.4a, and 3.4b, apply to multistorey buildings of a general class which is quite different from a building of a special class as described earlier?

Two main steps are involved in the analysis of the multistorey building models under consideration. These steps can be summarized as follows:

(1) Response spectrum analysis is carried out on the multistorey building model with floor 
rotations restrained (balanced building). The results of this analysis provide the maximum values of storey shear forces from which the floor forces, $F_{i}$, can be obtained. Spectral dynamic analysis is also carried out on corresponding torsionally coupled (unbalanced) multistorey building (identical to the balanced building models in mass, lateral stiffness, and $\Omega_{R}$ but where the CM does not coincide with $\mathrm{CR}$ ). Both types of building models are subjected to an earthquake motion represented by an idealized hyperbolic response spectrum, as shown in Fig. 3.2, given by $S_{a} / g=1 / T$. Flexible and stiff edges storey shear forces are then obtained. Since the building models are assumed to remain linearly elastic, the displacements of the resisting planes are directly proportional to the shear forces in such planes. Therefore, the ratio of shear force at any edge in an unbalanced building to that in the corresponding balanced building is equal to the ratio of the corresponding interstorey displacements. The design interstorey displacement ratios for flexible and stiff edges are then calculated.

(2) Static analysis is carried out to provide the design interstorey displacement ratios for flexible and stiff edges to verify the applicability of proposed design eccentricity expressions to general multistorey buildings. This is achieved by applying the floor forces, $F_{i}$, obtained from dynamic analysis in step (1) to the same building through points located as follows:

(i) To obtain the storey shear forces at flexible edge, the dynamic forces, $F_{i}$ are applied through points located at a distance of $0.05 b$ to the left of CM.

(ii) To calculate the storey shear forces at stiff edge, the dynamic forces, $F_{i}$ are applied through points located at a distance of $0.05 b$ to the right of $\mathrm{CM}\left(\Omega_{R} \geq 1\right)$ or at a distance of $0.1 b$ to the right of CR ( $\left.\Omega_{R}<1\right)$, depending on the value of $\Omega_{R}$. 
It should be noted that the design provisions specified in Eqs. 3.3 and 3.4 take into account the accidental eccentricity. Since the dynamic analysis results do not include accidental eccentricity effect, for a proper comparison the accidental eccentricity component should be removed from Eqs. 3.3 and 3.4. Considering that an eccentricity of $0.05 b$ is sufficient to account for accidental torsion, the design forces are obtained by applying the earthquake shear through points $\pm 0.05 b$ from the $\mathrm{CM}$.

The floor forces, $F_{i}$ are then applied to the corresponding torsionally balanced building models and a static analysis is carried out to obtain the storey shears in the flexible and stiff edge frames. Similar to step (1), the interstorey flexible and stiff edge displacement ratios are calculated from the values of storey shear forces obtained from the static analyses. The interstorey displacement ratios obtained from this step and those obtained from dynamic analysis, i. e. step (1) are then compared. The displacement ratios obtained from general multistorey dynamic and static analyses, i. e. steps (1) and (2), are also compared to the corresponding values of the equivalent single storey building.

Computer program SUPER-ETABS (Maison and Neuss, 1983) is used in carrying out the response spectrum dynamic analyses described in step (1). The same program is also used in carrying out the static analyses described in step (2). The Complete Quadratic Combination (CQC) method is used in modal superposition.

To calculate the stiff edge displacement ratio in step (2), for cases $\Omega_{R}<1$, the floor forces, $F_{i}$, obtained from dynamic analysis in step (1) should be applied at a point located at a distance of $0.1 b$ to the right of CR (toward the stiff edge). This cannot be done directly because the locations of centres of rigidity, CR, are not known. However, an indirect method 
of calculation, which requires three sets of analyses, is used:

(a) Static analysis with the floor forces, $F_{i}$, applied at a distance of $0.05 b$ to the left of centre of mass, CM.

(b) Static analysis with the floor forces, $F_{i}$, applied at a distance of $0.05 b$ to the right of centre of mass, CM.

(c) Static analysis with the floor forces, $F_{i}$, applied through the centre of mass, CM, in the torsionally balanced multistorey building models, which coincides with the centre of resistance, $\mathrm{CR}$.

No additional analyses are in fact required because steps (a) and (b) are similar to steps 2(i) and 2(ii) mentioned earlier while step (c) is obtained from the static analyses of the corresponding balanced multistorey building models discussed in step (2). Now we define the storey shear forces of the stiff edge obtained from the three sets of the previous analyses, i. e. (a), (b) and (c) as $V_{a}, V_{b}$, and $V_{c}$. The storey shear force due to the application of floor forces, $F_{i}$, obtained from dynamic analysis in step (1) at a distance of $0.1 b$ to the right of CR is given by

$$
V_{t}=V_{c}+V_{b}-V_{a}
$$

The multistorey building models selected for the analysis are assumed to be shear type of buildings. In such buildings, the static eccentricity, $e$, the total lateral stiffness, $K_{y}$, and the frequency ratio, $\Omega_{R}$, can be defined independently for each floor. Thus, the results obtained for the design interstorey displacement ratios for flexible and stiff edges in the static analysis of step (2) are expected to be the same as the those obtained from the proposed expressions for single storey buildings, i.e. Eqs. 3.21, 3.22, 3.23 and 3.24, provided the 
building is of a special class.

\subsection{RESULTS OF ANALYSIS}

To evaluate the effect of the variation of frequency ratio, $\Omega_{R}$ across the height on the torsional response of multistorey buildings of general class, the following examples are presented

\section{Example 1}

\section{Building Description}

The selected building in this example is a five-storey shear building. The plan view and elevation of the building model are shown in Fig. 3.3. The building model includes four resisting planes, three parallel to the $y$ axis and one along the $x$ axis passing through both the centre of mass, CM and the centre of rigidity, CR. The building is symmetrical about $x$ axis but asymmetrical about $y$ axis. As shown in Fig. 3.3, the centre of rigidity, CR is offset to the right from the centre of mass, CM. The floor width $b$ is taken to be $36 \mathrm{~m}$. The aspect ratio $a / b$ is set to be equal to 1 . The mass is uniformly distributed at floor levels and is taken to be $400 \mathrm{Mg}$ for each storey. The mass moment of inertia about $\mathrm{CM}$ is calculated to be $86,400 \mathrm{Mg} \cdot \mathrm{m}^{2}$. The height of each floor is taken to be $4.0 \mathrm{~m}$.

The total lateral stiffness, $K_{y}$, is set to be the same for each floor and is adjusted so that the first uncoupled translational period of the building is $1 \mathrm{~s}$. Table 3.1 presents the values of lateral stiffness for each resisting plane parallel to $y$ axis, $k_{y i}$, and also the total lateral stiffness, $K_{y}$, for each storey. Damping of $5 \%$ in each mode is considered in the 
analyses. The static eccentricity, $e$, is selected to be the same for all storeys. Six different multistorey building models with $e / b$ values of $0.05,0.1,0.15,0.2,0.25$, and 0.3 are considered. Two different cases are investigated:

(1) $\Omega_{R}$ is taken equal to 1.0 for the $1^{\text {st }}, 2^{\text {nd }}$ and $3^{\text {rd }}$ storeys, and 0.75 for the $4^{\text {th }}$ and $5^{\text {th }}$ storeys. (2) $\Omega_{R}$ is taken equal to 0.75 for the $1^{\text {st }}, 2^{\text {nd }}$ and $3^{\text {rd }}$ storeys, and 1.00 for the $4^{\text {th }}$ and $5^{\text {th }}$ storeys.

\section{Details of analysis}

Spectral dynamic analyses of the torsionally balanced and unbalanced building models mentioned above are carried out. The ground motions are represented by an idealized (hyperbolic) spectrum as shown in Fig. $3.2\left(S_{a} / g=1 / T\right)$. Maximum storey shears and floor forces, $F_{i}$, obtained from the analysis of a torsionally balanced building are presented in Table 3.2. Floor forces obtained from NBCC inverted triangle distribution of base shear are also presented in the table. A Complete Quadratic Combination, CQC method is used in combining the storey modal shears for both torsionally balanced and unbalanced multistorey building models. The interstorey displacement ratios for flexible and stiff edges are then calculated.

The building models are now analyzed statically with the previous floor forces, $F_{i}$, applied at distances of $\pm 0.05 b$ from $C M$, according to the procedures described earlier. The storey shears for torsionally balanced and unbalanced building models are obtained. The normalized interstorey displacement ratios for flexible and stiff edges are then calculated.

The interstorey displacement ratios for flexible and stiff edges obtained from dynamic analysis are compared with the corresponding values obtained from static analysis. Table 3.3 
presents the storey shears in the edge frames of the five storey building model with $\Omega_{R}=1.0$ for the $1^{\text {st }}, 2^{\text {nd }}$, and $3^{\text {rd }}$ floors and 0.75 for the $4^{\text {th }}$ and $5^{\text {th }}$ floors, $e=0.1 b$ for all floors. Table 3.4 shows the storey shears in the edge frames obtained from dynamic analysis for the same five storey building model. Table 3.5 presents the values of edge displacement ratios obtained from response spectrum analysis for single storey building model with $\Omega_{R}=1.0$.

The variation of interstorey displacement ratio for flexible edge is plotted as a function of $e / b$ in Fig. 3.4 for both cases 1 and 2. In Fig. 3.5, the variation of interstorey displacement ratio for stiff edge is plotted as a function of $e / b$ again for both cases 1 and 2 . The corresponding values for the single storey building, which has the same $\Omega_{R}$ and $e / b$ are also shown in the above figures. For the sake of comparison, the interstorey displacement ratios obtained from the static analysis according to the proposed design provisions are also presented.

It is observed from Fig. 3.4a that in Case 1 the displacement ratios for flexible edge of the multistorey building match fairly closely those of the corresponding single storey model for floors 1,2 and $3\left(\Omega_{R}=1.0\right)$ with single storey estimates being slightly higher. The single storey displacement ratios for $\Omega_{R}=0.75$ are quite different from the displacement ratios for floors 4 and 5 in the multistorey building, and, in fact, substantially lower.

Figure $3.4 \mathrm{~b}$ for Case 2 shows that the flexible edge displacement ratios for floors 1,2 , and $3\left(\Omega_{R}=0.75\right)$ again match fairly closely the single storey value, although the latter are somewhat lower. The displacement ratio for single storey model with $\Omega_{R}=1.0$ is significantly larger than the displacement ratios for floors 4 and 5 , which have $\Omega_{R}=1.0$.

It is seen from Fig. 3.5 that the variation of interstorey displacement ratio for stiff 
edge of the multistorey building closely matches with that for the corresponding single storey building for the top two floors, only for values of $e / b>0.20$, in Case $1\left(\Omega_{R}=0.75\right)$ and the bottom three floors in Case $2\left(\Omega_{R}=0.75\right)$ for all values of $e / b$. The results obtained from single storey models, however, underestimate the values of the stiff edge displacement ratio for the other storeys of the multistorey building models $\left(\Omega_{R}=1.00\right)$.

It is also observed from Figs. 3.4 and 3.5 that the proposed design provision for the flexible edge provides a conservative estimate for the flexible edge displacements in the multistorey building models selected for all values of $\Omega_{R}$ and $e / b$. However, the proposed provision for stiff edge underestimates the value for the stiff edge displacements in the multistorey building models for the bottom three floors in Case $1\left(\Omega_{R}=1.00\right)$ and the top two floors in Case $2\left(\Omega_{R}=1.00\right)$.

\section{Example 2}

\section{Building Description}

The building selected for this example is a ten-storey shear building. Figure 3.6 shows the plan view and elevation of the building model. The origin of the coordinate axes is taken at the centre of mass, CM. The building model includes five resisting planes, three parallel to the $y$ axis and two parallel to the $x$ axis. The $i$ th plane parallel to the $x$ axis has a stiffness, $k_{x i}$, while the $i$ th plane in the $y$ axis has a stiffness $k_{y i}$. The distribution of stiffness is symmetrical about the $x$ axis, but is asymmetrical about $y$ axis. The entire storey mass is assumed to be uniformly distributed at the floor level and is taken to be $400 \mathrm{Mg}$ for each storey. The mass moment of inertia is calculated to be $86,400 \mathrm{Mg} \cdot \mathrm{m}^{2}$. The building floors are 
assumed to be infinitely rigid in their own planes. The centre of rigidity, CR, lies on the $x$ axis at a distance $e$ from the centre of mass, CM. The floor width $b$ is taken to be $36 \mathrm{~m}$, aspect ratio as 1 , and the height of each floor as $4.0 \mathrm{~m}$.

Total lateral stiffness, $K_{y}$, has the same value for each storey and is adjusted so that the first uncoupled period for translational in $y$ direction is $1 \mathrm{~s}$. The values of the lateral stifnesses for resisting planes parallel to $y$ axis, $k_{y i}$ and the total lateral stiffness, $K_{y}$, for each storey are presented in Table 3.6 for $e=0.1 b$. Damping is set to be $5 \%$ for each mode in the analyses. The static eccentricity, $e$, is assumed to be the same for each storey. Six different multistorey building models with $e / b$ values of $0.05,0.1,0.15,0.2,0.25$, and 0.3 are considered. Two cases are investigated:

(1) $\Omega_{R}$ is equal to 1.0 for the $1^{\text {st }}, 2^{\text {nd }}, 3^{\text {rd }}, 4^{\text {th }}$ and $5^{\text {th }}$ storeys, and 0.75 for the $6^{\text {th }}, 7^{\text {th }}, 8^{\text {th }}, 9^{\text {th }}$ and $10^{\text {th }}$ storeys.

(2) $\Omega_{R}$ is equal to 0.75 for the $1^{\text {st }}, 2^{\text {nd }}, 3^{\text {rd }}, 4^{\text {th }}$ and $5^{\text {th }}$ storeys, and 1.00 for the $6^{\text {th }}, 7^{\text {th }}, 8^{\text {th }}, 9^{\text {th }}$ and $10^{\text {th }}$ storeys.

\section{Details of analysis}

A set of dynamic response spectrum analyses is carried out and the ratio of interstorey displacements for flexible and stiff edges in the torsionally balanced and unbalanced building models are calculated. A ground motion represented by a hyperbolic spectrum is used in the dynamic analysis. Storey shears and floor forces, $F_{i}$ are obtained from the analysis of the balanced building models. The values of floor forces, $F_{i}$ are shown in Table 3.7. The table also shows the storey lateral forces calculated according to NBCC distribution of base shear. 
The building models are subjected to static lateral forces, $F_{i}$ acting at $\pm 0.05 b$ from CM. The ratios of interstorey displacements for flexible and stiff edges in the torsionally balanced and unbalanced building models are then calculated.

Table 3.8 shows the values of interstorey displacement ratios for the flexible and stiff edges of torsionally balanced and unbalanced building models obtained from static analysis. Table 3.9 presents the values of interstorey displacement ratios for flexible and stiff edges obtained from dynamic analysis. The latter values are compared with those obtained from static analysis in Figs. 3.7 and 3.8. The corresponding single storey building values are also plotted for the sake of comparison. Figure 3.7a shows that for Case 1 the variation of interstorey displacement ratio for flexible edge of the multistorey building is fairly close to that for the corresponding single storey building for the bottom five floors $\left(\Omega_{R}=1.00\right)$ although the single storey estimates are somewhat higher. For the floors 6 to $10\left(\Omega_{R}=0.75\right)$, the corresponding single storey is substantially lower. Figure $3.7 \mathrm{~b}$ shows that for Case 2 the single storey estimate for $\Omega_{R}=0.75$ is close to the multistorey estimates for floors 1 to 5 , although somewhat lower. The single storey estimate for $\Omega_{R}=1.00$ is significantly larger than the multistorey estimates for floors 6 to 10. It is seen from Fig. 3.8 that the variation of interstorey displacement ratio for stiff edge of the multistorey building closely matches that for the corresponding single storey building for the top five floors, only for values of $e / b>0.20$, in Case $1\left(\Omega_{R}=0.75\right)$ and the bottom five floors in Case $2\left(\Omega_{R}=0.75\right)$ for all values of $e / b$.

Figure 3.7 shows that the proposed design provision for the flexible edge provides a quite conservative estimate for the flexible edge displacements in the multistorey building 
models selected for all values of $\Omega_{R}$ and $e / b$. However, Fig. 3.8 shows that the proposed provision for stiff edge underestimates the value for the stiff edge displacements in the multistorey building models for the bottom five floors in Case $1\left(\Omega_{R}=1.00\right)$ and the top five floors in Case $2\left(\Omega_{R}=1.00\right)$.

\section{Example 3}

\section{Building Description}

The building models selected in this example are similar to those used in the previous example except that the distribution of the frequency ratio, $\Omega_{R}$ across the height is as follows: (1) $\Omega_{R}$ is equal to 1.25 for the $1^{\text {st }}, 2^{\text {nd }}, 3^{\text {rd }}, 4^{\text {th }}$ and $5^{\text {th }}$ storeys, and 1.0 for the $6^{\text {th }}, 7^{\text {th }}, 8^{\text {th }}, 9^{\text {th }}$ and $10^{\text {th }}$ storeys.

(2) $\Omega_{R}$ is equal to 1.0 for the $1^{\text {st }}, 2^{\text {nd }}, 3^{\text {rd }}, 4^{\text {th }}$ and $5^{\text {th }}$ storeys, and 1.25 for the $6^{\text {th }}, 7^{\text {th }}, 8^{\text {th }}, 9^{\text {th }}$ and $10^{\text {th }}$ storeys.

\section{Details of analysis}

The dynamic and static analyses are carried out in the same sequence as in the previous example. Tables 3.10 and 3.11 present the interstorey displacement ratios for flexible and stiff edges of torsionally balanced and unbalanced building models with $e=0.1 b$ obtained from static and dynamic analyses respectively.

Figure 3.9 shows the variation of interstorey displacement ratio for flexible edge of the multistorey building with the eccentricity ratio $e / b$. The figure shows that the single storey values for displacement ratio provide a conservative estimate of edge displacements 
due to torsion in the multistorey buildings for only the bottom five floors in Case 1 and top five floors in Case $2\left(\Omega_{R}=1.25\right)$. For other floors the single storey estimates are significantly lower than the floor displacements in the multistorey building. In Fig. 3.10, the single storey values for stiff edge displacement ratio provide a conservative estimate of edge displacements in the multistorey buildings for only the top five floors in Case 1 and bottom five floors in Case $2\left(\Omega_{R}=1.00\right)$. Again, for other floors the single storey estimates are lower than the floor displacements in the multistorey building

It is obvious from Figs. 3.9 and 3.10 that the proposed design provisions are quite conservative for both flexible and stiff edges of the multistorey building models selected.

\section{Example 4}

\section{Building Description}

The multistorey building models selected in this example are similar to those used in the previous example except that the distribution of the frequency ratio, $\Omega_{R}$ across the height is as follows:

(1) $\Omega_{R}$ is equal to 1.25 for the $1^{\text {st }}, 2^{\text {nd }}, 3^{\text {rd }}, 4^{\text {th }}$ and $5^{\text {th }}$ storeys, and 0.75 for the $6^{\text {th }}, 7^{\text {th }}, 8^{\text {th }}, 9^{\text {th }}$ and $10^{\text {th }}$ storeys.

(2) $\Omega_{R}$ is equal to 0.75 for the $1^{\text {st }}, 2^{\text {nd }}, 3^{\text {rd }}, 4^{\text {th }}$ and $5^{\text {th }}$ storeys, and 1.25 for the $6^{\text {th }}, 7^{\text {th }}, 8^{\text {th }}, 9^{\text {th }}$ and $10^{\text {th }}$ storeys.

\section{Details of analysis}

The dynamic and static analyses are carried out in the same sequence as in the 
previous examples. Table 3.12 presents the interstorey displacement ratios for the flexible and stiff edges of torsionally balanced and unbalanced building models with $e=0.1 b$ obtained from response spectrum dynamic analysis.

The results of the analysis are presented in Figs. 3.11 and 3.12. It is evident from Fig. 3.11 that the flexible edge displacement ratio for a single storey building significantly underestimates the interstorey displacement ratio for the top five floors of the multistorey buildings in Case 1 and the bottom five floors in Case $2\left(\Omega_{R}=0.75\right)$. For other floors, single storey results overestimate the interstorey displacement ratio for flexible edge. For the stiff edge, Fig. 3.12, the interstorey displacement ratio of the multistorey buildings matches closely with that for the corresponding single storey building for the top five floors in Case 1 and the bottom five floors in Case $2\left(\Omega_{R}=0.75\right)$. The results obtained from single storey models, however, underestimate the values of stiff edge interstorey displacement ratio for the other storeys of the multistorey buildings.

It is observed from Figs. 3.11 and 3.12 that the proposed design provisions give conservative estimates of both the flexible and stiff edge displacements in the multistorey building models selected.

\section{Example 5}

\section{Building Description}

The building models used in this example are similar to those used in the previous example except that in this example, three values are selected for the frequency ratio, $\Omega_{R}$. The frequency ratio distribution across the height is now as follows: 
(1) $\Omega_{R}$ is equal to 1.00 for the $1^{\text {st }}, 2^{\text {nd }}, 3^{\text {rd }}$ and $4^{\text {th }}$ storeys, and 1.25 for the $5^{\text {th }}, 6^{\text {th }}$ and $7^{\text {th }}$ storeys, 0.75 for the $8^{\text {th }}, 9^{\text {th }}$ and $10^{\text {th }}$ storeys.

(2) $\Omega_{R}$ is equal to 0.75 for the $1^{\text {st }}, 2^{\text {nd }}, 3^{\text {rd }}$ and $4^{\text {th }}$ storeys, and 1.25 for the $5^{\text {th }}, 6^{\text {th }}$ and $7^{\text {th }}$ storeys, 1.00 for the $8^{\text {th }}, 9^{\text {th }}$ and $10^{\text {th }}$ storeys.

\section{Details of analysis}

Dynamic and static analyses are carried out in a manner similar to that in the previous examples. The interstorey displacement ratios for flexible and stiff edges of torsionally balanced and unbalanced building models with $e=0.1 b$ obtained from response dynamic analysis are presented in Table 3.13.

The results of analysis are presented in Figs. 3.13 and 3.14. It is observed from Fig. 3.13 that the variation of the interstorey displacement ratio of flexible edge for the multistorey building models matches closely with that for the corresponding single storey buildings for the bottom four floors in Case 1 and the top three floors in Case $2\left(\Omega_{R}=1.00\right)$. For the $5^{\text {th }}, 6^{\text {th }}$ and $7^{\text {th }}$ floors, single storey results overestimate the interstorey displacement ratio for flexible edge $\left(\Omega_{R}=1.25\right)$. However, the single storey values of flexible displacement ratio underestimate the interstorey displacement ratio for flexible edge in multistorey buildings for the top three floors in Case 1 and bottom four floors in Case $2\left(\Omega_{R}=0.75\right)$.

For the stiff edge, Fig. 3.14 shows that the variation of the interstorey displacement ratio of the multistorey buildings matches closely with that for the corresponding single storey buildings for the bottom four floors in Case 1 and the top three floors in Case 2 $\left(\Omega_{R}=1.00\right)$. For the top three floors in Case 1 and the bottom four floors in Case 2, single 
storey results provide a conservative estimate for the interstorey displacement ratio of stiff edge for values of $e / b>0.17\left(\Omega_{R}=0.75\right)$. The results obtained from single storey models, however, underestimate the values of stiff edge interstorey displacement ratio for the other storeys of the multistorey buildings $\left(\Omega_{R}=1.25\right)$.

It is observed from Figs. 3.13 and 3.14 that the proposed design provision for flexible edge give conservative estimates for the interstorey displacement ratios in the multistorey building models selected. Proposed expressions for stiff edge also provide conservative estimates for the displacement ratios in multistorey buildings except for the bottom four floors in Case 1 corresponding to $e / b$ values between 0.09 and 0.23 and the top three floors in Case 2 for values of $e / b>0.25\left(\Omega_{R}=1.00\right)$.

\section{Example 6}

\section{Building Description}

The building models selected in this example are similar to those used in the previous example except that the distribution of the frequency ratio, $\Omega_{R}$ across the height is as follows:

(1) $\Omega_{R}$ is equal to 1.00 for the $1^{\text {st }}, 2^{\text {nd }}, 3^{\text {rd }}$ and $4^{\text {th }}$ storeys, and 0.75 for the $5^{\text {th }}, 6^{\text {th }}$ and $7^{\text {th }}$ storeys, 1.25 for the $8^{\text {th }}, 9^{\text {th }}$ and $10^{\text {th }}$ storeys.

(2) $\Omega_{R}$ is equal to 1.25 for the $1^{\text {st }}, 2^{\text {nd }}, 3^{\text {rd }}$ and $4^{\text {th }}$ storeys, and 0.75 for the $5^{\text {th }}, 6^{\text {th }}$ and $7^{\text {th }}$ storeys, 1.00 for the $8^{\text {th }}, 9^{\text {th }}$ and $10^{\text {th }}$ storeys. 


\section{Details of analysis}

Dynamic and static analyses are carried out in a manner similar to that in the previous examples. The interstorey displacement ratios for flexible and stiff edges of torsionally balanced and unbalanced building models with $e=0.1 b$ obtained from response dynamic analysis are presented in Table 3.14 .

The results of analysis are presented in Figs. 3.15 and 3.16. It is evident from Fig. 3.15 that the single storey values of flexible displacement ratio underestimate the interstorey displacement ratio for flexible edge in multistorey buildings for the $5^{\text {th }}, 6^{\text {th }}$ and $7^{\text {th }}$ floors in both cases $\left(\Omega_{R}=0.75\right)$. The variation of the interstorey displacement ratio of flexible edge for the multistorey building models matches closely with that for the corresponding single storey buildings for the top three floors in Case $2\left(\Omega_{R}=1.00\right)$. For all other floors, single storey results overestimate the interstorey displacement ratio for flexible edge $\left(\Omega_{R}=1.00\right.$ and 1.25$)$.

For the stiff edge, Fig. 3.16 shows that the variation of the interstorey displacement ratio of the multistorey buildings matches closely with that for the corresponding single storey buildings for the $5^{\text {th }}, 6^{\text {th }}$ and $7^{\text {th }}$ floors in Case 1 for values of $e / b>0.20$, and also the $5^{\text {th }}, 6^{\text {th }}$ and $7^{\text {th }}$ floors in Case 2 for values of $e / b>0.11\left(\Omega_{R}=0.75\right)$. The values also match closely for the top three floors in Case $1\left(\Omega_{R}=1.00\right)$. The results obtained from single storey models, however, underestimate the values of stiff edge interstorey displacement ratio for the other storeys of the multistorey buildings $\left(\Omega_{R}=1.00\right.$ and 1.25$)$.

It is observed from Figs. 3.15 and 3.16 that the proposed design expressions for flexible edge provide conservative estimates for the interstorey displacement ratios in the 
multistorey building models selected. Proposed expressions for stiff edge also provide conservative estimates for displacement ratios in the multistorey buildings except for the bottom four floors in Case 1 and the top three floors in Case 2 for values of $e / b<0.20$ $\left(\Omega_{R}=1.00\right)$

\subsection{ALTERNATIVE PROVISIONS TO ACCOUNT FOR TORSIONAL STIFFNESS}

The results presented by Humar and Kumar (1998a and 1998b) show that torsional stiffness plays a major role in determining the magnitude of torsional response. This is supported by the results presented in the previous sections. The flexible and stiff edge displacements experience a significant increase as $\Omega_{R}$ falls below 1.0. Expression given by Eq. 3.3 gives a conservative prediction of the increased displacement of the flexible edge. Equation 3.4a is however no longer satisfactory for estimating the stiff edge displacement. The alternative expression of Eq. 3.4b has been suggested for this situation.

Another reasonable approach to design would be to prohibit the use of structural systems with $\Omega_{R}<1.0$, or to require a dynamic analysis when such is the case. Since the determination of $\Omega_{R}$ may be cumbersome, an alternative measure of torsional stiffness is desired. For this purpose it is useful to consider a measure similar to that suggested in UBC (1997) and NEHRP (2000).

In a manner similar to UBC and NEHRP a parameter $B_{x}$ is defined for each level $x$ 
to measure the torsional sensitivity. Parameter $B_{x}$ is given by

$$
B_{x}=\frac{\delta_{\max }}{\delta_{a v e}}
$$

where

$\delta_{\max }=$ the maximum displacement of the structure at level $x$ in the direction of the earthquake induced by the equivalent static forces acting at distances $\pm 0.1 D_{n x}$ from the centres of mass at each floor.

$\delta_{\text {ave }}=$ the average of the displacements at the extreme points of the structure at level $x$ produced by the forces used in calculating $\delta_{\max }\left(\delta_{a v e}=\left(\delta_{\max }+\delta_{\min }\right) / 2\right)$

$D_{n x}=$ the plan dimension of the building at level $x$ perpendicular to the direction of earthquake forces.

The maximum value of $B_{x}$ is referred to as $B$. For building with $B \leq 1.7$ the effect of torsional irregularity is accounted for by applying torsional moments about a vertical axis at each level throughout the building derived for each of the following load cases considered separately

$$
\begin{aligned}
& T_{x}=F_{x}\left(e_{x}+0.1 D_{n x}\right) \\
& T_{x}=F_{x}\left(e_{x}-0.1 D_{n x}\right)
\end{aligned}
$$

where $F_{x}$ is the earthquake force at level $x$ and where each element is designed for the most severe effect of the above load cases. For buildings with $B>1.7$, a dynamic analysis procedure must be used in the design. 
The cut-off value of $B$ factor $(B=1.7)$ is based on analytical response studies of single storey building models. The maximum displacement, $\delta_{\max }$ (flexible edge displacement, $\Delta_{f c}$ ) induced by the equivalent static forces acting at distances $\pm 0.1 D_{n x}$ from the centre of mass, CM can be obtained from Eq. 3.21. By replacing $e_{d 1}$ in Eq. 3.21 with $e_{d l}$ obtained from Eq. 3.3 we get

$$
\delta_{\max }=\Delta_{f c}=\frac{V_{o}}{K_{y}}+\frac{V_{o}(e+0.1 b)}{K_{\theta R}}\left(e+\frac{b}{2}\right)
$$

In a similar manner, the minimum displacement, $\delta_{\min }$ (stiff edge displacement, $\Delta_{s c}$ ) may be obtained from Eq. 3.22 by replacing $e_{d 2}$ with $e+0.1 b$

$$
\delta_{\min }=\Delta_{s c}=\frac{V_{o}}{K_{y}}-\frac{V_{o}(e+0.1 b)}{K_{\theta R}}\left(\frac{b}{2}-e\right)
$$

The average displacement, $\delta_{a v e}$ is given by

$$
\delta_{\text {ave }}=\frac{\left(\delta_{\max }+\delta_{\min }\right)}{2}=\frac{V_{o}}{K_{y}}+\frac{V_{o}(e+0.1 b)}{K_{\theta R}} e
$$


Factor $B$ is now obtained from Eqs. 3.28 and 3.30

$$
B=\frac{\delta_{\max }}{\delta_{\text {ave }}}=\frac{1+\frac{1}{\Omega_{R}^{2}} \frac{b^{2}}{r^{2}}\left(\frac{e}{b}+0.1\right)\left(\frac{e}{b}+\frac{1}{2}\right)}{1+\frac{1}{\Omega_{R}^{2}} \frac{b^{2}}{r^{2}}\left(\frac{e}{b}+0.1\right)\left(\frac{e}{b}\right)}
$$

The ratio $\delta_{\text {max }} / \delta_{\text {ave }}$ given by Eq. 3.31 is plotted as a function of $e / b$ for four different frequency ratios, $\Omega_{R}=0.75,1.00,1.25$ and 1.50 and for four different aspect ratios, $\alpha=0.33$, $0.5,1.0$ and 3.0 in Figs. 3.17 to 3.20 respectively. The value of 1.7 is selected as the maximum value of $\delta_{\max } / \delta_{\text {ave }}$ corresponding to frequency ratio, $\Omega_{R}=1.0$ and aspect ratio, $\alpha=1.0$ as shown in Fig. 3.19. This selection of $B$ will preclude the use of structural systems with $\Omega_{R}=0.75$ except for very small eccentricities; unless a dynamic analysis is adopted for design. For lower aspect ratio such as $0.5, \Omega_{R}<1.25$ is precluded.

To illustrate the application of the new NBCC code provisions to multistorey buildings of general class, the values of $B_{x}$ factor introduced in Eq. 3.26 are calculated for each level $x$ of the multistorey building models studied in the previous examples. Specifically, the interstorey shears and displacements have been calculated for five-storey and ten-storey building models of Examples 1 and 2. Tables 3.15 and 3.16 show the values of $B_{x}$ factor for each storey. It is noted from the values that for these buildings, $B_{x}$ is less than 1.7 and the code provision will allow the use of equivalent static load method of design and Eq. 3.3 and 3.4a. The results presented earlier show that the code proposals are quite conservative for the design of flexible edge plane but are not so for the design of soft edge plane. This is because of high torsionally flexibility in some floors even though the value of 
$B_{x}$ just passes the 1.7 limit. It highlights the importance of improving the torsional stiffness.

\subsection{SUMMARY AND CONCLUSIONS}

This chapter presents the results obtained from analytical studies conducted to study the elastic torsional response of a variety of asymmetric multistorey buildings of general class in which the ratios of torsional to translational stiffness vary significantly along the height of the building. Response spectrum dynamic analyses are carried out to obtain the exact response of the buildings. The results obtained from dynamic analyses are then compared to the results obtained according to design provisions proposed by Humar and Kumar (1998a). The dynamic analysis results are also compared to those of single storey buildings.

Based on the previous results presented in this chapter, the following conclusions can be drawn:

(1) The response values obtained from the analysis of corresponding single storey models do not match with the response values obtained from the dynamic analysis of the multistorey buildings of general class.

(2) When applying the design eccentricity provisions proposed by Humar and Kumar (1998a), the response values obtained from the static analysis of the multistorey buildings of general class provide a conservative estimate of flexible edge interstorey displacements in multistorey buildings for all values of frequency ratios, $\Omega_{R}$ and $e / b$. For stiff edge, the values are also conservative except for frequency ratios, $\Omega_{R}=1.00$ when the proposed design provisions underestimate the response values obtained from the dynamic analysis of 
multistorey buildings. It is therefore recommended that the proposed design expressions for stiff edge, Eqs. 3.4a, and 3.4b be modified as follows:

$$
\begin{aligned}
e_{s} & =e-0.1 b & & \text { for } \Omega_{R} \geq 1.25 \\
& =-0.1 b & & \text { for } \Omega_{R}<1.25
\end{aligned}
$$

(3) The alternative method of measuring torsional sensitivity, which is based on the ratio of maximum floor edge displacement to the average floor displacement, is a satisfactory measure of torsional sensitivity where frequency ratios, $\Omega_{R}$ does not change significantly over the height. For large variations and torsional flexibility, a dynamic analyses may be the best course of action. 
Table 3.1 Storey lateral stifnesses of five-storey building models

$\Omega_{R}=1.0$ (floors 1,2 and 3 ) and 0.75 (floors 4 and 5), $e=0.1 b$ (all floors)

\begin{tabular}{|c|c|c|c|c|}
\hline Floor & $\begin{array}{c}\text { Flexible edge } \\
\text { stiffness }(\mathrm{kN} / \mathrm{m})\end{array}$ & $\begin{array}{c}\text { Middle plane } \\
\text { stiffness }(\mathrm{kN} / \mathrm{m})\end{array}$ & $\begin{array}{c}\text { Stiff edge } \\
\text { stiffness }(\mathrm{kN} / \mathrm{m})\end{array}$ & $\begin{array}{c}\text { Storey total } \\
\text { stiffness }(\mathrm{kN} / \mathrm{m})\end{array}$ \\
\hline 5 & 20953.75 & 114029.15 & 59938.61 & 194921.51 \\
\hline 4 & 20953.75 & 114029.15 & 59938.61 & 194921.51 \\
\hline 3 & 49380.26 & 57177.05 & 88364.20 & 194921.51 \\
\hline 2 & 49380.26 & 57177.05 & 88364.20 & 194921.51 \\
\hline 1 & 49380.26 & 57177.05 & 88364.20 & 194921.51 \\
\hline
\end{tabular}

Table 3.2 Storey shears and forces obtained from dynamic analysis of five-storey torsionally balanced building, $\Omega_{R}=1.0$ (floors 1,2 and 3) and 0.75 (floors 4 and 5)

\begin{tabular}{|c|c|c|c|}
\hline Floor & $\begin{array}{c}\text { Max storey } \\
\text { shear }(\mathrm{kN})\end{array}$ & $\begin{array}{c}\text { Floor force, } \\
F_{i}(\mathrm{kN})\end{array}$ & $\begin{array}{c}\text { NBCC } \\
\text { floor force }(\mathrm{kN})\end{array}$ \\
\hline 5 & 7022.89 & 7022.89 & 6069.89 \\
\hline 4 & 10926.28 & 3903.39 & 4855.91 \\
\hline 3 & 13771.58 & 2845.30 & 3641.94 \\
\hline 2 & 16136.33 & 2364.75 & 2427.96 \\
\hline 1 & 18209.68 & 2073.35 & 1213.98 \\
\hline
\end{tabular}


Table 3.3 Shear in edge frames obtained from static analysis for five-storey building $\Omega_{R}=1.0$ (floors 1,2 and 3 ) and 0.75 (floors 4 and 5), $e=0.1 b$ (all floors)

\begin{tabular}{|c|c|c|c|c|c|c|}
\hline \multirow{2}{*}{ Floor } & \multicolumn{2}{|c|}{$\begin{array}{c}\text { Shear in torsionally } \\
\text { balanced building }(\mathrm{kN})\end{array}$} & \multicolumn{2}{|c|}{$\begin{array}{c}\text { Shear in torsionally } \\
\text { unbalanced building }(\mathrm{kN})\end{array}$} & $\bar{\Delta}_{f}$ & $\bar{\Delta}_{s}$ \\
\cline { 2 - 6 } & flexible edge & stiff edge & flexible edge & stiff edge & & \\
\hline 5 & 754.96 & 2159.54 & 1479.72 & 3081.66 & 1.960 & 1.427 \\
\hline 4 & 1174.56 & 3359.84 & 2302.16 & 4794.49 & 1.960 & 1.427 \\
\hline 3 & 3488.82 & 6243.10 & 5372.76 & 5493.94 & 1.540 & 0.880 \\
\hline 2 & 4087.88 & 7315.12 & 6295.32 & 6437.32 & 1.540 & 0.880 \\
\hline 1 & 4613.16 & 8255.04 & 7104.20 & 7264.44 & 1.540 & 0.880 \\
\hline
\end{tabular}

Table 3.4 Shear in edge frames obtained from dynamic analysis for five-storey building $\Omega_{R}=1.0$ (floors 1,2 and 3 ) and 0.75 (floors 4 and 5), $e=0.1 b$ (all floors)

\begin{tabular}{|c|c|c|c|c|c|c|}
\hline \multirow{2}{*}{ Floor } & \multicolumn{2}{|c|}{$\begin{array}{c}\text { Shear in torsionally } \\
\text { balanced building }(\mathrm{kN})\end{array}$} & \multicolumn{2}{|c|}{$\begin{array}{c}\text { Shear in torsionally } \\
\text { unbalanced building }(\mathrm{kN})\end{array}$} & \multirow{\Delta_{f}}{*}{} & $\bar{\Delta}_{s}$ \\
\cline { 2 - 6 } & flexible edge & stiff edge & flexible edge & stiff edge & & \\
\hline 5 & 755.00 & 2159.60 & 1177.80 & 3037.80 & 1.560 & 1.407 \\
\hline 4 & 1174.60 & 3359.80 & 1995.00 & 4601.40 & 1.698 & 1.370 \\
\hline 3 & 3488.80 & 6243.00 & 4037.80 & 6160.80 & 1.157 & 0.987 \\
\hline 2 & 4087.80 & 7315.20 & 4709.20 & 7224.00 & 1.152 & 0.988 \\
\hline 1 & 4613.20 & 8255.00 & 5210.40 & 8159.20 & 1.129 & 0.988 \\
\hline
\end{tabular}


Table 3.5 Normalized edge displacement ratios obtained from response spectrum analysis for single storey, $\Omega_{R}=1.0$

\begin{tabular}{|c|c|c|}
\hline e/b & $\bar{\Delta}_{f}$ & $\overline{\Delta_{s}}$ \\
& & \\
\hline 0.05 & 1.194 & 1.003 \\
\hline 0.10 & 1.318 & 0.924 \\
\hline 0.15 & 1.435 & 0.843 \\
\hline 0.20 & 1.553 & 0.767 \\
\hline 0.25 & 1.672 & 0.701 \\
\hline 0.30 & 1.794 & 0.646 \\
\hline
\end{tabular}

Table 3.6 Storey lateral stifnesses of ten-storey building models, $\Omega_{R}=1.0$ (floors $1,2,3,4$ and 5) and 0.75 (floors 6, 7, 8, 9 and 10), $e=0.1 b$ (all floors)

\begin{tabular}{|c|c|c|c|c|}
\hline Floor & $\begin{array}{c}\text { Flexible edge } \\
\text { stiffness }(\mathrm{kN} / \mathrm{m})\end{array}$ & $\begin{array}{c}\text { Middle plane } \\
\text { stiffness }(\mathrm{kN} / \mathrm{m})\end{array}$ & $\begin{array}{c}\text { Stiff edge } \\
\text { stiffness }(\mathrm{kN} / \mathrm{m})\end{array}$ & $\begin{array}{c}\text { Storey total } \\
\text { stiffness }(\mathrm{kN} / \mathrm{m})\end{array}$ \\
\hline 10 & 62737.37 & 440058.03 & 204123.08 & 706918.48 \\
\hline 9 & 62737.37 & 440058.03 & 204123.08 & 706918.48 \\
\hline 8 & 62737.37 & 440058.03 & 204123.08 & 706918.48 \\
\hline 7 & 62737.37 & 440058.03 & 204123.08 & 706918.48 \\
\hline 6 & 62737.37 & 440058.03 & 204123.08 & 706918.48 \\
\hline 5 & 155520.59 & 254491.59 & 296906.30 & 706918.48 \\
\hline 4 & 155520.59 & 254491.59 & 296906.30 & 706918.48 \\
\hline 3 & 155520.59 & 254491.59 & 296906.30 & 706918.48 \\
\hline 2 & 155520.59 & 254491.59 & 296906.30 & 706918.48 \\
\hline 1 & 155520.59 & 254491.59 & 296906.30 & 706918.48 \\
\hline
\end{tabular}


Table 3.7 Storey shears and forces obtained from dynamic analysis of torsionally balanced ten-storey building

$\Omega_{R}=1.0$ (floors $1,2,3,4$ and 5) and 0.75 (floors 6, 7, 8, 9 and 10)

\begin{tabular}{|c|c|c|c|}
\hline Floor & $\begin{array}{c}\text { Max storey } \\
\text { shear }(\mathrm{kN})\end{array}$ & $\begin{array}{c}\text { Floor force, } \\
F_{i}(\mathrm{kN})\end{array}$ & $\begin{array}{c}\text { NBCC } \\
\text { floor force }(\mathrm{kN})\end{array}$ \\
\hline 10 & 9175.43 & 9175.43 & 6576.11 \\
\hline 9 & 14747.08 & 5571.65 & 5918.50 \\
\hline 8 & 18718.58 & 3971.50 & 5260.89 \\
\hline 7 & 21998.46 & 3279.88 & 4603.28 \\
\hline 6 & 24862.75 & 2864.29 & 3945.67 \\
\hline 5 & 27442.52 & 2579.77 & 3288.06 \\
\hline 4 & 29813.24 & 2370.72 & 2630.45 \\
\hline 3 & 32022.94 & 2209.70 & 1972.83 \\
\hline 2 & 34108.49 & 2085.55 & 1315.22 \\
\hline 1 & 36168.62 & 2060.13 & 657.61 \\
\hline
\end{tabular}


Table 3.8 Shear in edge frames obtained from static analysis for ten-storey building $\Omega_{R}=1.0$ (floors $1,2,3,4$ and 5) and 0.75 (floors 6, 7, 8,9 and 10), $e=0.1 b$ (all floors)

\begin{tabular}{|c|c|c|c|c|c|c|}
\hline \multirow{2}{*}{ Floor } & \multicolumn{2}{|c|}{$\begin{array}{c}\text { Shear in torsionally } \\
\text { balanced building }(\mathrm{kN})\end{array}$} & \multicolumn{2}{c|}{$\begin{array}{c}\text { Shear in torsionally } \\
\text { unbalanced building }(\mathrm{kN})\end{array}$} & $\bar{\Delta}_{f}$ & $\bar{\Delta}_{s}$ \\
\cline { 2 - 6 } & flexible edge & stiff edge & flexible edge & stiff edge & & \\
\hline 10 & 814.30 & 2649.44 & 1596.06 & 3779.84 & 1.960 & 1.427 \\
\hline 9 & 1308.78 & 4258.26 & 2565.24 & 6075.10 & 1.960 & 1.427 \\
\hline 8 & 1661.26 & 5405.04 & 3256.08 & 7711.17 & 1.960 & 1.427 \\
\hline 7 & 1952.34 & 6352.12 & 3826.60 & 9062.33 & 1.960 & 1.427 \\
\hline 6 & 2206.54 & 7179.18 & 4324.84 & 10242.28 & 1.960 & 1.427 \\
\hline 5 & 6037.32 & 11525.88 & 9297.52 & 10142.74 & 1.540 & 0.880 \\
\hline 4 & 6558.86 & 12521.58 & 10100.74 & 11018.94 & 1.540 & 0.880 \\
\hline 3 & 7045.00 & 13449.66 & 10849.36 & 11835.66 & 1.540 & 0.880 \\
\hline 2 & 7503.82 & 14325.58 & 11555.94 & 12606.46 & 1.540 & 0.880 \\
\hline 1 & 7957.04 & 15190.84 & 12253.90 & 13367.88 & 1.540 & 0.880 \\
\hline
\end{tabular}


Table 3.9 Shear in edge frames obtained from dynamic analysis for ten-storey building $\Omega_{R}=1.0$ (floors $1,2,3,4$ and 5) and 0.75 (floors 6, 7, 8, 9 and 10), $e=0.1 b$ (all floors)

\begin{tabular}{|c|c|c|c|c|c|c|}
\hline \multirow{2}{*}{ Floor } & \multicolumn{2}{|c|}{$\begin{array}{c}\text { Shear in torsionally } \\
\text { balanced building }(\mathrm{kN})\end{array}$} & \multicolumn{2}{c|}{$\begin{array}{c}\text { Shear in torsionally } \\
\text { unbalanced building }(\mathrm{kN})\end{array}$} & $\bar{\Delta}_{f}$ & $\bar{\Delta}_{s}$ \\
\cline { 2 - 6 } & flexible edge & stiff edge & flexible edge & stiff edge & & \\
\hline 10 & 814.30 & 2649.44 & 1232.64 & 3697.82 & 1.514 & 1.396 \\
\hline 9 & 1308.78 & 4258.26 & 1879.04 & 6066.26 & 1.436 & 1.425 \\
\hline 8 & 1661.26 & 5405.04 & 2537.76 & 7439.24 & 1.528 & 1.376 \\
\hline 7 & 1952.34 & 6352.12 & 3116.08 & 8733.00 & 1.596 & 1.375 \\
\hline 6 & 2206.54 & 7179.18 & 3579.86 & 9749.96 & 1.622 & 1.358 \\
\hline 5 & 6037.32 & 11525.88 & 6636.40 & 11580.70 & 1.099 & 1.005 \\
\hline 4 & 6558.86 & 12521.58 & 7209.64 & 12596.16 & 1.099 & 1.006 \\
\hline 3 & 7045.00 & 13449.66 & 7660.52 & 13584.18 & 1.087 & 1.010 \\
\hline 2 & 7503.82 & 14325.58 & 8059.58 & 14482.96 & 1.074 & 1.011 \\
\hline 1 & 7957.04 & 15190.84 & 8519.84 & 15262.46 & 1.071 & 1.005 \\
\hline
\end{tabular}


Table 3.10 Shear in edge frames obtained from static analysis for ten-storey building $\Omega_{R}=1.25$ (floors $1,2,3,4$ and 5) and 1.0 (floors 6, 7, 8, 9 and 10), $e=0.1 b$ (all floors)

\begin{tabular}{|c|c|c|c|c|c|c|}
\hline \multirow[t]{2}{*}{ Floor } & \multicolumn{2}{|c|}{$\begin{array}{l}\text { Shear in torsionally } \\
\text { balanced building }(\mathrm{kN})\end{array}$} & \multicolumn{2}{|c|}{$\begin{array}{c}\text { Shear in torsionally } \\
\text { unbalanced building }(\mathrm{kN})\end{array}$} & \multirow[t]{2}{*}{$\overline{\Delta_{f}}$} & \multirow[t]{2}{*}{$\overline{\Delta_{s}}$} \\
\hline & flexible edge & stiff edge & flexible edge & stiff edge & & \\
\hline 10 & 1406.92 & 3241.98 & 2166.64 & 2852.90 & 1.540 & 0.880 \\
\hline 9 & 2261.26 & 5210.64 & 3482.32 & 4585.38 & 1.540 & 0.880 \\
\hline 8 & 2870.22 & 6613.90 & 4420.12 & 5820.26 & 1.540 & 0.880 \\
\hline 7 & 3373.14 & 7772.80 & 5194.62 & 6840.08 & 1.540 & 0.880 \\
\hline 6 & 3812.34 & 8784.84 & 5870.98 & 7730.68 & 1.540 & 0.880 \\
\hline 5 & 7809.66 & 13298.24 & 10508.7 & 12276.92 & 1.346 & 0.923 \\
\hline 4 & 8484.32 & 14447.04 & 11416.52 & 13337.50 & 1.346 & 0.923 \\
\hline 3 & 9113.16 & 15517.84 & 12262.7 & 14326.04 & 1.346 & 0.923 \\
\hline 2 & 9706.68 & 16528.46 & 13061.32 & 15259.04 & 1.346 & 0.923 \\
\hline 1 & 10292.94 & 17526.78 & 13850.22 & 16180.70 & 1.346 & 0.923 \\
\hline
\end{tabular}


Table 3.11 Shear in edge frames obtained from dynamic analysis for ten-storey building $\Omega_{R}=1.25$ (floors $1,2,3,4$ and 5) and 1.0 (floors $6,7,8,9$ and 10), $e=0.1 b$ (all floors)

\begin{tabular}{|c|c|c|c|c|c|c|}
\hline \multirow{2}{*}{ Floor } & \multicolumn{2}{|c|}{$\begin{array}{c}\text { Shear in torsionally } \\
\text { balanced building }(\mathrm{kN})\end{array}$} & \multicolumn{2}{|c|}{$\begin{array}{c}\text { Shear in torsionally } \\
\text { unbalanced building }(\mathrm{kN})\end{array}$} & $\bar{\Delta}_{f}$ & $\bar{\Delta}_{s}$ \\
\cline { 2 - 6 } & flexible edge & stiff edge & flexible edge & stiff edge & & \\
\hline 10 & 1406.92 & 3241.98 & 2287.48 & 2346.98 & 1.626 & 0.724 \\
\hline 9 & 2261.26 & 5210.64 & 3515.36 & 3927.74 & 1.555 & 0.754 \\
\hline 8 & 2870.22 & 6613.90 & 4478.68 & 4874.52 & 1.560 & 0.737 \\
\hline 7 & 3373.14 & 7772.80 & 5302.72 & 5565.72 & 1.572 & 0.716 \\
\hline 6 & 3812.34 & 8784.84 & 6043.28 & 6167.50 & 1.585 & 0.702 \\
\hline 5 & 7809.66 & 13298.24 & 10042.44 & 9088.92 & 1.286 & 0.683 \\
\hline 4 & 8484.32 & 14447.04 & 10910.36 & 9895.76 & 1.286 & 0.685 \\
\hline 3 & 9113.16 & 15517.84 & 11727.12 & 10674.86 & 1.287 & 0.688 \\
\hline 2 & 9706.68 & 16528.46 & 12453.30 & 11435.06 & 1.283 & 0.692 \\
\hline 1 & 10292.94 & 17526.78 & 13071.52 & 12315.44 & 1.270 & 0.703 \\
\hline
\end{tabular}


Table 3.12 Shear in edge frames obtained from dynamic analysis for ten-storey building $\Omega_{R}=1.25$ (floors $1,2,3,4$ and 5) and 0.75 (floors 6, 7, 8, 9 and 10), $e=0.1 b$ (all floors)

\begin{tabular}{|c|c|c|c|c|c|c|}
\hline \multirow{2}{*}{ Floor } & \multicolumn{2}{|c|}{$\begin{array}{c}\text { Shear in torsionally } \\
\text { balanced building }(\mathrm{kN})\end{array}$} & \multicolumn{2}{|c|}{$\begin{array}{c}\text { Shear in torsionally } \\
\text { unbalanced building }(\mathrm{kN})\end{array}$} & $\bar{\Delta}_{f}$ & $\bar{\Delta}_{s}$ \\
\cline { 2 - 6 } & flexible edge & stiff edge & flexible edge & stiff edge & & \\
\hline 10 & 470.26 & 2305.32 & 850.30 & 3242.70 & 1.808 & 1.407 \\
\hline 9 & 755.80 & 3705.20 & 1397.52 & 5107.12 & 1.849 & 1.378 \\
\hline 8 & 959.36 & 4703.04 & 1905.62 & 6095.40 & 1.986 & 1.296 \\
\hline 7 & 1127.46 & 5527.12 & 2329.52 & 6932.18 & 2.066 & 1.254 \\
\hline 6 & 1274.24 & 6246.76 & 2678.08 & 7551.66 & 2.102 & 1.209 \\
\hline 5 & 7809.66 & 13298.22 & 8911.16 & 10046.78 & 1.141 & 0.755 \\
\hline 4 & 8484.32 & 14447.02 & 9663.14 & 10885.40 & 1.139 & 0.753 \\
\hline 3 & 9113.16 & 15517.82 & 10242.08 & 11829.96 & 1.124 & 0.762 \\
\hline 2 & 9706.66 & 16528.44 & 10732.14 & 12774.36 & 1.106 & 0.773 \\
\hline 1 & 10292.94 & 17526.76 & 11267.10 & 13750.78 & 1.095 & 0.785 \\
\hline
\end{tabular}


Table 3.13 Shear in edge frames obtained from dynamic analysis for ten-storey building $\Omega_{R}=1.0$ (floors 1, 2, 3 and 4), 1.25 (floors 5, 6 and 7) and 0.75 (floors 8, 9 and 10), $e=0.1 b$ (all floors)

\begin{tabular}{|c|c|c|c|c|c|c|}
\hline \multirow{2}{*}{ Floor } & \multicolumn{2}{|c|}{$\begin{array}{c}\text { Shear in torsionally } \\
\text { balanced building }(\mathrm{kN})\end{array}$} & \multicolumn{2}{|c|}{$\begin{array}{c}\text { Shear in torsionally } \\
\text { unbalanced building }(\mathrm{kN})\end{array}$} & $\bar{\Delta}_{f}$ & $\bar{\Delta}_{s}$ \\
\cline { 2 - 6 } & flexible edge & stiff edge & flexible edge & stiff edge & & \\
\hline 10 & 470.26 & 2305.32 & 946.78 & 3331.68 & 2.013 & 1.445 \\
\hline 9 & 755.80 & 3705.20 & 1421.22 & 5040.18 & 1.880 & 1.360 \\
\hline 8 & 959.36 & 4703.04 & 1868.56 & 6113.54 & 1.948 & 1.300 \\
\hline 7 & 6260.38 & 10660.14 & 6592.00 & 8479.58 & 1.053 & 0.795 \\
\hline 6 & 7075.50 & 12048.12 & 7606.34 & 9470.28 & 1.075 & 0.786 \\
\hline 5 & 7809.66 & 13298.24 & 8403.18 & 10386.98 & 1.076 & 0.781 \\
\hline 4 & 4571.44 & 10534.00 & 6212.74 & 9316.92 & 1.359 & 0.884 \\
\hline 3 & 4910.26 & 11314.78 & 6691.30 & 10022.36 & 1.363 & 0.886 \\
\hline 2 & 5230.06 & 12051.68 & 7070.28 & 10772.32 & 1.352 & 0.894 \\
\hline 1 & 5545.94 & 12779.58 & 7398.72 & 11463.90 & 1.334 & 0.897 \\
\hline
\end{tabular}


Table 3.14 Shear in edge frames obtained from dynamic analysis for ten-storey building $\Omega_{R}=1.0$ (floors 1, 2, 3 and 4), 0.75 (floors 5,6 and 7) and 1.25 (floors 8, 9 and 10) $e=0.1 b$ (all floors)

\begin{tabular}{|c|c|c|c|c|c|c|}
\hline \multirow{2}{*}{ Floor } & \multicolumn{2}{|c|}{$\begin{array}{c}\text { Shear in torsionally } \\
\text { balanced building }(\mathrm{kN})\end{array}$} & \multicolumn{2}{|c|}{$\begin{array}{c}\text { Shear in torsionally } \\
\text { unbalanced building }(\mathrm{kN})\end{array}$} & $\bar{\Delta}_{f}$ & $\bar{\Delta}_{s}$ \\
\cline { 2 - 6 } & flexible edge & stiff edge & flexible edge & stiff edge & & \\
\hline 10 & 2611.18 & 4446.28 & 2369.92 & 3579.74 & 0.908 & 0.805 \\
\hline 9 & 4196.76 & 7146.22 & 3895.98 & 6082.94 & 0.928 & 0.851 \\
\hline 8 & 5326.98 & 9070.76 & 4838.74 & 7918.30 & 0.908 & 0.873 \\
\hline 7 & 1127.46 & 5527.12 & 1857.00 & 7567.18 & 1.647 & 1.369 \\
\hline 6 & 1274.24 & 6246.76 & 2089.06 & 8542.98 & 1.639 & 1.368 \\
\hline 5 & 1406.46 & 6894.94 & 2308.94 & 9384.86 & 1.642 & 1.361 \\
\hline 4 & 4571.44 & 10534.00 & 5002.80 & 10677.50 & 1.094 & 1.014 \\
\hline 3 & 4910.26 & 11314.78 & 5301.12 & 11494.00 & 1.080 & 1.016 \\
\hline 2 & 5230.06 & 12051.68 & 5646.84 & 12233.62 & 1.080 & 1.015 \\
\hline 1 & 5545.94 & 12779.58 & 6038.14 & 12871.44 & 1.089 & 1.007 \\
\hline
\end{tabular}


Table 3.15 Torsional sensitivity factor, $B_{x}$ obtained from static analysis for five-storey torsionally unbalanced building

$\Omega_{R}=1.0$ (floors 1,2 and 3) and 0.75 (floors 4 and 5), $e=0.1 b$ (all floors)

\begin{tabular}{|c|c|c|c|c|c|}
\hline \multirow{2}{*}{ Floor } & \multicolumn{2}{|c|}{$\begin{array}{c}\text { Storey shear } \\
(\mathrm{kN})\end{array}$} & \multirow{2}{*}{$\begin{array}{c}\text { Storey displacement } \\
(\mathrm{m})\end{array}$} \\
\cline { 2 - 5 } & flexible edge & stiff edge & flexible edge & stiff edge & \\
\hline 5 & 16012.19 & 1023.00 & 0.6345 & 0.1418 & 1.635 \\
\hline 4 & 24911.92 & 1591.60 & 0.5524 & 0.1365 & 1.603 \\
\hline 3 & 23687.12 & 7161.22 & 0.4246 & 0.1284 & 1.536 \\
\hline 2 & 27754.49 & 8390.89 & 0.3031 & 0.0916 & 1.536 \\
\hline 1 & 31320.65 & 9469.03 & 0.1607 & 0.0486 & 1.536 \\
\hline
\end{tabular}


Table 3.16 Torsional sensitivity factor, $B_{x}$ obtained from static analysis for ten-storey torsionally unbalanced building $\Omega_{R}=1.0$ (floors $1,2,3,4$ and 5) and 0.75 (floors $6,7,8,9$ and 10), $e=0.1 b$ (all floors)

\begin{tabular}{|c|c|c|c|c|c|}
\hline \multirow{2}{*}{ Floor } & \multicolumn{2}{|c|}{$\begin{array}{c}\text { Storey shear } \\
(\mathrm{kN})\end{array}$} & \multirow{2}{*}{ Storey displacement } \\
\cline { 2 - 5 } & \multicolumn{2}{|c|}{$B_{x}$} \\
\cline { 2 - 5 } & flexible edge & stiff edge & flexible edge & stiff edge & \\
\hline 10 & 20919.98 & 1336.56 & 0.6769 & 0.1358 & 1.666 \\
\hline 9 & 33623.34 & 2148.16 & 0.6473 & 0.1339 & 1.657 \\
\hline 8 & 42678.36 & 2726.68 & 0.5997 & 0.1309 & 1.642 \\
\hline 7 & 50156.49 & 3204.45 & 0.5394 & 0.1270 & 1.619 \\
\hline 6 & 56687.77 & 3621.68 & 0.4684 & 0.1225 & 1.585 \\
\hline 5 & 47201.13 & 14270.11 & 0.3882 & 0.1174 & 1.536 \\
\hline 4 & 51278.77 & 15502.88 & 0.3214 & 0.0972 & 1.536 \\
\hline 3 & 55079.46 & 16651.93 & 0.2489 & 0.0753 & 1.536 \\
\hline 2 & 58666.60 & 17736.41 & 0.1710 & 0.0517 & 1.536 \\
\hline 1 & 62210.03 & 18807.68 & 0.0880 & 0.0266 & 1.536 \\
\hline
\end{tabular}




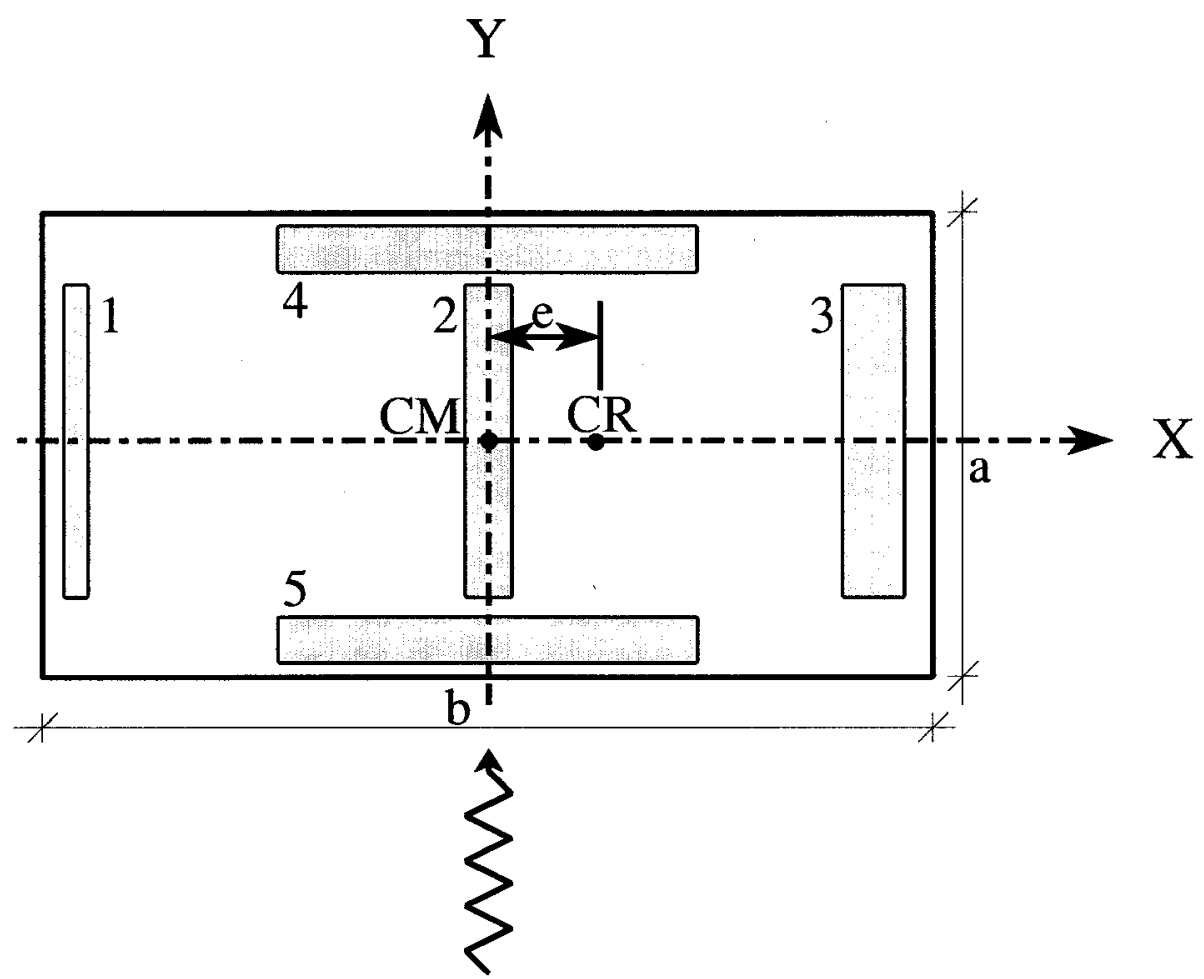

Earthquake direction

Fig. 3.1 Plan view of the structural model 


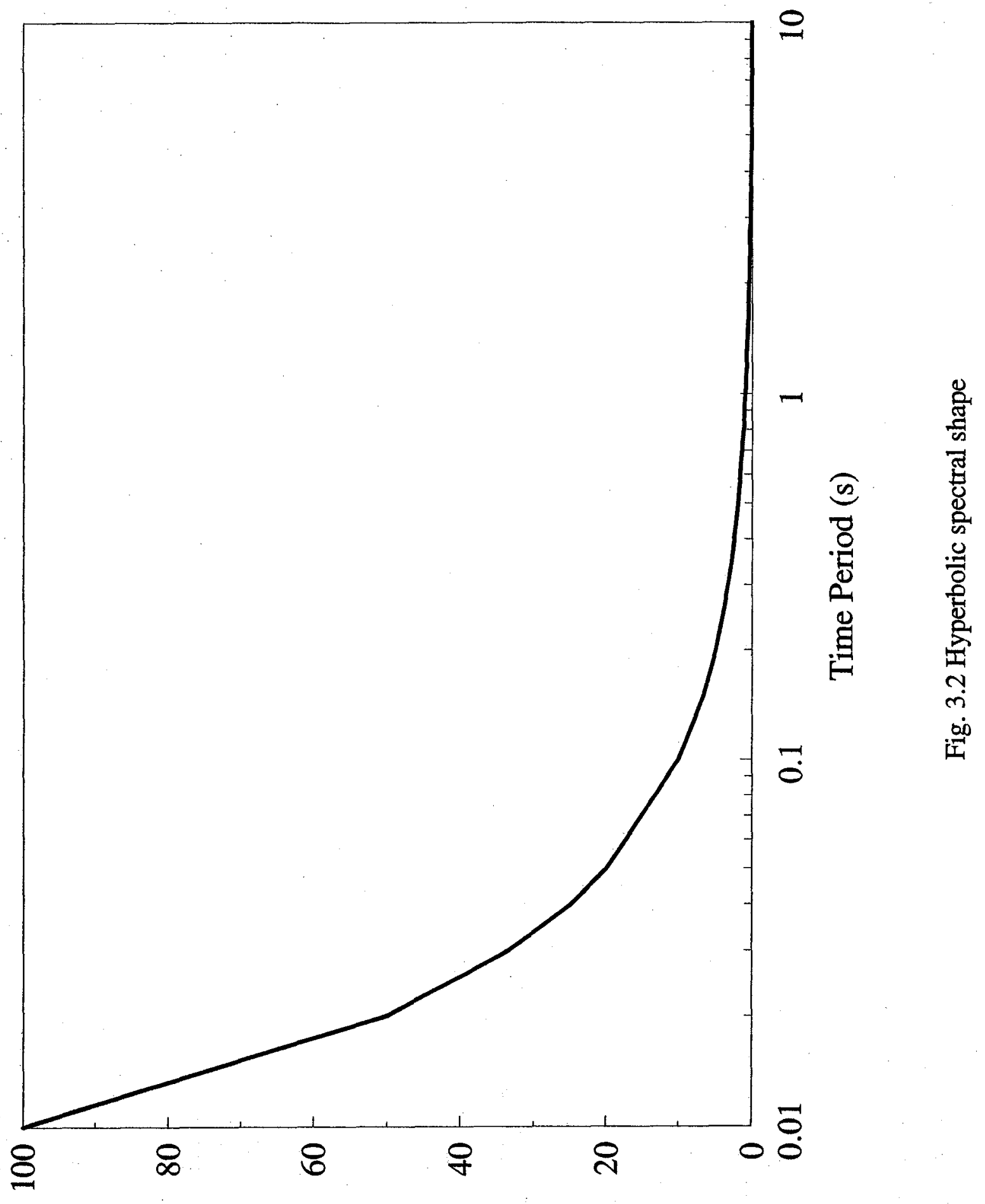

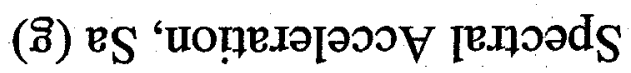




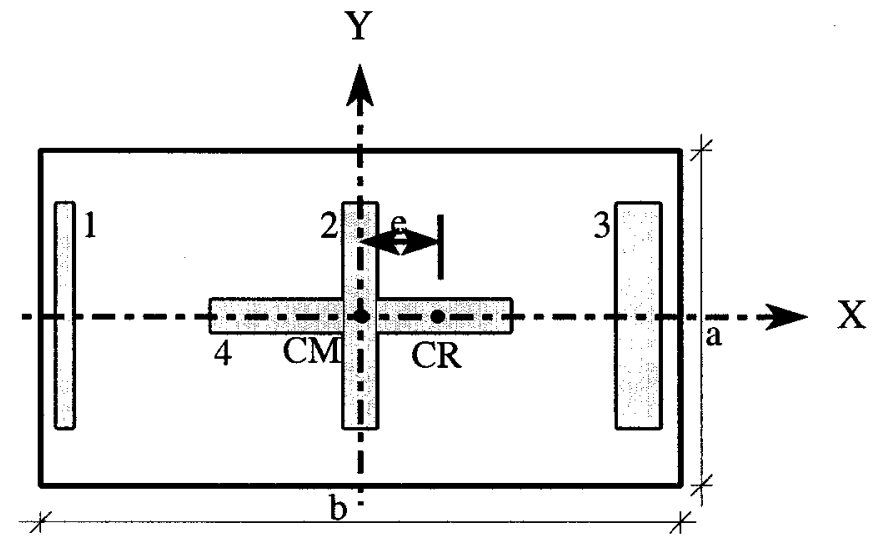

(a)

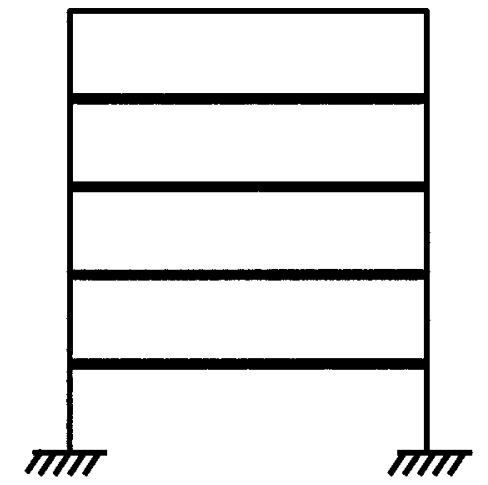

(b)

Fig. 3.3 Five storey shear frame, (a) plan view (b) elevation 

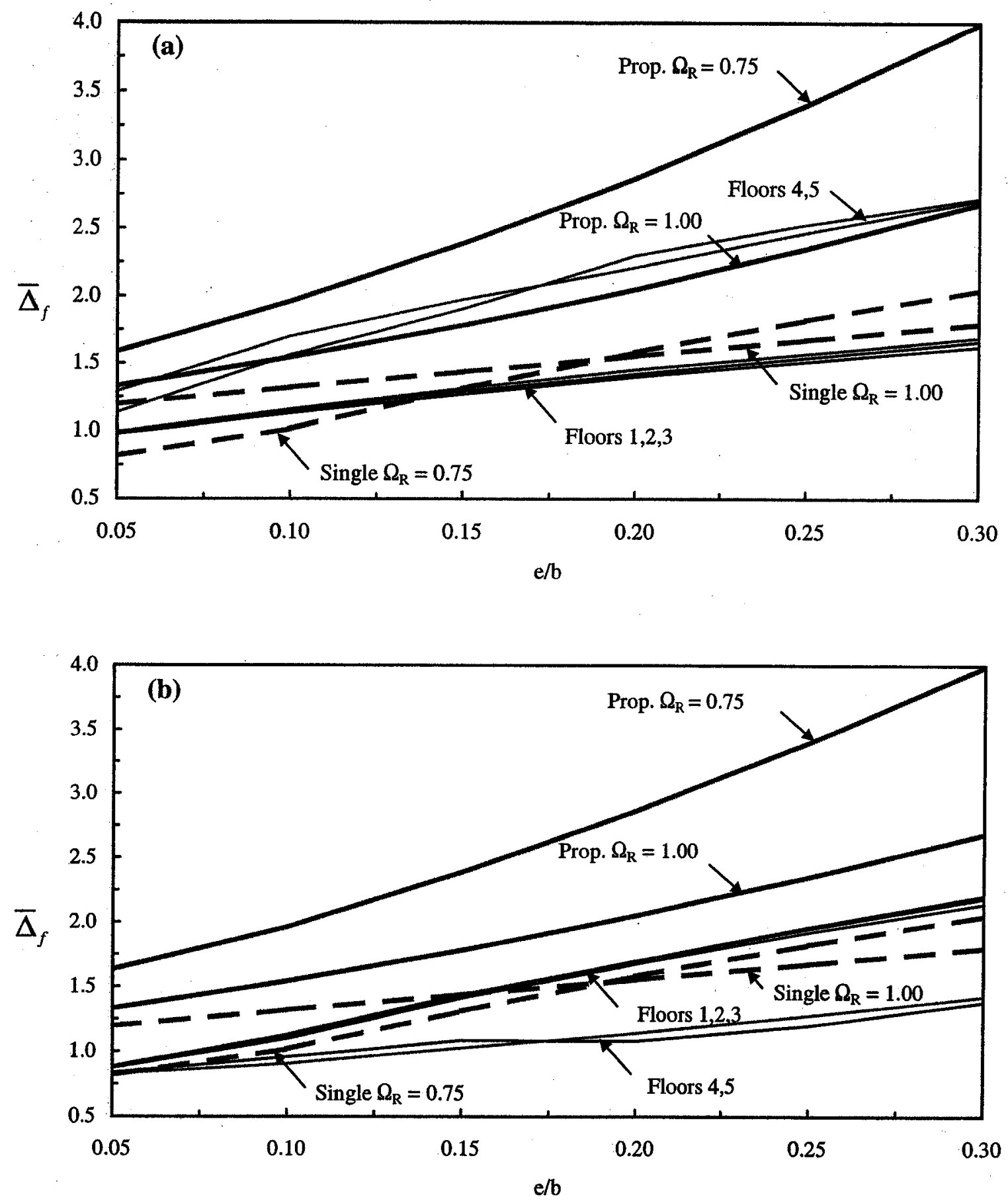

Fig. 3.4 Interstorey displacement at flexible edge of a building of example 1, (a) $\Omega_{R}=1.00$ (floors 1,2 and 3), $=0.75$ (floors 4 and 5) (b) $\Omega_{R}=0.75$ (floors 1,2 and 3), $=1.00$ (floors 4 and 5) 

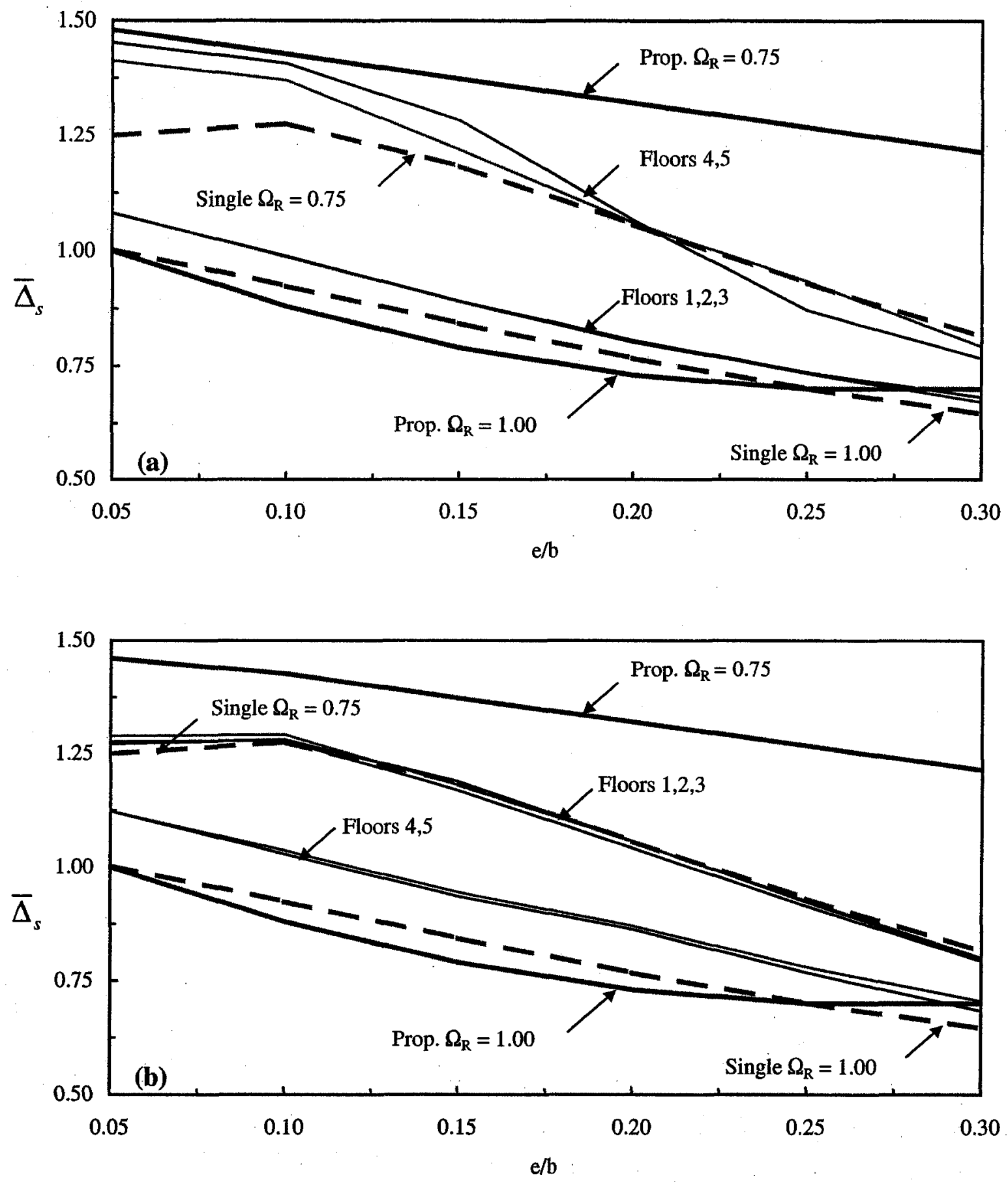

Fig. 3.5 Interstorey displacement at stiff edge of a building of example 1,

(a) $\Omega_{R}=1.00$ (floors 1,2 and 3), $=0.75$ (floors 4 and 5)

(b) $\Omega_{R}=0.75$ (floors 1,2 and 3), $=1.00$ (floors 4 and 5) 


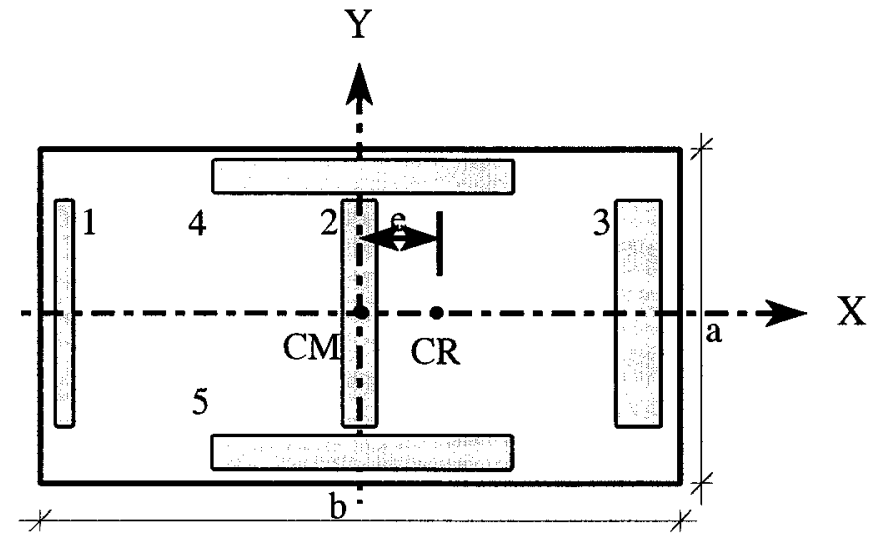

(a)

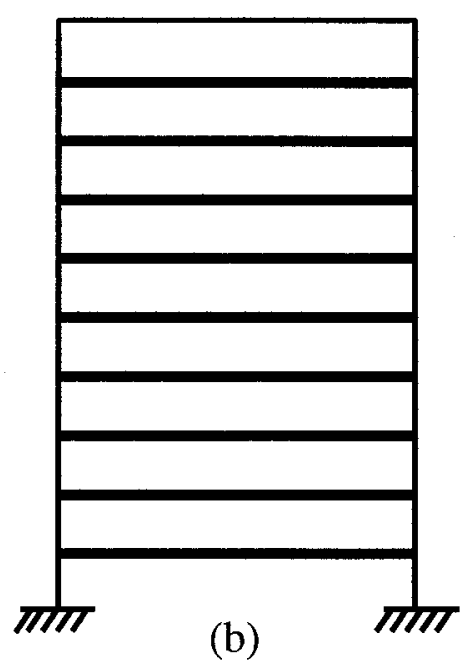

Fig. 3.6 Ten storey shear frame, (a) plan view (b) elevation 

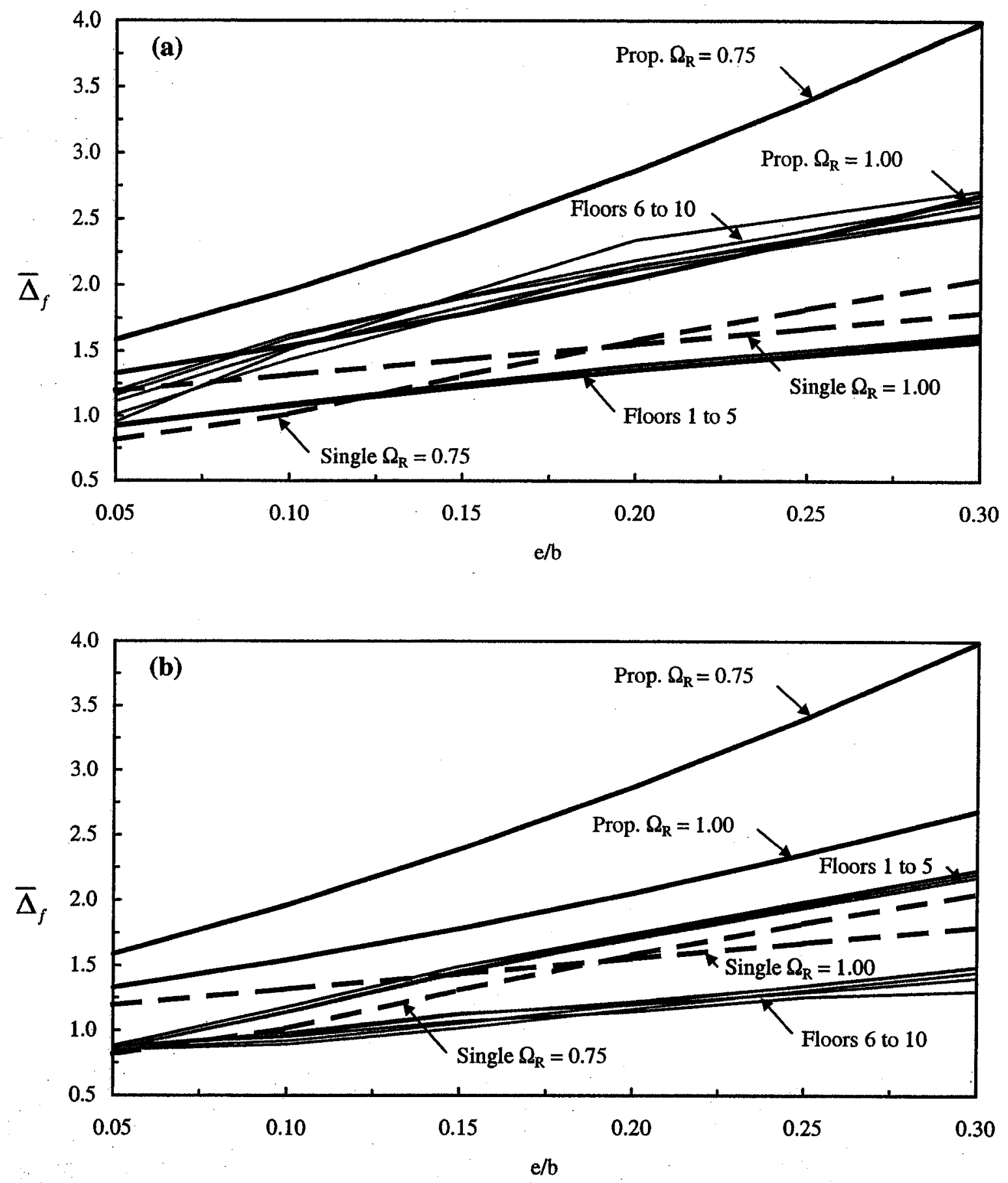

Fig. 3.7 Interstorey displacement at flexible edge of a building of example 2,

(a) $\Omega_{R}=1.00$ (floors 1 to 5 ), $=0.75$ (floors 6 to 10 )

(b) $\Omega_{R}=0.75$ (floors 1 to 5 ), $=1.00$ (floors 6 to 10 ) 

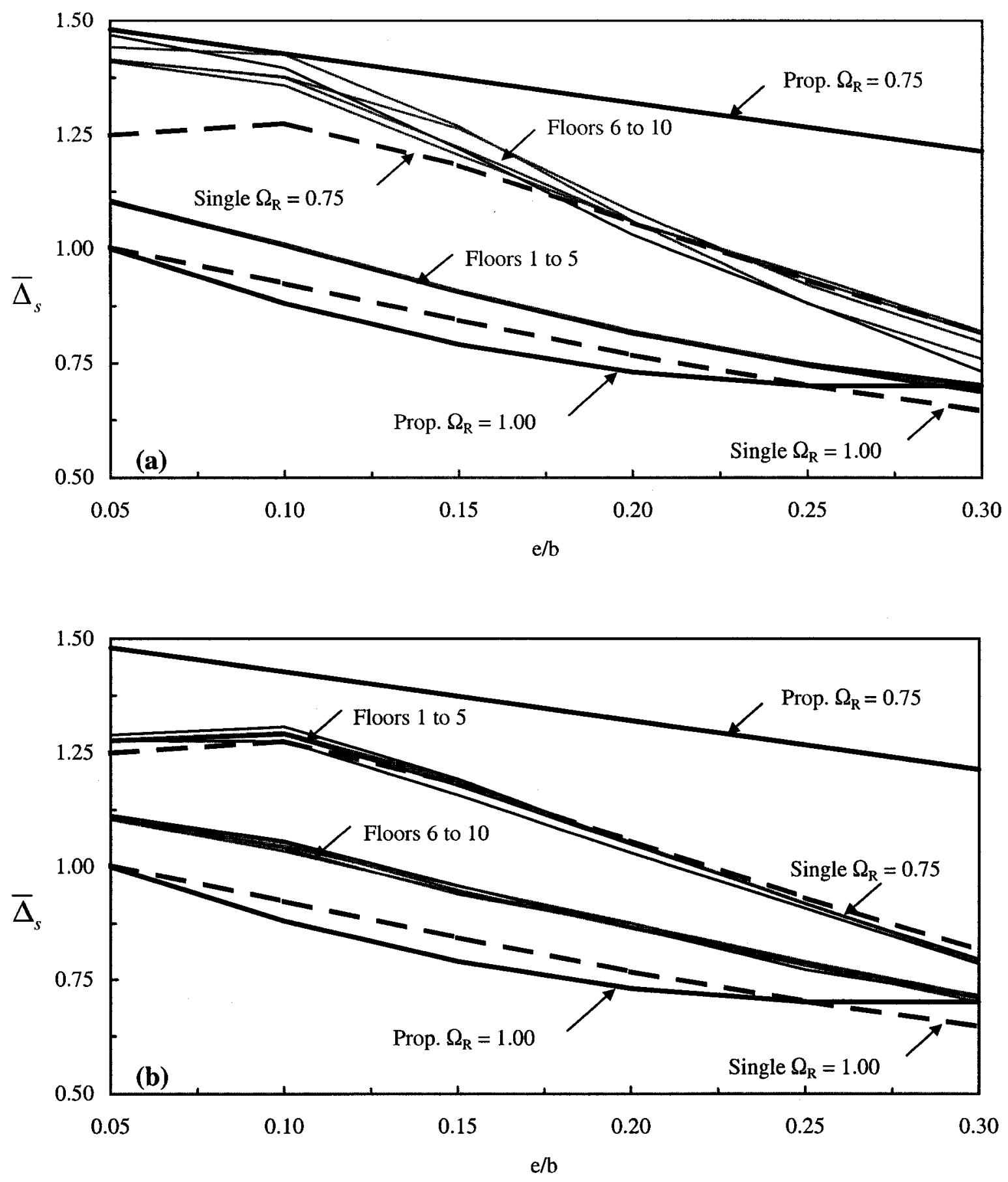

Fig. 3.8 Interstorey displacement at stiff edge of a building of example 2,

(a) $\Omega_{R}=1.00$ (floors 1 to 5 ), $=0.75$ (floors 6 to 10 )

(b) $\Omega_{R}=0.75$ (floors 1 to 5 ), $=1.00$ (floors 6 to 10 ) 

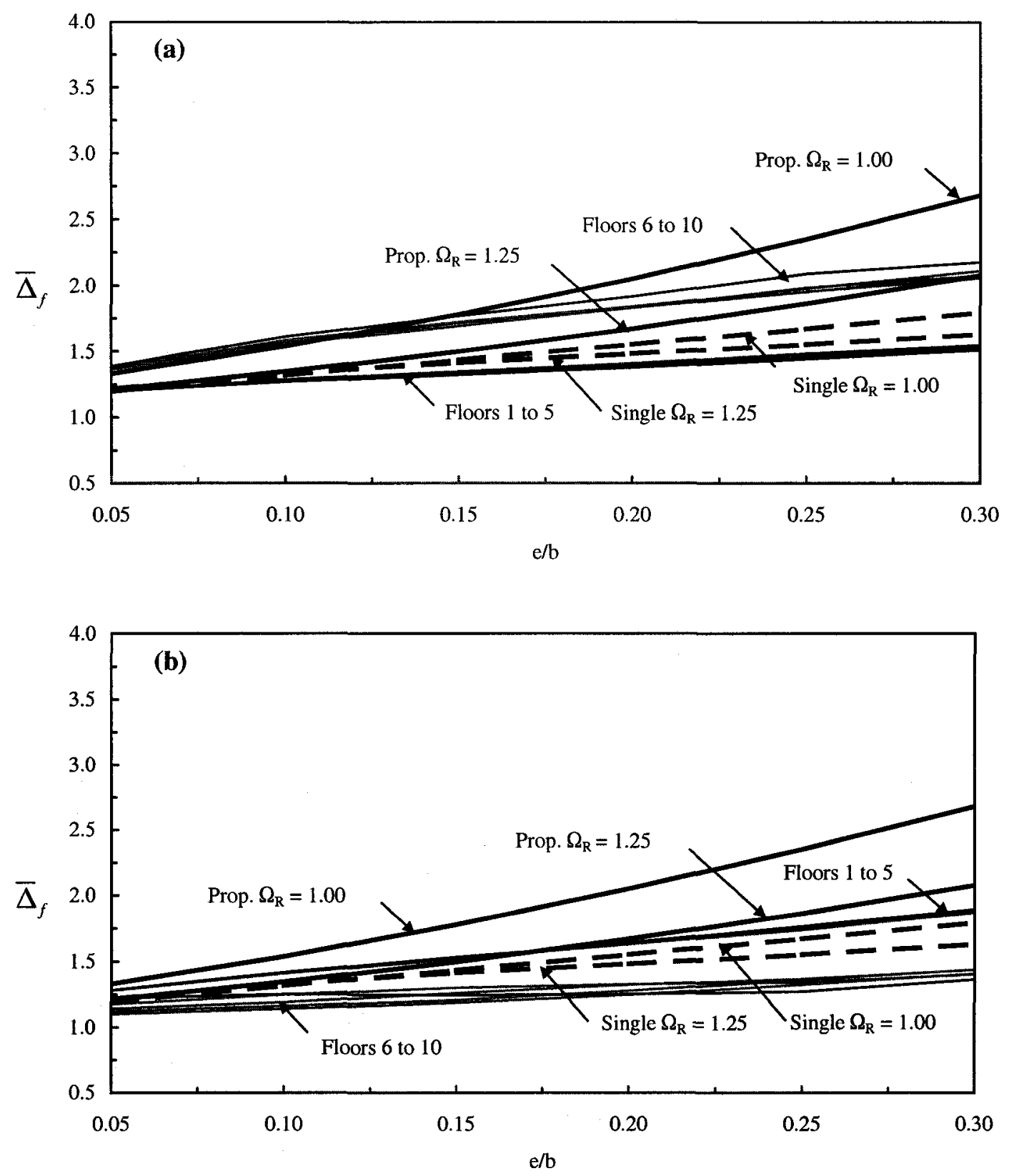

Fig. 3.9 Interstorey displacement at flexible edge of a building of example 3,

(a) $\Omega_{R}=1.25$ (floors 1 to 5 ), $=1.00$ (floors 6 to 10 )

(b) $\Omega_{R}=1.00$ (floors 1 to 5 ), $=1.25$ (floors 6 to 10 ) 

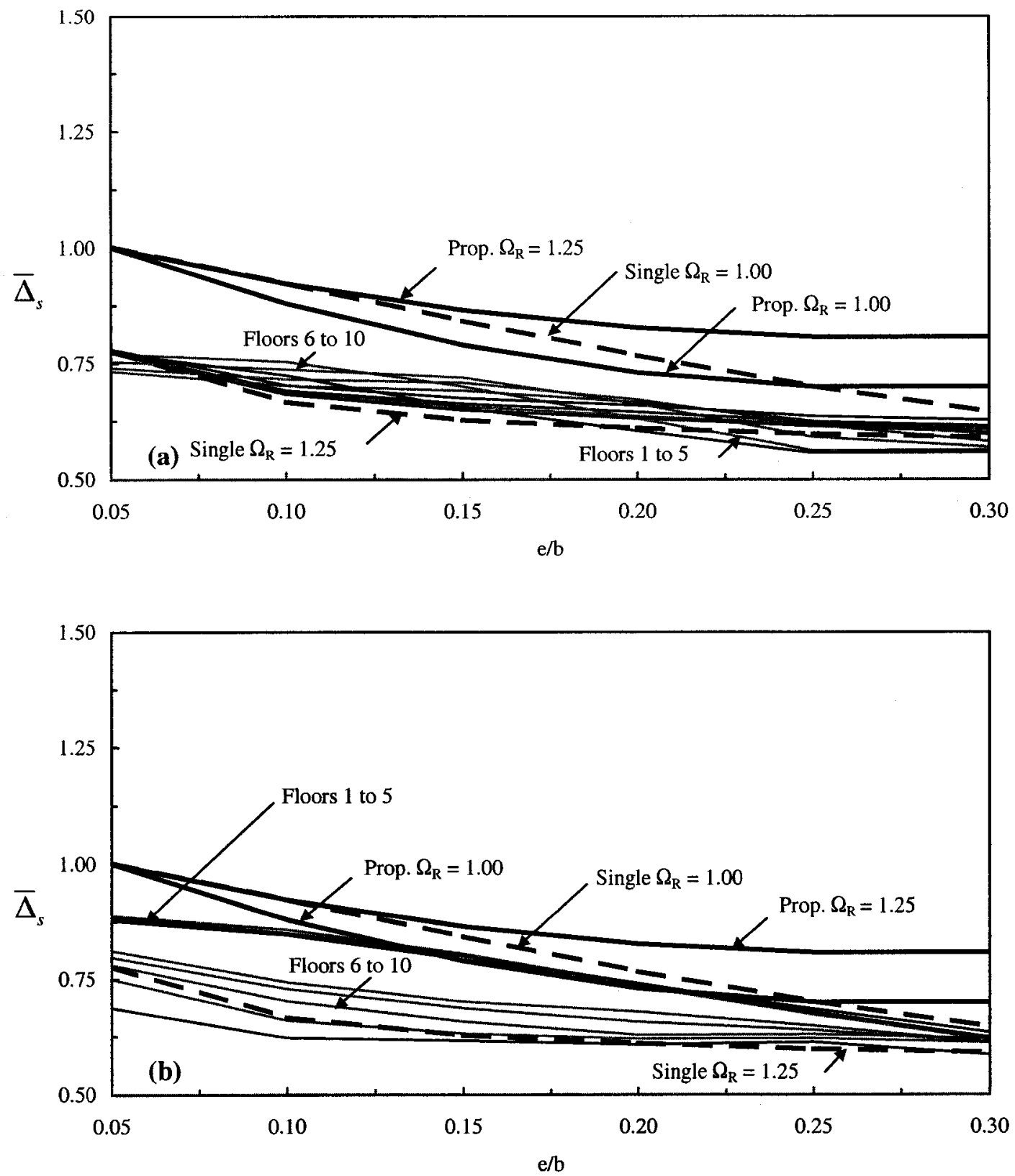

Fig. 3.10 Interstorey displacement at stiff edge of a building of example 3,

(a) $\Omega_{R}=1.25$ (floors 1 to 5 ), $=1.00$ (floors 6 to 10)

(b) $\Omega_{R}=1.00$ (floors 1 to 5 ), $=1.25$ (floors 6 to 10 ) 

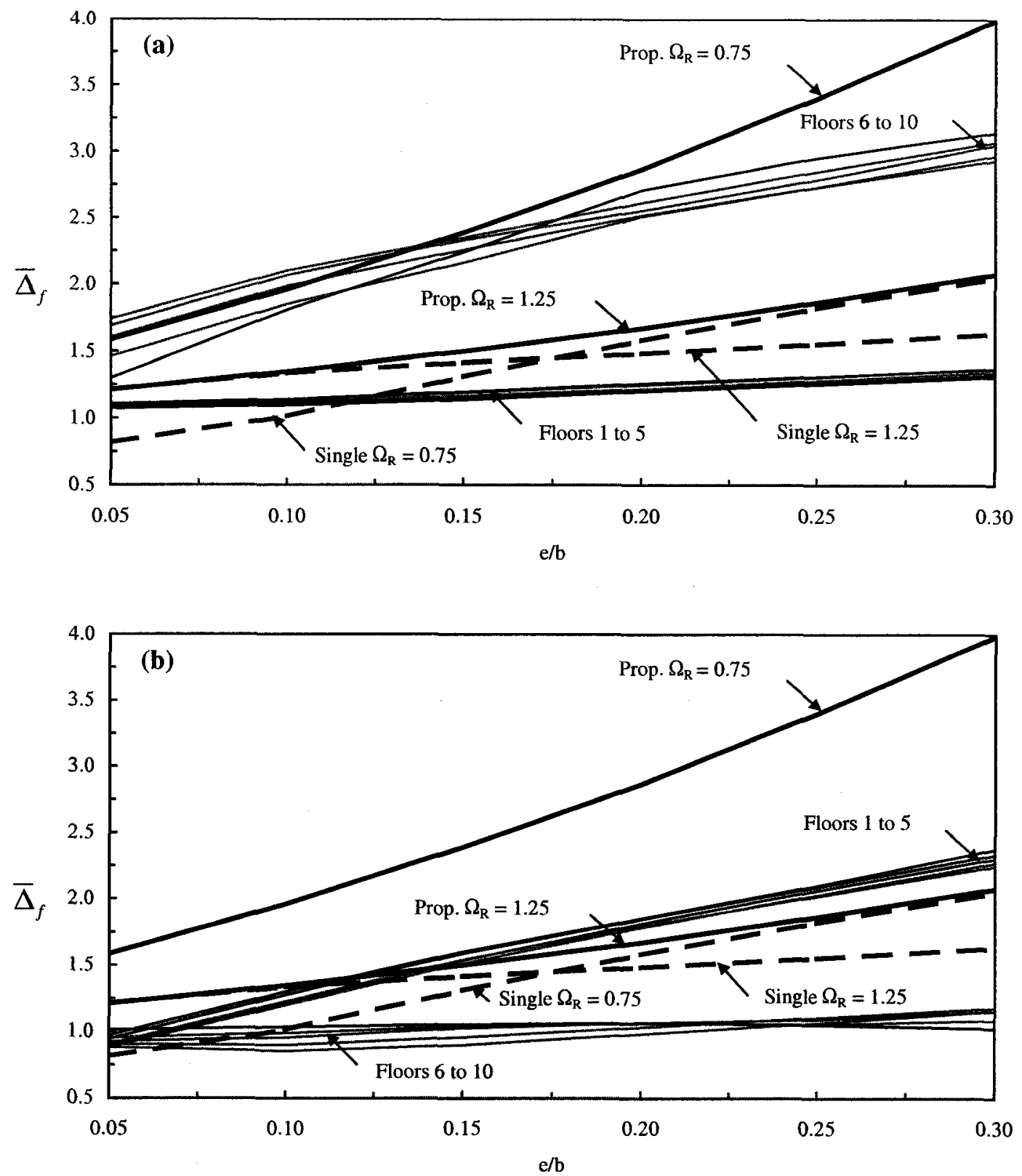

Fig. 3.11 Interstorey displacement at flexible edge of a building of example 4, (a) $\Omega_{R}=1.25$ (floors 1 to 5 ), $=0.75$ (floors 6 to 10 )

(b) $\Omega_{R}=0.75$ (floors 1 to 5 ), $=1.25$ (floors 6 to 10 )

142 

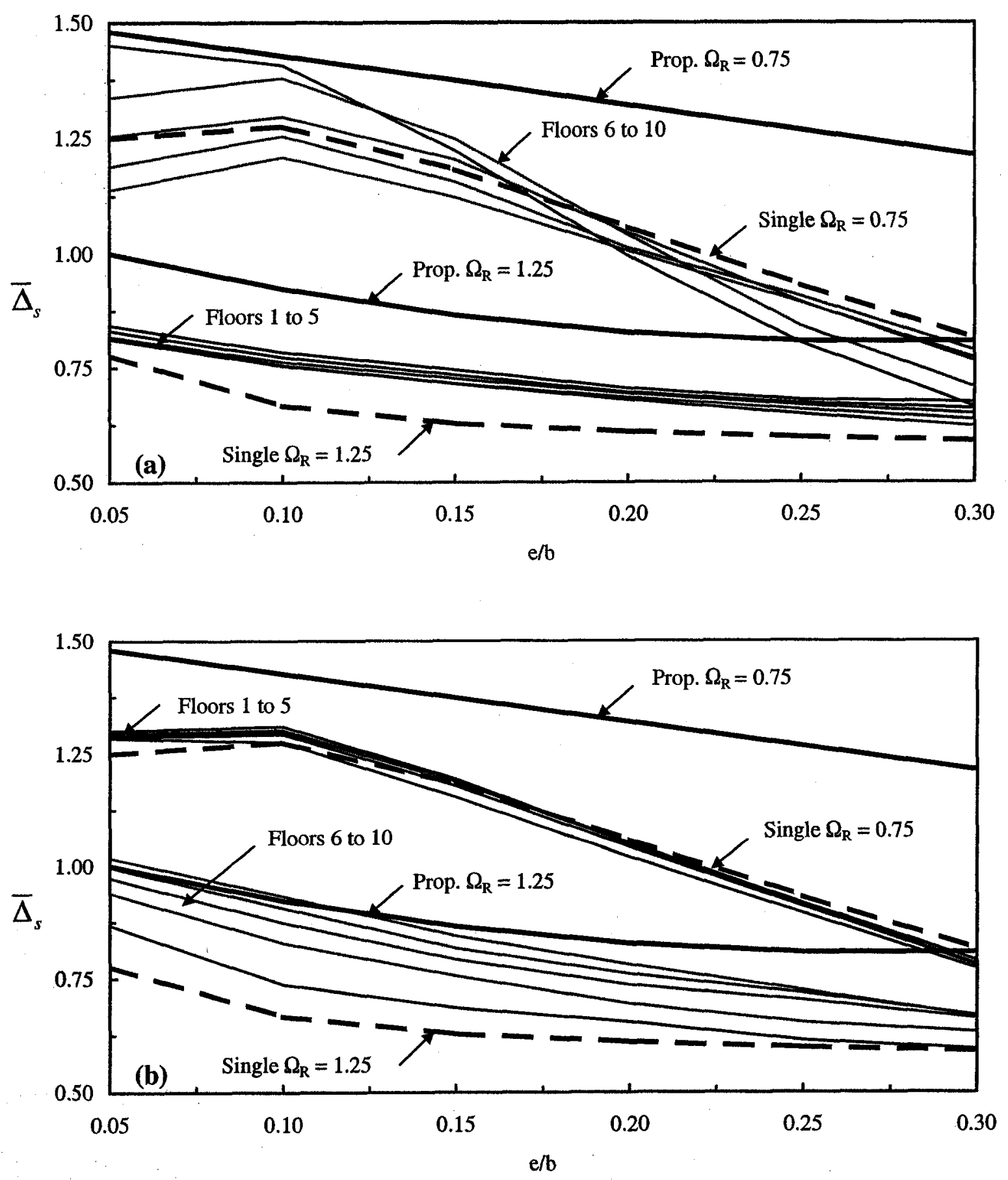

Fig. 3.12 Interstorey displacement at stiff edge of a building of example 4,

(a) $\Omega_{R}=1.25$ (floors 1 to 5 ), $=0.75$ (floors 6 to 10 )

(b) $\Omega_{R}=0.75$ (floors 1 to 5 ), $=1.25$ (floors 6 to 10 ) 

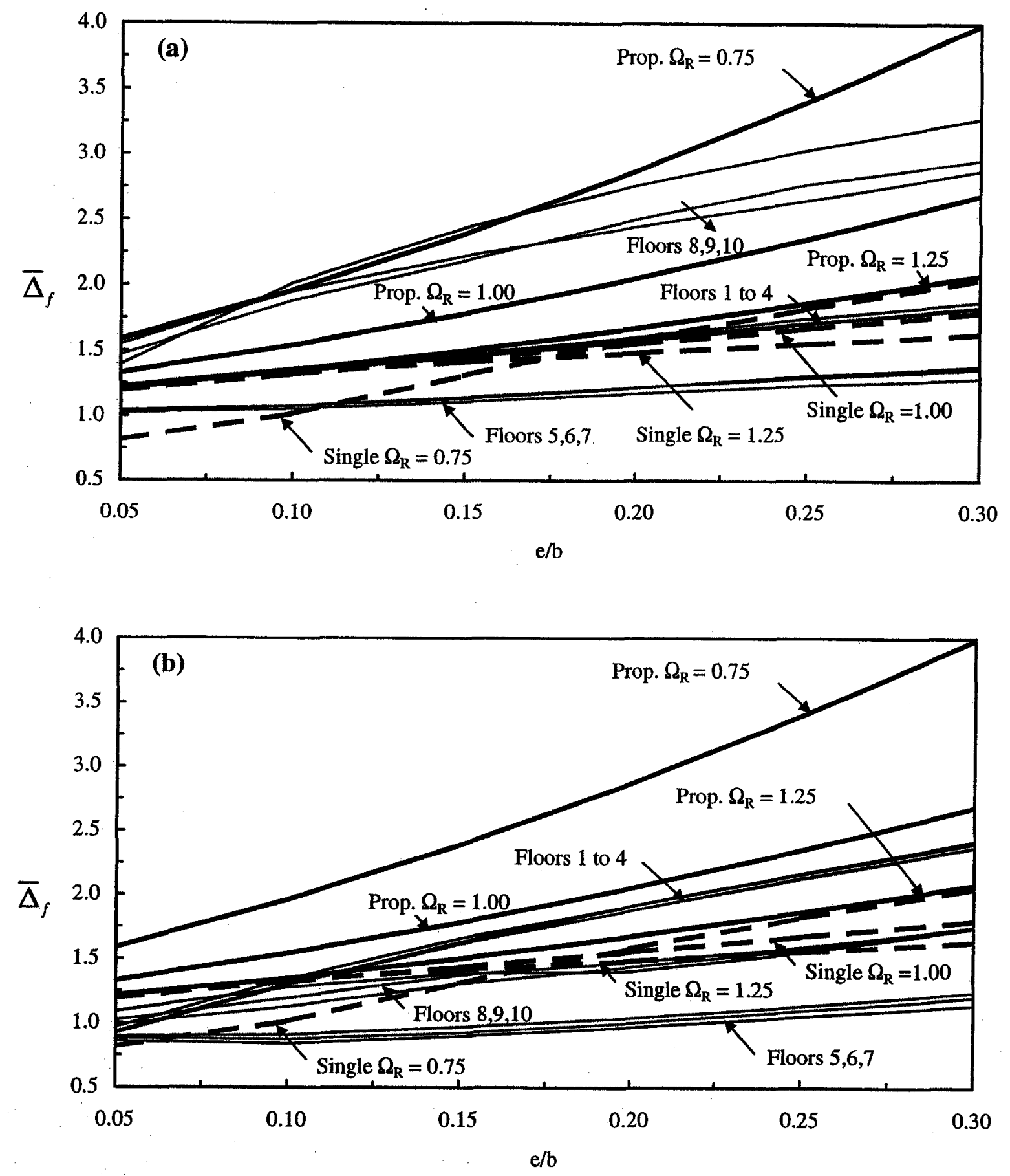

Fig. 3.13 Interstorey displacement at flexible edge of a building of example 5, (a) $\Omega_{R}=1.00$ (floors 1 to 4 ), 1.25 (floors 5 to 7 ), 0.75 (floors 8 to 10) (b) $\Omega_{R}=0.75$ (floors 1 to 4 ), 1.25 (floors 5 to 7 ), 1.00 (floors 8 to 10) 

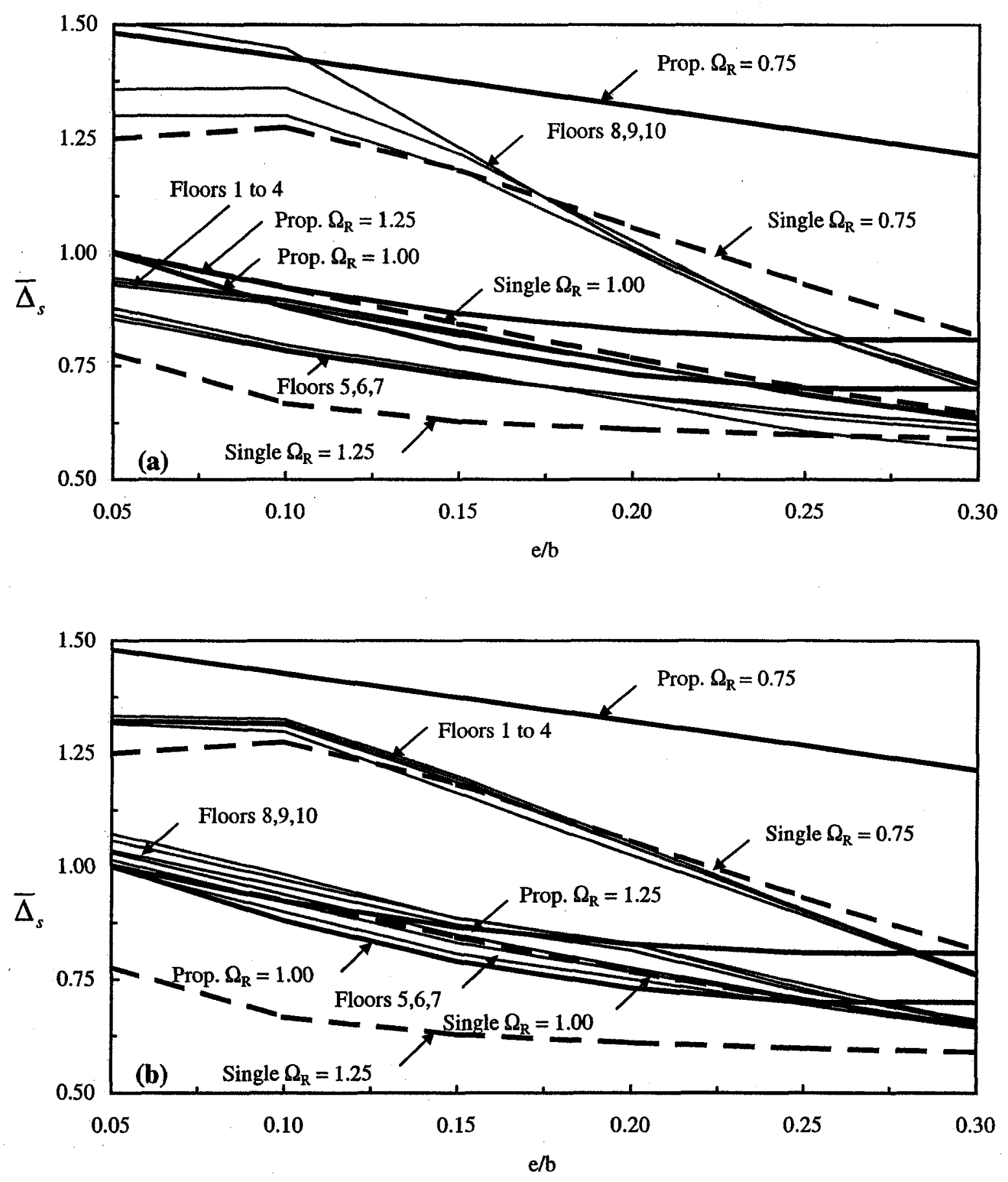

Fig. 3.14 Interstorey displacement at stiff edge of a building of example 5,

(a) $\Omega_{R}=1.00$ (floors 1 to 4 ), 1.25 (floors 5 to 7 ), 0.75 (floors 8 to 10 )

(b) $\Omega_{R}=0.75$ (floors 1 to 4 ), 1.25 (floors 5 to 7 ), 1.00 (floors 8 to 10 ) 

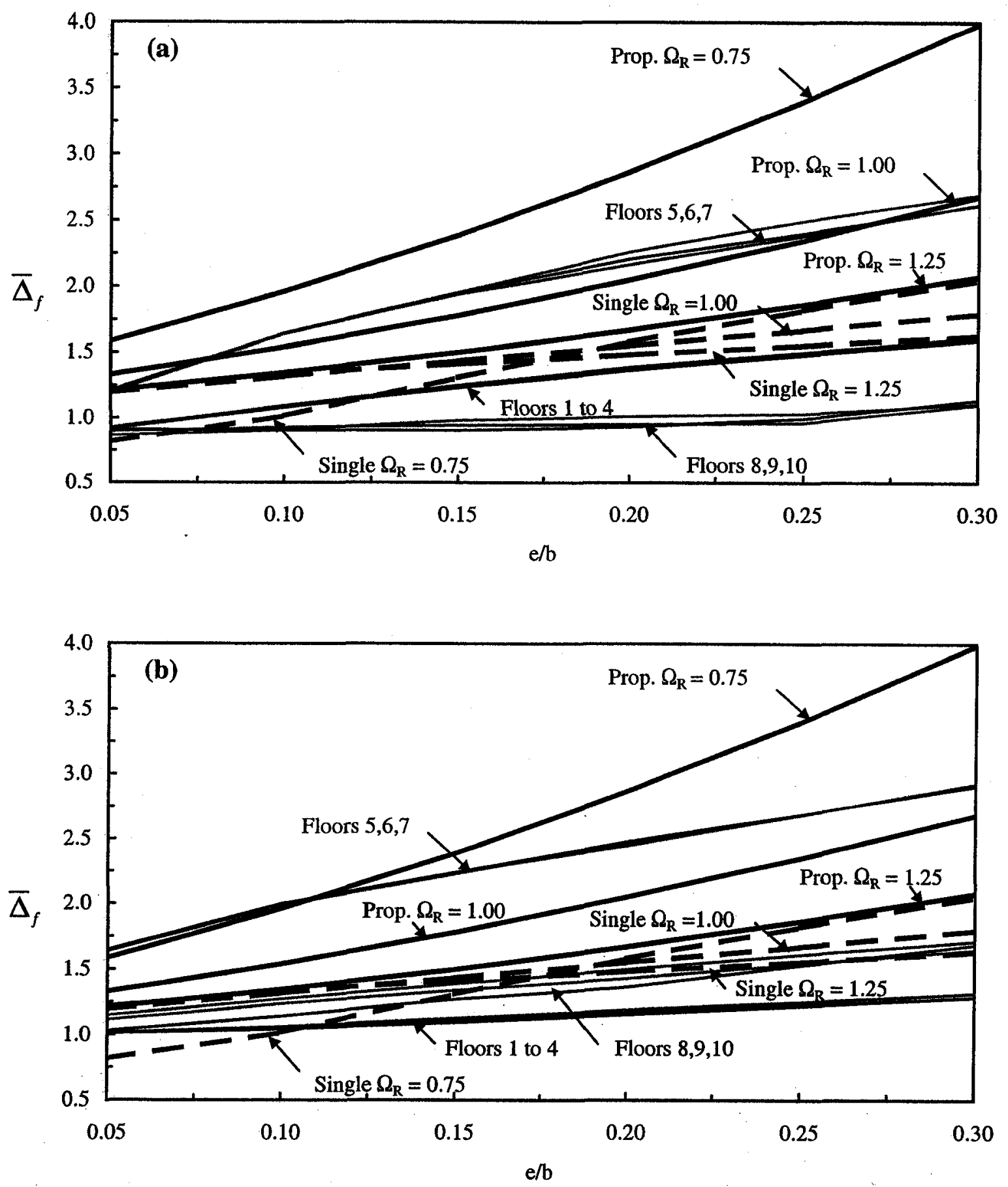

Fig. 3.15 Interstorey displacement at flexible edge of a building of example 6, (a) $\Omega_{R}=1.00$ (floors 1 to 4 ), 0.75 (floors 5 to 7), 1.25 (floors 8 to 10) (b) $\Omega_{R}=1.25$ (floors 1 to 4 ), 0.75 (floors 5 to 7), 1.00 (floors 8 to 10) 

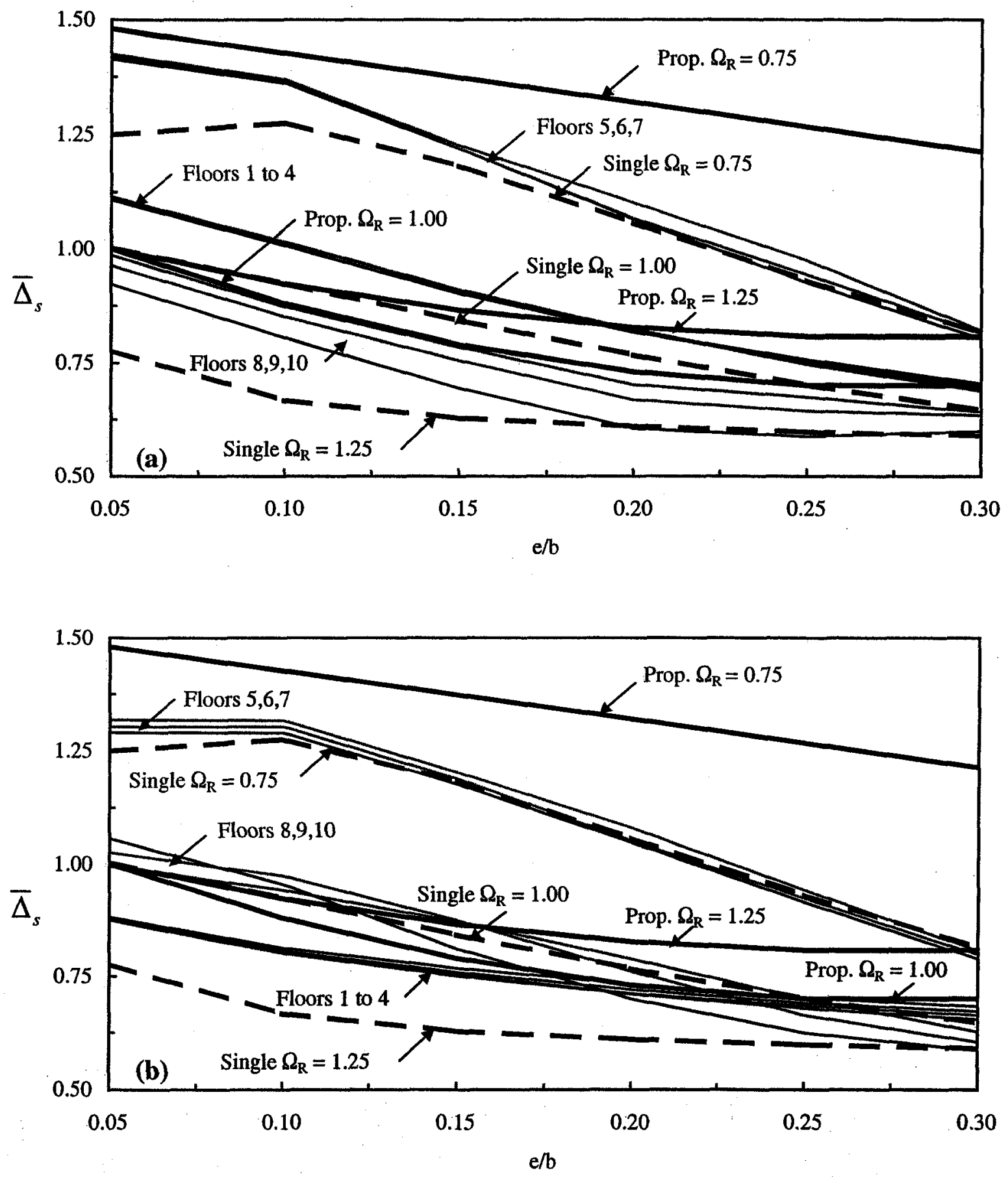

Fig. 3.16 Interstorey displacement at stiff edge of a building of example 6,

(a) $\Omega_{R}=1.00$ (floors 1 to 4 ), 0.75 (floors 5 to 7 ), 1.25 (floors 8 to 10)

(b) $\Omega_{R}=1.25$ (floors 1 to 4 ), 0.75 (floors 5 to 7 ), 1.00 (floors 8 to 10) 


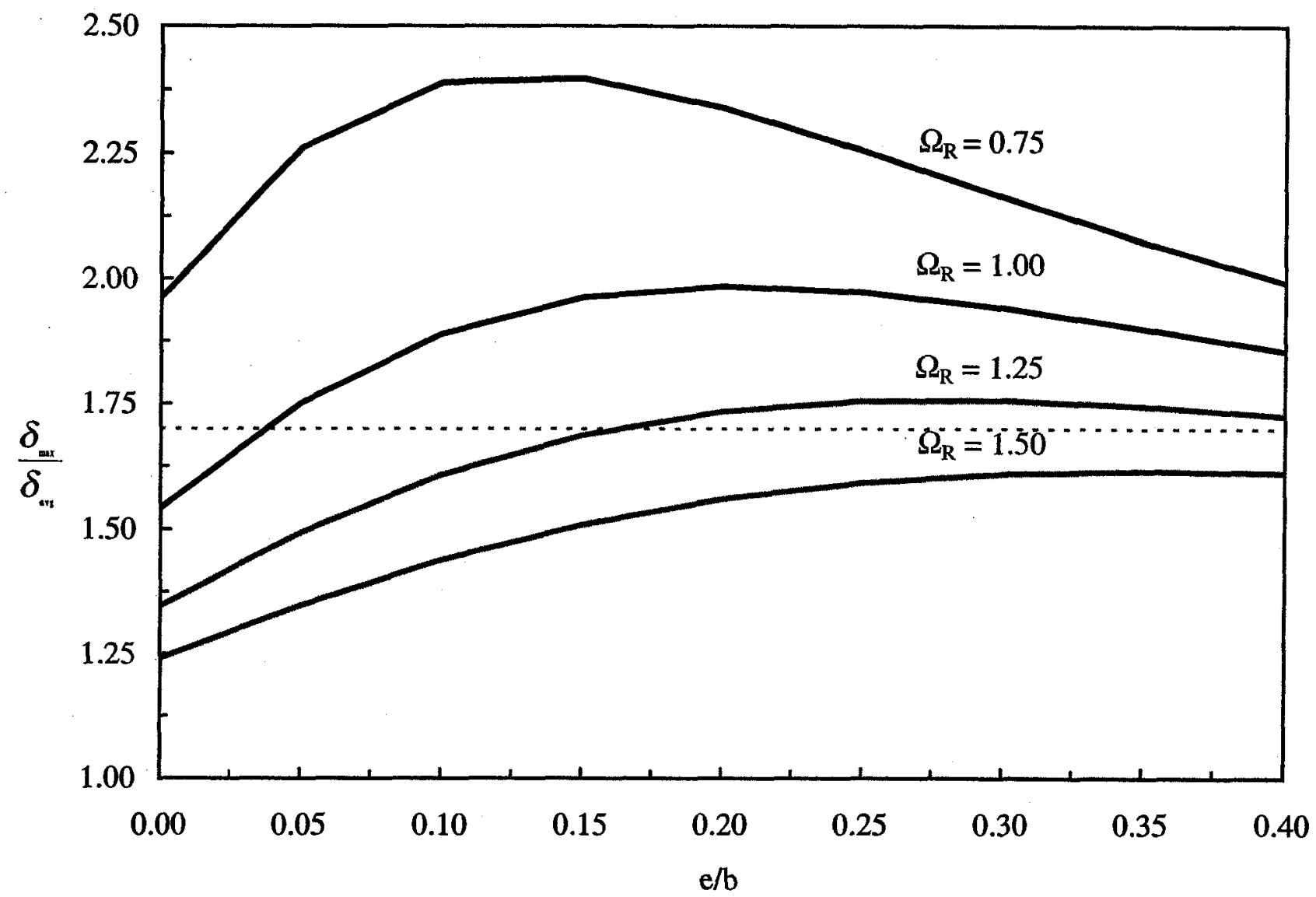

Fig. 3.17 Torsional sensitivity of single storey buildings, aspect ratio $=0.33$ 


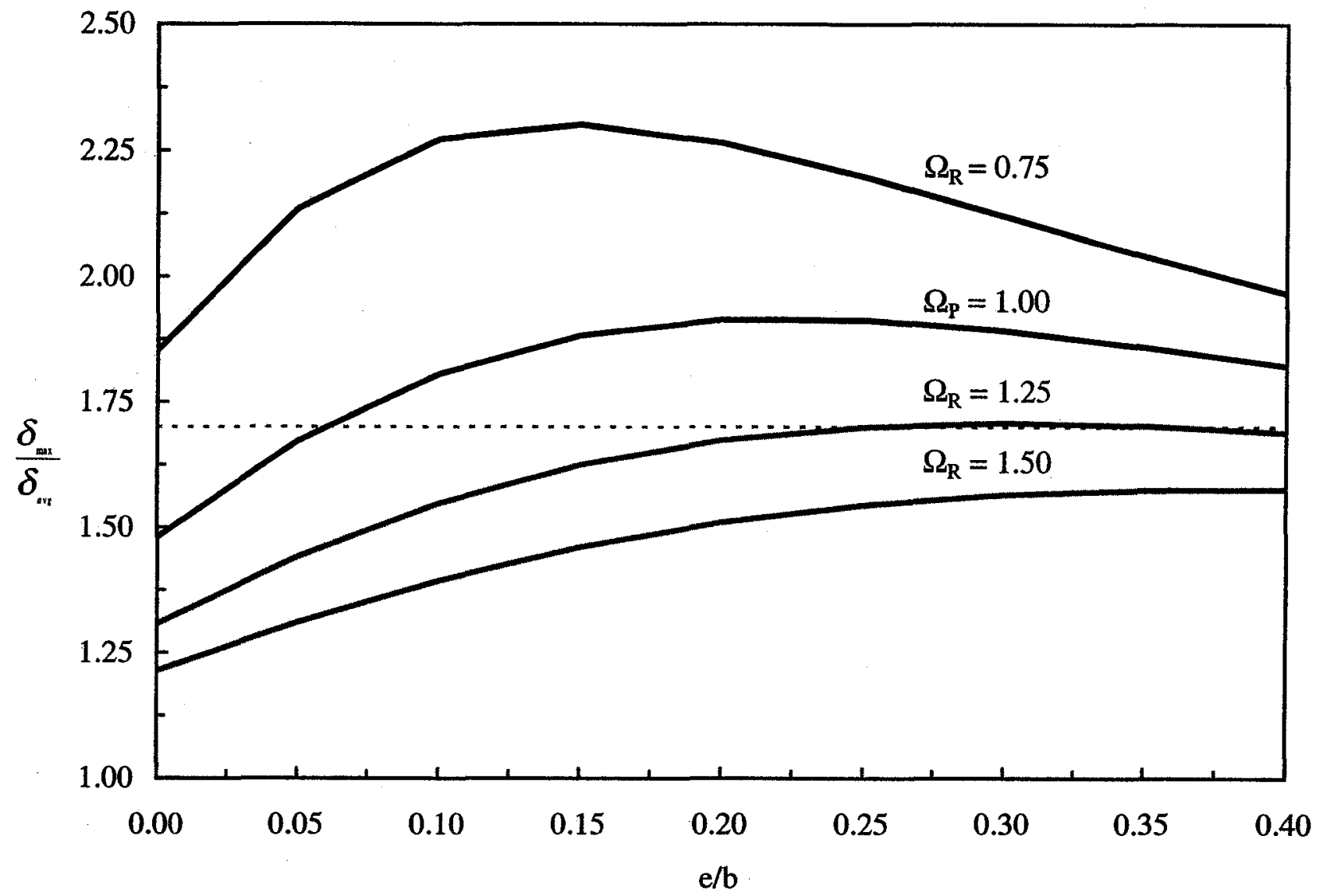

Fig. 3.18 Torsional sensitivity of single storey buildings, aspect ratio $=0.50$ 


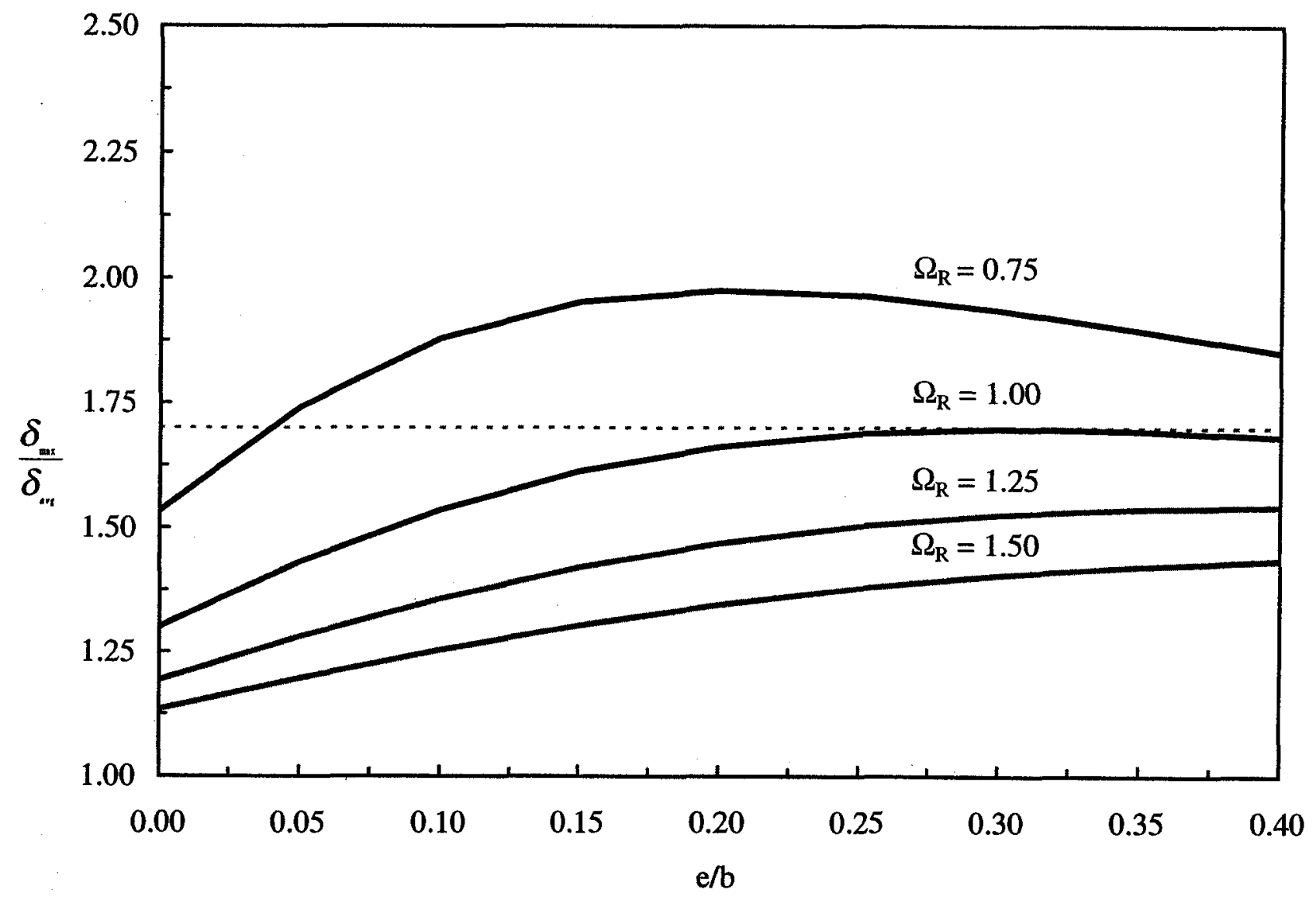

Fig. 3.19 Torsional sensitivity of single storey buildings, aspect ratio $=1.00$ 


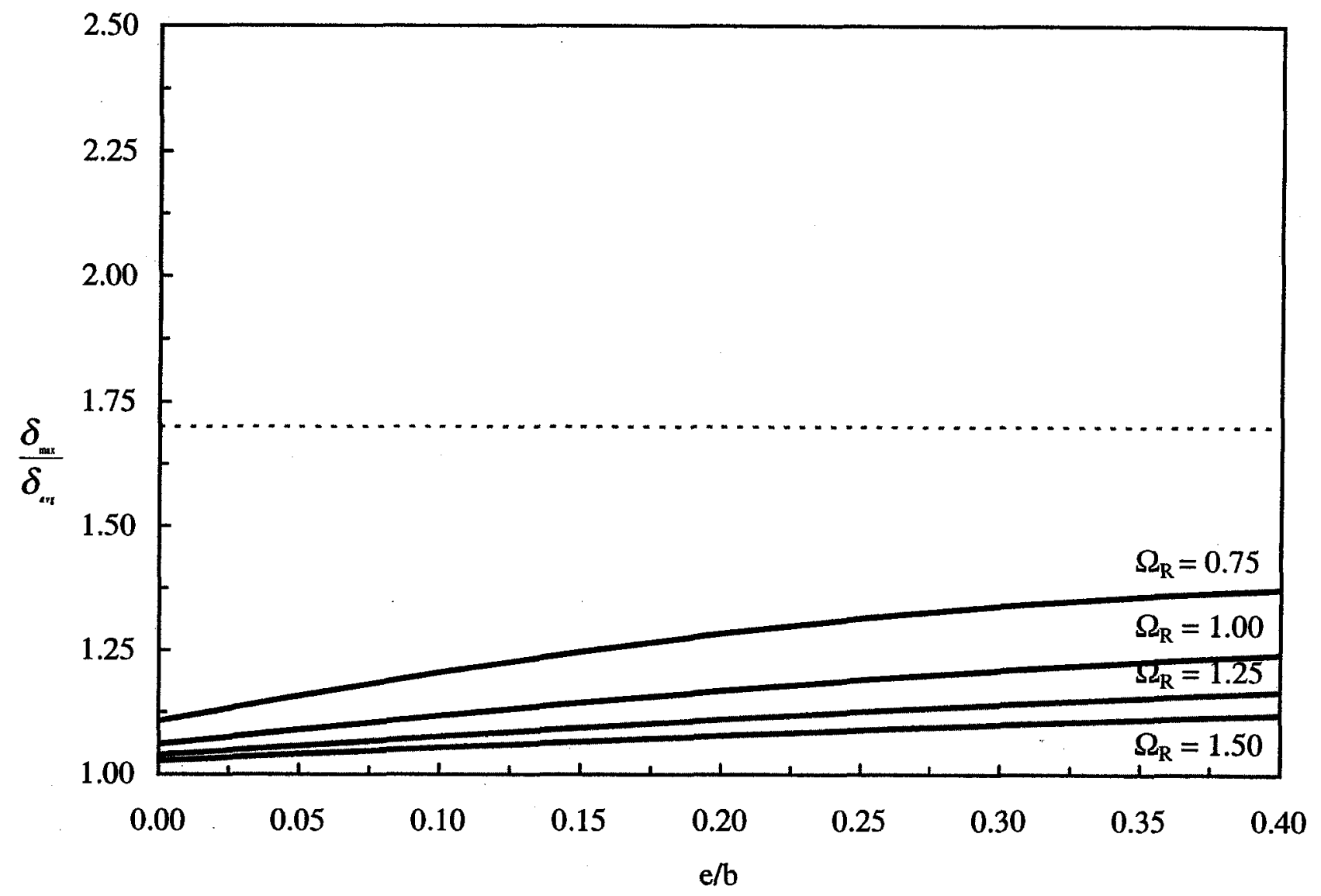

Fig. 3.20 Torsional sensitivity of single storey buildings, aspect ratio $=3.00$ 


\section{CHAPTER 4}

\section{INELASTIC ANALYSIS OF HIGHER MODE EFFECT}

\subsection{INTRODUCTION}

As stated earlier in Chapter 2, in the equivalent static procedure of design based on UHS, the elastic base shear is calculated from the spectral acceleration corresponding to the first mode period. That ignores the effect of higher modes on the response. Adjustment factors must be applied to the base shear determined from the first mode period to obtain a better estimate of the seismic forces. These factors were derived for several different structural types including moment-resisting frames, braced frames, flexural walls, coupled flexural walls and hybrid systems, assuming that the structures remained elastic, and the results were presented in Chapter 2.

A majority of structures, however, are designed for only a fraction of the elastic seismic forces. Such structures are expected to undergo significant inelastic deformations during a major earthquake. The objective of design is to limit the inelastic deformations and the resulting ductility demand to the ductility capacity of the building. It is therefore of interest to investigate the effect of higher modes on ductility and strength demands in multistorey buildings.

In a multistorey building, the ductility and strength demands depend on several 
different factors, such as the characteristics of both the lateral load resisting systems and the ground motion, and the distribution of the storey strength and stiffness across the height. A study of the inelastic response should therefore cover the effect of these factors.

\subsection{OBJECTIVES}

The intent of the study presented in this chapter is to investigate whether the higher mode factors obtained from the elastic dynamic and static analyses are effective in accounting for the impact of higher modes on the strength demand in an inelastic multistorey building associated with a specified ductility ratio. The storey ductility ratio is defined here as the ratio of a maximum dynamic interstorey displacement to the interstorey yield displacement. The strength demand associated with a specific storey ductility ratio is considered the basic design parameter.

An attempt is made to develop representative values of the higher mode factor for common structural configurations to help in designing structures with sufficient strength so as to limit the storey ductility to a specific target ductility value. This factor will be called "strength modification factor". The study presented in this chapter is an extension of the work carried out by Humar and Rahgozar (2000).

\subsection{DISCRIPTION OF BUILDING MODEL}

The same building model as the one designed in Chapter 2 and shown in Fig. 2.2, is studied in order to gain an insight into the basic inelastic dynamic behavior patterns. The 
building floors are assumed to be infinitely rigid in their own planes and the torsional effects are neglected. The response of the building can be studied by analyzing a single planar frame. Computer program DRAIN-2DX (Prakash and Powell, 1993) is used in carrying out the inelastic two-dimensional static and dynamic analyses.

Two different types of commonly used lateral force resisting systems are considered in the present study (Humar and Rahgozar 2000):

(a) Moment-resisting frame

(b) Flexural wall

Details of the two framing systems are presented in the following sections. The periods and modal masses for the first five modes of the two multistorey frame types are presented in Table 4.1 for $5,10,20$, and 30 storeys.

\subsubsection{Moment Resisting Frame (MRF)}

Similar to the models selected in Chapter 2, regular two dimensional single-bay steel frames with widely spaced elastic modal periods are studied. The frame model is comprised of rigidly connected beams and columns. The frame width is taken to be $8.0 \mathrm{~m}$ and the floor to floor height is assumed to be $3.5 \mathrm{~m}$ for all floors. The modulus of elasticity is assumed to be $200,000 \mathrm{MPa}$. The ratio of the sum of beam stiffness to the sum of the column stiffness in each storey is set to be $1 / 8$. The relative values of the storey strengths are selected so that under a set of storey forces distributed in an inverted triangular shape, the interstorey displacements are approximately the same. Even though the NBCC 2005 uses different 
equations for estimating the natural periods of different structures, the period is obtained here from equation, $T=0.1 \mathrm{~N}$, for all the models studied, where $N$ is the number of storeys. Four models are selected with $5,10,20$, and 30 storeys with fundamental period, $T_{1}$ of 0.5 , $1.0,2.0$, and $3.0 \mathrm{~s}$, respectively. The absolute values of the member moment of inertia are adjusted so as to give these periods. The mass tributary to each level of the frame is the same and is taken as $27.59 \mathrm{Mg}$.

\subsubsection{Flexural Wall}

Four different reinforced concrete flexural wall structures are selected: 5, 10, 20, and 30 storeys. The walls have a uniform width of $8.0 \mathrm{~m}$ and a storey height of 3.5 . The structure is also uniform along the height. The modulus of elasticity is assumed to be 20,000 MPa. The mass tributary to each level of the wall is expected to be higher than the one for the frame, but it is scaled down for simplicity and is taken as $27.59 \mathrm{Mg}$. The four selected structure models have fundamental period, $T_{l}$ of $0.5,1.0,2.0$, and $3.0 \mathrm{~s}$, respectively. Here also, the fundamental period is obtained from equation, $T=0.1 N \mathrm{~s}$, for all the models studied, where $N$ is the number of storeys. The stem thickness is adjusted to give these values.

Table 4.2 presents the cross sectional moment of inertia for all members of the considered models. The general assumptions made in the analyses of these models are as follows:

(1) Members strengths are designed so that all of the plastic hinges develop 
simultaneously under the NBCC equivalent static lateral load pattern. The moment capacity at plastic hinges is thus selected to be equal to the design moments at the corresponding member ends.

(2) Rayleigh damping is used in dynamic analysis. The damping value is selected to be $5 \%$ of critical for the first two modes.

(3) Axial deformations in the beams and columns in the moment-resisting frames, and in the flexural walls are neglected.

(4) P- $\Delta$ effect is not taken into consideration.

(5) For each member, inelastic deformations in the moment-resisting frames as well as in the flexural walls are concentrated at plastic hinges at the ends of the elements. The plastic hinges are assumed to have an elasto-plastic force-displacement or moment-rotation relationships. No strain hardening is considered.

(6) The effect of gravity loads is not considered in assessing the ductility demand.

(7) UHS for two Canadian cities, Vancouver representing the west and Montreal representing the east, are used in developing the spectrum compatible ground motion histories used in the time-history analysis.

\subsection{SPECTRUM-COMPATIBLE TIME HISTORIES}

The selection of appropriate earthquake records is a very important issue in seismic design. If actual earthquake records are to be used, they should be only those records whose source distance and magnitude are similar to those affecting the site under consideration and 
which are adjusted so that their spectra closely match the UHS corresponding to the design earthquake level. As an alternative, UHS compatible ground motion time histories developed by Atkinson and Beresnev (1998) can be used. The latter ground motion time histories are simulated ground motion records whose spectra match the hazard spectrum for the site. Atkinson and Beresnev (1998) have produced physically realistic time histories which not only match the hazard spectrum, but also are representative of motions for specified magnitude-distance scenarios in the regions of interest.

As stated earlier in Chapters 1 and 2, the uniform hazard spectrum can be treated as a composite of the spectra of a range of earthquakes which contribute most to the hazard corresponding to a specified probability level. Generally, small earthquakes near the site are dominant contributors in the short period range, and large earthquakes at a greater distance contribute more strongly in long period range. Taking these factors into consideration, a set of two different types of ground motions was developed to match the UHS for each particular site of interest. One of these ground motions corresponds to a low magnitude earthquake at a short distance, and is used to match the short period range, such as from 0.1 to $0.5 \mathrm{~s}$. The other ground motion corresponds to a high magnitude earthquake at a long distance and is used to mach the long period range from 0.5 to $5.0 \mathrm{~s}$.

Atkinson and Beresnev have suggested that the 1/500 p.a. spectra for eastern Canadian sites can be adequately represented by an event of M5.5 for the short period range and an event of M7.0 for the long period range. The distances at which these events are placed depend on the seismicity rate of that site area. Similarly, for western Canadian sites, 
M6.0 and M7.2 events can be used to match, respectively, the short and long period ranges of the spectra. Each of the simulated earthquake is scaled by a factor called, fine-tune factor (FTF), so as to match the target spectra as closely as possible. This fine-tune factor is equivalent to adjusting the number of standard deviations from the median. For the $1 / 1000$ p.a. spectra, the same magnitudes of earthquake events as for the $1 / 500$ p. a. spectra, can be used, but the corresponding fine-tune factors need to be adjusted.

The UHS for 1/2500 p.a. spectra are approximated, in the case of eastern Canadian locations, by M6.0 events for short and M7.0 events for long period ranges, and in the case of western Canadian locations, by M6.5 events for short and M7.2 events for long period ranges. $1 / 2500$ p.a. events are used in this study as input in the inelastic analyses. Table 4.3 shows the magnitude-distance and fine-tune factors for $1 / 2500$ p.a. events in Vancouver, representing western Canadian sites and Montreal, representing eastern Canadian sites.

In this study, the acceleration time histories produced by Atkinson and Beresnev, (1998) are used. These records simulate the elastic UHS with a 2500 year recurrence earthquake hazard level for selected cities in both the West and the East. One set of records for Vancouver in the West and another set of records for Montreal in the East are considered. Each set contains four records, two are for the short period range and the other two are for the long period range. Time step is taken to be $0.01 \mathrm{~s}$ for all the records. Figures 4.1 and 4.2 show the variation of the ground acceleration with time for these records for cities of Vancouver in the West and Montreal in the East. The spectra for the ground motions have been compared with the UHS in the paper by Atkinson and Beresnev (1998). 
Constant ductility inelastic response spectra for the above UHS compatible ground motion time histories are developed using the SAP 2000, (1997) computer program. The spectra are developed for the short period and long period time histories for both Vancouver and Montreal and for selected ductility values, $\mu=1.0,2.0,3.0$ and 4.0. Figures. 4.3 and 4.4 show the elastic and inelastic spectra for the cities of Vancouver and Montreal obtained for short and long period ranges. Each spectrum is the average of the spectra obtained from the series of the records in each range.

\subsection{ANALYSIS PROCEDURES}

A comprehensive study on the ductility and strength demands in two multistorey structural models is carried out. The main purpose of this analysis is to develop an amplification factor that would result in a modified strength that must be provided in a multistorey model so that it limits the storey ductility demand in each storey to the corresponding target ductility value.

\subsubsection{Storey Ductility Ratio}

The storey ductility ratios along the height of multistorey frame subjected to a given UHS are calculated as follows:

(1) The geographic location of the structure is selected and the associated inelastic UHS is identified.

(2) For any given structural system, selected location, and fundamental period, the spectral 
acceleration, $S_{a \mu}$, corresponding to a given target ductility, produced in the associated SDOF system, is calculated.

(3) The base shear of multistorey structure is then calculated according to the following equation:

$$
V_{b}=S_{a \mu}\left(T_{1}\right) W
$$

where $V_{b}$, is the base shear, and $\mathrm{W}$ is the total gravity weight of the frame. This base shear is used in calculating the strengths of members by carrying out a static analysis of the structure for the lateral loads obtained by distributing the base shear according to the NBCC 2005 code provisions, as described earlier in Chapter 2. It should be noted that all storeys are assumed to yield at the same time due to the way the base shear is distributed.

(4) A nonlinear dynamic time history analysis is then carried out using computer program DRAIN-2DX (Prakash and Powell, 1993) to determine the maximum interstorey drifts. These drifts are considered to be the maximum inelastic storey drifts.

(5) The yield storey displacements are also required to calculate the storey ductility. They can simply be obtained from the static analysis performed at step (3) which provides the member strengths.

(6) The storey ductility ratio is then calculated as the ratio of the maximum dynamic inelastic storey displacement, obtained from dynamic analysis in step (4), to the yield storey displacement obtained from static analysis in step (3). 


\subsubsection{Storey Ductility Demand}

To study the storey ductility demands, inelastic dynamic analyses are carried out for a moment-resisting frame, and a flexural wall. A series of static and dynamic time history analyses are performed. The following combinations are considered: two locations, west and east; two simulated time histories for each location (Atkinson and Beresnev,1998); two structural types; four structural models of 5, 10, 20 and 30 storeys for each type, and two target ductility, $\mu=2.0$ and 4.0. According to NBCC 2005, a target ductility, $\mu=4.0$ represents a ductile behavior while a target ductility ratio, $\mu=2.0$ represents a nominally ductile behavior.

Figures $4.5 \mathrm{a}$ and $\mathrm{b}$ show the variation of storey ductility demands across the height for 20 storey moment-resisting frame subjected to the long period trial 1 record (Atkinson and Beresnev,1998) of the West city of Vancouver and East city of Montreal, for a target ductility $\mu=4.0$. It can be clearly observed from the figures that the first storey has the highest ductility demand across the frame height. It can also be noticed that the ductility demands for the upper storeys are higher compared to those in the middle of the building. This can be attributed to the effect of higher modes.

Figures $4.6 \mathrm{a}$ and $\mathrm{b}$ show the variation of storey ductility demands across the height for 20 storey flexural wall subjected to the long period trial 1 record of the West city of Vancouver and East city of Montreal, for a target ductility $\mu=4.0$. Similar to the momentresisting frame, the figures show that the lower storeys have the highest ductility demand across the frame height. In all figures, the vertical dashed line represents the target ductility. 
The following observations can be made from the results presented in the previous figures:

(1) Distribution of the base shear according to NBCC 2005 does not lead to equal ductility demand in all storeys.

(2) The ductility demand is always higher than the target ductility in the first storey. It is also the highest among all storeys.

(3) The storey ductility demand increases in the upper storeys compared to the middle ones. This can be clearly attributed to the effect of higher modes.

Figures $4.7 \mathrm{a}$ and $\mathrm{b}$ show the variation of first storey ductility demand with fundamental period for moment-resisting frame located in Montreal or Vancouver while Figures $4.8 \mathrm{a}$ and $\mathrm{b}$ show the same variation for flexural wall located in same cities. The horizontal dashed line in all Figures represents the target ductility, $\mu=4.0$.

The following observations can be drawn from the results presented in the previous figures:

(1) The variation of storey ductility depends significantly on the seismicity of the location. The first storey ductility demands are higher in Canadian East location than in the West locations.

(2) The storey ductility increases monotonically with the first mode period of both structural models studied. 


\subsection{CALCULATION OF THE STRENGTH MODIFICATION FACTOR}

Based on the previous discussion, it can be clearly observed that the ductility demands for multistorey buildings vary significantly across the height even when we distribute the base shear according to the NBCC 2005 provisions. In the first storey, the ductility demand is higher than the target ductility in all cases. In the light of these facts, it is implied that the base shear strength capacity should be modified so as to provide a capacity that is higher than the inelastic strength demands. It may be reasoned on the basis of results presented in Figs. 4.7 and 4.8 that for the storeys where the ductility demands are less than the target ductility, a strength modification factor of less than unity should be selected, whereas for the storeys where the ductility demands are higher than the target ductility, a strength modification factor of more than one should be selected. However, selecting a different modification factor for each storey would be quite a complex task especially because of the fact that the storey ductility demands depend on many different factors as stated earlier in this chapter. An alternative simple method, which is adopted in this study, is to increase the design base shear by multiplying it by an appropriate value and to distribute the new base shear across the height according to NBCC 2005 provisions. This value will be called "strength modification factor".

The computation of the strength modification factor, which should be applied to the strength calculated according Eq. 4.1, which is based only on the first mode, requires an iterative procedure. For each iteration, two different approaches have been adopted:

(1) Strengths are modified for each storey. 
(2) Strengths are update for the first storey only.

\subsubsection{Strength Modified for Each Storey}

The procedure of calculating the strength modification factor is as follows:

(1) The base shear, $V_{v}$, corresponding to the associated SDOF and to the design earthquake inelastic spectrum $(\mu=2$ or $\mu=4)$ is calculated according to Eq. 4.1 . This base shear is then distributed across the height according to NBCC 2005. The internal forces are now obtained from a static analysis. The yield interstorey drift, $\Delta_{y}$, is also obtained for each storey from this analysis.

(2) The strengths of resisting members are set to equal the internal forces obtained in step (1) above. Inelastic dynamic analysis of the structure subjected to the design ground motion is then carried out. The maximum interstorey drift, $\Delta_{i}$, is obtained for each storey from such an analysis.

(3) The storey ductility demand is then calculated for each storey across the height. The strength modification factor is calculated for the first storey assuming it to be equal to the ductility demand for this storey divided by the target ductility for the same storey.

(4) The base shear, $V_{v}$, calculated in step (1) is modified by multiplying it by the strength modification factor calculated in step (3) and the static analysis is repeated with the new modified strength (base shear) replacing the old one. It should be noted that any modification made to the base shear will automatically affect the strength 
capacities of all the resisting elements as well as the storey yield displacements in all storeys.

(5) This procedure is continued until the storey ductility in the first storey, computed in step (3), becomes equal to the target ductility. At this stage, the strength modification factor, $M_{v m}$, will be calculated as the last modified base shear (strength), $V_{m}$, of MDOF divided by the first base shear (strength) of the associated SDOF calculated according to Eq. 4.1.

\subsubsection{Strength Modified for First Storey Only}

As described in the previous sections, the ductility demand is generally higher than the target ductility in the first storey of all structural models. In all other storeys, ductility demands are usually less than the target ductility. One might think that it would be more appropriate to modify the strength of first storey only leaving the strengths for other storeys unchanged. This issue will be investigated in this section.

The iterative procedure for calculating the strength modification factor presented in the previous section is still applied. A total of 64 inelastic iterative dynamic analyses are repeated to study the effect of modifying the strength for the first storey only. The new strength modification factor will be called $M_{v o}$.

\subsection{ANALYTICAL RESULTS AND DISCUSSION}

Analytical results of strength modification factor calculation are shown in Fig 4.9a 
and $\mathrm{b}$ and $4.10 \mathrm{a}$ and $\mathrm{b}$. Figures $4.9 \mathrm{a}$ and $\mathrm{b}$ show the variation of the strength modification factors, $M_{v m}$, and $M_{v o}$, with the fundamental period, for a moment-resisting frame located in Vancouver and Montreal, with target ductility $\mu=4.0$. The variation of the strength modification factor, $M_{v m}$, with the period for the frame with target ductility $\mu=2.0$ is also shown. The figures also show the variation of the strength modification factor, $M_{v}$, with the period for the frame with target ductility $\mu=1.0$ (elastic). Figures $4.10 \mathrm{a}$ and $\mathrm{b}$ show the variation of the strength modification factors, $M_{v m}$, and $M_{v o}$, with the fundamental period, for a flexural wall located in Vancouver and Montreal, with target ductility $\mu=4.0$. The variation of the strength modification factor, $M_{v m}$, with the period for the wall with target ductility $\mu=2.0$ is also shown. The figures also show the variation of the strength modification factor, $M_{v}$, with the period for the wall with target ductility $\mu=1.0$ (elastic). From the two figures, the following observations can be made:

(1) Similar to elastic analysis results presented in Chapter 2, strength modification factor is period dependent whether the strength is modified for all storeys or for first storey only. This factor increases with period. In all cases, the factor's rate of increase is higher for the Eastern region than for the Western region of Canada. For example, for the flexural wall systems in the West, $M_{v m}$ factor varies from 1.27 to 2.43 , while in the East it ranges from 1.96 to 4.37 . Factor $M_{v o}$ varies from 1.25 to 2.59 in the West, while it varies from 1.74 to 5.75 in the East. These values correspond to fundamental time period that ranges from 0.5 to $3.0 \mathrm{~s}$. It is also observed that the rate of increase for $M_{v o}$ factor is higher than the one for $M_{v m}$.

(2) For both analysis approaches, the strength modification factor is found to be strongly 
dependent on the type of ground motion. For the same fundamental period, structures subjected to records in the East usually have larger factor values than their counterparts in the West. These results are similar to the findings obtained from elastic analysis of Chapter 2. (3) For all structural models, it is observed from the results of height wise variation of ductility, not all of which are presented here, that the ductility in the upper storeys does not exceed the corresponding target ductility before or after modifying the strength whether for all storeys or only for the first storey.

(4) From the figures it is seen that the strength modification factor, $M_{v o}$ (strengths are modified for first storey only) is generally higher than the factor, $M_{v m}$ (strengths are modified for all storeys). The difference between the two values increases with an increase in the fundamental period.

(5) In all cases, the strength modification factor increases with an increase in the target ductility. The structure designed for larger ductilities requires larger strength modification factor. For example, for a 10-storey moment-resisting frame, located in the East, the value of $M_{v m}$ factor is 1.18 corresponding to target ductility $\mu=2.0$, while the value for the same factor is 1.57 when corresponding to target ductility $\quad \mu=4.0$.

(6) For a given fundamental period, ground motion, and target ductility, the values for both factors $M_{v m}$, and $M_{v o}$ are higher for the flexural wall system than for the moment-resisting frame. 


\subsection{SUMMARY AND CONCLUSIONS}

To investigate the higher mode effect in MDOF structures, nonlinear dynamic time history analyses are carried out for two common structural types; moment-resisting frames and flexural walls. The UHS-2500 compatible records developed by Atkinson and Beresnev, (1998) for Vancouver and Montreal, representing the West and the East Canadian cities, are used in the analyses. The results of the nonlinear dynamic analyses of multistorey structures show that the storey ductility varies across the height. The first storey ductility demand is the highest among all storeys and is always higher than the target ductility of the associated SDOF system. Two different approaches are adopted in this study to propose a strength modification factor to limit the storey ductility demand to the desired target ductility: (a) modify the strength for all storeys; and (b) modify the strength for only the first storey. In both proposed approaches, the strength modification factor is selected so that the highest ductility demand in the MDOF system is equal to or less than the target ductility for which the base shear for the associated SDOF system has been calculated.

Based on the results presented in this study, the following conclusions are obtained: (1) The equivalent static procedures included in many seismic codes including NBCC 1995 do not fully account for the effect of higher modes on response. The results presented in this chapter show clearly that the ductility demands for MDOF systems differ significantly from those of associated SDOF systems. The implication is that the base shear strength capacities of MDOF systems must be modified from the inelastic strength demands of the equivalent SDOF systems, in order to limit the storey ductility demand to the desired target ductility. 
Adjustment factors that must be applied to the base shear determined from the first mode period are derived in this study to achieve the previous goal.

(2) Similar to the elastic analysis presented in Chapter 2, the strength modification factor is found to be dependent on the structure type and the type of ground motion. In addition, it also depends on the target ductility. It increases with an increase in the first mode period of the structure and the ductility ratio and is higher for eastern locations than western locations.

(3) Modifying the first storey strength alone often requires a higher strength modification factor compared to the other one when the strength for all storeys is modified. However, increasing only the strength of the first storey may be economically and practically more effective than increasing the strength of all storeys even though the amplification factor is higher.

(4) There is good agreement in the trend of $M_{v}$ factors obtained from the elastic dynamic and static analyses presented in Chapter 2 and the $M_{v m}$, and $M_{v o}$ factors obtained in this chapter from the inelastic dynamic and static analyses. The latter factors are higher for both momentresisting frame and flexural wall structural models. From analytical results presented here, it can be observed that the ductility demand exceeds the target ductility only in the lower storeys. The elastic $M_{v}$ factors may therefore be considered adequate provided the ductility capacity of the lower storey could be increased as suggested here. Additional studies would be useful in verifying this. 
Table 4.1 Modal periods and modal masses (\% of total mass) for MDOF models, (a) Moment-resisting frames, and (b) Flexural walls (Humar and Rahgozar 2000)

\begin{tabular}{|c|c|c|c|c|c|c|c|c|}
\hline (a) & \multicolumn{2}{|c|}{ 5-storey } & \multicolumn{2}{c|}{ 10-storey } & \multicolumn{2}{c|}{ 20-storey } & \multicolumn{2}{|c|}{ 30-storey } \\
\hline $\begin{array}{c}\text { Mode } \\
\text { No. }\end{array}$ & $\begin{array}{c}\text { T } \\
(\mathbf{s})\end{array}$ & $\begin{array}{c}\text { Modal } \\
\text { mass } \\
\%\end{array}$ & $\begin{array}{c}\text { T } \\
\text { (s) }\end{array}$ & $\begin{array}{c}\text { Modal } \\
\text { mass } \\
\%\end{array}$ & $\begin{array}{c}\text { T } \\
(\mathbf{s})\end{array}$ & $\begin{array}{c}\text { Modal } \\
\text { mass } \\
\%\end{array}$ & $\begin{array}{c}\text { T } \\
(\mathbf{s})\end{array}$ & $\begin{array}{c}\text { Modal } \\
\text { mass } \\
\%\end{array}$ \\
\hline 1 & 0.500 & 74 & 1.000 & 75 & 2.000 & 76 & 3.000 & 77 \\
\hline 2 & 0.177 & 14 & 0.371 & 11 & 0.746 & 11 & 1.107 & 10 \\
\hline 3 & 0.088 & 7 & 0.212 & 5 & 0.445 & 4 & 0.665 & 4 \\
\hline 4 & 0.049 & 4 & 0.137 & 3 & 0.309 & 2 & 0.469 & 2 \\
\hline 5 & 0.032 & 2 & 0.095 & 2 & 0.230 & 2 & 0.357 & 1 \\
\hline
\end{tabular}

\begin{tabular}{|c|c|c|c|c|c|c|c|c|}
\hline (b) & \multicolumn{2}{|c|}{ 5-storey } & \multicolumn{2}{c|}{ 10-storey } & \multicolumn{2}{c|}{ 20-storey } & \multicolumn{2}{|c|}{ 30-storey } \\
\hline $\begin{array}{c}\text { Mode } \\
\text { No. }\end{array}$ & $\begin{array}{c}\mathbf{T} \\
(\mathbf{s})\end{array}$ & $\begin{array}{c}\text { Modal } \\
\text { mass } \\
\mathbf{\%}\end{array}$ & $\begin{array}{c}\mathbf{T} \\
(\mathbf{s})\end{array}$ & $\begin{array}{c}\text { Modal } \\
\text { mass } \\
\mathbf{\%}\end{array}$ & $\begin{array}{c}\mathbf{T} \\
(\mathbf{s})\end{array}$ & $\begin{array}{c}\text { Modal } \\
\text { mass } \\
\%\end{array}$ & $\begin{array}{c}\mathbf{T} \\
(\mathbf{s})\end{array}$ & $\begin{array}{c}\text { Modal } \\
\text { mass } \\
\%\end{array}$ \\
\hline 1 & 0.500 & 68 & 1.000 & 64 & 2.000 & 63 & 3.000 & 62 \\
\hline 2 & 0.078 & 21 & 0.158 & 20 & 0.319 & 19 & 0.478 & 19 \\
\hline 3 & 0.028 & 7 & 0.056 & 7 & 0.114 & 7 & 0.171 & 7 \\
\hline 4 & 0.014 & 3 & 0.029 & 3 & 0.058 & 3 & 0.087 & 3 \\
\hline 5 & 0.010 & 1 & 0.017 & 2 & 0.035 & 2 & 0.053 & 2 \\
\hline
\end{tabular}


Table 4.2 Cross sectional moment of inertia for the structural types studied

(a) Five storey models

\begin{tabular}{|c|c|c|c|}
\hline \multirow[b]{2}{*}{ Storey } & \multicolumn{2}{|c|}{ Moment-resisting frame } & \multirow{2}{*}{$\begin{array}{l}\text { Flexural wall } \\
\text { Stem } \\
\left(\mathrm{mm}^{4} \times 10^{11}\right)\end{array}$} \\
\hline & $\begin{array}{l}\text { Column } \\
\left(\mathrm{mm}^{4} \times 10^{9}\right)\end{array}$ & $\underset{\left(\mathrm{mm}^{4} \times 10^{9}\right)}{\text { Beam }}$ & \\
\hline 1 & 3.761 & 2.149 & 0.681 \\
\hline 2 & 3.501 & 2.006 & 0.681 \\
\hline 3 & 3.009 & 1.720 & 0.681 \\
\hline 4 & 2.257 & 1.290 & 0.681 \\
\hline 5 & 0.719 & 0.439 & 0.681 \\
\hline
\end{tabular}

(b) Ten storey models

\begin{tabular}{cccc}
\hline Storey & \multicolumn{2}{c}{ Moment-resisting frame } & Flexural wall \\
Column & $\left(\mathrm{mm}^{4} \times 10^{9}\right)$ & $\begin{array}{c}\text { Beam } \\
\left(\mathrm{mm}^{4} \times 10^{9}\right)\end{array}$ & $\begin{array}{c}\text { Stem } \\
\left(\mathrm{mm}^{4} \times 10^{11}\right)\end{array}$ \\
\hline 1 & 3.929 & 2.245 & 2.286 \\
2 & 3.862 & 2.207 & 2.286 \\
3 & 3.729 & 2.131 & 2.286 \\
4 & 3.530 & 2.017 & 2.286 \\
5 & 3.264 & 1.865 & 2.286 \\
6 & 2.932 & 1.676 & 2.286 \\
7 & 2.534 & 1.448 & 2.286 \\
8 & 2.069 & 1.182 & 2.286 \\
9 & 1.537 & 0.878 & 2.286 \\
10 & 0.539 & 0.329 & 2.286 \\
\hline
\end{tabular}


(c) Twenty storey models

\begin{tabular}{cccc}
\hline Storey & $\begin{array}{c}\text { Moment-resisting frame } \\
\text { Column } \\
\left(\mathrm{mm}^{4} \times 10^{9}\right)\end{array}$ & $\begin{array}{c}\text { Beam } \\
\left(\mathrm{mm}^{4} \times 10^{9}\right)\end{array}$ & $\begin{array}{c}\text { Flexural wall } \\
\text { Stem } \\
\left(\mathrm{mm}^{4} \times 10^{11}\right)\end{array}$ \\
\hline 1 & 3.999 & 2.285 & 8.331 \\
2 & 3.983 & 2.276 & 8.331 \\
3 & 3.950 & 2.257 & 8.331 \\
4 & 3.901 & 2.229 & 8.331 \\
5 & 3.835 & 2.192 & 8.331 \\
6 & 3.753 & 2.145 & 8.331 \\
7 & 3.655 & 2.089 & 8.331 \\
8 & 3.541 & 2.023 & 8.331 \\
9 & 3.409 & 1.948 & 8.331 \\
10 & 3.262 & 1.853 & 8.331 \\
11 & 3.093 & 1.771 & 8.331 \\
12 & 2.918 & 1.668 & 8.331 \\
13 & 2.722 & 1.555 & 8.331 \\
14 & 2.509 & 1.434 & 8.331 \\
15 & 2.280 & 1.303 & 8.331 \\
16 & 2.034 & 1.162 & 8.331 \\
17 & 1.772 & 1.012 & 8.331 \\
18 & 1.493 & 0.853 & 8.331 \\
19 & 1.199 & 0.685 & 8.331 \\
20 & 0.509 & 0.311 & 8.331 \\
\hline
\end{tabular}

172 
(d) Thirty storey models

\begin{tabular}{|c|c|c|c|}
\hline \multirow[b]{2}{*}{ Storey } & \multicolumn{2}{|c|}{ Moment-resisting frame } & \multirow{2}{*}{$\begin{array}{c}\text { Flexural wall } \\
\text { Stem } \\
\left(\mathrm{mm}^{4} \times 10^{11}\right)\end{array}$} \\
\hline & $\begin{array}{c}\text { Column } \\
\left(\mathrm{mm}^{4} \times 10^{9}\right)\end{array}$ & $\begin{array}{c}\text { Beam } \\
\left(\mathrm{mm}^{4} \times 10^{9}\right)\end{array}$ & \\
\hline 1 & 3.977 & 2.273 & 18.153 \\
\hline 2 & 3.970 & 2.269 & 18.153 \\
\hline 3 & 3.957 & 2.261 & 18.153 \\
\hline 4 & 3.937 & 2.250 & 18.153 \\
\hline 5 & 3.910 & 2.234 & 18.153 \\
\hline 6 & 3.876 & 2.215 & 18.153 \\
\hline 7 & 3.835 & 2.192 & 18.153 \\
\hline 8 & 3.788 & 2.165 & 18.153 \\
\hline 9 & 3.734 & 2.134 & 18.153 \\
\hline 10 & 3.673 & 2.099 & 18.153 \\
\hline 11 & 3.606 & 2.060 & 18.153 \\
\hline 12 & 3.531 & 2.018 & 18.153 \\
\hline 13 & 3.450 & 1.972 & 18.153 \\
\hline 14 & 3.454 & 1.972 & 18.153 \\
\hline 15 & 3.268 & 1.867 & 18.153 \\
\hline 16 & 3.166 & 1.794 & 18.153 \\
\hline 17 & 3.058 & 1.748 & 18.153 \\
\hline 18 & 2.943 & 1.683 & 18.153 \\
\hline 19 & 2.822 & 1.612 & 18.153 \\
\hline 20 & 2.693 & 1.539 & 18.153 \\
\hline 21 & 2.558 & 1.462 & 18.153 \\
\hline 22 & 2.416 & 1.381 & 18.153 \\
\hline 23 & 2.268 & 1.296 & 18.153 \\
\hline 24 & 2.112 & 1.207 & 18.153 \\
\hline 25 & 1.950 & 1.114 & 18.153 \\
\hline 26 & 1.781 & 1.018 & 18.153 \\
\hline 27 & 1.606 & 0.917 & 18.153 \\
\hline 28 & 1.423 & 0.813 & 18.153 \\
\hline 29 & 1.234 & 0.705 & 18.153 \\
\hline 30 & 0.596 & 0.364 & 18.153 \\
\hline
\end{tabular}

173 
Table 4.3 Magnitude, distance and fine tune factors (FTF) for UHS compatible motions, (Atkinson and Beresnev, 1998)

\begin{tabular}{|c|c|c|c|c|c|c|c|}
\hline \multirow{2}{*}{$\begin{array}{c}\text { Hazard } \\
\text { Level }\end{array}$} & $\begin{array}{c}\text { Period } \\
\text { Range }\end{array}$ & \multicolumn{4}{|c|}{ Vancouver } & \multicolumn{3}{c|}{ Montreal } \\
\cline { 3 - 8 } & & Magnitude & Distance & FTF & Magnitude & Distance & FTF \\
\hline \multirow{2}{*}{$\begin{array}{c}\text { UHS- } \\
2500\end{array}$} & Short & 6.5 & $30 \mathrm{~km}$ & 1.0 & 6.0 & $30 \mathrm{~km}$ & 0.85 \\
\cline { 2 - 8 } & Long & 7.2 & $70 \mathrm{~km}$ & 1.0 & 7.0 & $70 \mathrm{~km}$ & 0.90 \\
\hline
\end{tabular}



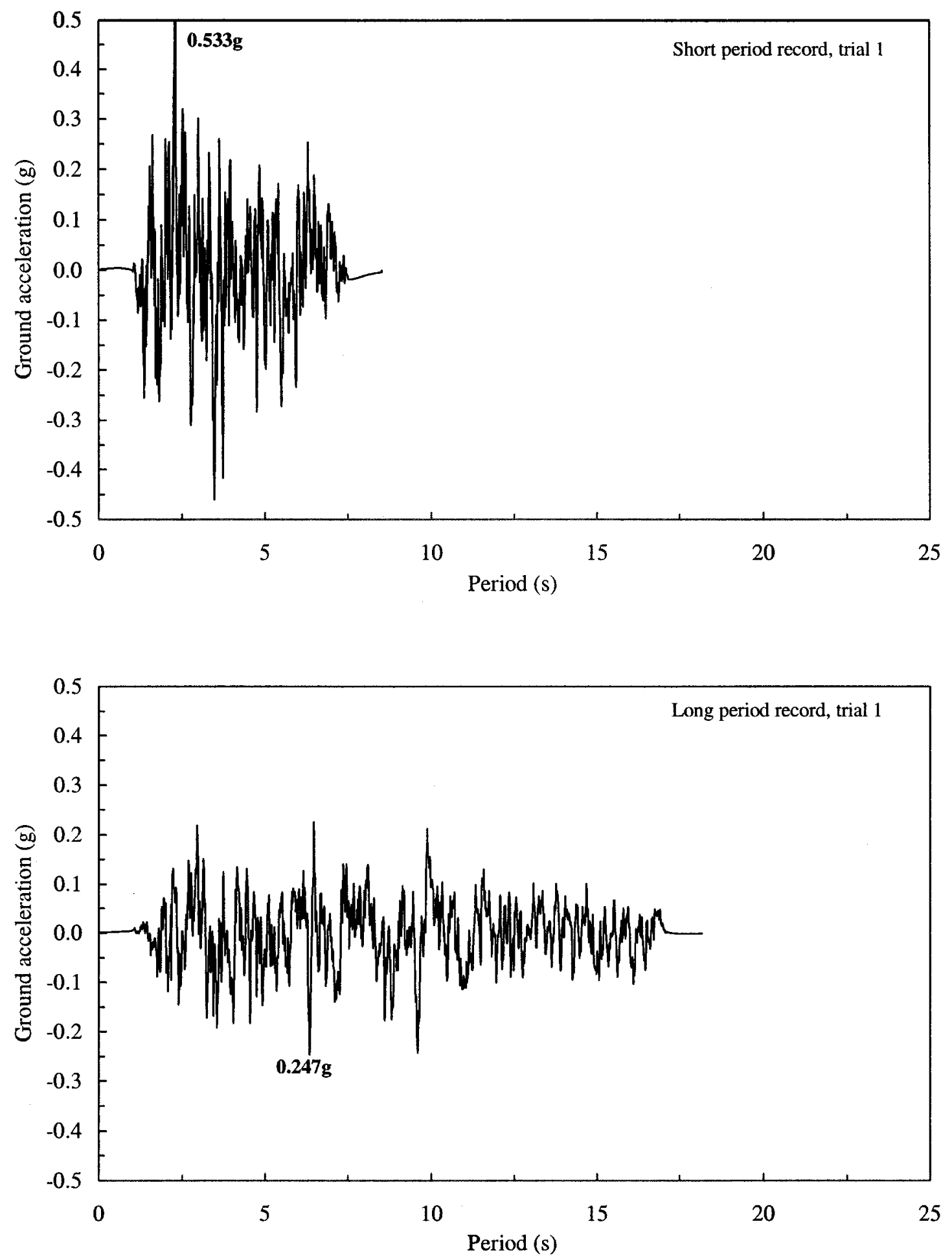

Fig. 4.1 The UHS compatible acceleration time histories used for Vancouver 

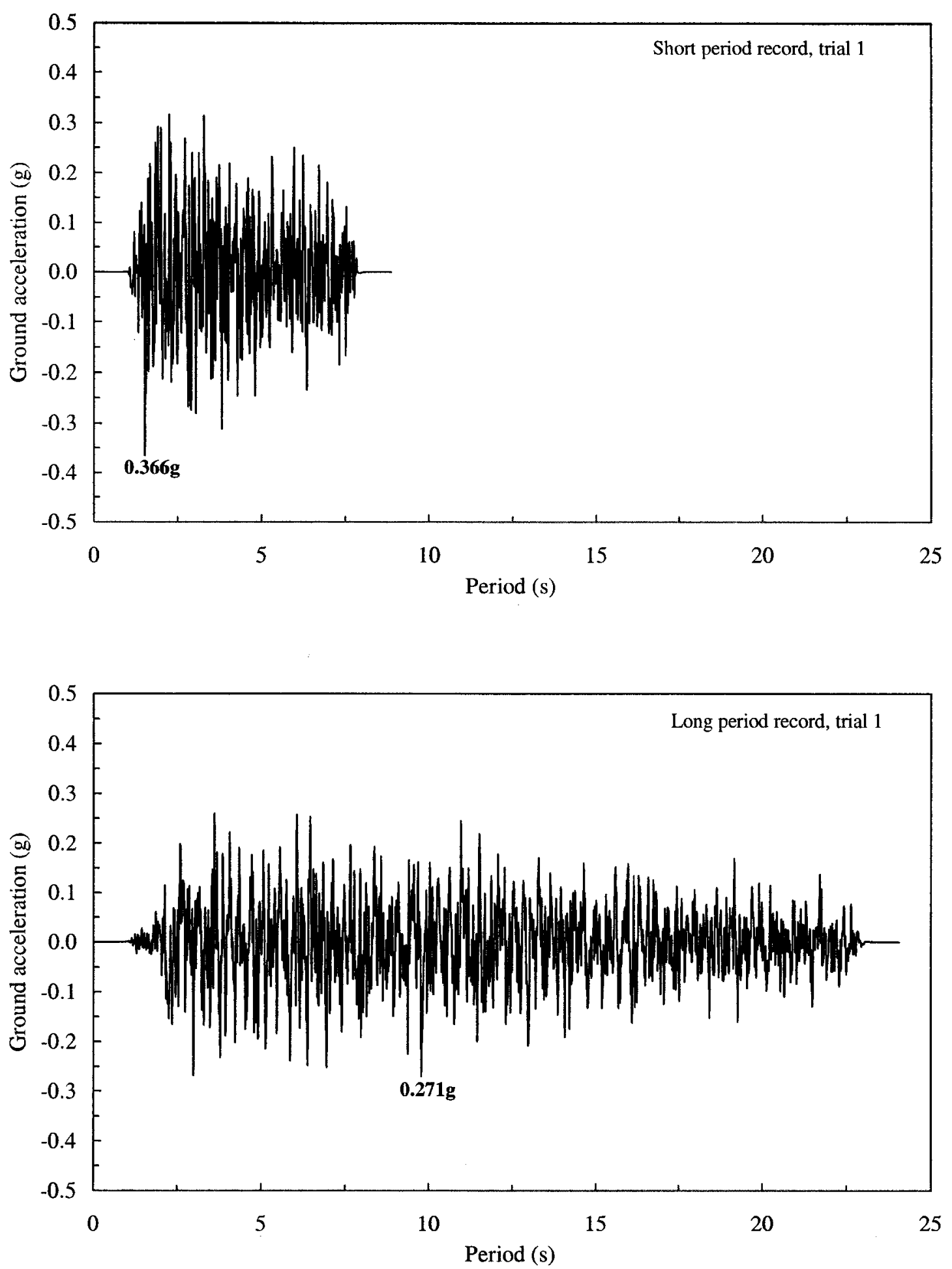

4.2 The UHS compatible acceleration time histories used for Montreal 

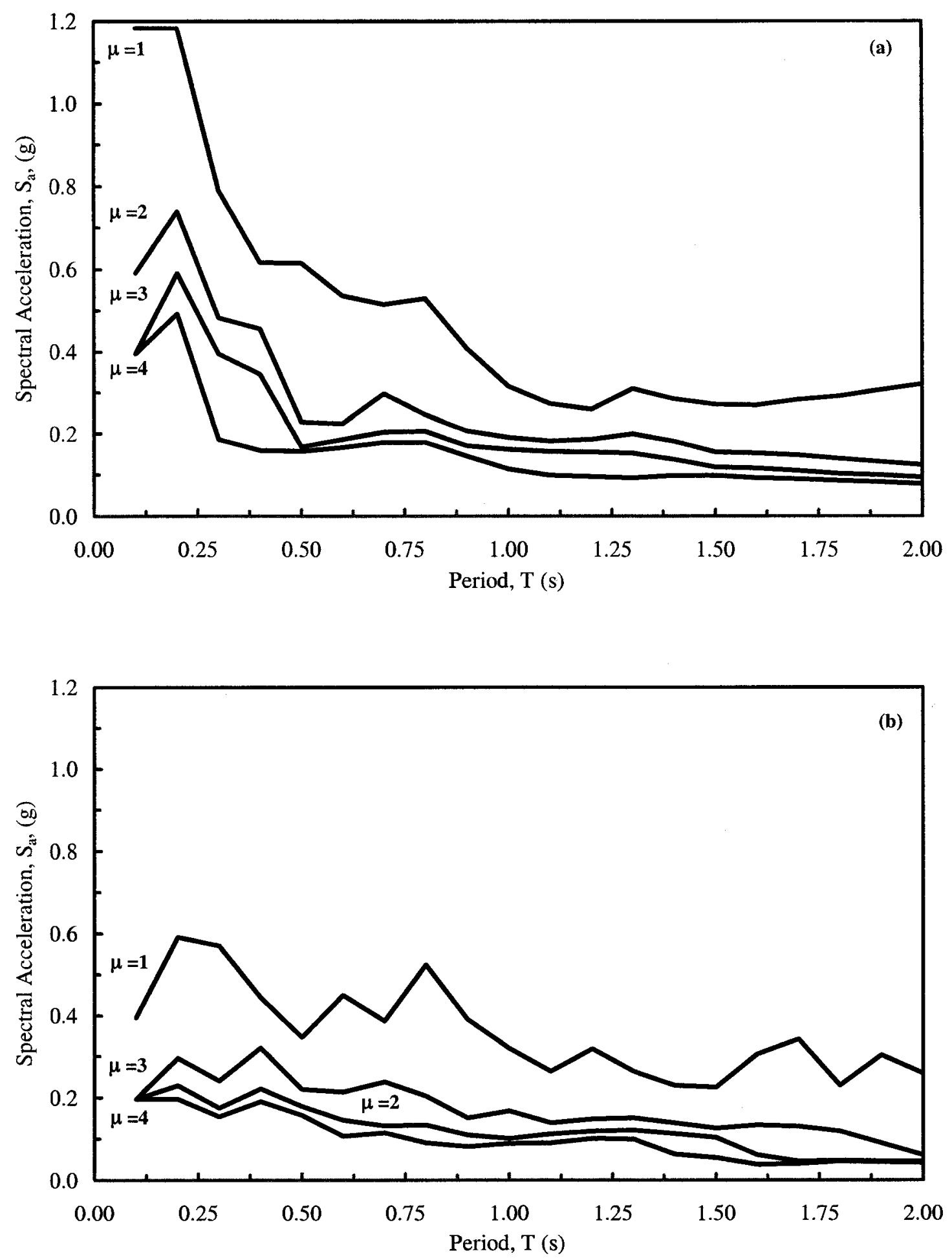

Fig. 4.3 Elastic and inelastic spectra for city of Vancouver $\begin{array}{ll}\text { (a) Short range records } & \text { (b) Long range record }\end{array}$ 

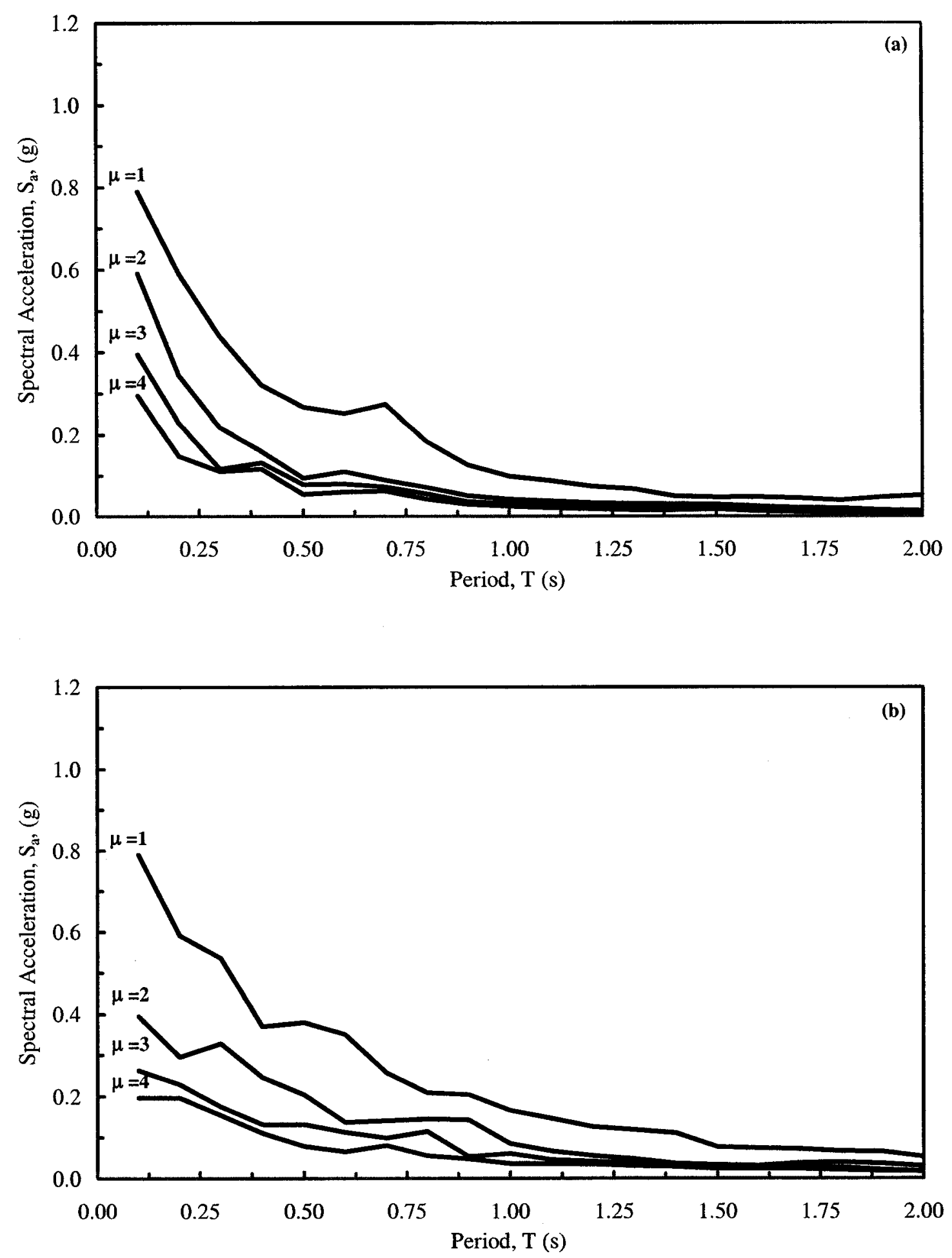

Fig. 4.4 Elastic and inelastic spectra for city of Montreal
(a) Short range records
(b) Long range record 


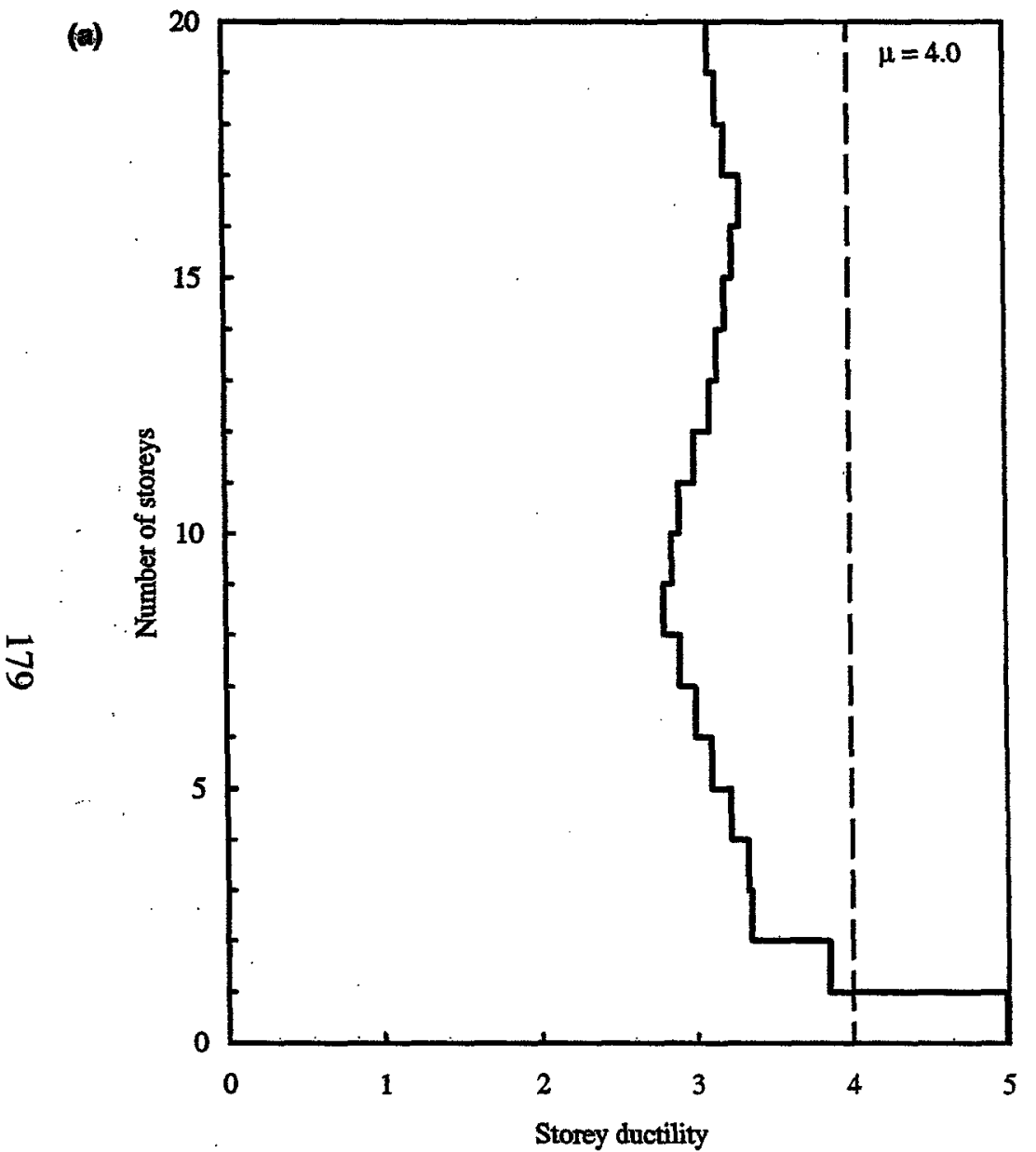

(b)

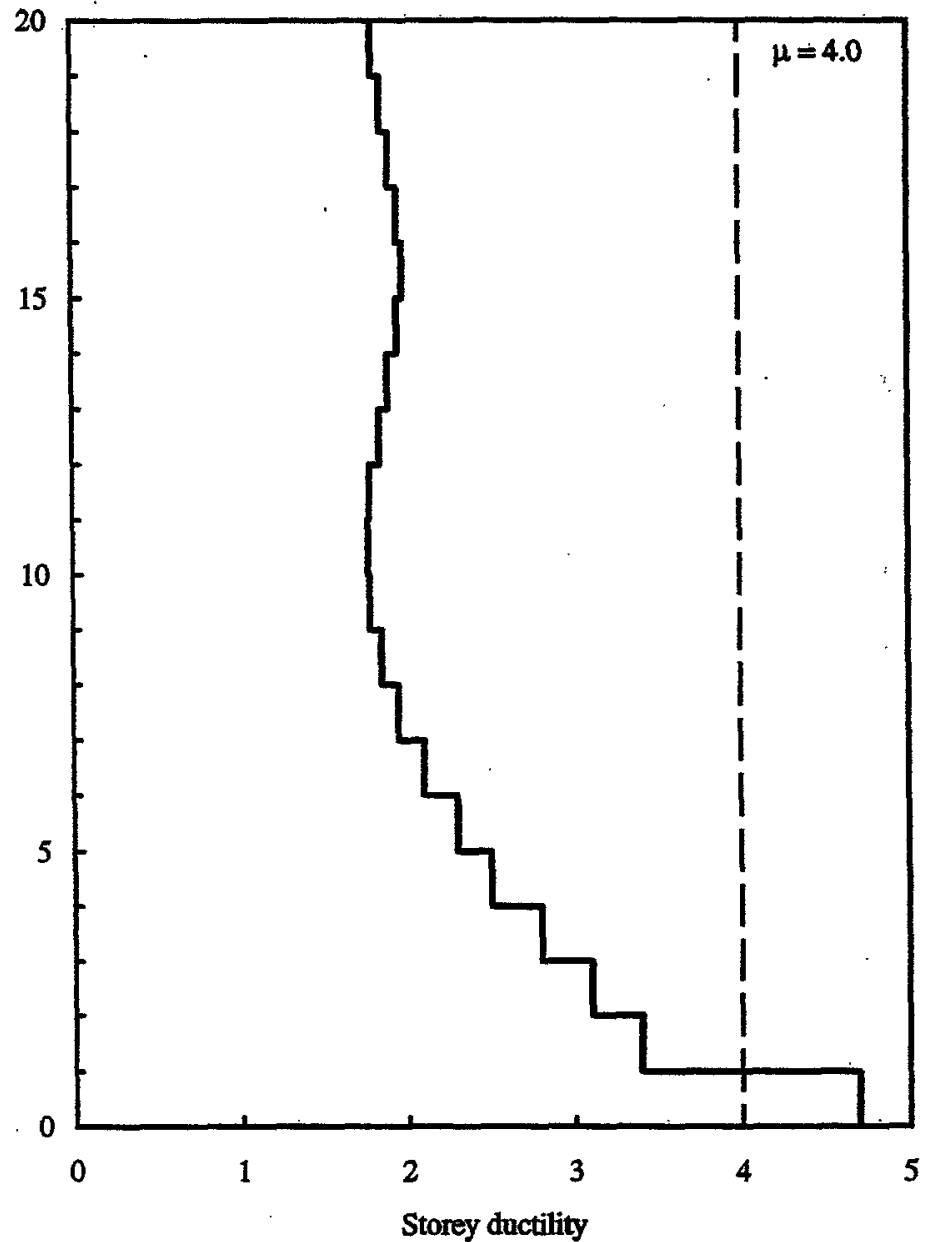

Fig. 4.5 Height wise storey ductility demands for a 20-storey MRF subjected to long period record with associated SDOF target ductility, $\mu=4.0$ (a) Located in East Canada (b) Located in West Canada 
(b)

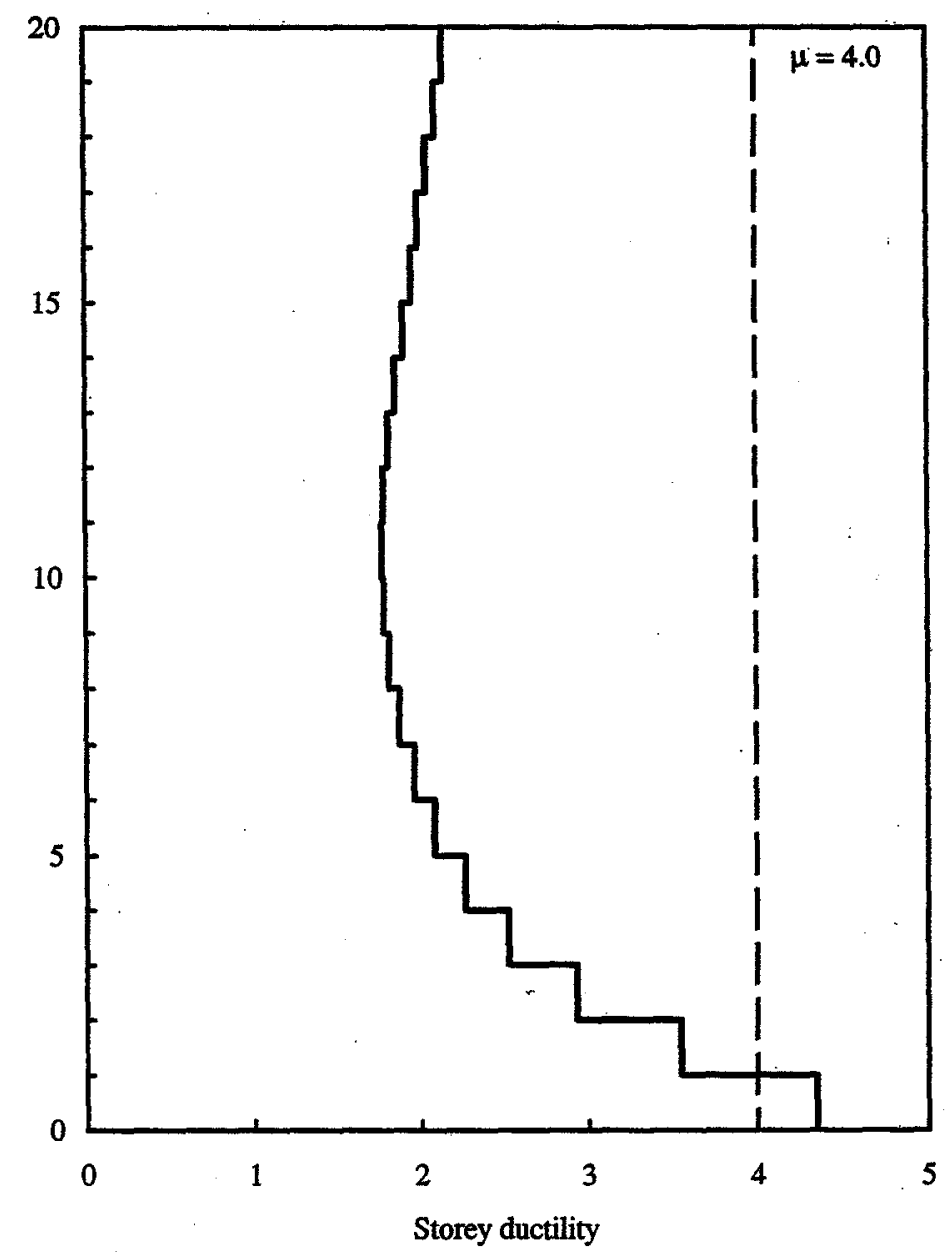

Fig. 4.6 Height wise storey ductility demands for a 20-storey flexural wall subjected to long period record with associated SDOF target ductility, $\mu=4.0$

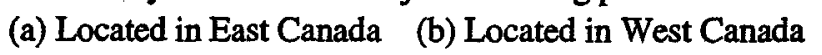



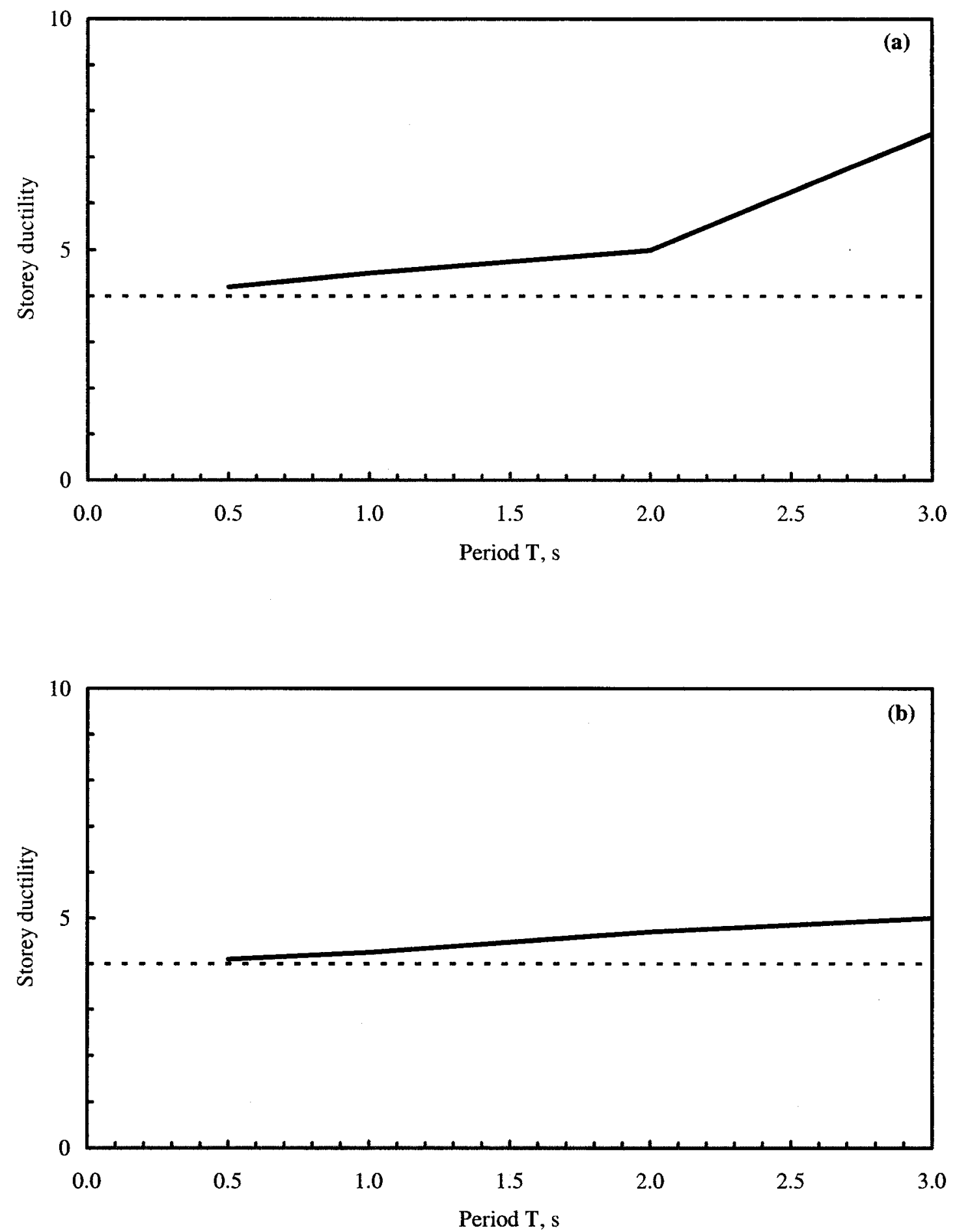

Fig. 4.7 Variation of first storey ductility demand with period for moment-resisting frame located in (a) Montreal (b) Vancouver 

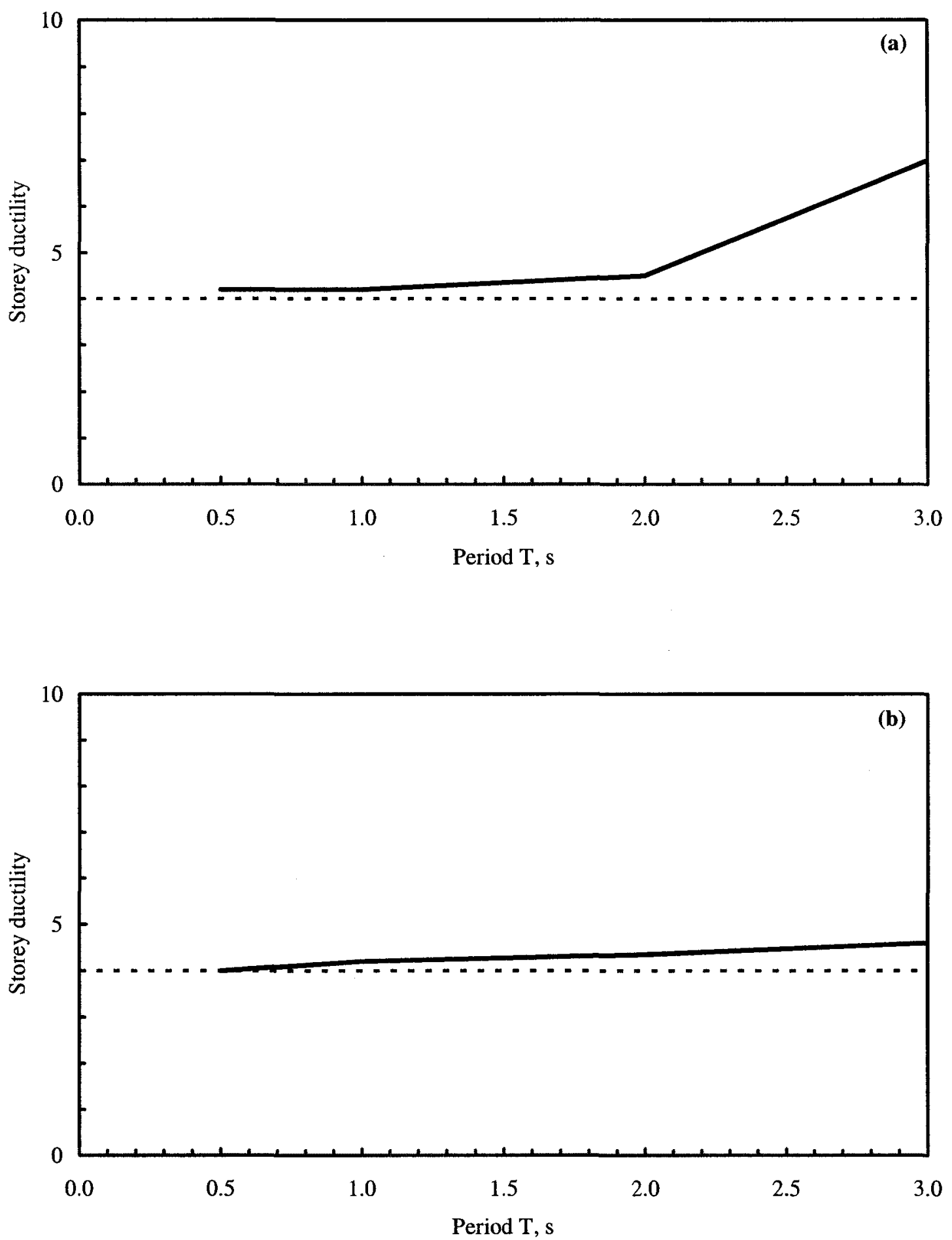

Fig. 4.8 Variation of first storey ductility demand with period for flexural wall located in (a) Montreal (b) Vancouver 

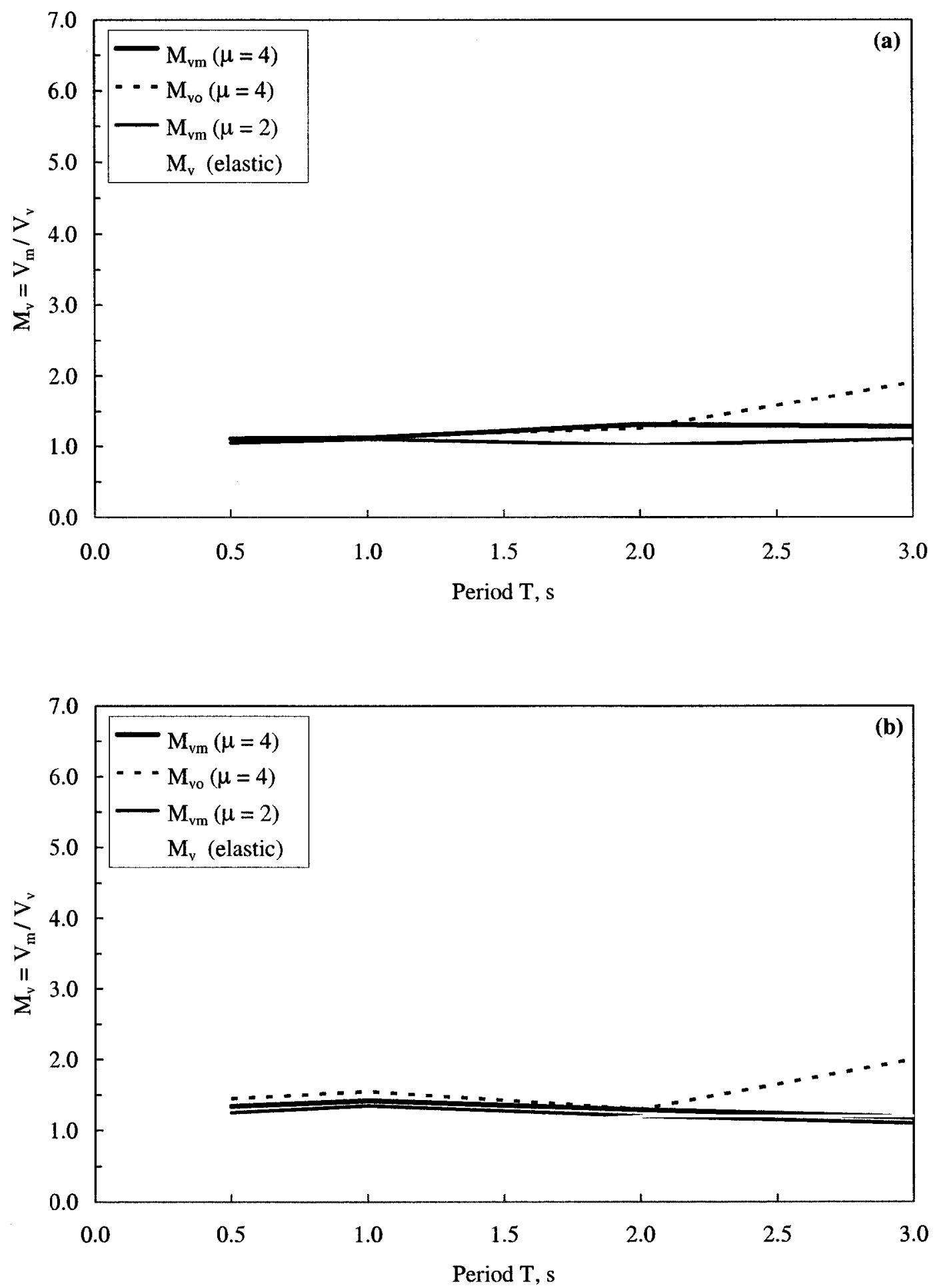

Fig. 4.9 Variation of $M_{v}, M_{v 0}$ and $M_{v m}$ factors with period for $\mu=2$ and 4 for a moment-resisting frame located in (a) Vancouver (b) Montreal 

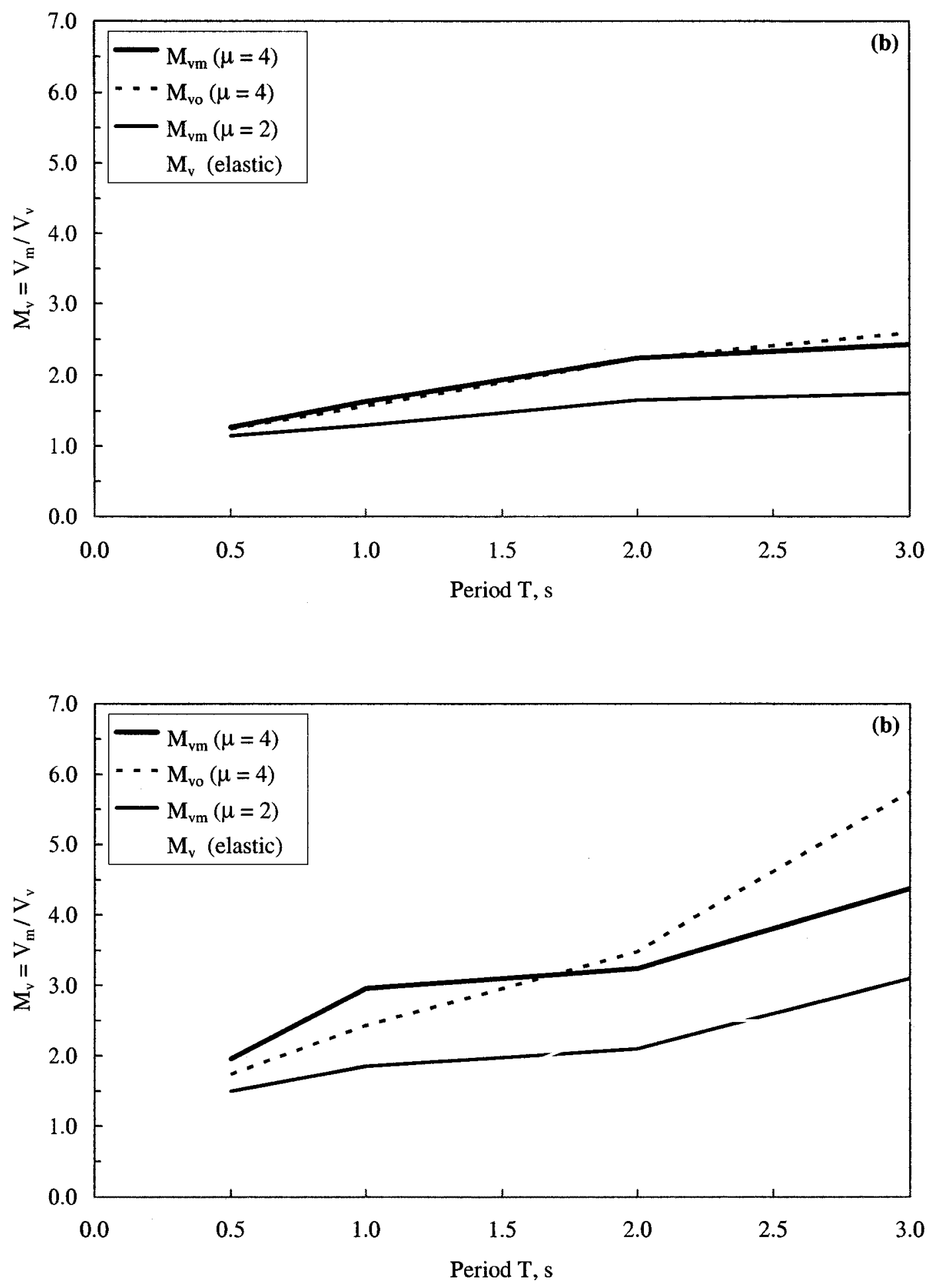

Fig. 4.10 Variation of $M_{v}, M_{v o}$ and $M_{v m}$ factors with period for $\mu=2$ and 4 for a flexural wall located in (a) Vancouver (b) Montreal 


\section{CHAPTER 5}

\section{P-A EFFECT ON SEISMIC RESPONSE}

\subsection{INTRODUCTION}

When a flexible building structure is subjected to lateral seismic force, the gravity loads acting through the lateral displacements lead to additional shears and moments throughout the entire structure. These additional shears and moments are caused by what is referred to as " P- $\Delta$ effect " and they tend to reduce the capacity of the structure to resist the seismic lateral forces.

A factor that governs the magnitude of $\mathrm{P}-\Delta$ effect is the lateral displacements induced in the structure by earthquake forces. Most buildings are designed to have a strength that is a fraction of the strength required to resist the forces derived from an elastic response spectrum. This implies that a building structure is expected to undergo inelastic deformation during the design earthquakes. If this deflection is excessive or if the gravity loads are large, $\mathrm{P}-\Delta$ effect may lead to instability in the structure.

Inelastic deformation causes damage to the structure. The level of damage should be kept within the capacity of the structure to sustain such damage without collapse. Various measures have been adopted to assess the damage level and the damage capacity. The simplest of these measures is the so-called ductility ratio, $\mu$ which is defined as the ratio of 
the total deformation, $\Delta_{i}$ to the yield deformation, $\Delta_{y}\left(\mu=\Delta_{i} / \Delta_{y}\right)$. The objective of the earthquake design is to determine the value of $V_{y}$ that will limit the ductility demand to within the ductility capacity.

The stability of the structure under elastic and inelastic deformations caused by earthquakes is a direct function of both the axial load and the lateral displacement. Stability considerations dictate that drift be controlled. As stated by several seismic code provisions including NBCC 1995, certain limits should be applied on calculated drifts. A stability problem is resolved by limiting the drift of vertical load carrying elements and the resulting secondary moments and shears produced by the axial loads and deflections (P- $\Delta$ effects). Under small lateral deformations, secondary stresses are normally within tolerable limits. However, buildings with heavy vertical loads and larger deformations can lead to significant secondary forces arising from $\mathrm{P}-\Delta$ effect. The drift limits provide an upper bound for such effects.

Strength and deformation capacities of elements and structures can be evaluated with reasonable confidence in the elastic range of response. However, excursions into the inelastic range of behavior complicate the process of calculating these ultimate capacities, and the maximum ductilities that can be developed. As inelastic behavior is relied upon to a greater extent in the dissipation of seismic input energy, the destabilization effect of gravity becomes more significant in structural design. In addition, advances in construction technology are allowing the fabrication of more slender structures than in the past, which may lead to increased lateral displacements. 
The foregoing discussion shows that it would be desirable to investigate the structure's behavior and to account for $\mathrm{P}-\Delta$ effect in order to enhance our understanding of the condition that may lead to collapse, and to insure public safety during extreme events.

\subsection{P- $\triangle$ BEHAVIOR}

Some basic concepts for characterizing the P- $\Delta$ effect in inelastic SDOF structures under lateral and gravity loads are described below, along with an overall view of the fundamental structural behavior. Figure 5.1 shows a single bay, single storey structure, with an infinitely stiff beam. The lateral stiffness of the structure, ignoring P- $\Delta$ effect is $K_{0}=24 E I / L^{3}$. The lateral load-displacement relationship for the structure is shown in Fig. 5.2. Elastic-perfectly plastic structural response (neglecting P- $\Delta$ effect) is assumed. The response modified by the influence of $\mathrm{P}-\Delta$ is also shown.

The most well known measure for P- $\Delta$ effect, in both SDOF and MDOF buildings is called stability factor, $\theta$. This factor is determined by the following equation:

$$
\theta=\frac{P_{x} \Delta_{e x}}{V_{x} H_{x}}
$$

where,

$P_{x}=$ the total vertical design load above level $x$; when calculating the vertical design load for purposes of determining $\mathrm{P}-\Delta$, the individual load factors need not exceed 1.0 .

$\Delta_{e x}=$ the elastic drift of storey $x$ occurring simultaneously with $V_{x}$.

$V_{x}=$ the storey shear force acting between level $x$ and $x-1$.

$H_{x}=$ the storey height below level $x$. 
Equation 5.1a is expressed in the following alternative form in NEHRP (2000).

$$
\theta=\frac{P_{x} \Delta_{x u}}{V_{x u} H_{x} C_{d}}
$$

where,

$\Delta_{x u}=$ the ultimate or design storey drift.

$V_{x u}=$ the storey shear occurring simultaneously with $\Delta_{x u}$.

$C_{d}=$ the deflection amplification factor.

It should be noted that according to the NEHRP provisions, the ultimate drift (design storey drift) at the shear $V_{x}$ is $C_{d}$ times the elastic drift in storey $x$. Thus, stability factor, $\theta$, in Eq. $5.1 \mathrm{~b}$ is based on the elastic drift and is equivalent to that given by Eq. 5.1a.

Stability factor, $\theta$, appears to be the most significant parameter affecting behavior. Analyses are carried out here on different building structures to more accurately quantify the impact of this factor in combination with other parameters, such as strength, stiffness, strain hardening, ductility, ground motion duration and frequency content of the ground motion.

\subsection{LITERATURE REVIEW}

As stated earlier, analyses have been carried out by many researchers to investigate the P- $\Delta$ effect on single storey and multistorey buildings. Paulay (1978) has examined the likely effects of secondary moments due to the gravity load as the structure is being laterally displaced during inelastic seismic response, by studying the response of 18-storey ductile reinforced concrete frames. He has suggested that if the strength demand due to P- $\Delta$ effect exceeds $15 \%$ of the ideal lateral load carrying capacity of a subframe, this strength demand 
should be met. Recommendations have been made for the estimation of critical inelastic drifts in the lower half of the frame.

Montgomery (1981) has studied the influence of P- $\Delta$ effects on the elastic and inelastic response of buildings subjected to earthquake ground motion. The results of the study, in which the stability factor approach was used for estimating the P- $\Delta$ effect, suggest that the response of certain types of well-designed buildings is not significantly influenced by P- $\Delta$ effects.

Bernal (1987) has investigated the inelastic P- $\Delta$ effect. Amplification factors to account for gravity-induced effects in inelastic dynamic response were computed. Some of the currently used P- $\Delta$ amplification factors were discussed in the light of the results obtained.

Three different amplification factors that have been proposed to account for P- $\Delta$ effects in the seismic design of multistorey building structures have been described and compared by Tremblay et al, (1999). Nonlinear dynamic analyses of a 20 -storey steel moment resisting frame were carried out under earthquake ground motions typical of eastern and western Canada to evaluate the gravity load effects, and to assess the effectiveness of each type of amplification factor in accounting for these effects. It was found that all three approaches maintained the ductility demand within the level computed without P- $\Delta$ effects, but lateral deformations were generally larger than those obtained neglecting the gravity loads. Nonlinear dynamic analyses were also performed on a shear beam model of the same building to examine the possibility of using such simple models for studying the dynamic stability of buildings subjected to ground motions. The shear beam model did not predict 
adequately the seismic behaviour of steel moment frame for which P- $\Delta$ effects are significant.

Gupta and Krawinkler (2000) have carried out inelastic dynamic analyses on various analytical models of 3,9 and 20 storey frame structures designed for different seismic conditions (Los Angeles, Seatle, and Boston). The buildings were subjected to sets of ground motions representing specific hazard levels. The main objectives of their study were:

(1) Illustrate $\mathrm{P}-\Delta$ sensitive behavior

(2) Identify structural and ground-motion characteristics that trigger $\mathrm{P}-\Delta$ sensitive response

(3) Demonstrate the sensitivity of predicted behavior to analytical modeling

(4) Contribute to the development of engineering guidelines for protection against excessive P- $\Delta$ effects.

\subsection{NBCC CODE PROVISIONS FOR DESIGN AGAINST P-A EFFECT}

As stated earlier in Chapter 2, the minimum design lateral seismic force at the base of the structure, $V$, according to the NBCC 1995 provisions is equal to:

$$
V=\left[\frac{V_{e}}{R}\right] U
$$

where, $V_{e}=v I S F W$ is the equivalent seismic force representing elastic response, $U$ is a calibration factor equal to 0.6 , and $R$ is the force modification factor. The $R$ factor reflects the ability of a structure to dissipate energy through inelastic behavior under severe ground shaking and varies from 1.0 for brittle lateral systems to 4.0 for ductile structures. The 
parameter $v$ is the zonal velocity ratio for the site, $I$ is the seismic importance factor, $S$ is the seismic response factor, $F$ is the foundation factor, and $W$ is the seismic weight. The $S$ factor is equal to $1.5 / \sqrt{T_{1}}$ for buildings with a fundamental period of vibration, $T_{l}$, equal to or longer than $0.5 \mathrm{~s}$. The seismic weight includes $100 \%$ of the dead load, $60 \%$ of the storage load, and $25 \%$ of the snow load.

The minimum lateral seismic force is assumed to correspond primarily to the response of the building in its fundamental mode of vibration. Therefore, the lateral inertia force, $F_{x}$, acting at any level, $x$, is given by

$$
F_{x}=\left(V-F_{t}\right)\left(\frac{W_{x} h_{x}}{\sum_{i=1}^{N} W_{i} h_{i}}\right)
$$

where, $N$ is the total number of storeys, $W_{x}$ is the seismic weight at the level under consideration, and $h_{x}$ is the height of that storey relative to the base of the structure. The lateral force, $F_{t}$ is a fraction of $V$, which is concentrated at the top of the structure to account for high vibration modes effects. This force is equal to $0.07 T_{1} V$, but needs not to exceed $0.25 \mathrm{~V}$ and may be neglected when $T_{l}$ is less than $0.7 \mathrm{~s}$. The storey shear force at a given storey, $V_{x}$, can then be determined by summing up the lateral forces acting at and above that storey.

The 1990 edition of the NBCC required that P- $\triangle$ effect be taken into account in the seismic design of buildings, but no practical methodology was proposed. Significant changes were introduced in NBCC 1995 to account for the P- $\triangle$ effect under seismic loading. 
Appendix $J$ to the NBCC 1995 User's Guide includes a procedure which is based on the assumption that multistorey buildings deform laterally in shear and that the storey shear, $V_{x}$, versus storey drift, $\Delta_{\mathrm{x}}$, relationship corresponds to that given in Fig. 5.2.

The design storey shear at any level is increased to account for the P- $\Delta$ effects, as given by

$$
V_{x}^{*}=V_{x}+\frac{P_{x} \Delta_{m x}}{h_{s x}}
$$

where, $h_{s x}$ is the storey height and $P_{x}$ is the total gravity load carried by the columns at level $x$, acting at and above the level under consideration. In the evaluation of $P_{x}$, the dead load factor is taken as 1.0 , while the live load factor is equal to 1.0 for storage and assembly occupancies and 0.5 for other live loads, including snow load. The live load may be reduced for large tributary areas. In Eq. 5.4, the storey drift, $\Delta_{\mathrm{mx}}$, is the maximum expected inelastic storey deflection, which is equal to $R$ times the elastic storey drift, $\Delta_{\mathrm{x}}$, computed under the prescribed lateral seismic forces. In Appendix J to the NBCC 1995 User's Guide, Eq. 5.4 is presented in the form:

$$
V_{x}^{*}=V_{x}\left(1+\theta_{N B C C}\right)
$$

and,

$$
\theta_{N B C C}=\frac{P_{x} \Delta_{m x}}{V_{x} h_{s x}}
$$

where, $\theta_{N B C C}$ is a stability factor which corresponds to the ratio of the second-order storey shear force to the seismic storey shear prescribed in the code. This factor has to be evaluated 
at each storey. The lateral load amplification factor corresponding to the NBCC seismic provisions, $\phi_{N B C C}$, is then equal to

$$
\phi_{N B C C}=1+\theta_{N B C C}
$$

The NBCC 1995 suggests that P- $\triangle$ effect can be neglected if the stability factor, $\theta_{N B C C}$, is less than 0.10 . On the other hand, it requires that the structure be stiffened if $\theta_{N B C C}$ exceeds 0.40 . It should be emphasized that $\theta_{N B C C}$ is based on the maximum inelastic displacement, while the parameter used in the studies presented here is a stability factor $\theta$ based on displacement and shear within the elastic range.

\subsection{OBJECTIVES}

In accounting for $\mathrm{P}-\Delta$ effect in buildings, significant uncertainties exist, these should be addressed and resolved. Some of the issues addressed in this study are:

(1) Assess the significance of P- $\Delta$ effect in buildings subjected to earthquakes.

(2) Investigate the effect of strength and stiffness on P- $\Delta$.

(3) Investigate the effect of strain hardening, ductility and ground motion duration and frequency content on $\mathrm{P}-\Delta$.

(4) Develop a method to account for $\mathrm{P}-\Delta$ effect in buildings.

\subsection{MODEL AND ANALYSIS PROCEDURES}

In order to analytically predict the nature of $\mathrm{P}-\Delta$ effect in buildings, a simple and practical model that would represent the behaviour of a real frame is needed. The selected 
model is a simple shear frame as shown in Fig. 5.1, which is subjected to a lateral load $V$ and gravity loads $P / 2$ applied vertically along each column. The lateral storey stiffness is $K_{0}$. The plastic moment capacity of the column cross section is $M_{p}$. Plastic hinges will form simultaneously at the top and bottom of each column when the lateral load reaches $V_{y 0}=4 M_{p} / H$, where $H$ is the storey height.

In the analysis several assumptions are made concerning the loading and mass of the selected frame:

(a) The frame is free to translate in the transverse direction.

(b) The beam-column joints are assumed to be rigid.

(c) The tributary mass is lumped at the top of each column of the model.

(d) Each frame member is modelled using only a beam-column element. Nodal points of the structure are located at the intersections of the element centre lines.

(e) For simplicity, the analysis is restricted to the effect of gravity and seismic loads. Other design and operational loads, such as thermal effect, pressure, wind loading or the effects of various combinations are also expected to affect the performance of the frame structure. However, the effect of these loads is beyond the scope of the present research.

(f) The distributed gravity loads are modelled as being concentrated loads applied to the nodes at the beam-column joints. This has no effect on the response when the beam is considered as being infinitely stiff.

Computer program DRAIN-2DX (Prakash and Powell, 1993) is used in carrying out 
the inelastic two-dimensional static and dynamic analyses.

The load deflection relationship considered in the analysis is a straight line with a slope of $K_{0}$ until the deflection reaches $\Delta_{y 0}=V_{y 0} / K_{0}$. Beyond this the shape will depend on the amount of strain hardening. If there is no strain hardening the load deflection relationship is a horizontal straight line. The entire load deflection relationship is shown by curve $a$ in Fig. 5.3. P- $\Delta$ effect occurs when the gravity loads shown in Fig. 5.1 alter the shape of the load deflection relationship. The altered shape of the load deflection relationship is shown by curve $b$ in Fig. 5.3. The slope of the initial straight line is altered to $K_{0}(1-\theta)$, where the stability factor, $\theta=P / H K_{0}$. This definition is similar to the one used in NEHRP (2000). The lateral load corresponding to yield is reduced to $V_{y 0}(1-\theta)$, but the yield deflection remains unaltered. The post-yield stiffness is now negative and is given by $-K_{0} \theta$. Although a negative stiffness does not necessarily cause instability in a system subjected to dynamic loads arising from seismic action, it makes the system vulnerable to such instability. This vulnerability increases if the system is strained far into the post-yield range and the earthquake motion is of long duration.

To compensate for the P- $\Delta$ effect one may increase the strength without changing the stiffness. If we increase the strength to $V_{y 1}=V_{y 0} /(1-\theta)$, the revised load deflection relationship taking $\mathrm{P}-\Delta$ effect into account will be as shown by curve $\mathrm{c}$ in Fig. 5.3. The yield load has now been restored to $V_{y 0}$. The yield displacement increases to $\Delta_{y 0} /(1-\theta)$. The post-yield stiffness is still negative; however, because the system excursion into the post- 
yield region will now be reduced, it may be less vulnerable to instability.

An alternative way of compensating for $P-\Delta$ effect is to increase the stiffness without changing the strength. Let the increased stiffness be $K_{l}$, and let us assume that $K_{l}$ is selected such that after taking into account the P- $\Delta$ effect it reduces to the original stiffness $K_{0}$. We now have

$$
\begin{aligned}
& K_{1}\left(1-\theta_{1}\right)=K_{0} \\
& K_{1}\left(1-\frac{P}{H K_{1}}\right)=K_{0} \\
& K_{1}=K_{0}+\frac{P}{H}=K_{0}(1+\theta)
\end{aligned}
$$

It is easily shown that

$$
\theta_{1}=\frac{\theta}{1+\theta}
$$

The load deflection relationship taking P- $\Delta$ effect into account is now as shown by curve $c$ in Fig. 5.4. The initial stiffness is $K_{0}$ and the post-yield stiffness is $-K_{1} \theta_{1}=-K_{0} \theta$. However, the yield strength is always less than the original strength. Thus

$$
V_{y 1}=\frac{V_{y 0}}{1+\theta}
$$

We may elect to compensate for P- $\Delta$ effect by increasing both the strength and the stiffness. It may be noted that this is a more realistic scenario. As shown by Paulay (1998), 
for reinforced concrete elements the stiffness is more or less proportional to strength, so that an increase in strength automatically results in a proportionate increase in stiffness. For steel sections also, the selection of a section with higher strength will also in general result in an increase in the stiffness. A possible selection for increased strength and stiffness is as follows:

$$
\begin{aligned}
& K_{1}=K_{0}(1+\theta) \\
& V_{y 1}=V_{y 0}(1+\theta)
\end{aligned}
$$

so that

$$
\frac{V_{y 1}}{K_{1}}=\frac{V_{y 0}}{K_{0}}=\Delta_{y 0}
$$

The revised load deflection relationship is now shown by curve $c$ in Fig. 5.5. The initial stiffness and yield load have both been restored to their original values; however, the postyield stiffness is still negative.

The curves in Figs. 5.3 through 5.5 have been obtained by a push over analysis using program DRAIN-2DX (Prakash and Powell, 1993). The data used in the analysis are as follows: $H=4 \mathrm{~m}, K_{0 . .}=24,375 \mathrm{kN} / \mathrm{m}, M_{p}=450 \mathrm{kN} \mathrm{m}$, which gives $V_{y 0}=450 \mathrm{kN}$, and $P=9,750 \mathrm{kN}$. The stability factor works out to $\theta=0.1$.

Our primary interest is to examine the effect of $\mathrm{P}-\Delta$ on the response of the structure to an earthquake ground motion. For this purpose, the floor mass in Fig. 5.2 is selected as 154.36 tonne. This gives a vibration period of $0.5 \mathrm{~s}$ not considering the $\mathrm{P}-\Delta$ effect. The latter 
softens the structure, reducing the lateral stiffness to $K_{0}(1-\theta)=21,938 \mathrm{kN} / \mathrm{m}$ and increasing the period to $0.527 \mathrm{~s}$. The force displacement relationship for the frame is elasto-plastic with a yield displacement $\Delta_{\mathrm{y}}=0.01846 \mathrm{~m}$. The frame is subjected to the $1940 \mathrm{El}$-Centro ground motion. The history of the lateral displacement of the frame for the first 40 seconds is shown in Fig. 5.6, in which curve $a$ shows the response without taking the P- $\Delta$ effect into account while curve $b$ shows the response when P- $\Delta$ effect has been considered. For the purpose of comparison the elastic response is shown by curve $c$. If the frame remains elastic it vibrates about its position of rest and returns to its undeformed state when the ground motion ceases. On the other hand, as seen from curve $a$ the elasto plastic frame drifts away from its initial position and vibrates about a displaced configuration, so that even when the ground motion has ceased the frame does not return to its initial position and a residual displacement remains. This tendency to ratchet is increased in the presence of P- $\Delta$ effect. The displacement continues to increase, and if the ground motion persists, the frame will become unstable.

It may be noted as a matter of interest that the maximum displacement in the elastic response is $0.0607 \mathrm{~m}$. For the ealsto-plastic system without P- $\Delta$ effect the maximum displacement is $0.0463 \mathrm{~m}$. The ductility demand is given by $0.0463 / 0.0185=2.51$.

\subsection{EFFECT OF STRAIN HARDENING}

As stated earlier, a negative post-yield stiffness makes the system vulnerable to instability in the presence of P- $\Delta$ effect. This may be mitigated to some extent if the forcedisplacement relationship for the structure has a positive slope in the post-yield region in the 
absence of $\mathrm{P}-\Delta$, as would be the case when the material exhibits strain hardening. The usual practice to account for strain hardening is to assume that the force-displacement relationship is bilinear with the slope of the post-yield branch being a certain percent of the initial slope. The force-displacement relationships for the frame of Fig. 5.2 with a strain hardening modulus $20 \%$ of the initial elastic modulus are shown in Fig.5.7, in which curve $a$ shows the relationship without considering P- $\Delta$ and curve $b$ that with $\mathrm{P}-\Delta$.

Now suppose that the maximum displacement in the frame is $\mu \Delta_{y o}$, where $\mu$ is defined as the ductility ratio. To offset the effect of $\mathrm{P}-\Delta$ we increase both the stiffness and the strength, such that at the maximum displacement of $\mu \Delta_{y o}$ the strengthened frame has the same resistance in presence of $\mathrm{P}-\Delta$ as the original structure without $\mathrm{P}-\Delta$. We assume that Eq. 5.12 is satisfied. It is then easily shown that

$$
V_{y 1}=V_{y 0} \frac{1+(\mu-1) \alpha+\theta \mu}{1+(\mu-1) \alpha}
$$

where $\alpha K_{0}$ is the slope of the post yield branch of force displacement relationship. The force displacement relationship with the enhanced strength and stiffness is shown by curve $c$ in Fig. 5.7. With $\alpha=0.2, \theta=0.1$, and $\mu=3$ we have $V_{y l}=1.214 V_{y 0}$. Also the resistance at $\mu \Delta_{y o}$ is $1.4 V_{y 0}$.

As an alternative, we may leave the stiffness unchanged but increase the strength such 
that in the presence of P- $\Delta$ the resistance at a displacement of $\mu \Delta_{y o}$ is the same as that without the P- $\Delta$ effect for the original frame but with the unchanged strength. In this case

$$
\Delta_{y 0}=\frac{V_{y 0}}{K_{0}}, \quad \Delta_{y 1}=\frac{V_{y 1}}{K_{0}}, \quad \frac{\Delta_{y 1}}{\Delta_{y 0}}=\frac{V_{y 1}}{V_{y 0}}
$$

and we can show that

$$
V_{y 1}=V_{y 0} \frac{1-\alpha+\mu \theta}{1-\alpha}
$$

With the values of various parameters previously specified, we get $V_{y l}=1.375 V_{y 0}$. The new force displacement relationship including the P- $\Delta$ effect is now shown by curve $d$ in Fig. 5.7 . When $\theta>\alpha$, the second branch of the force displacement relationship will have a negative slope. Again, we increase both the strength and stiffness, and require that a displacement of $\mu \Delta_{y}$ the strengthened frame has the same resistance in presence of $\mathrm{P}-\Delta$ as the original structure without $\mathrm{P}-\Delta$. The increased strength is still given by Eq. 5.13. However, if we may consider it sufficient to ensure that at a displacement of $\mu \Delta_{y}$ the resistance of the strengthened frame in the presence of P- $\Delta$ is equal $V_{y 0}$, then

$$
V_{y 1}=V_{y 0} \frac{1+\theta \mu}{1+(\mu-1) \alpha}
$$


A complete study of the effect of strain hardening on P- $\Delta$ with different ground motions is presented in Section 5.11.

\subsection{COMPENSATING FOR P-A EFFECT, EXAMPLES}

Consider the frame of Fig. 5.1 and assume that there is no strain hardening unless stated otherwise. As seen from Fig. 5.6 without any strengthening the frame is likely to become unstable when subjected to the El-Centro earthquake. We now use different strategies for the strengthening of the frame.

\section{Example1}

In this case we increase the strength to $V_{y 1}=V_{y 0} /(1-\theta)=450 / 0.9=500 \mathrm{kN}$ without changing the stiffness. Note that the presence of P- $\Delta$ effect changes the period to $0.527 \mathrm{~s}$ and the damping to $5.27 \%$. The displacement response to El-Centro is now as shown by curve $c$ in Fig. 5.8. As before curve $a$ shows the response of the original frame without $P-\Delta$ and curve $b$ shows the response of the original frame with $\mathrm{P}-\Delta$. Strengthening has improved the response, still a marked ratcheting effect is present and instability is likely.

\section{Example 2}

We increase the stiffness as given by Eq. 5.8, but do not change the strength. The revised stiffness is $26,813 \mathrm{kN} / \mathrm{m}$. The stability factor changes to $P /\left(K_{l} H\right)=0.0909$, and with P- $\Delta$ effect the stiffness reduces back to $24,375 \mathrm{kN} / \mathrm{m}$. Thus both the period and the damping 
remain unchanged at $0.5 \mathrm{~s}$ and $5 \%$, respectively. The response of the strengthened frame to El-Centro is shown by curve $c$ in Fig. 5.9. In comparison to the response of original frame shown by curve $b$, the strengthened frame shows an improved response, but there is still significant ratcheting and a likelihood of instability. In fact, the response is worse than that of the frame with an increase in strength without changing the stiffness. The fact that the damping in the latter is $5.27 \%$ and the period is $0.527 \mathrm{~s}$ may explain this observation. In general, an improvement in stiffness does not necessarily have a beneficial effect.

\section{Example 3}

In this case we increase both the stiffness and the strength according to Eq. 5.11. The revised values are $26,813 \mathrm{kN} / \mathrm{m}$ and $495 \mathrm{kN}$, respectively. The response of the strengthened frame to El-Centro is shown by curve $c$ in Fig. 5.10. In comparison to the response of original frame shown by curve $b$ the strengthened frame shows an improved response, but there is still significant ratcheting and a likelihood of instability. In fact, the response is about the same or worse than that of the frame with an increase in strength without changing the stiffness.

\section{Example 4}

In this example, we leave the stiffness and strength unchanged at $24,375 \mathrm{kN} / \mathrm{m}$ and $450 \mathrm{kN}$, respectively. However, we assume that the force displacement relationship shows 
strain hardening effect, with the slope of the second branch being $10 \%$ of that of the initial branch. The response without P- $\Delta$ is shown by curve $a$ in Fig.5.11, while that with P- $\Delta$ effect is shown by curve $b$. The latter curve is almost identical to the curve $a$ in Fig. 5.6. This is because in the inelastic range the slope of the strain hardening branch is compensated exactly by the stability factor, that is, $\alpha-\theta=0$, so that the second branch becomes a horizontal straight line similar to that in the elasto plastic case represented by curve $a$ in Fig. 5.6. The presence of strain hardening reduces the possibility of instability, as long as the second branch does not have a negative slope, that is when $\alpha$ is equal to or greater than $\theta$.

\section{Example 5}

As another example, consider the case when the force displacement relationship is elasto plastic, but the strength and stiffness are both enhanced according to Eq. 5.13. With $\alpha=0$, and $\mu=3$ we get $V_{y l}=1.3 V_{y}$, and $K_{1}=1.3 K_{0}$. The response without P- $\Delta$ and no enhancement is shown by the curve $a$ in Fig. 5.12 and is identical to that shown in Fig. 5.6, curve $a$. The response with enhanced strength and stiffness and including P- $\Delta$ is shown by curve $b$ in Fig. 5.12, and is not much different from that of the original frame with no P- $\Delta$. The enhanced strength and stiffness have made the response quite satisfactory.

\section{Example 6}

In this example we assume that the frame possesses strain hardening and the slope of 203 
the second branch is $5 \%$ of that of the first branch. Thus $\alpha=0.05$. The stability factor is still 0.1 , hence in the presence of $\mathrm{P}-\Delta$ the slope of the second branch will become negative. The response without $\mathrm{P}-\Delta$ is shown by curve $a$ in Fig. 5.13 , while that with $\mathrm{P}-\Delta$ is shown by curve $b$. The negative slope of the second branch has increased the tendency for ratcheting. The strength and stiffness are both increased according to Eq. 5.16. The revised response including P- $\Delta$ effect is shown by curve $c$. The response has improved, and is in fact close to that of the elasto plastic system without P- $\Delta$ shown by curve $a$ in Fig. 5.6. For comparison curve $a$ of Fig. 5.6 is re-plotted in Fig. 5.14. Also shown in that figure is the response curve $c$ of Fig. 5.13.

\subsection{EFFECT OF DUCTILITY}

To find the effect of ductility on P- $\Delta$, time history dynamic analysis are carried out using DRAIN-2DX (Prakash and Powell, 1993) for the frame of Examples 1 through 4 with selected values of strengths. The strength, $V_{y 0}$ is selected to be: $300,350,400,450,500$ and $550 \mathrm{kN}$ respectively. An elasto-plastic force displacement relationship is considered. The stability factor, $\theta$ is assumed to be 0.1 and the frame stiffness $K_{0}$, is assumed to be $24,375 \mathrm{kN} / \mathrm{m}$. The frame with the new strength is then subjected to one of the following five different earthquake ground motions (Naumoski et al 1988):

\section{(a) High A/V ratio}

Parkfield, California, USA. 27 June, 1966. 
Helena, Montana, USA. 31 October, 1935

\section{(b) Medium A/V ratio}

El-Centro, California. USA. 18 May, 1940

Kern County, California. USA 21 July, 1952

Monte Negro, Yugoslavia. 15 April, 1979

Using dynamic analysis and iterative procedure each ground motion is scaled so as to produce a ductility demand in the original frame, with a lateral strength of $450 \mathrm{kN}$, equal to 3.0 without including P- $\Delta$ effect. The scale factors are shown in Table 5.1. Once the target ductility is achieved, dynamic analysis is performed for the scaled ground motion with $P-\Delta$ effect included.

For Montana 1935 ground motion, Figures 5.15 through 5.18 show the history of the lateral displacement of the frame for strength, $V_{y 0}$ of $300,350,400$, and $500 \mathrm{kN}$. In all the figures, curve $a$ shows the original frame without P- $\Delta$ effect, while curve $b$ shows the original frame with P- $\Delta$ effect. The response of the frame with a modified strength (modified ductility) is shown by curve $c$.

As seen from Fig. 5.15 relating to the frame with strength, $V_{y 0}=300 \mathrm{kN}$ and unchanged stiffness, $K_{0}=24,375 \mathrm{kN} / \mathrm{m}$, the ductility increase results in the collapse of the original frame. At strength, $V_{y 0}=350$ and $400 \mathrm{kN}$, the response of the frame becomes more vulnerable compared to its response when $V_{y 0}=450 \mathrm{kN}$, as shown in Figs. 5.16 and 5.17. When the strength, $V_{y 0}$ is increased further (i.e. the ductility is decreased), the response of the 
frame is improved as seen from Fig. 5.18. Similar results were obtained when the analyses were repeated with stiffness increased from $K_{0}$ to $K_{I}=K_{0}(1+\theta)$. However, the results have not been presented here.

Table 5.1 presents the values of ductility factor, $\mu$ for the five different earthquake ground motions stated above and for the different strength values. The P- $\Delta$ effect causes collapse in many cases. This is indicated by the notation N/A in Table 5.1. It may be observed that, in general, lower strength, which is expected to result in higher ductility, makes the structure more vulnerable to instability through $\mathrm{P}-\Delta$ effect. This is to be expected, because longer excursion into inelastic range would increase the chance of ratcheting. However, several anomalous results can be observed in Table 5.1. As an example, for the El-Centro motion an improvement in the strength (with an expected reduction in ductility demand), in fact, makes the system more vulnerable to instability. The effect of P- $\Delta$ and changed strength alter the characteristics of the structure. The inelastic response depends on the details of the ground motion and on the characteristics of the structure, in some cases leading to increased ratcheting even as the strength is increased as shown in Fig. 5.19 when the original frame is subjected to E1-Centro ground motion.

One conclusion that could be drawn from this is that when the post-yield stiffness is negative because of P- $\Delta$ effect, the system becomes very sensitive the nature of earthquake and is always vulnerable to instability. In general, an improvement in the strength would be expected to lead to smaller ductility demand and a reduced tendency for instability, but such 
increased strength does not guarantee a stable behavior.

\subsection{EFFECT OF GROUND MOTION DURATION}

To assess the effect of duration of ground motion, the El-Centro ground motion was placed back-to-back forming an augmented earthquake. The response of the original frame with an elasto-plastic force displacement relationship to the modified ground motion was obtained and is shown in Figs. 5.20, 5.21, and 5.22. Curve $a$ shows the original frame without P- $\Delta$ effect, and curve $b$ shows the original frame with P- $\Delta$ effect, while curve $c$ shows the frame with increased strength, or increased stiffness, or increased strength and stiffness. It is observed from the figures that the P- $\Delta$ effect has caused the frame to collapse after 56 seconds in all cases. This proves that $\mathrm{P}-\Delta$ effect becomes more significant with longer duration earthquakes. This is because when a system starts to ratchet, its displacement keeps on increasing in one direction with continued exposure to ground motion, eventually leading to collapse if the earthquake lasts long enough.

A frame similar to the original frame but with a strain hardening ratio, $\alpha=10 \%$ and no increase in stiffness and ductility is then studied. Figure 5.23 shows that this frame is less vulnerable to instability when subjected to augmented long El-Centro earthquake. Curve $a$ in Fig. 5.23 shows the frame without P- $\Delta$ effect, and curve $b$ shows the frame with P- $\Delta$ effect. The latter curve is almost identical to the curve $a$ in Figs. 5.20, 5.21, and 5.22 which show the response of the original frame with no P- $\Delta$ effect. This is because in elastic range the 
slope of the strain hardening branch is compensated exactly by the stability factor as $\alpha-\theta=0$. The second branch becomes a horizontal straight line similar to that in the elastoplastic case represented by curve $a$ in Fig. 5.20. The presence of strain hardening reduces the possibility of instability, as long as the second branch does not have a negative slope, that is when $\alpha$ is equal to or greater than $\theta$.

The same back-to-back El-Centro ground motion is applied to both the original frame model with an elasto-plastic relationship and the same frame strengthened according to Eq. 5.13. The use of proposed Eq. 5.13 to increases the strength, and hence the stiffness, enhances the performance of the frame compared to the frames whose strength or stiffness or both are increased according to the procedure described in Eqs. 5.8, 5.9 and 5.10. Although the frame whose strength is enhanced according to Eq. 5.13 has experienced a significant amount of ratcheting, it does not collapse and its behavior has improved as shown in Fig. 5.24. In the figure, curve $a$ shows the original frame without $\mathrm{P}-\Delta$ effect while curve $b$ shows the enhanced frame with P- $\Delta$ effect and $V_{y l}=1.3 V_{y 0}$ and $K_{I}=1.3 K_{0}$.

Similar findings are reached when applying the proposed Eq. 5.16 on a frame model similar to the original frame but with a strain hardening ratio, $\alpha=5 \%$. The performance of the enhanced frame has improved as shown in Fig 5.25. In that figure, the response of the frame without P- $\Delta$ and with a strain hardening ratio, $\alpha=5 \%$, is shown by curve $a$, while that with P- $\Delta$ and $\alpha=5 \%$ is shown by curve $b$. The response of the strengthened frame including $\mathrm{P}-\Delta$ is shown by curve $c$. As shown earlier for the enhanced frame, considering $\alpha=5 \%$, and $\mu=3$ we get $V_{y l}=1.182 V_{y}$, and $K_{1}=1.182 K_{0}$. It can be observed that by strengthening the 
frame according to the proposed Eq. 5.16 the performance of the frame has significantly improved and the frame does not collapse. On the other hand, without a strength improvement, the original frame collapses under P- $\Delta$ effect as shown by curve $b$.

\subsection{EFFECT OF STRAIN HARDENINIG WITH DIFFERENT GROUND MOTIONS}

To assess the effect of strain hardening on P- $\Delta$, analyses must be repeated for different earthquake ground motions. The time history dynamic analyses have been carried out for enhanced frame models similar to the original frame but with strain hardening. The frame models are then subjected to the five selected ground motions referred to in Section 5.9 before and after enhancement. The following two cases of enhancement are considered:

(a) Strain hardening ratio, $\alpha=\theta=10 \%$, strengthened according to proposed Eqs 5.13 and 5.16 .

(b) Strain hardening ratio, $\alpha=12 \%$ and $\theta=10 \%$, strengthened according to proposed Eq 5.13.

Figures 5.26 to 5.30 show the effect of enhancing the frame when the strain hardening ratio, $\alpha$ is selected to be equal to the stability factor, $\theta$. In all figures, curve $a$ shows the lateral displacement of the frame without P- $\Delta$ effect but with strain hardening, while curve $b$ shows the lateral displacement of the frame with strain hardening and P- $\Delta$ 
effect. Curve $c$ shows the response of the frame that has been enhanced according to Eq. 5.13 while curve $d$ shows the response of the frame that has been enhanced according to Eq. 5.16. In both cases, the strain hardening ratio is $10 \%$. It can be noticed from the figures that enhancement according to the proposed Eqs. 5.13 and 5.16 helps in improving the performance of the frame with strain hardening when subjected to El-Centro, Montana, and Monte Negro ground motions. These observations can be verified by referring to Figs. 5.26, 5.28 and 5.29. On the other hand, the performance of the frame with strain hardening becomes worse when enhanced by Eqs. 5.13 and 5.16, and subjected to Kern County and Parkfield ground motions. This is shown clearly in Figs. 5.27, and 5.30.

Figures 5.31 to 5.35 show the effect of a higher value of strain hardening ratio, $\alpha$, a value higher than the stability factor, $\theta$. In these figures, curve $a$ shows the lateral displacement of the frame without P- $\Delta$ effect but with $\alpha=12 \%$, while curve $b$ shows the lateral displacement of the frame when $\alpha=12 \%$ and with P- $\Delta$ effect. Curve $c$ shows the response of the frame enhanced according to Eq. 5.13. Enhancement according to the proposed Eq. 5.13 helps in improving the performance of the frame with $12 \%$ strain hardening ratio, when subjected to El-Centro, Montana, and Monte Negro ground motions. These observations can be verified by referring to Figs. 5.31, 5.33 and 5.34. Again, the performance of the frame with $12 \%$ strain hardening ratio becomes worse with enhancement when the frame is subjected to Kern County and Parkfield ground motions. This is clearly observed in Figs. 5.32, and 5.35. It is also noticed from the figures, that the responses of the 
frame with and without P- $\Delta$, when $\alpha>\theta$, are quite close to each other and that the enhancement using Eq. 5.13 does not significantly improve the performance.

It can be concluded from the previous discussion that when significant strain hardening is present, $\mathrm{P}-\Delta$ effect decreases, specially when $\alpha>\theta$. When the strain hardening ratio is selected to be higher than the stability factor, there will be no need to enhance the frame to reduce the effect of P- $\Delta$.

\subsection{MDOF FRAME STRUCTURE}

To have a better understanding of P- $\Delta$ effect and to appropriately evaluate the effectiveness of using the proposed Eqs. 5.13 and 5.16, MDOF building structures should be investigated. A 10-storey 3-bay steel frame is designed and analyzed. Figure 5.36 shows the plan and the elevation views of the multistorey building studied. It is assumed that the lateral load resistance in the building is provided by moment-resisting steel frames. For the frame studied, the bay spans are selected to be $10.0 \mathrm{~m}$ in both directions and all storeys have a height of $4.0 \mathrm{~m}$. Design for gravity and earthquake forces is carried out according to the NBCC 2005 provisions. Load combinations are given by the following equations:

$$
\begin{aligned}
& 1.25 D+1.5 L \\
& 1.0 D+0.5 \mathrm{~L}+1.0 E
\end{aligned}
$$

where $D$ represents dead load, $L$ is the live load, and $E$ is the earthquake load. The dead load is assumed to be $3.4 \mathrm{kN} / \mathrm{m}^{2}$ and the live load is taken as $2.4 \mathrm{kN} / \mathrm{m}^{2}$. A uniform reduction 
factor of 0.7 is applied to the live load for the design of both beams and columns.

The NBCC 2005 requirements for seismic design specify that the earthquake base shear should be obtained from a uniform hazard spectrum (UHS) for the site under consideration. The UHS of the city of Vancouver in West Canada, shown in Fig. 1.2, is used in calculating the frame base shear. The fundamental period of the frame, $T_{1}$ is calculated according to the following equation:

$$
T_{1}=0.085(H)^{3 / 4}
$$

where $H$ is the total height of the frame. Equation 2.3 is used to obtain the base shear. Assuming that the frame is a ductile moment-resisting steel frame, the ductility related strength modification factor, $R_{d}$ is taken as 5.0 and the overstrength related factor, $R_{o}$ as 1.5 according to the recommendations of NBCC 2005 . The base shear is calculated to be $385.81 \mathrm{kN}$.

In designing the building frame, a strong-column-weak beam principle is adopted so that plastic hinges do not form in the columns, except at the base. According to CSA A23.3, the sum of the strengths of columns meeting at a joint are designed to be larger than the sum of the strengths of beams meeting at the same joint according to the following equation:

$$
\Sigma M_{r c} \geq 1.2 \Sigma M_{n b}
$$

where $\sum M_{r c}$ is the sum of the factored moment resistances of the columns meeting at the joint and $\sum M_{n b}$ is the sum of the nominal moment resistances of the beams meeting at the same joint.

The ultimate allowable inelastic storey drift is limited to $2.5 \%$ of the storey height. 
The yield stress of the steel is taken to be $300 \mathrm{MPa}$. No strain hardening is considered for both beams and columns. The analyses yield the modal periods as well as the effective modal masses, which are presented in Table 5.2. P- $\Delta$ effect is not included in calculating the values presented in the Table. The column and beam sections required to resist the calculated design moments, shears and axial forces are selected from the list of available sections given in Handbook of Steel Construction (2000). All beams cross sections are selected to be W610X91. The columns cross-sections are selected to be as follows:

(a) Bottom five storeys: W310X283 for interior columns, W310X202 for the exterior columns.

(b) Top five storeys: W310X253 for interior columns, W310X129 for the exterior columns.

The moment-resisting frame is subjected to an incremental static push-over analysis for the gravity and earthquake forces tributary to it with P- $\Delta$ effect not included. In carrying out the analysis, the gravity loads are held constant at their full value implied in load combination given by Eq. $5.17 \mathrm{~b}$. The lateral earthquake forces are assumed to be distributed along the frame height according to the NBCC but without subtracting the top force $F_{i}$. The lateral forces are then increased in suitable increments until a mechanism forms. The plastic hinges are assumed to form only at the ends of the members. The moment-rotation relationship for each hinge is taken to be bilinear. The complete base shear versus top floor lateral deflection for the 10-storey frame is shown in Fig 5.37 for two cases: with and without $\mathrm{P}-\Delta$ effect. It is clearly noticed from the figure that P- $\Delta$ effect causes instability and the 
post-yield stiffness becomes negative.

The stability factor, $\theta$ is then calculated for each storey according to Eq. 5.1a, which states that the stability factor, $\theta_{x}=\left(P_{x} \Delta_{e x}\right) /\left(h_{s x} V_{x}\right)$. The storey lateral deformations, $\Delta_{x u}$, are obtained from the linear elastic portion of the pushover curve with no P- $\Delta$ effect included. As stated earlier in Section 5.2, $h_{s x}$ is the storey height, $P_{x}$ is the total gravity load carried by the columns at level $x$, acting at and above the level under consideration, and $V_{x}$ is the storey shear. The stability factor values are found to be $0.076,0.114,0.110,0.098$ and 0.084 for storeys one to five, respectively, and $0.075,0.061,0.046,0.031$ and 0.017 for storeys six to ten, respectively.

After carrying out the static analysis, a series of dynamic time history analyses are performed as described in the following paragraphs.

(1) The 10-storey moment-resisting frame is subjected to the following earthquake ground motions:

(a) El-Centro, California, USA. 18 May, 1940

(b) Kern County, California. USA 21 July, 1952

Scale factors are determined for each ground motion so that they would produce an elastic base shear equal to $R_{d} \times R_{o} \mathrm{x} V_{b s}$, where, as stated earlier, the ductility factor, $R_{d}=5$, the overstrength factor, $R_{o}=1.5$, and $V_{b s}$ is the inelastic design base shear that was calculated in the design of the frame based on NBCC 2005 provisions and is equal to $385.81 \mathrm{kN}$. The value of the elastic base shear is calculated to be $2893.58 \mathrm{kN}$. The scale factors are determined to be 2.29 for El-Centro and 5.07 for Kern County. To perform the 
elastic dynamic analysis, the moment capacities of all members are significantly increased to prevent any plastic hinge formation. The maximum elastic top frame displacement is then obtained from the lateral force-displacement time history with no P- $\Delta$ effect included.

(2) Once the scale factor is determined, inelastic dynamic analysis is carried out with the frame subjected to the scaled ground motion, with and without P- $\Delta$ effect included. Again, the maximum inelastic top frame displacement is obtained from the lateral forcedisplacement time history with no P- $\Delta$ effect included. The elastic and inelastic displacements are close although not identical.

(3) The frame is then enhanced Eq. 5.11. To achieve this, the plastic moment capacity, $M_{p}$, the axial strength, $P_{y}$ and the cross sectional moment of inertia, $I_{x}$ for all members are increased by a factor $(1+\theta)$. For simplicity, an average value of $\theta$ equal to 0.1 is selected for all storeys. Thus, the strength and stiffness of all members are enhanced by 1.1. Inelastic dynamic analysis is then carried out with the frame subjected to the scaled ground motions with and without $P-\Delta$ effect included.

The computer program DRAIN-2DX (Prakash and Powell, 1993) is used to conduct both the static nonlinear push-over and elastic and inelastic dynamic time history analyses. Figure 5.38 shows the history of lateral top frame displacement caused by scaled El-Centro ground motion (scale factor $=2.29$ ). . Curve $a$ shows the inelastic frame response without P- $\Delta$ effect, while curve $b$ shows the response with P- $\Delta$ effect included. The elastic frame response without P- $\Delta$ effect is shown by curve $c$. From the figure, the maximum elastic displacement is seen to be $0.85 \mathrm{~m}$, while the maximum inelastic displacement with no P- $\Delta$ effect is $0.53 \mathrm{~m}$. 
The inelastic displacement is found to be less than $0.65 \mathrm{~m}$, the limit beyond which the slope of base shear versus roof displacement becomes negative as shown in Fig. 5.37. Thus, instability due to P- $\Delta$ effect is not expected. This fact is confirmed by Fig. 5.38 where the frame inelastic responses, with and without $\mathrm{P}-\Delta$ effect, are found to be significantly close.

To better study the instability effect caused by $\mathrm{P}-\Delta$, a higher scale factor is applied to El-Centro ground motion (scale factor $=3.00$ ). The inelastic frame responses, with and without P- $\Delta$ effect included, is shown in Fig. 5.39. Curve $a$ shows the inelastic frame top displacement without P- $\Delta$ effect, while curve $b$ shows the response with P- $\Delta$ effect included. The maximum top displacement without $\mathrm{P}-\Delta$ effect is found to be $0.71 \mathrm{~m}$ which is greater than $0.65 \mathrm{~m}$, the limit beyond which the slope of base shear versus roof displacement becomes negative. In this case, the instability due to $\mathrm{P}-\Delta$ effect is expected. This is confirmed by the results shown by curve $b$ in Fig. 5.39. To guard against instability caused by P- $\Delta$ effect, the frame members are then strengthened using Eq. 5.11. The strength and stiffness of each member are enhanced by 1.1 as stated earlier in step (3). The response results are shown in Fig 5.39 along with the original frame results. In the figure, the history of lateral top enhanced frame displacement caused by the scaled El-Centro ground motion (scale factor $=3.00$ ) without P- $\Delta$ effect is shown by curve $c$. Curve $d$ shows the response with P- $\Delta$ effect included. It is clear from curve $b$ in the figure that the P- $\Delta$ effect has caused significant instability in the original frame as the frame response drifts away from its initial position and never goes back to its initial position even when the ground motion has ceased. 
In comparison, the response of the enhanced frame with $\mathrm{P}-\Delta$ effect included, shown by curve $d$, is improved, although that there is still some ratcheting. The enhancement has successfully reduced the possibility of instability and made the response satisfactory. It may be noted that the maximum top displacement without $\mathrm{P}-\Delta$ effect is now $0.67 \mathrm{~m}$ compared to $0.71 \mathrm{~m}$ for the original frame.

Figure 5.40 shows the results obtained from the pushover analysis, with and without P- $\Delta$ effect, for the enhanced frame in comparison with the original one. Although the response of enhanced frame still shows instability caused by $P-\Delta$ effect, the deflections of the enhanced frame are smaller than those of the original frame for the same base shear.

The previous dynamic analysis is repeated for the frame subjected to Kern County earthquake ground motion. Figure 5.41 shows the history of lateral top frame displacement caused by scaled Kern County ground motion (scale factor $=5.07$ ). Curve $a$ shows the inelastic frame response without P- $\Delta$ effect, while curve $b$ shows the response with P- $\Delta$ effect included. The elastic frame response without P- $\Delta$ effect is shown by curve $c$. From the figure, the maximum elastic displacement, with no $\mathrm{P}-\Delta$, is found to be $0.65 \mathrm{~m}$, while the maximum inelastic displacement, with no $\mathrm{P}-\Delta$, is $0.63 \mathrm{~m}$. The inelastic displacement is found to be less than $0.65 \mathrm{~m}$, the limit beyond which the slope of base shear versus roof displacement becomes negative as shown in Fig. 5.37. Again, instability due to P- $\Delta$ effect is not expected. This is confirmed by the results shown in Fig. 5.41 where the frame top displacements, with and without P- $\Delta$ effect, as shown by curves $a$ and $b$, are not too different.

Next, a higher scale factor of 6.00 is applied to Kern County ground motion and 217 
responses are calculated for this stronger earthquake. The inelastic frame responses, with and without P- $\Delta$ effect included, are shown in Fig. 5.42. Curve $a$ shows the inelastic frame top displacement without $\mathrm{P}-\Delta$ effect, while curve $b$ shows the response with $\mathrm{P}-\Delta$ effect included. The maximum top displacement without $P-\Delta$ effect is found to be $0.72 \mathrm{~m}$ which is again greater than $0.65 \mathrm{~m}$, the limit beyond which the slope of base shear versus roof displacement becomes negative. Instability due to P- $\Delta$ effect is therefore likely, which is confirmed by the results shown by curve $b$ in Fig. 5.42. To mitigate the effect of P- $\Delta$, the frame members are strengthened by a factor of 1.1 using Eq. 5.11. The response results are shown in Fig 5.42 along with the original frame results. In the figure, the history of lateral top enhanced frame displacement caused by the scaled Kern County ground motion ( scale factor $=6.00$ ) without P- $\Delta$ effect is shown by curve $c$. Curve $d$ shows the response with P- $\Delta$ effect included. Curve $b$ shows that the $\mathrm{P}-\Delta$ effect has caused ratcheting of the original frame and there is a likelihood of instability. The response of the enhanced frame with P- $\Delta$ effect included, shown by curve $d$, shows improvement and the enhancement has made the response satisfactory.

The previous discussion suggests a conservative mean of finding out whether P- $\Delta$ effect will cause instability or not, without performing an inelastic analysis. The procedure is to obtain the maximum displacement from an elastic spectrum of the earthquake corresponding to the first mode period of the structure, and to assume that the inelastic displacement will be similar. That is in fact the case when the frame is subjected to in Kern County earthquake ground motion, leading to maximum elastic and inelastic top displacements of $0.65 \mathrm{~m}$ and $0.63 \mathrm{~m}$. In the case of El-Centro ground motion, the maximum 
elastic displacement $(0.85 \mathrm{~m})$ is significantly higher than the inelastic displacement $(0.53 \mathrm{~m})$. Although the equal displacement concept may be conservative for comparatively long period structures, it can be considered a reasonable assumption. Having got the maximum displacement, one should carry out a push over analysis and obtain the displacement corresponding to the limit beyond which instability could occur ( $0.65 \mathrm{~m}$ in our case). Beyond this limit, the slope of the pushover curve will become negative. If the inelastic displacement determined as above is found higher than the displacement at this limit, instability due to P- $\Delta$ effect is likely and strengthening is required. These findings are consistent with those for the SDOF stated earlier, that as long as the stiffness is positive instability is unlikely and no strengthening may be required.

\subsection{SUMMARY AND CONCLUSIONS}

Nonlinear static and dynamic analyses under earthquake ground motions have been carried out on single and multistorey frames to assess the effect of P- $\Delta$. A single storey and a 10-storey steel moment-resisting frames have been studied to evaluate the efficiency of proposed equations for calculating the amplification factors to account for P- $\Delta$ effect. Five ground motions were used in these analyses. The main findings of the study are summarized as follows:

(1) The P- $\Delta$ effect results in an increase in the lateral deformations of the structure and may lead to instability whenever it causes the second branch of the forcedisplacement relationship to have a negative slope. Instability is more likely if the 
response is gone far into the inelastic range and the duration of the ground motion is long.

(2) Several measures may mitigate the effect of P- $\Delta$. A decrease in the stability factor is helpful in improving the performance of building structures. A decrease in expected ductility demand obtained by increasing the strength may also be helpful in some cases.

(3) Increasing the strain hardening ratio to be equal or higher than the stability factor would improve the response against P- $\Delta$ because the second branch will still have a positive slope and instability would be less likely: When the strain hardening ratio is selected to be higher than the stability factor, there is no need to enhance the frame strength or stiffness to reduce the effect of $\mathrm{P}-\Delta$. For an elasto-plastic force displacement relationship or when the strain hardening ratio is less than the stability factor, enhancement of both strength and stiffness according to the proposed equations would help but does not guarantee against instability.

(4) The ground motion duration has a great effect on P- $\Delta$. The longer the ground motion duration the greater is the effect of $\mathrm{P}-\Delta$.

(5) The proposed P- $\Delta$ amplification factors are generally effective in enhancing the response and guarding against post-earthquake instability of single and multistorey moment-resisting frames. However, as stated earlier, when the strain hardening is sufficient to ensure a positive post-yield slope in the force-displacement relationship enhancement is not necessary. 
(6) A conservative method is proposed to find out whether or not P- $\Delta$ effect will cause instability in a MDOF system, without performing an inelastic analysis. The procedure is to obtain the maximum displacement from an elastic spectrum of the earthquake corresponding to the first mode period, and to assume that the inelastic displacement will be similar. This equal displacement concept is known to be reasonable for long period structures. For short period structures, equal energy concept described in the literature may be used. However, P- $\Delta$ effect is more predominant in taller structures with long periods. A push over analysis is then performed to obtain the displacement corresponding to the limit beyond which instability would occur. If the inelastic displacement determined as outlined above is found to be smaller than the displacement at this limit, instability due to P- $\Delta$ effect is not likely, otherwise instability may occur and strengthening may be required. 
Table 5.1 Values of ductility factor, $\mu$ for different earthquake arrangements

\begin{tabular}{|c|c|c|c|c|c|c|c|c|}
\hline \multirow{2}{*}{ Earthquake } & \multirow{2}{*}{$\begin{array}{c}\text { Scale } \\
\text { Factor }\end{array}$} & \multirow{2}{*}{$\begin{array}{c}\begin{array}{c}\text { Without } \\
\text { P- } \Delta \text { effect }\end{array} \\
V_{\mathrm{y} 0}=450 \mathrm{kN} \\
\end{array}$} & \multicolumn{6}{|c|}{$\begin{array}{c}\text { With } \\
\text { P- } \Delta \text { effect }\end{array}$} \\
\hline & & & $\mathrm{V}_{\mathrm{y} 0}=550 \mathrm{kN}$ & $V_{\mathrm{v} 0}=500 \mathrm{kN}$ & $\mathrm{V}_{\mathrm{y} 0}=450 \mathrm{kN}$ & $\mathrm{V}_{\mathrm{y} 0}=400 \mathrm{kN}$ & $\mathrm{V}_{\mathrm{v} 0}=350 \mathrm{kN}$ & $V_{\mathrm{y} 0}=300 \mathrm{kN}$ \\
\hline $\begin{array}{l}\text { El-Centro } \\
1940\end{array}$ & 1.30 & 2.96 & (11.48) & (N/A) & 5.15 & N/A & N/A & N/A \\
\hline $\begin{array}{l}\text { Parkfield } \\
1966\end{array}$ & 4.30 & 3.05 & N/A & N/A & N/A & N/A & N/A & N/A \\
\hline $\begin{array}{l}\text { Montana } \\
1935 \\
\end{array}$ & 5.70 & 2.99 & 3.05 & 3.39 & 4.30 & 5.16 & 6.56 & N/A \\
\hline $\begin{array}{l}\text { Monte } \\
\text { Negro } \\
1979 \\
\end{array}$ & 1.55 & 2.97 & $10.98^{*}$ & N/A & N/A & N/A & N/A & N/A \\
\hline $\begin{array}{l}\text { Kern } \\
\text { County } \\
1952 \\
\end{array}$ & 1.90 & 3.03 & 3.31 & 3.90 & $(2.80)$ & N/A & N/A & N/A \\
\hline Average & & 3.00 & 3.18 & 3.65 & 4.73 & 5.16 & 6.56 & N/A \\
\hline
\end{tabular}

Note: Ductility values shown between brackets are anomalous.

* This value is acceptable but it is not taken in average calculation because it is extreme. 
Table 5.2 Modal period and modal mass (\% of total mass) for the 10 -storey moment-resisting frame model (no P- $\Delta$ )

\begin{tabular}{|c|c|c|}
\hline $\begin{array}{c}\text { Mode } \\
\text { No. }\end{array}$ & $\begin{array}{c}\text { T } \\
(\mathbf{s})\end{array}$ & $\begin{array}{c}\text { Modal Mass } \\
\text { \% }\end{array}$ \\
\hline 1 & 2.716 & 80.484 \\
\hline 2 & 0.897 & 9.987 \\
\hline 3 & 0.514 & 3.709 \\
\hline 4 & 0.350 & 2.117 \\
\hline 5 & 0.257 & 1.300 \\
\hline 6 & 0.200 & 0.945 \\
\hline 7 & 0.163 & 0.598 \\
\hline 8 & 0.137 & 0.423 \\
\hline 9 & 0.124 & 0.250 \\
\hline 10 & 0.109 & 0.187 \\
\hline
\end{tabular}




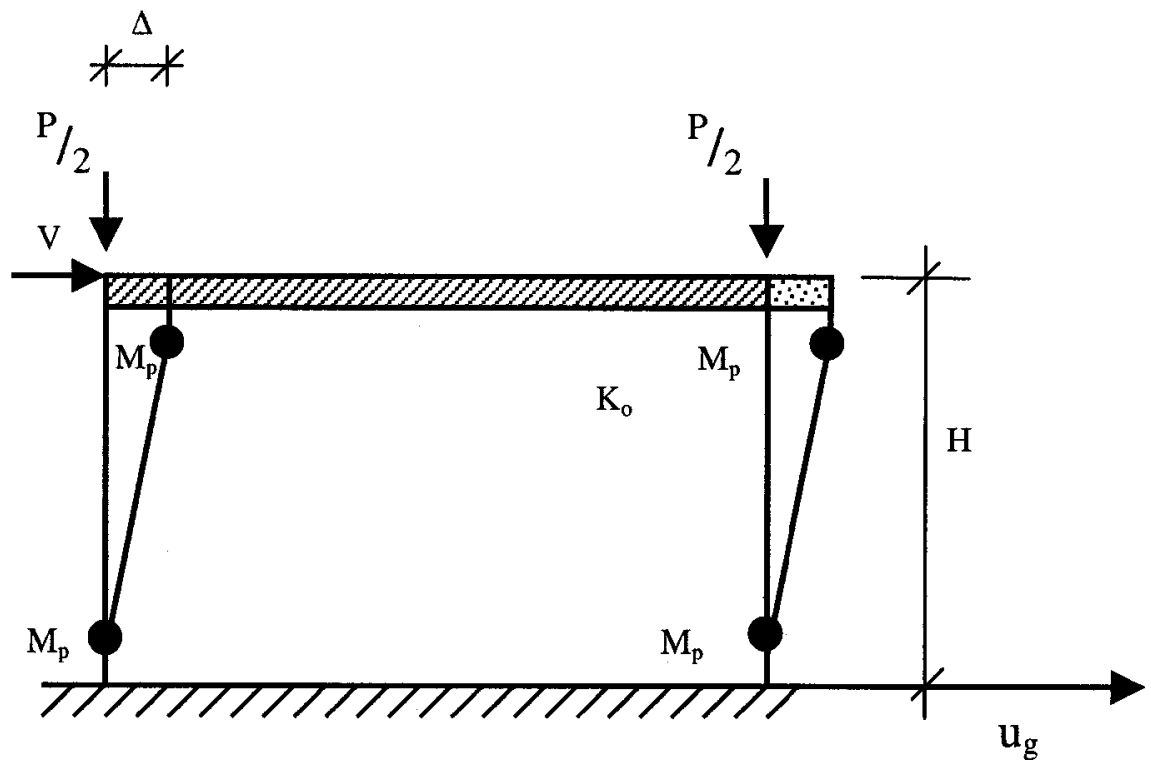

Fig. 5.1 A single storey shear frame model

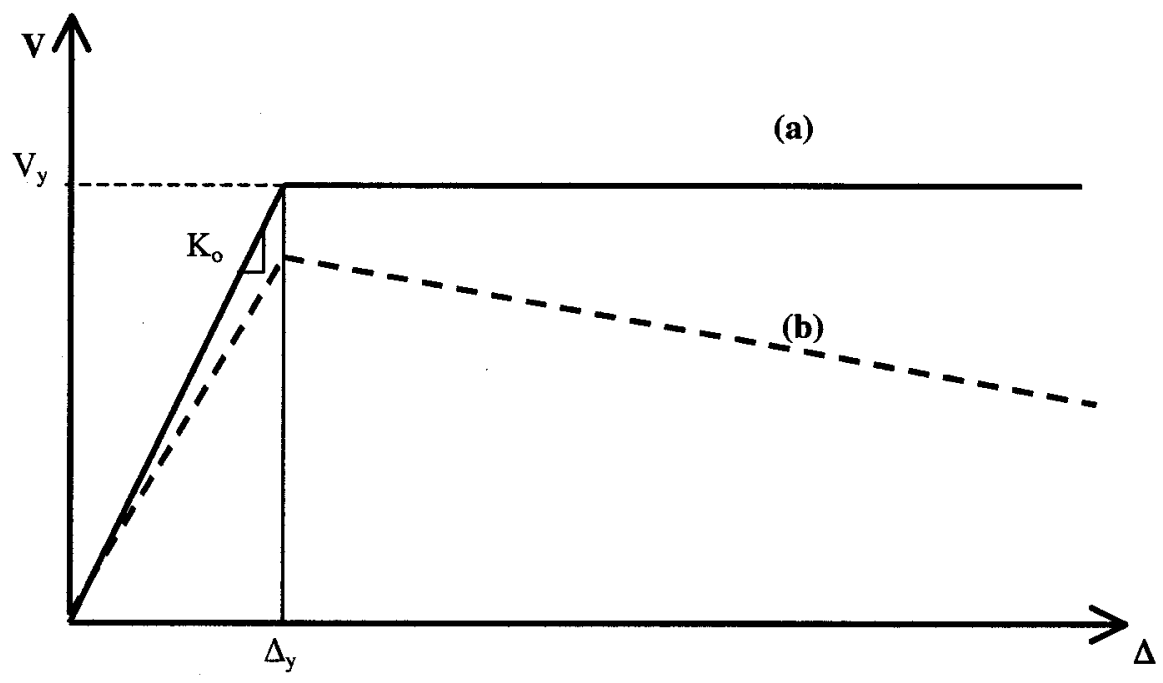

Fig. 5.2 Lateral load versus displacement relationship for a single storey frame (a) elasto-plastic, no P- $\Delta$, (b) elasto-plastic, with P- $\Delta$ 


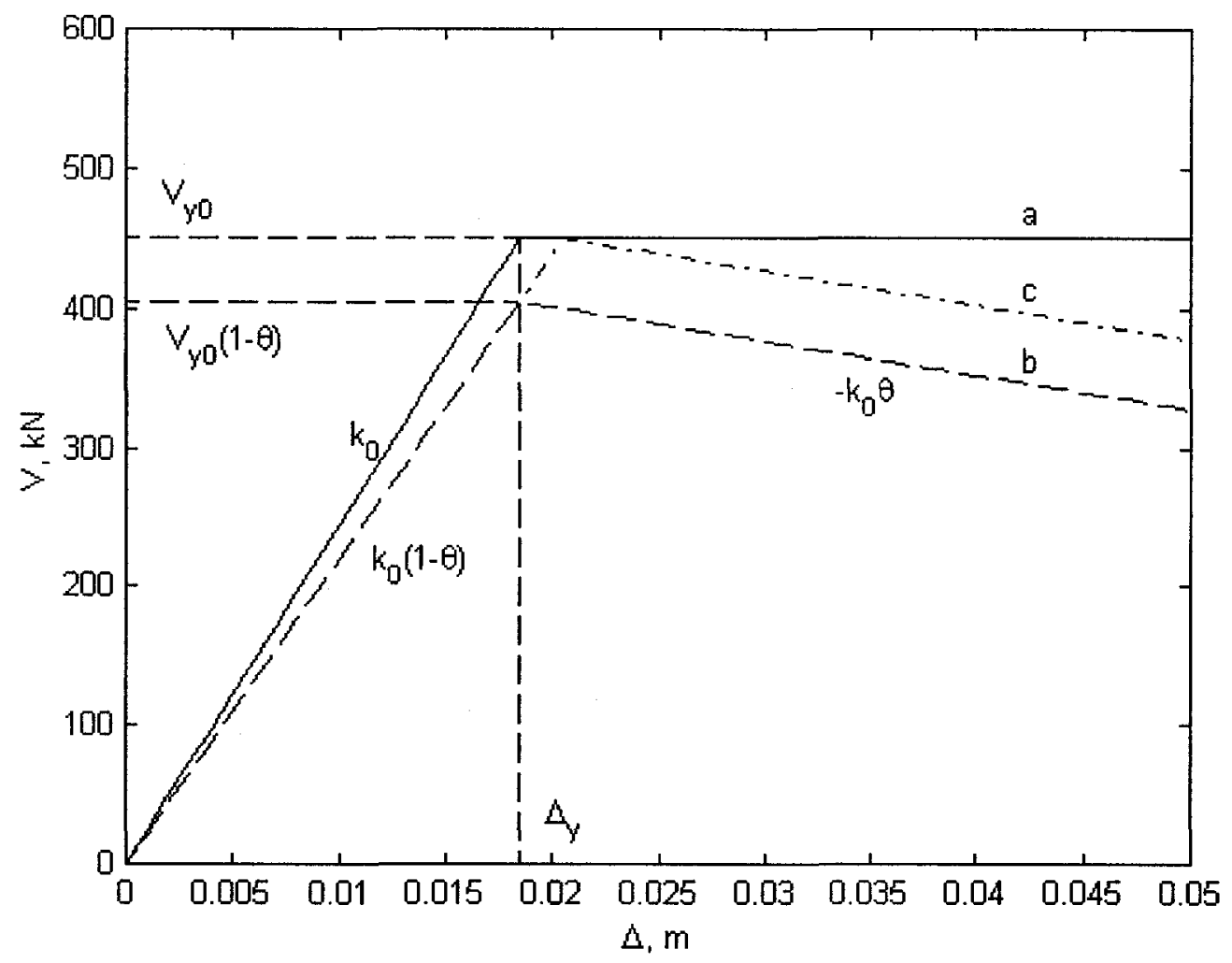

Fig. 5.3 Load deflection relationship for the frame shown in Fig. 5.1, compensating for P- $\Delta$ by increasing the strength, (a) no P- $\Delta$, (b) with P- $\Delta$, (c) increased strength and $\mathrm{P}-\Delta$ 


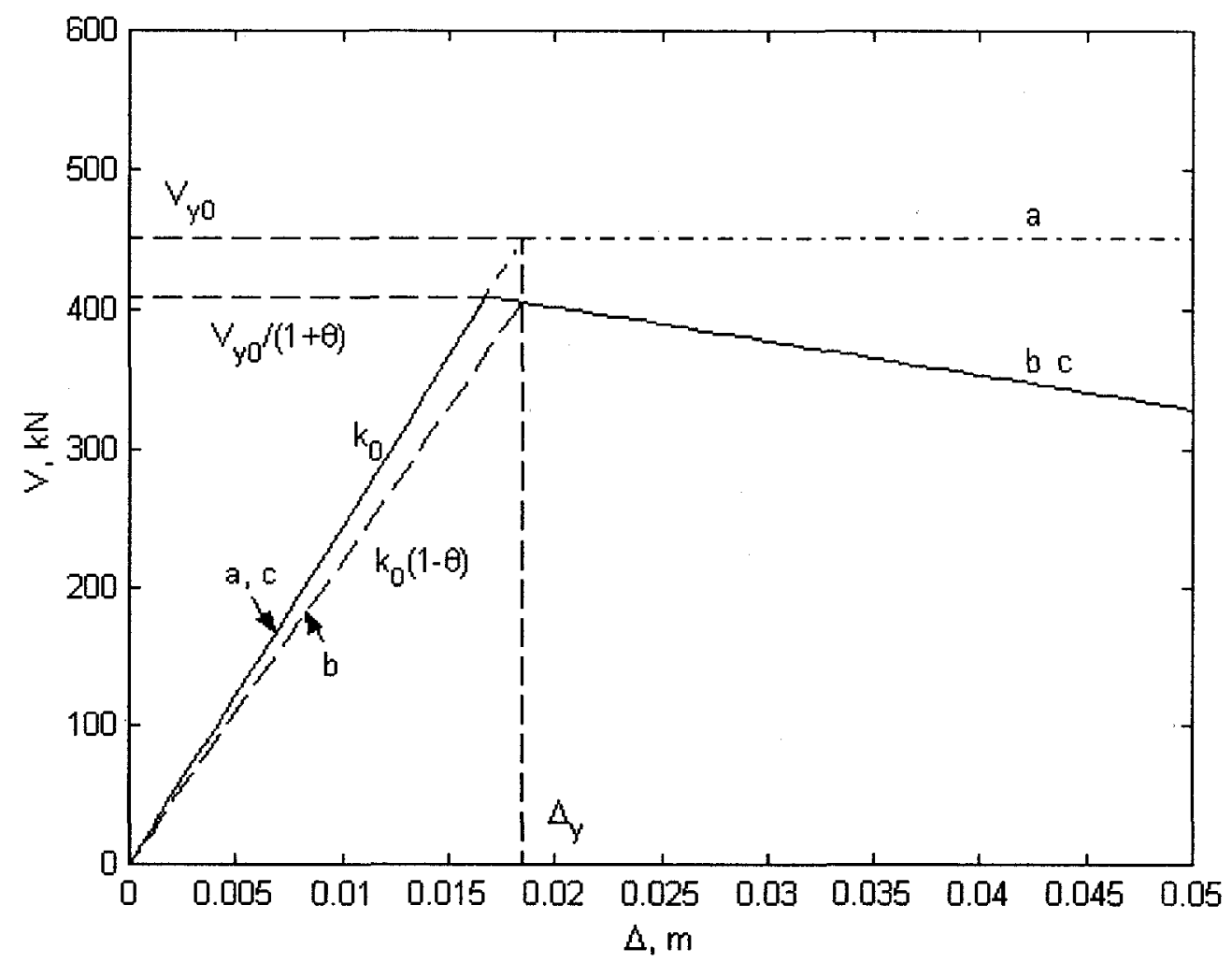

Fig. 5.4 Load deflection relationship for the frame shown in Fig. 5.1, compensating for P- $\Delta$ by increasing the stiffness, (a) no P- $\Delta$, (b) with P- $\Delta$, (c) increased stiffness and $\mathrm{P}-\Delta$ 


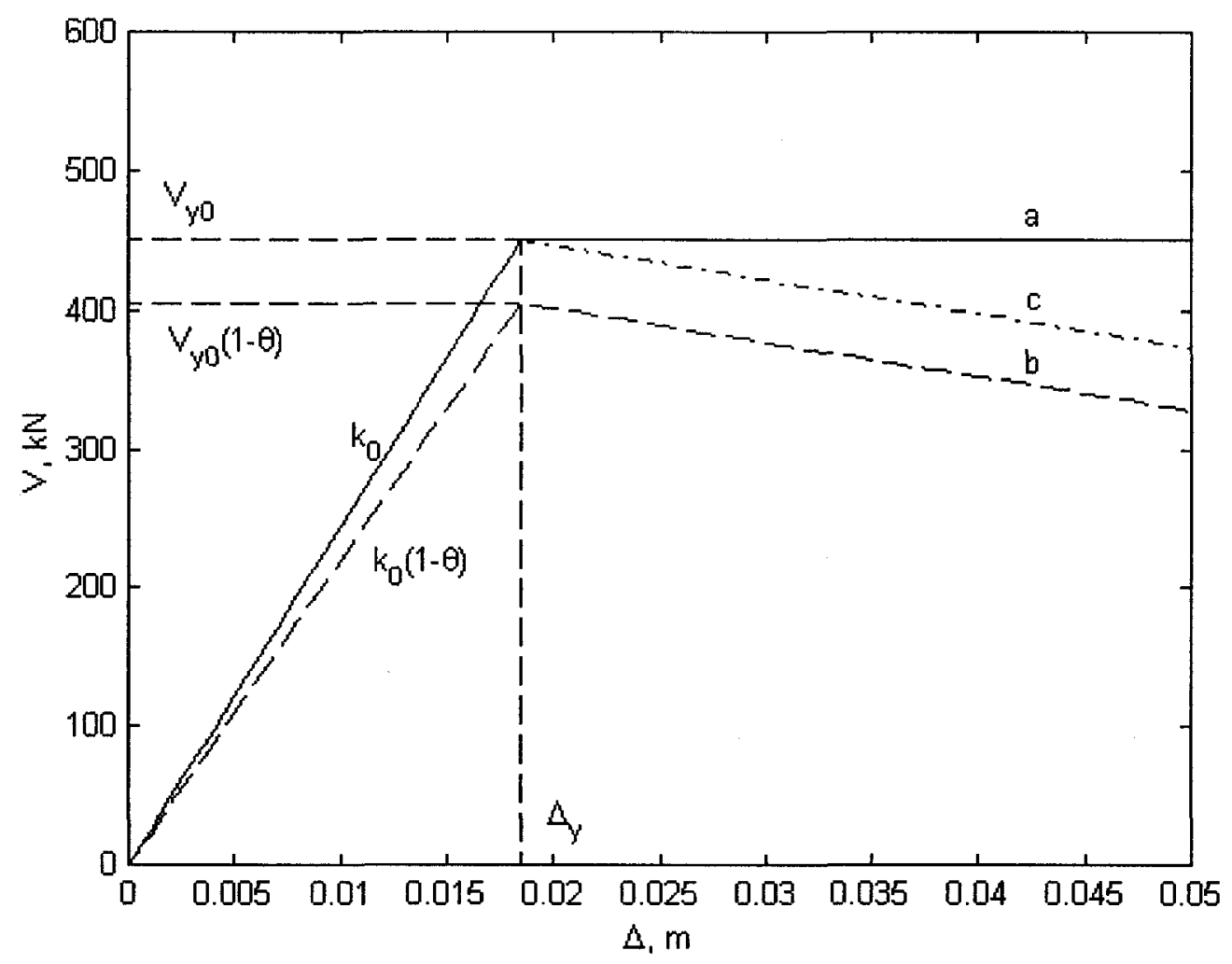

Fig. 5.5 Load deflection relationship for the frame shown in Fig. 5.1, compensating for P- $\Delta$ by increasing both the strength and the stiffness, (a) no P- $\Delta$, (b) with P- $\Delta$, (c) increased strength and stiffness and P- $\Delta$ 


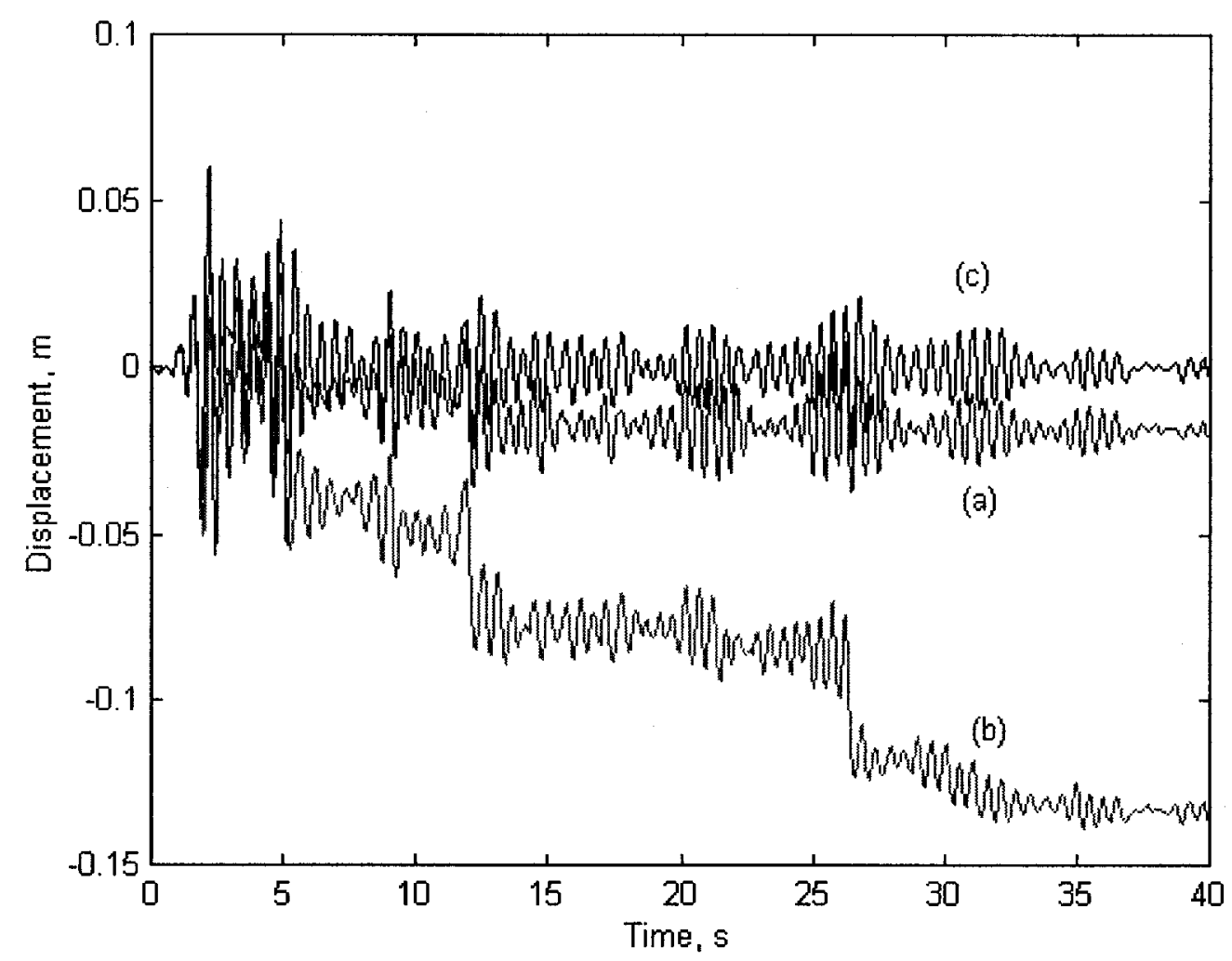

Fig. 5.6 History of lateral frame displacement caused by El-Centro 1940 ground motion, (a) without P- $\Delta$ effect, (b) with P- $\Delta$ effect and no compensation, (c) elastic response, no strain hardening in each case 


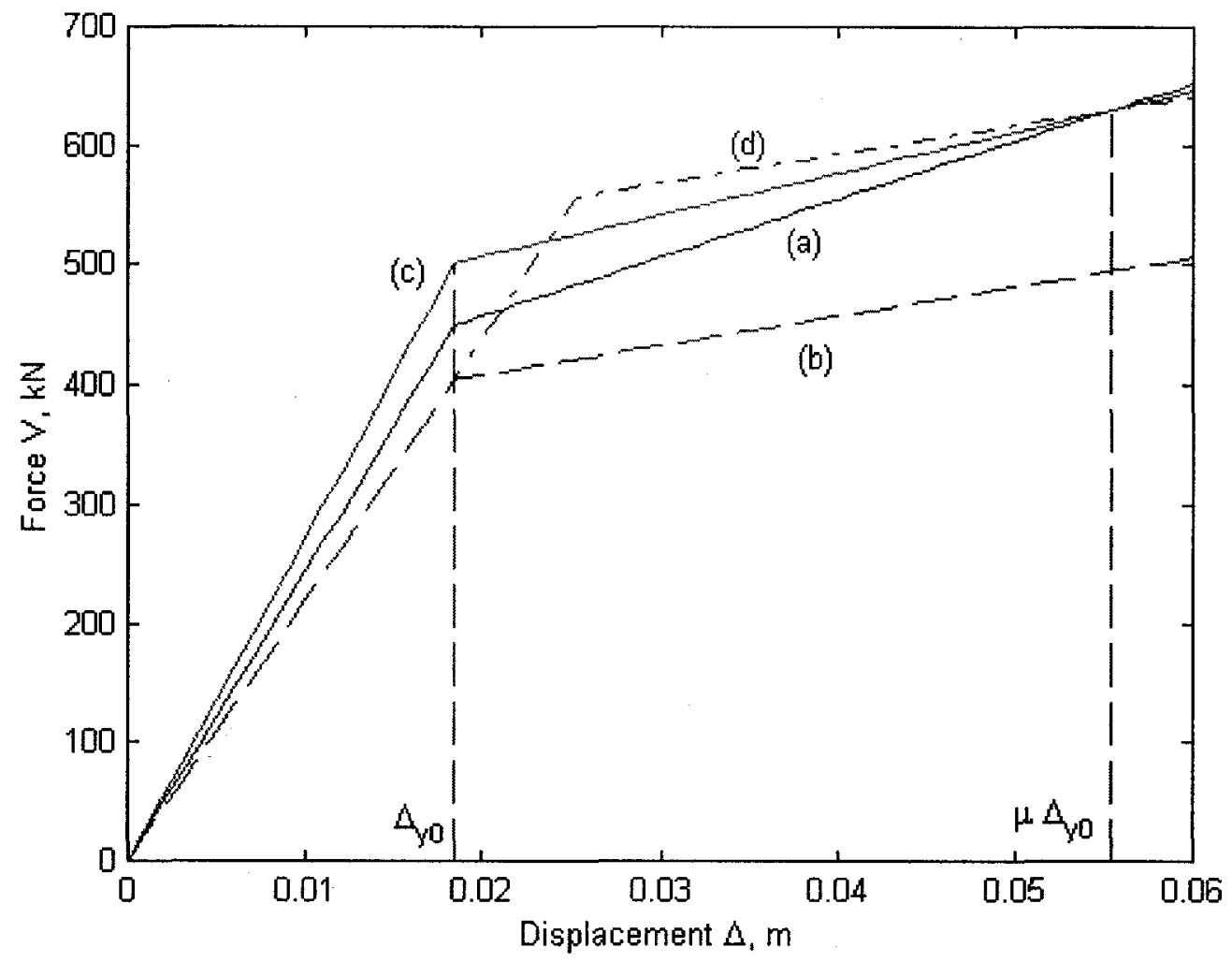

Fig. 5.7 Load displacement relationships for the frame of Fig. 5.1, with a strain hardening ratio of 0.2 , (a) no P- $\Delta$, (b) with P- $\Delta$, (c) increased strength and stiffness and $\mathrm{P}-\Delta,(\mathrm{d})$ increased strength and P- $\Delta$ 


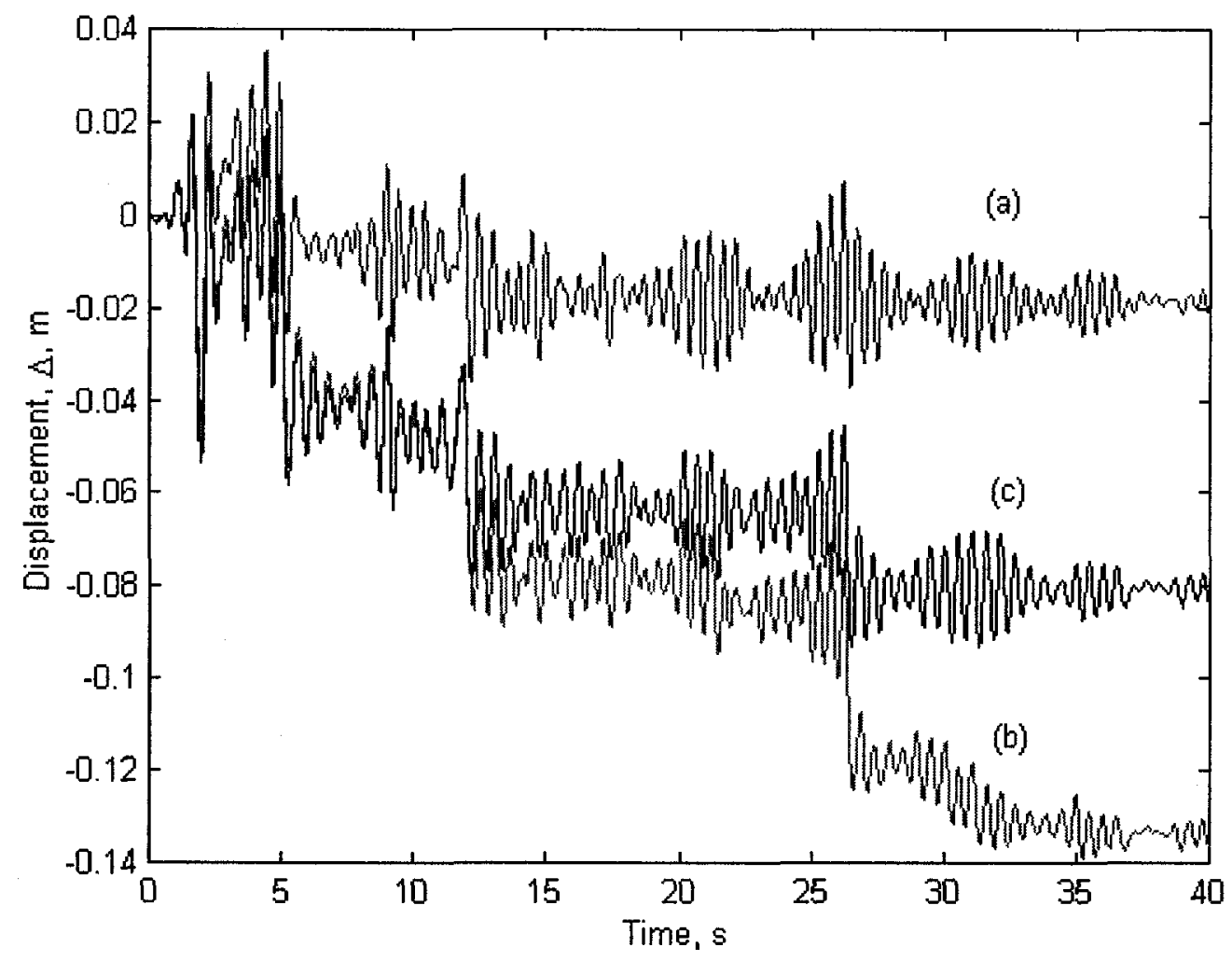

Fig. 5.8 History of lateral frame displacement caused by El-Centro 1940 ground motion,(a) original frame without P- $\Delta$ effect, (b) original frame with P- $\Delta$ effect, (c) frame with a strength $\mathrm{V}_{\mathrm{y} 1}=\mathrm{V}_{\mathrm{y} 0} /(1-\theta)$ and P- $\Delta$ effect, no strain hardening in each case 


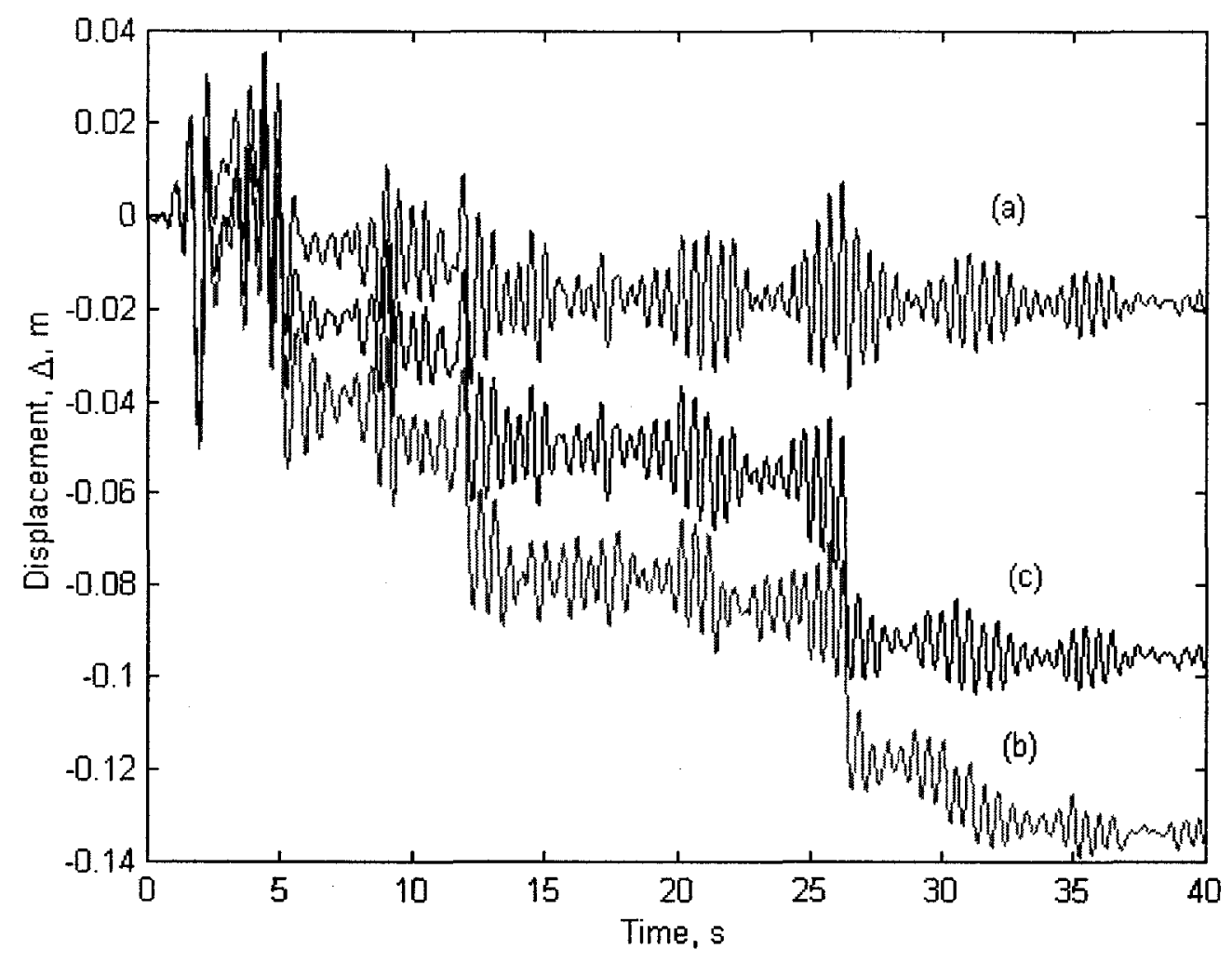

Fig. 5.9 History of lateral frame displacement caused by El-Centro 1940 ground motion, (a) original frame without P- $\Delta$ effect, (b) original frame with $\mathrm{P}-\Delta$ effect, (c) frame with a stiffness $k_{1}=k_{0}(1+\theta)$ and P- $\Delta$ effect, no strain hardening in each case 


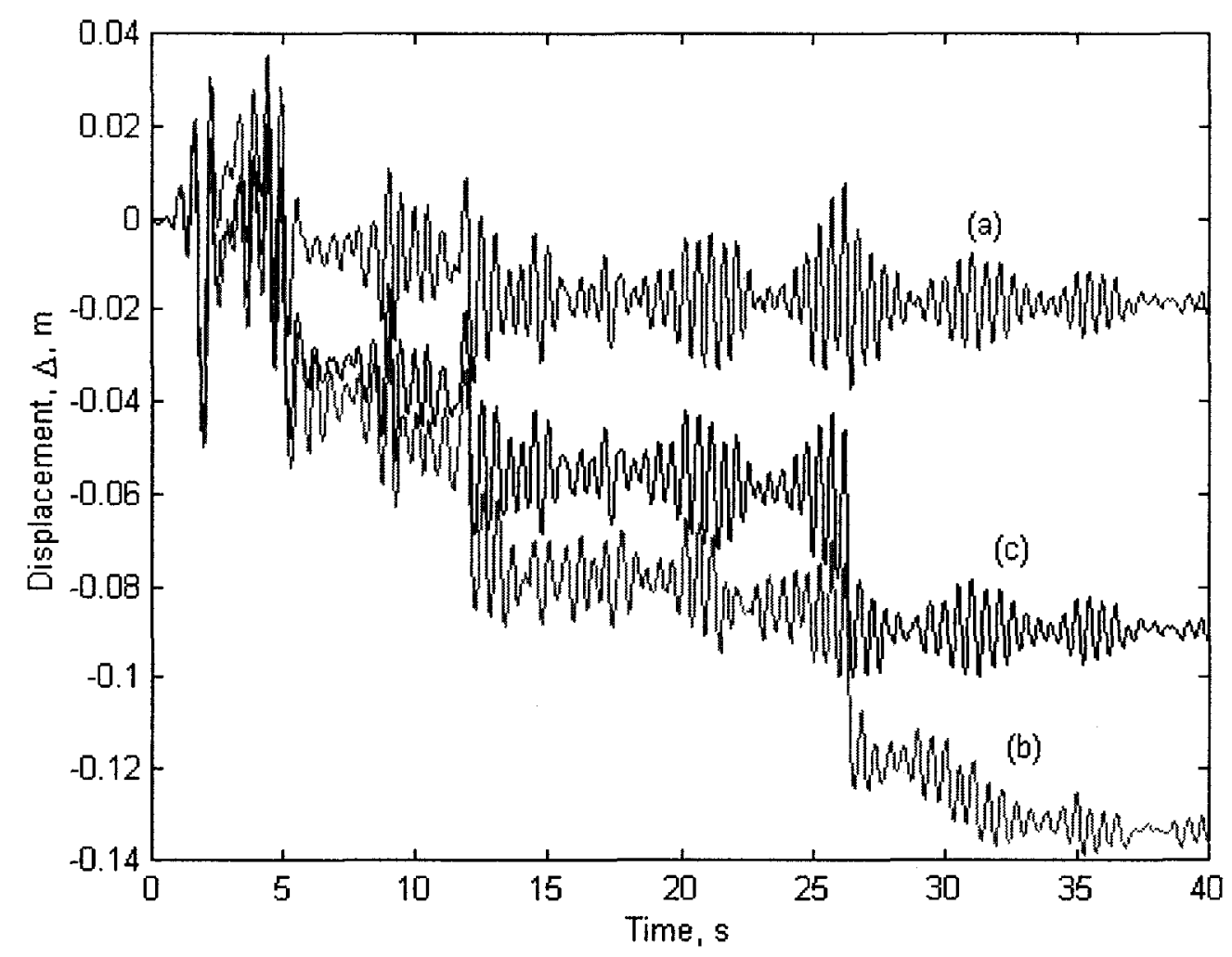

Fig. 5.10 History of lateral frame displacement caused by El-Centro 1940 ground motion, (a) original frame without P- $\Delta$ effect, (b) original frame with P- $\Delta$ effect, (c) frame with a strength $\mathrm{V}_{\mathrm{y} 1}=\mathrm{V}_{\mathrm{y} 0}(1+\theta)$, stiffness $\mathrm{k}_{1}=\mathrm{k}_{0}(1+\theta)$ and P- $\Delta$ effect, no strain hardening in each case 


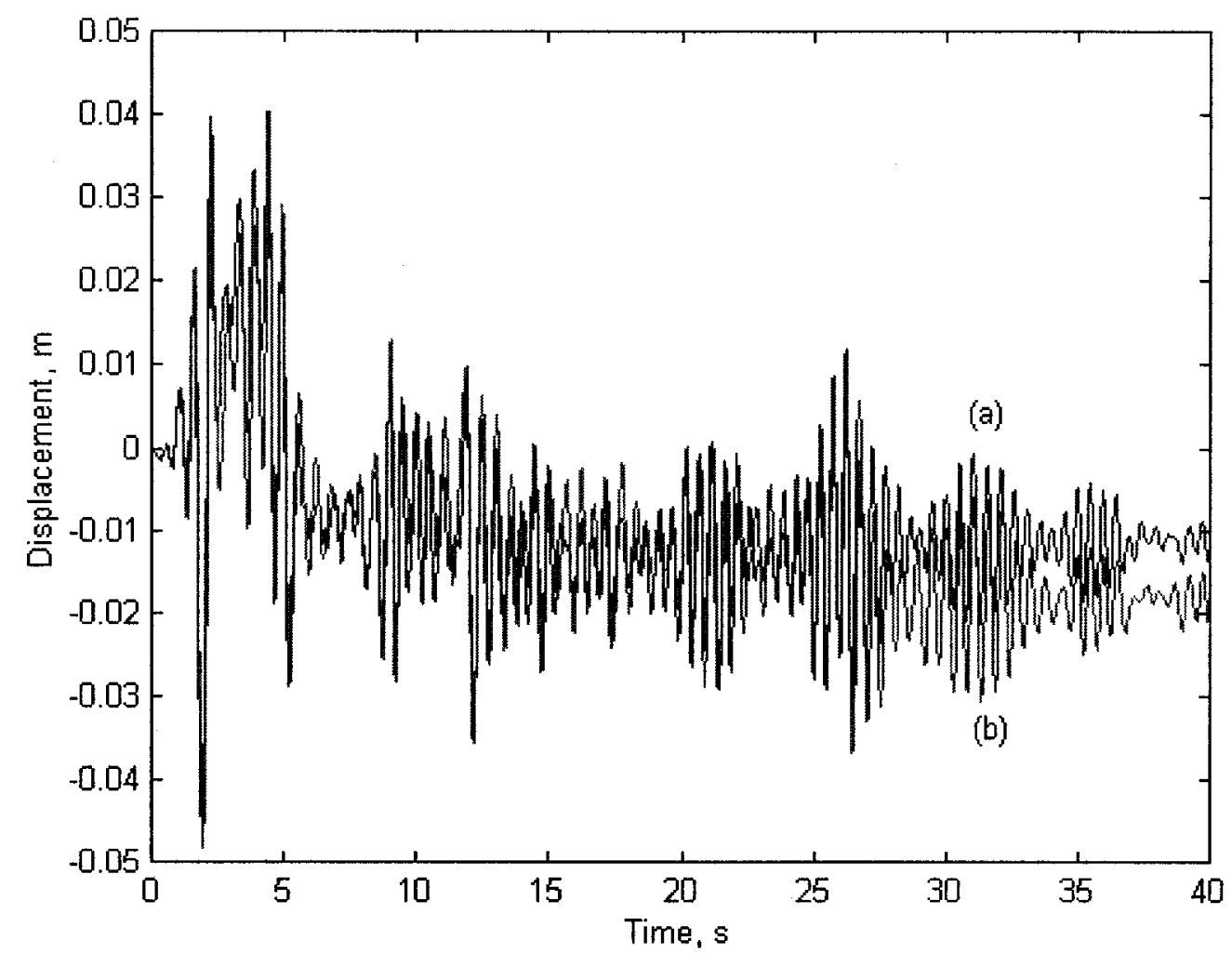

Fig. 5.11 History of lateral frame displacement caused by El-Centro 1940 ground motion, (a) original frame without P- $\Delta$ effect, but with $10 \%$ strain hardening, (b) original frame with $\mathrm{P}-\Delta$ effect and $10 \%$ strain hardening 


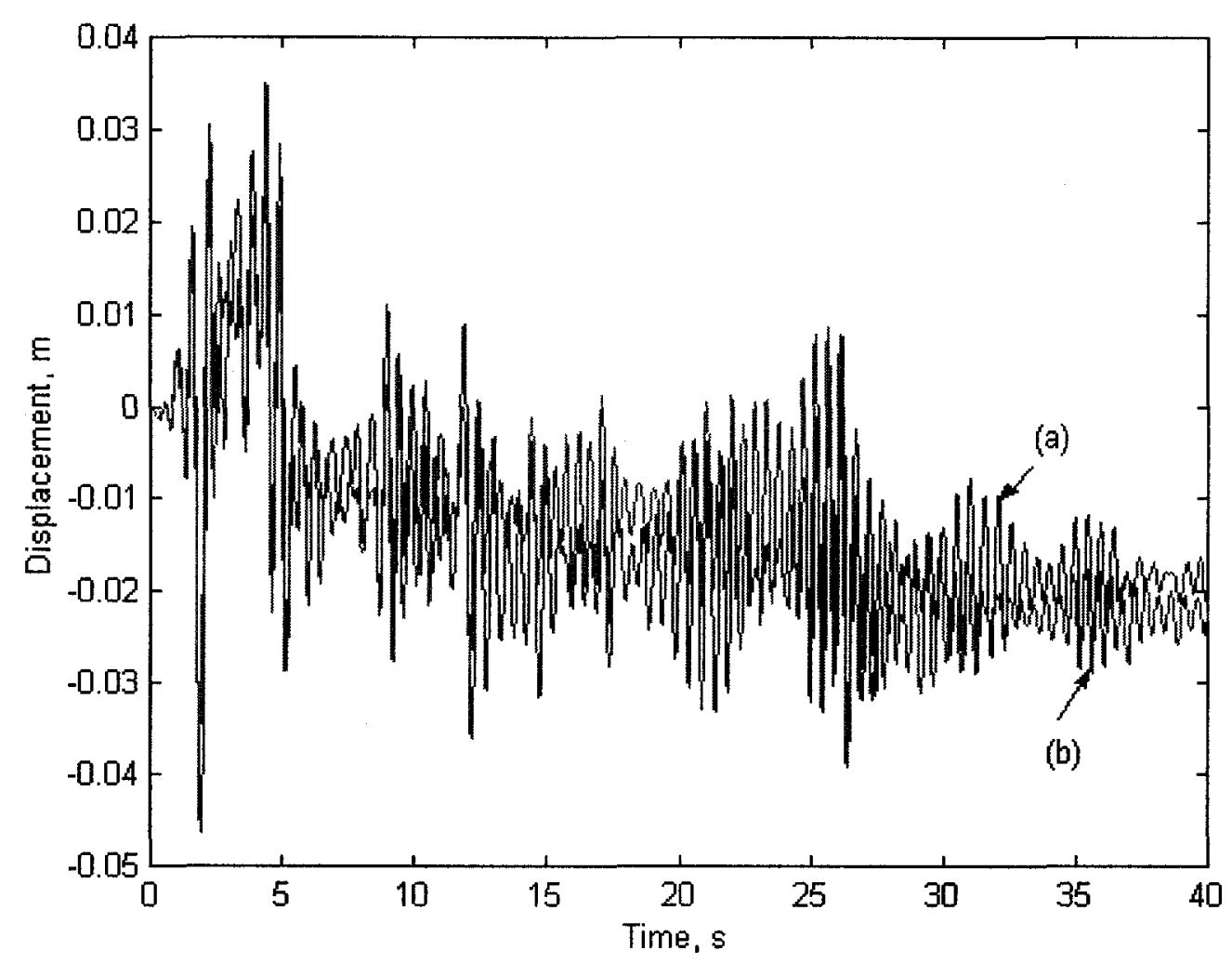

Fig. 5.12 History of lateral frame displacement caused by El-Centro 1940 ground motion, (a) original frame without P- $\Delta$ effect (b) original frame with P- $\Delta$ effect, both strength and stiffness enhanced by 1.3 , no strain hardening in each case 


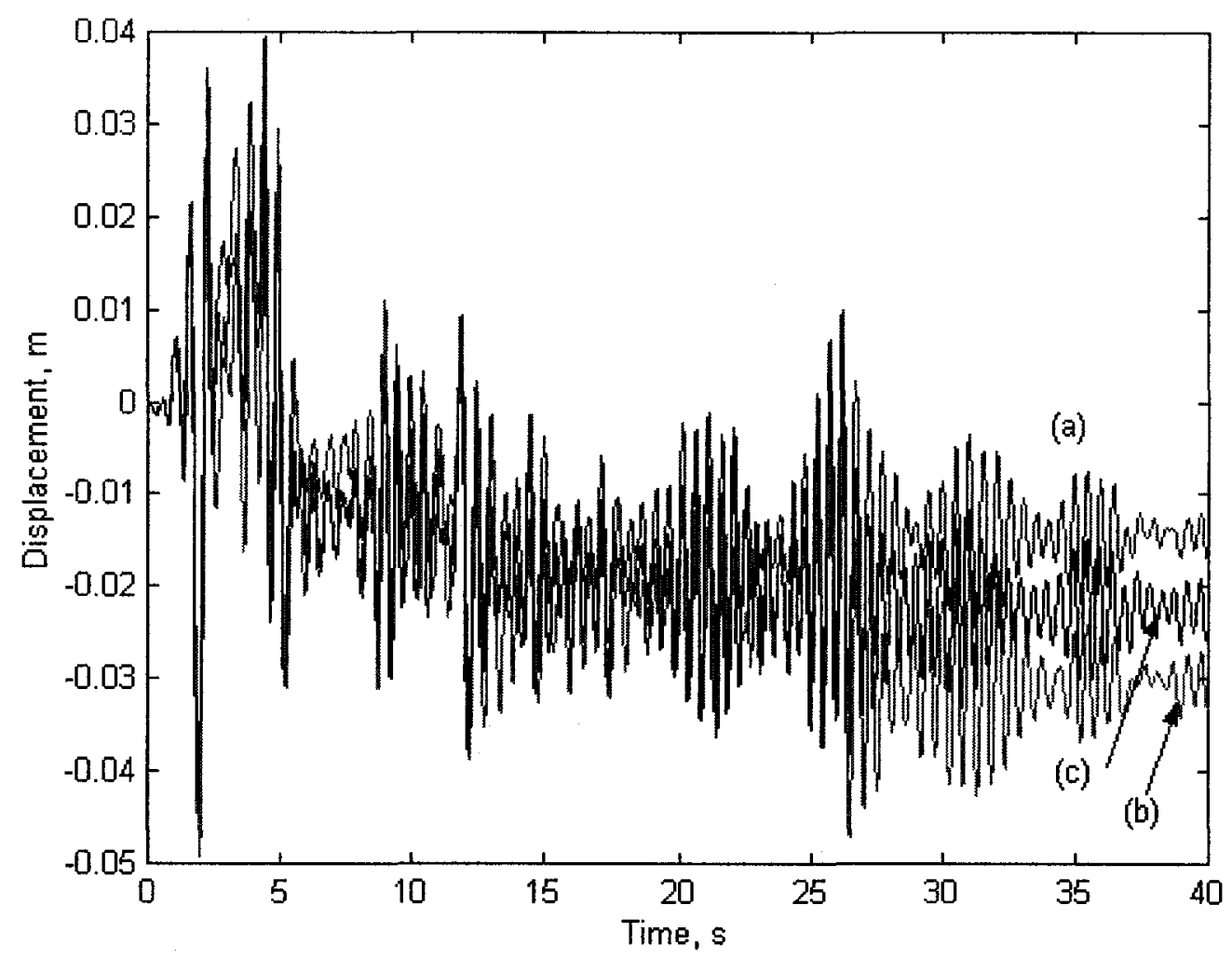

Fig. 5.13 History of lateral frame displacement caused by El-Centro 1940 ground motion, (a) frame with $5 \%$ strain hardening but without P- $\Delta$ effect (b) frame with $5 \%$ strain hardening and with P- $\Delta$ effect, (c) frame with $5 \%$ strain hardening, with P- $\Delta$ effect and with both strength and stiffness enhanced by 1.18 


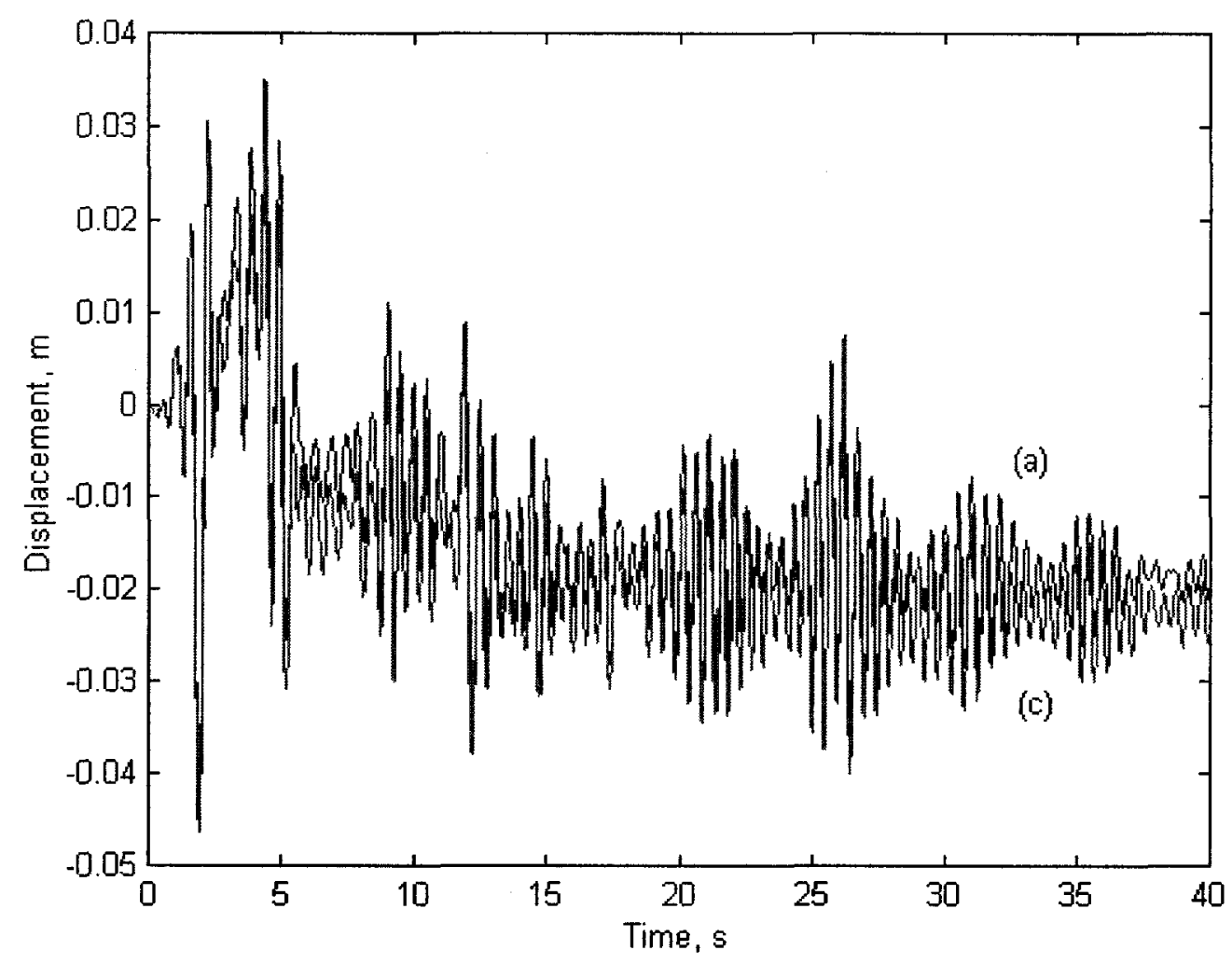

Fig. 5.14 History of lateral frame displacement caused by El-Centro 1940 ground motion, (a) frame with no strain hardening and without P- $\Delta$ effect (b) frame with 5\% strain hardening, with P- $\Delta$ effect and with both strength and stiffness enhanced by 1.18 


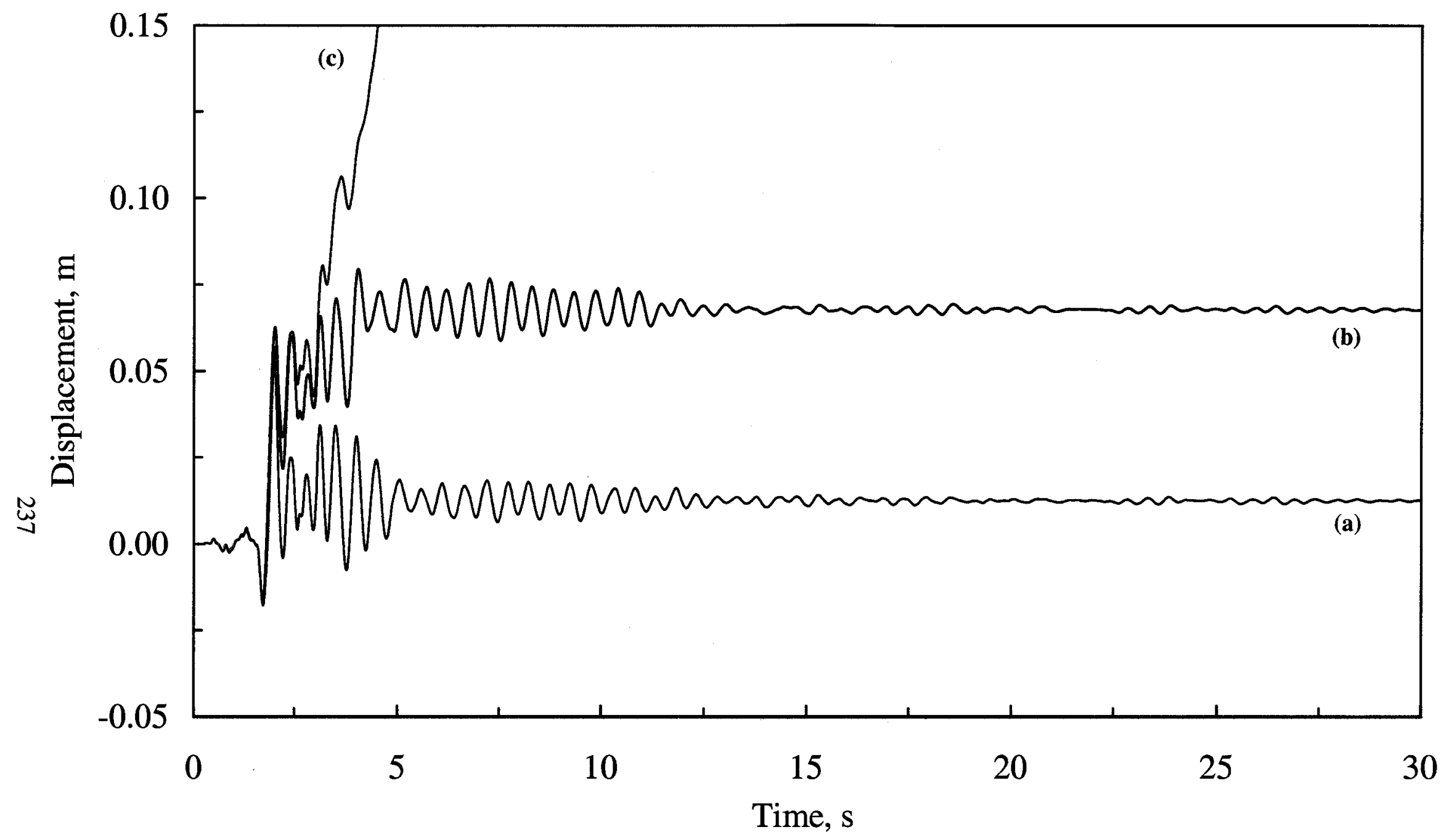

Fig. 5.15 History of lateral frame displacement caused by Montana 1935 ground motion (a) original frame without P- $\Delta$ effect, (b) original frame with P- $\Delta$ effect, (c) frame with a strength, $\mathrm{V}_{\mathrm{y} 1}=0.67 \mathrm{~V}_{\mathrm{yo}}$ and $\mathrm{P}-\Delta$ effect, no strain hardening in each case 


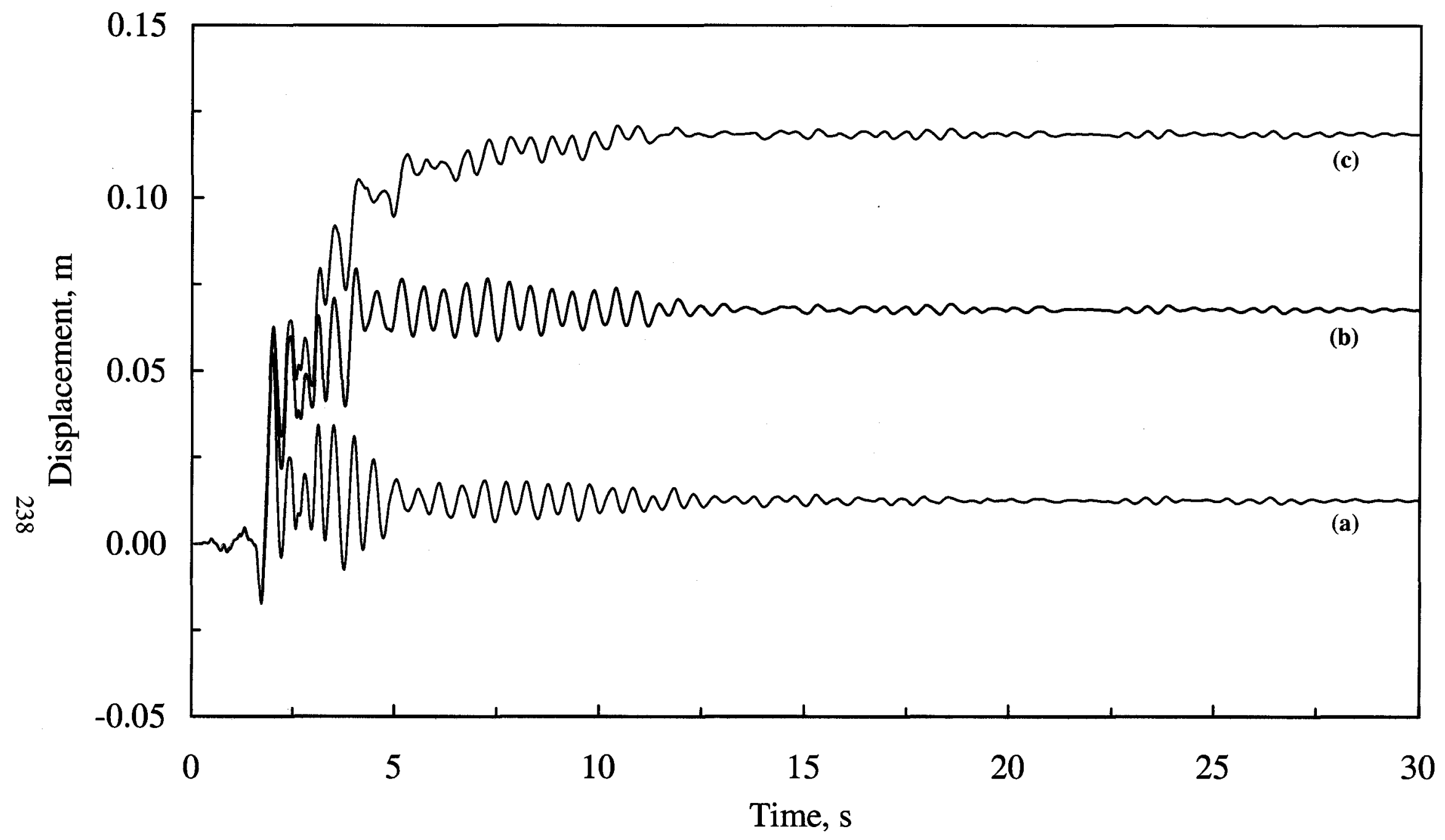

Fig. 5.16 History of lateral frame displacement caused by Montana 1935 ground motion (a) original frame without P- $\Delta$ effect, (b) original frame with P- $\Delta$ effect, (c) frame with a strength, $\mathrm{V}_{\mathrm{y} 1}=0.78 \mathrm{~V}_{\mathrm{yo}}$ and $\mathrm{P}-\Delta$ effect, no strain hardening in each case 


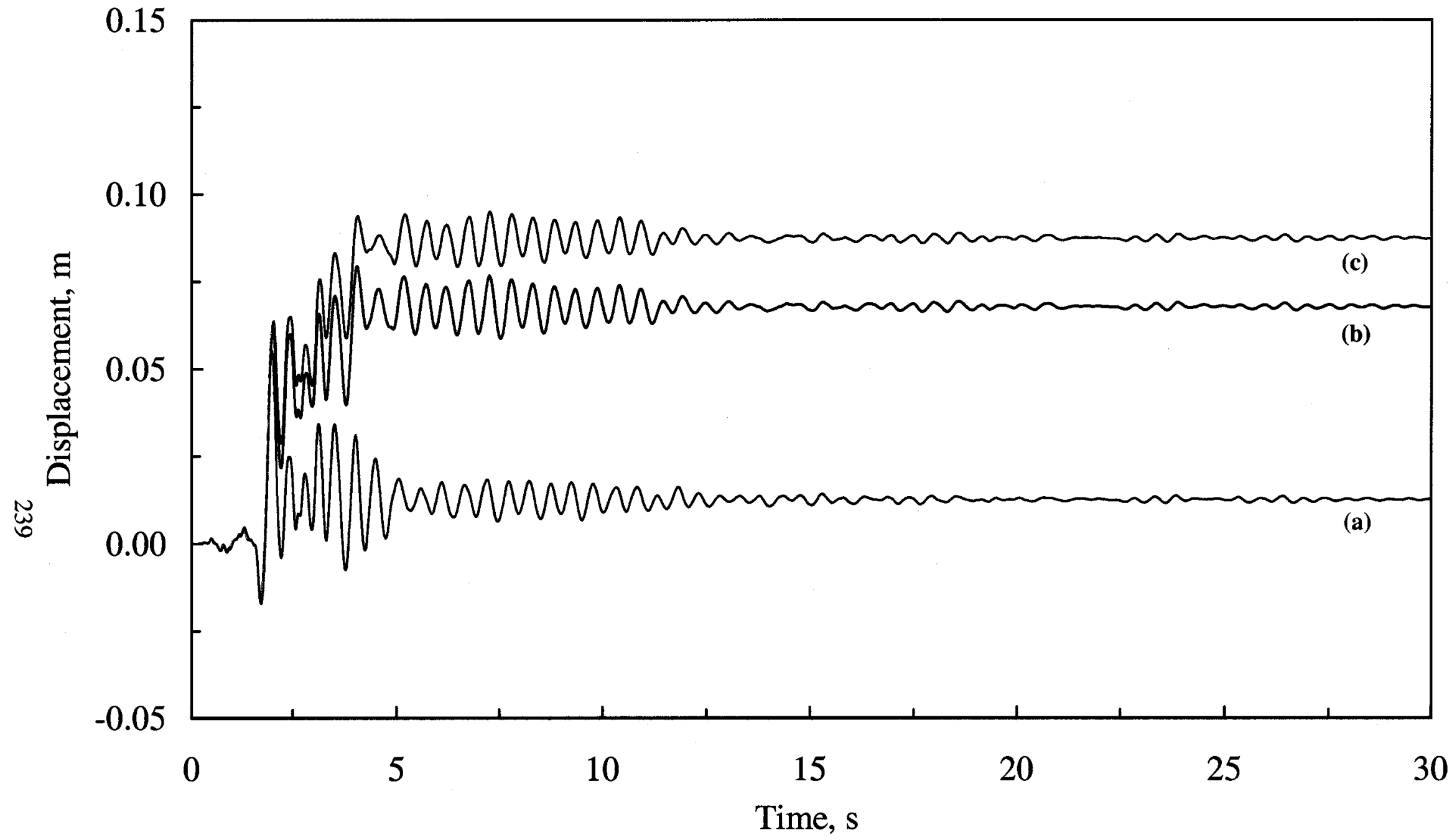

Fig. 5.17 History of lateral frame displacement caused by Montana 1935 ground motion (a) original frame without P- $\Delta$ effect, (b) original frame with P- $\Delta$ effect, (c) frame with a strength, $\mathrm{V}_{\mathrm{y} 1}=0.89 \mathrm{~V}_{\mathrm{yo}}$ and $\mathrm{P}-\Delta$ effect, no strain hardening in each case 


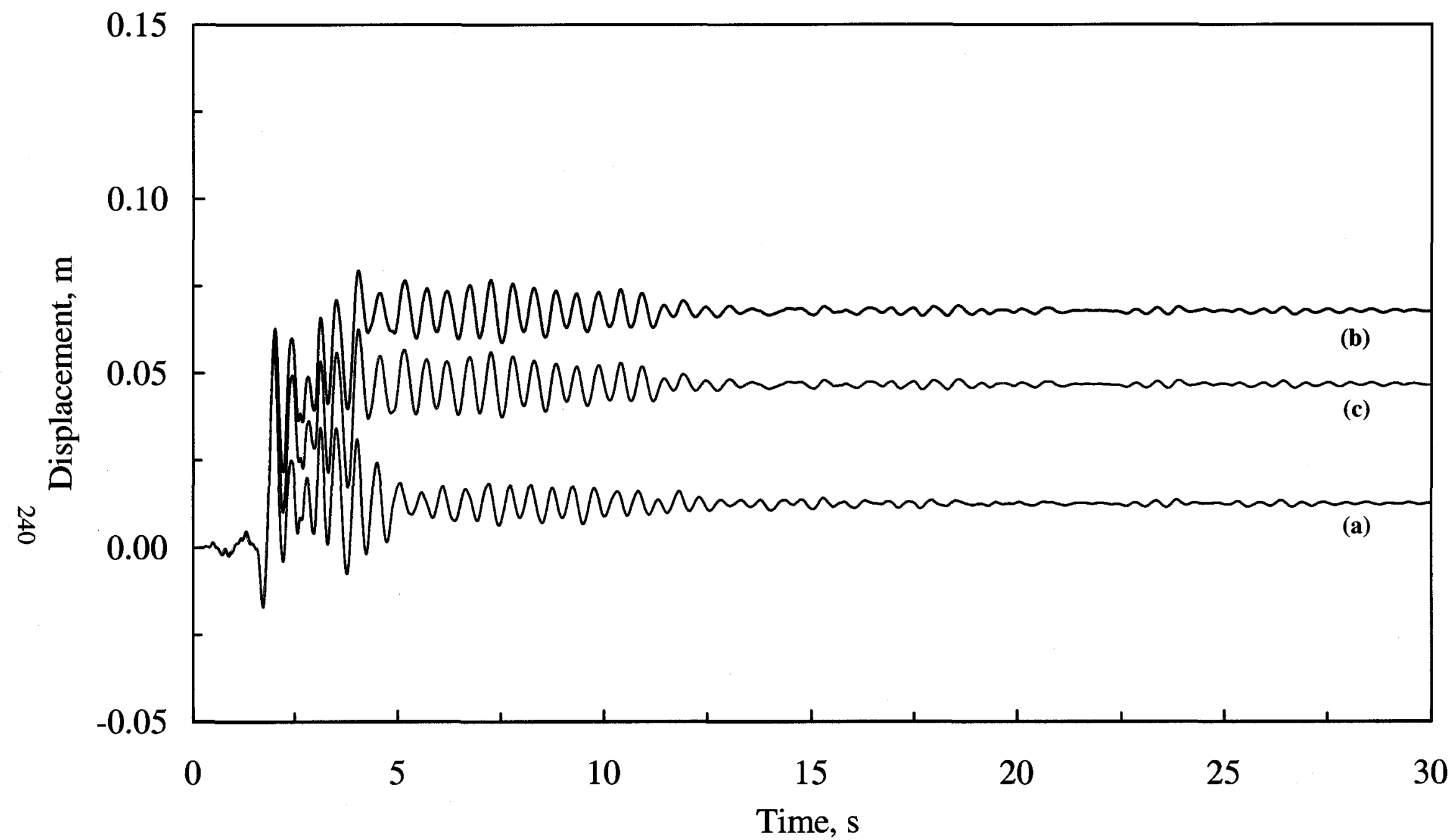

Fig. 5.18 History of lateral frame displacement caused by Montana 1935 ground motion (a) original frame without P- $\Delta$ effect, (b) original frame with P- $\Delta$ effect, (c) frame with a strength, $\mathrm{V}_{\mathrm{y} 1}=1.11 \mathrm{~V}_{\mathrm{yo}}$ and $\mathrm{P}-\Delta$ effect, no strain hardening in each case 


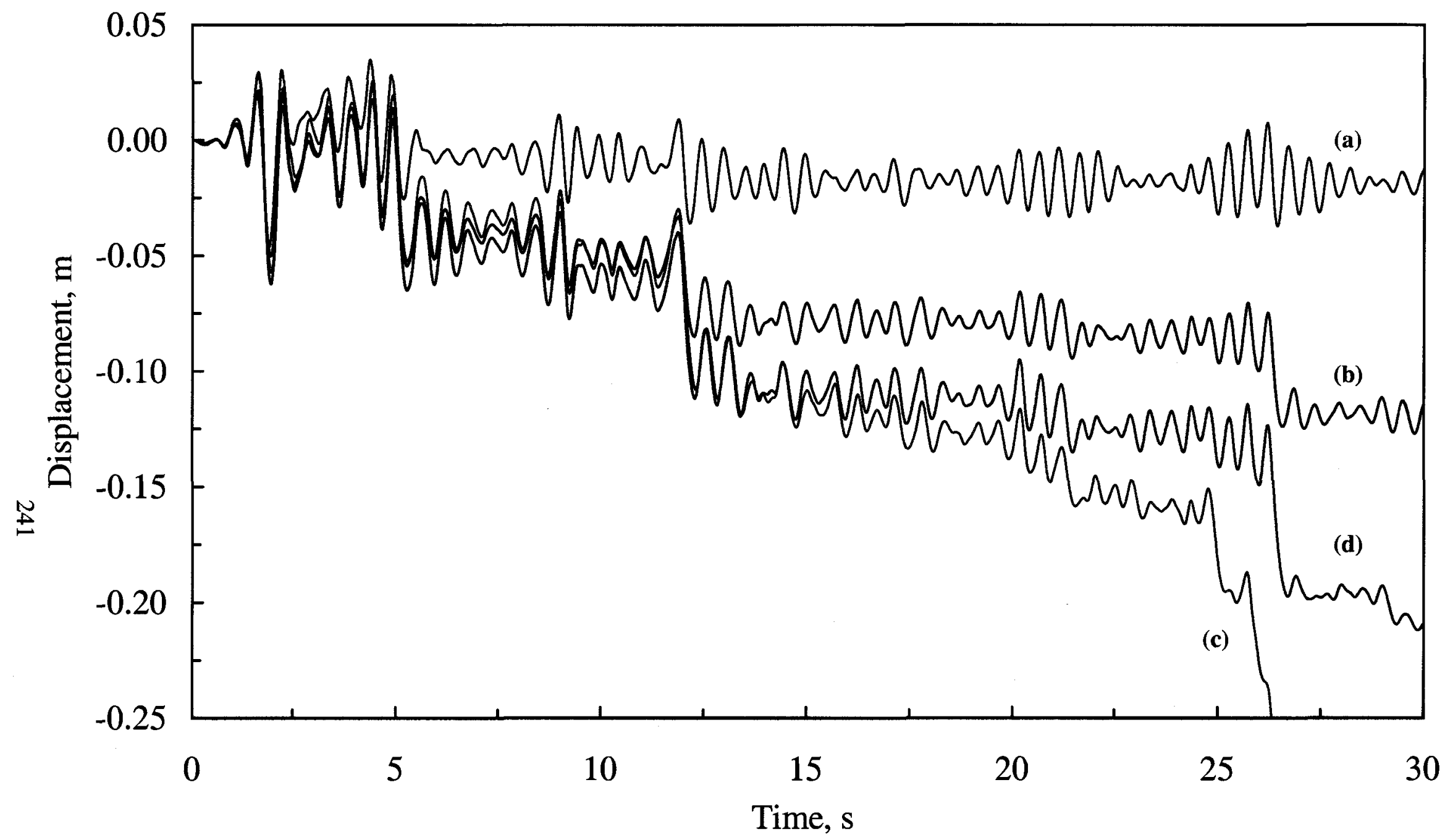

Fig. 5.19 History of lateral frame displacement caused by El-Centro 1940 ground motion (a) original frame without P- $\Delta$, (b) original frame with $\mathrm{P}-\Delta$, (c) frame with $\mathrm{V}_{\mathrm{y} 1}=1.11 \mathrm{~V}_{\mathrm{yo}}$ \& $\mathrm{P}$ $\Delta$, (d) frame with $\mathrm{V}_{\mathrm{y} 1}=1.22 \mathrm{~V}_{\mathrm{yo}}$ \& $\mathrm{P}-\Delta$, no strain hardening in each case 


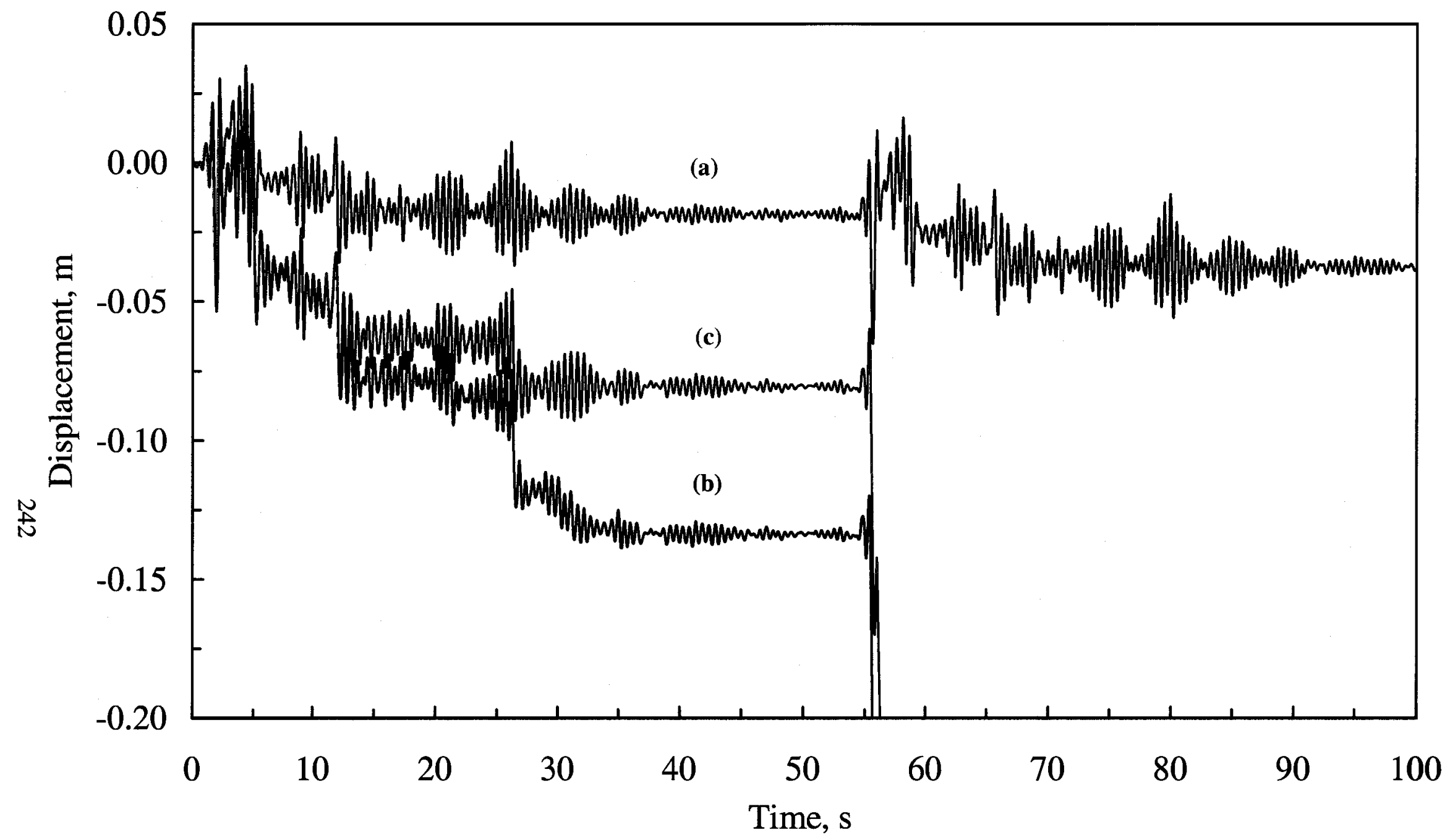

Fig. 5.20 History of lateral frame displacement caused by El-Centro 1940 ground motion back to back, (a) original frame without $\mathrm{P}-\Delta$, (b) original frame with $\mathrm{P}-\Delta$, (c) frame with a strength $\mathrm{V}_{\mathrm{y} 1}=\mathrm{V}_{\mathrm{yo}} /(1-\theta)$ and $\mathrm{P}-\Delta$ effect, no strain hardening in each case 


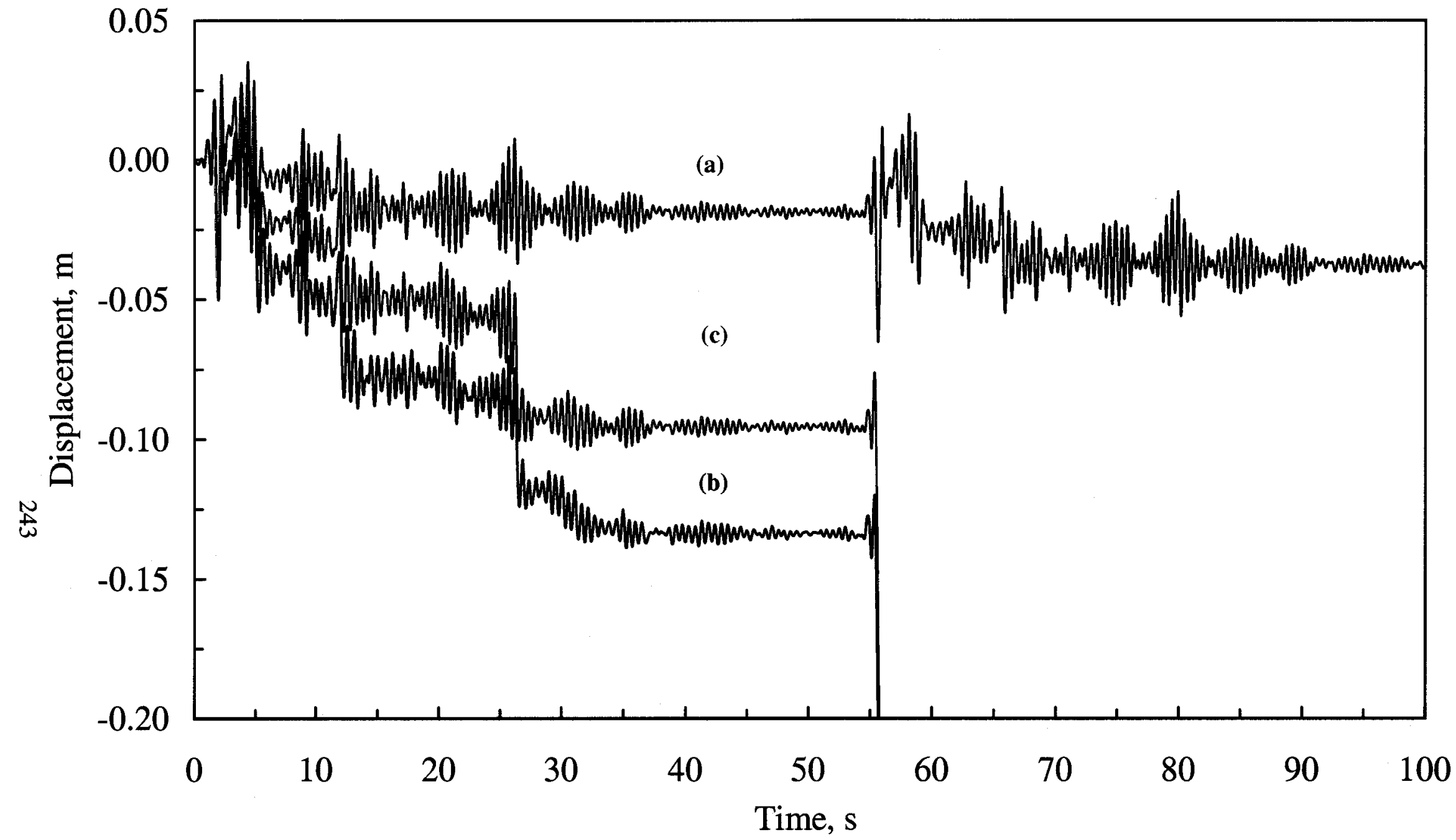

Fig. 5.21 History of lateral frame displacement caused by El-Centro 1940 ground motion back to back, (a) original frame without P- $\Delta$, (b) original frame with P- $\Delta$, (c) frame with a stiffness $K_{1}=K_{0}(1+\theta)$ and $P-\Delta$ effect, no strain hardening in each case 


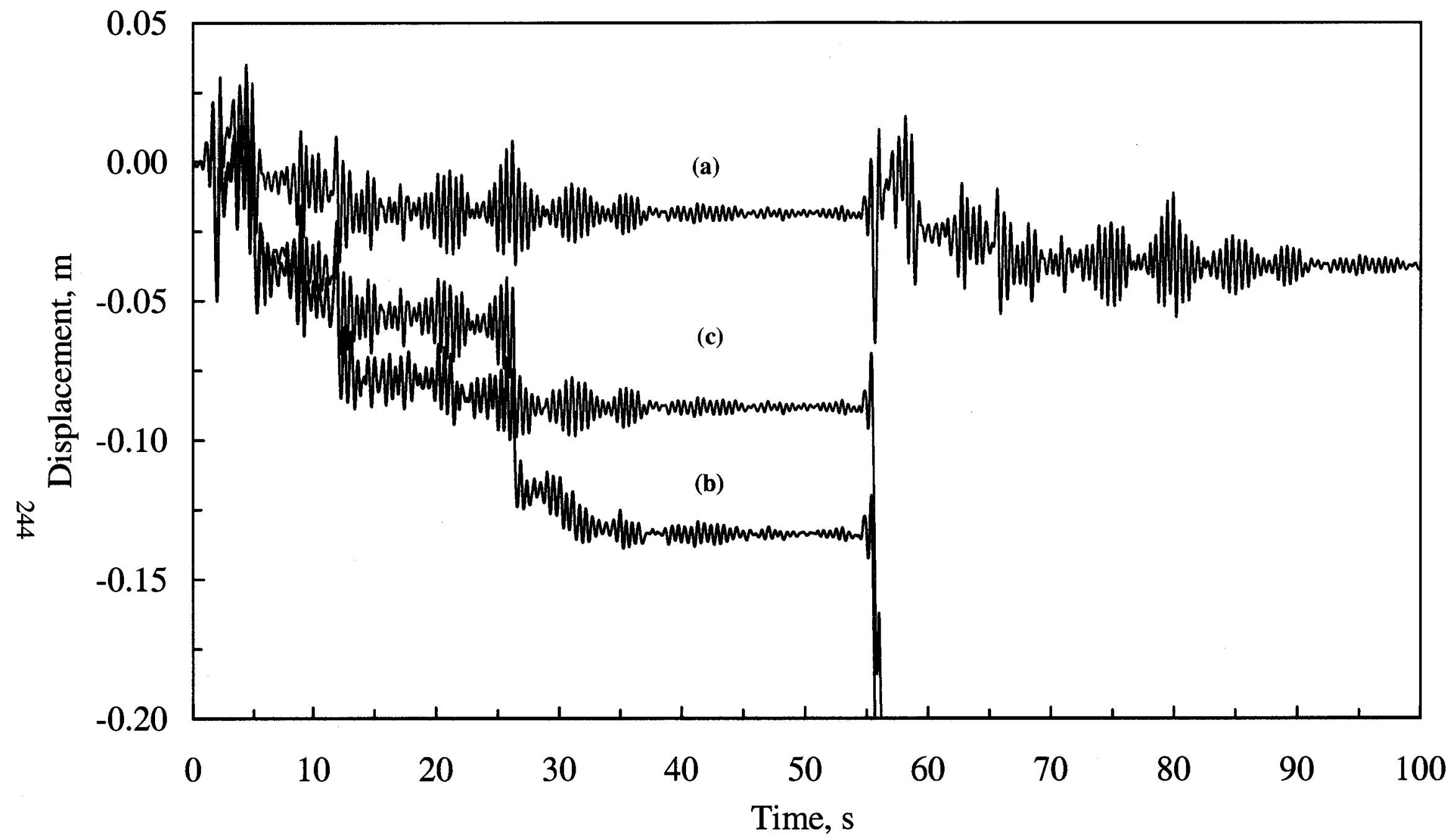

Fig. 5.22 History of lateral frame displacement caused by El-Centro 1940 ground motion back to back, (a) original frame without $P-\Delta$, (b) original frame with $P-\Delta$, (c) frame with $V_{y 1}=V_{y 0}(1+$ $\theta), K_{1}=K_{o}(1+\theta)$ and $P-\Delta$ effect, no strain hardening in each case 


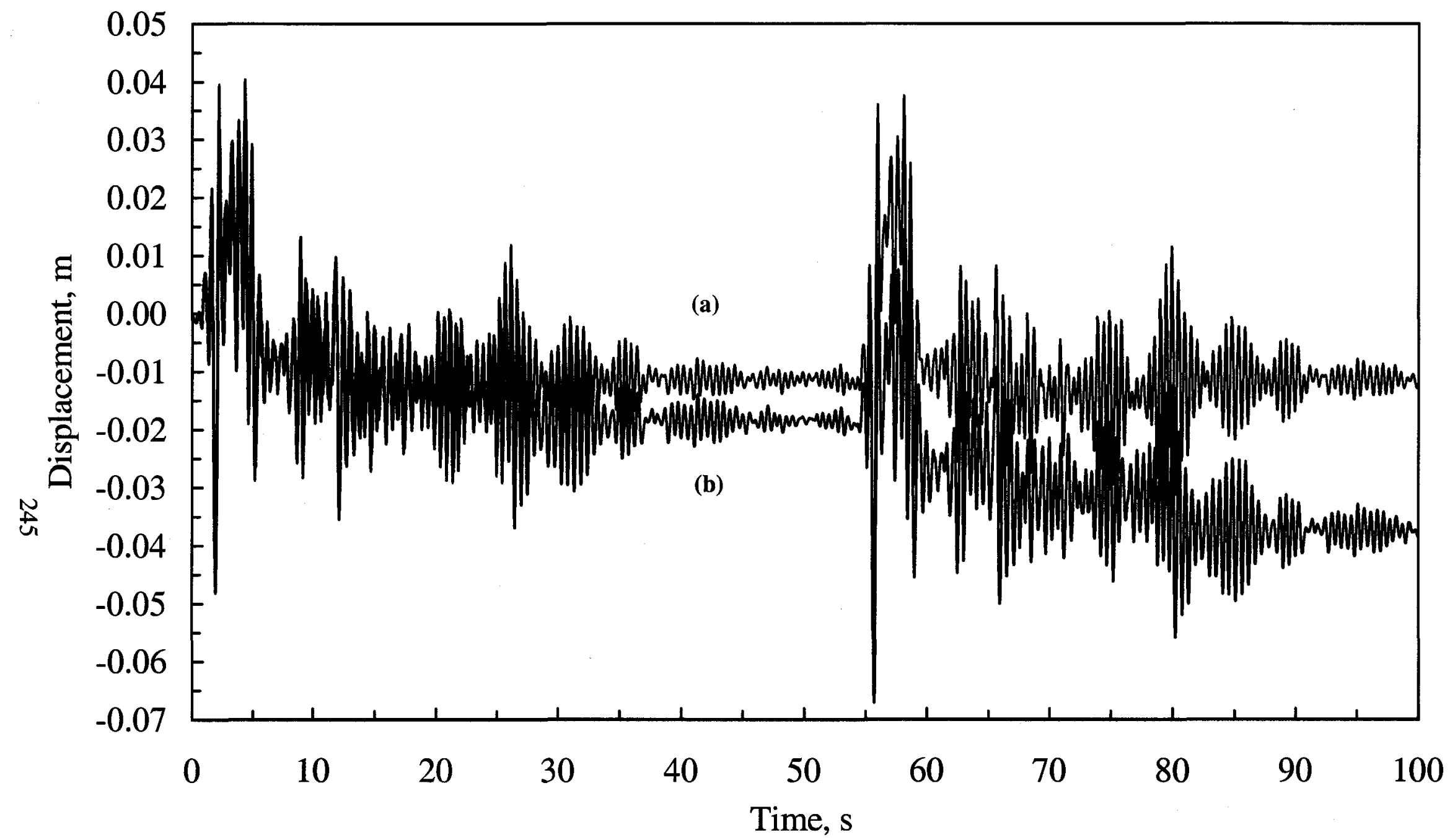

Fig. 5.23 History of lateral frame displacement caused by El-Centro 1940 ground motion back to back, (a) frame without P- $\Delta$ effect, with $\alpha=10 \%$ (b) frame with P- $\Delta$ effect and $\alpha=10 \%$ 


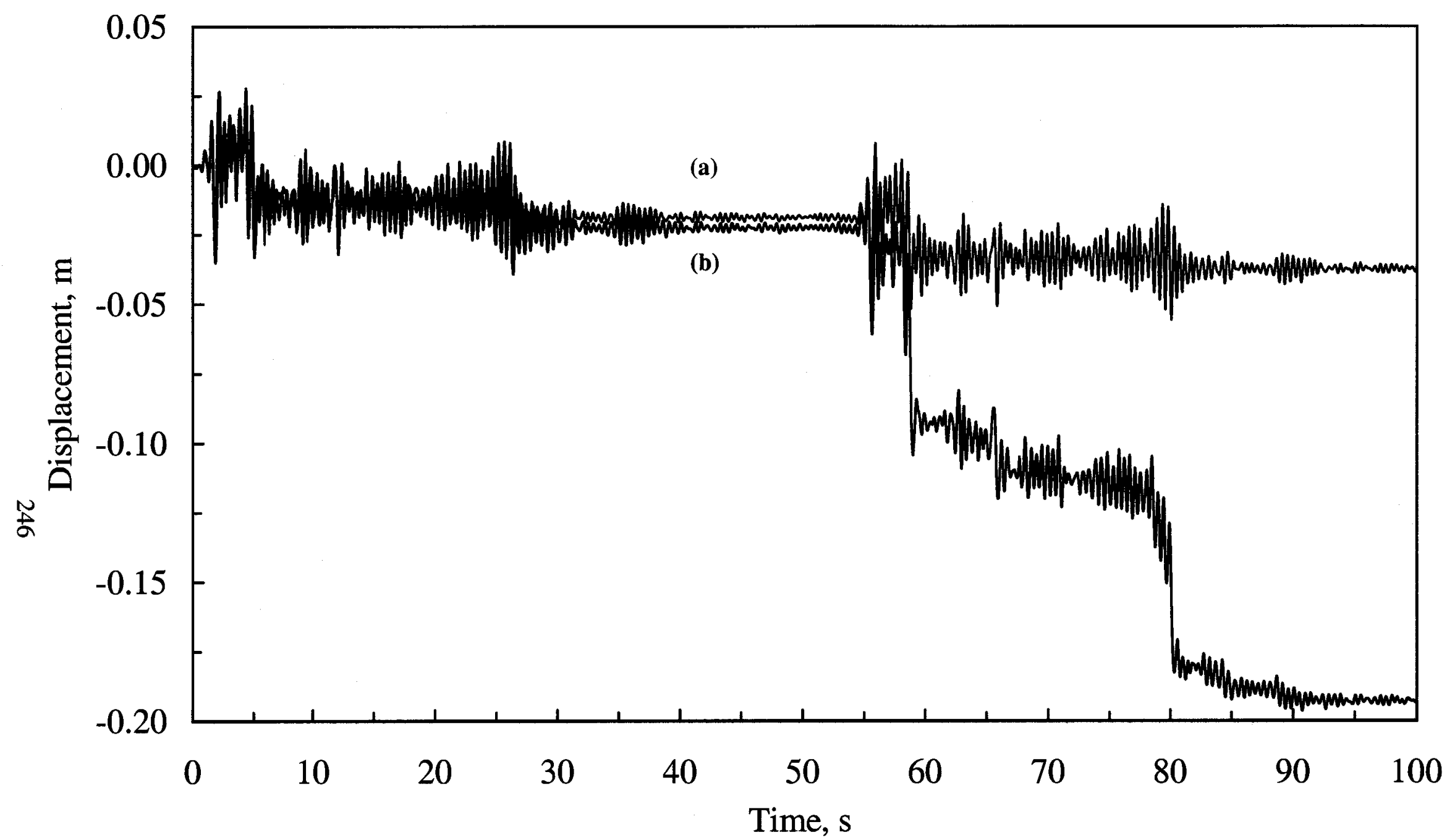

Fig. 5.24 History of lateral frame displacement caused by El-Centro 1940 ground motion back to back, (a) original frame without P- $\Delta$ effect (b) original frame with P- $\Delta$ effect, both strength and stiffness enhanced by 1.3, no strain hardening in each case 


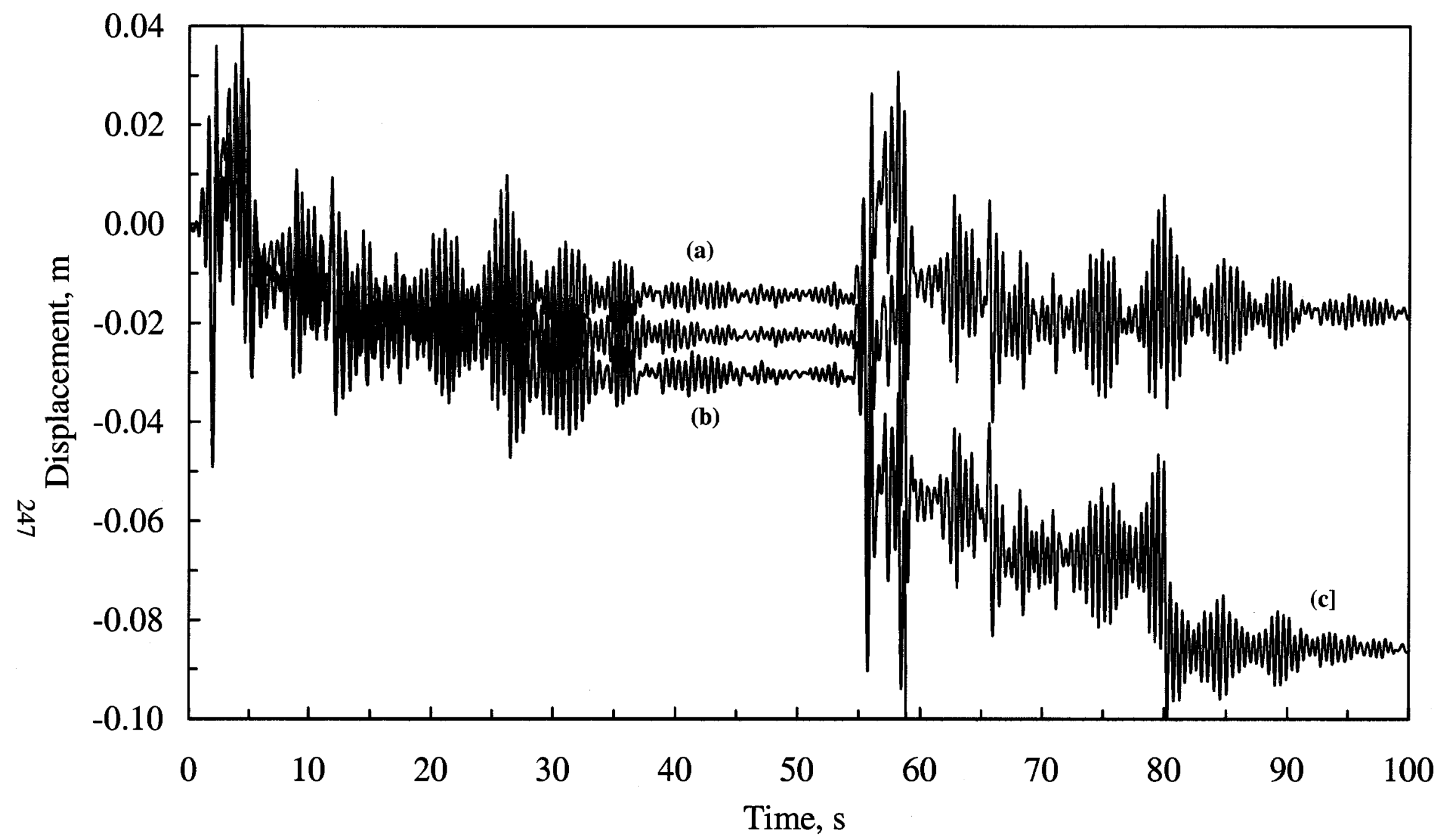

Fig. 5.25 History of lateral frame displacement caused by El-Centro ground motion back to back, (a) frame without P- $\Delta$ and $\alpha=5 \%$, (b) frame with P- $\Delta$ and $\alpha=5 \%$, (c) frame with P- $\Delta$, $\alpha=5 \%$ and with both strength and stifness enhanced by 1.18 


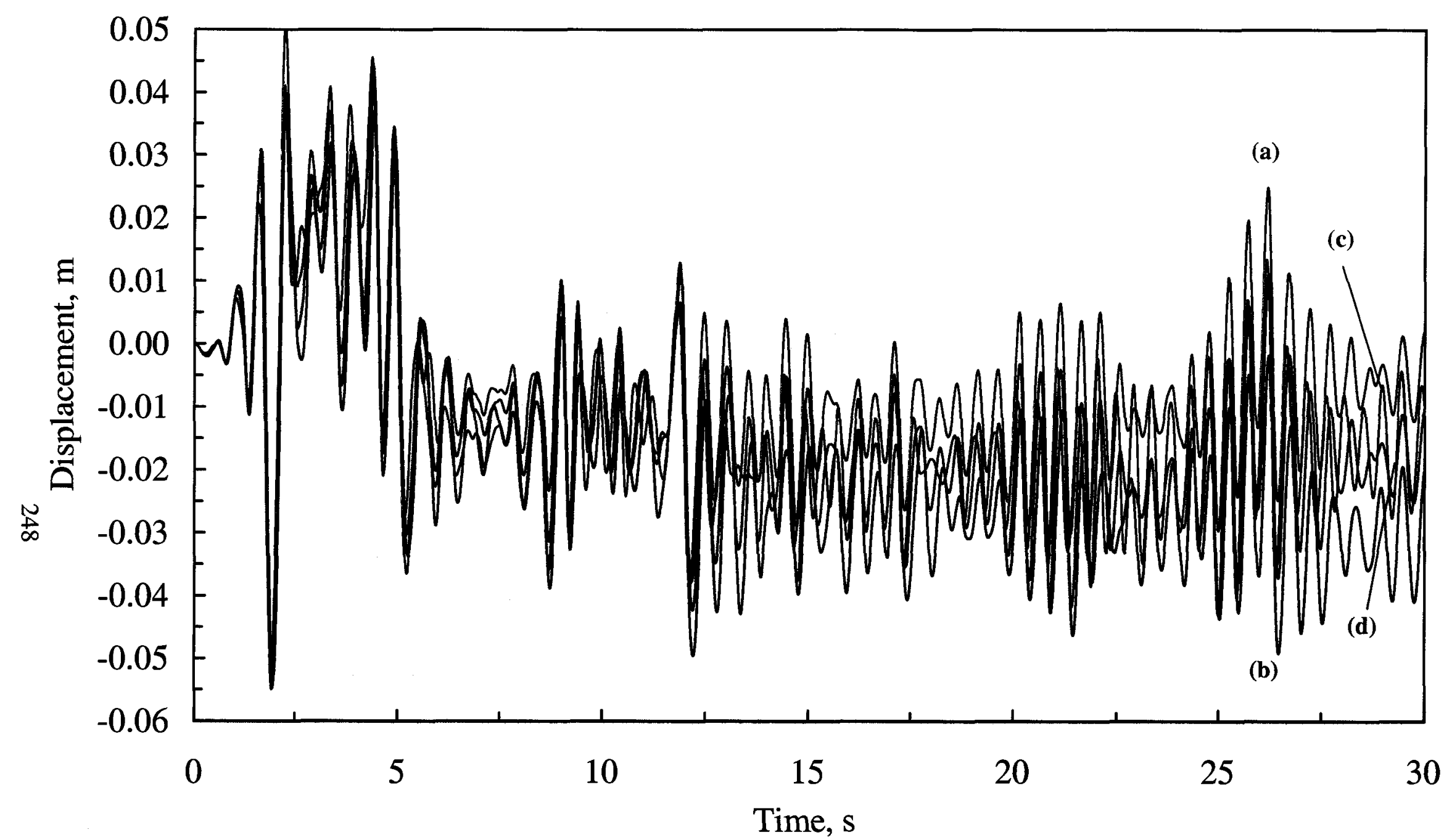

Fig. 5.26 History of lateral frame displacement caused by El-Centro 1940 ground motion, (a) frame without P- $\Delta$ and $\alpha=10 \%$, (b) frame with P- $\Delta$ and $\alpha=10 \%$, (c) enhanced frame with P$\Delta$ and $\alpha=10 \%$ (Eq. 5.13), (d) enhanced frame with P- $\Delta$ and $\alpha=10 \%$ (Eq. 5.16) 


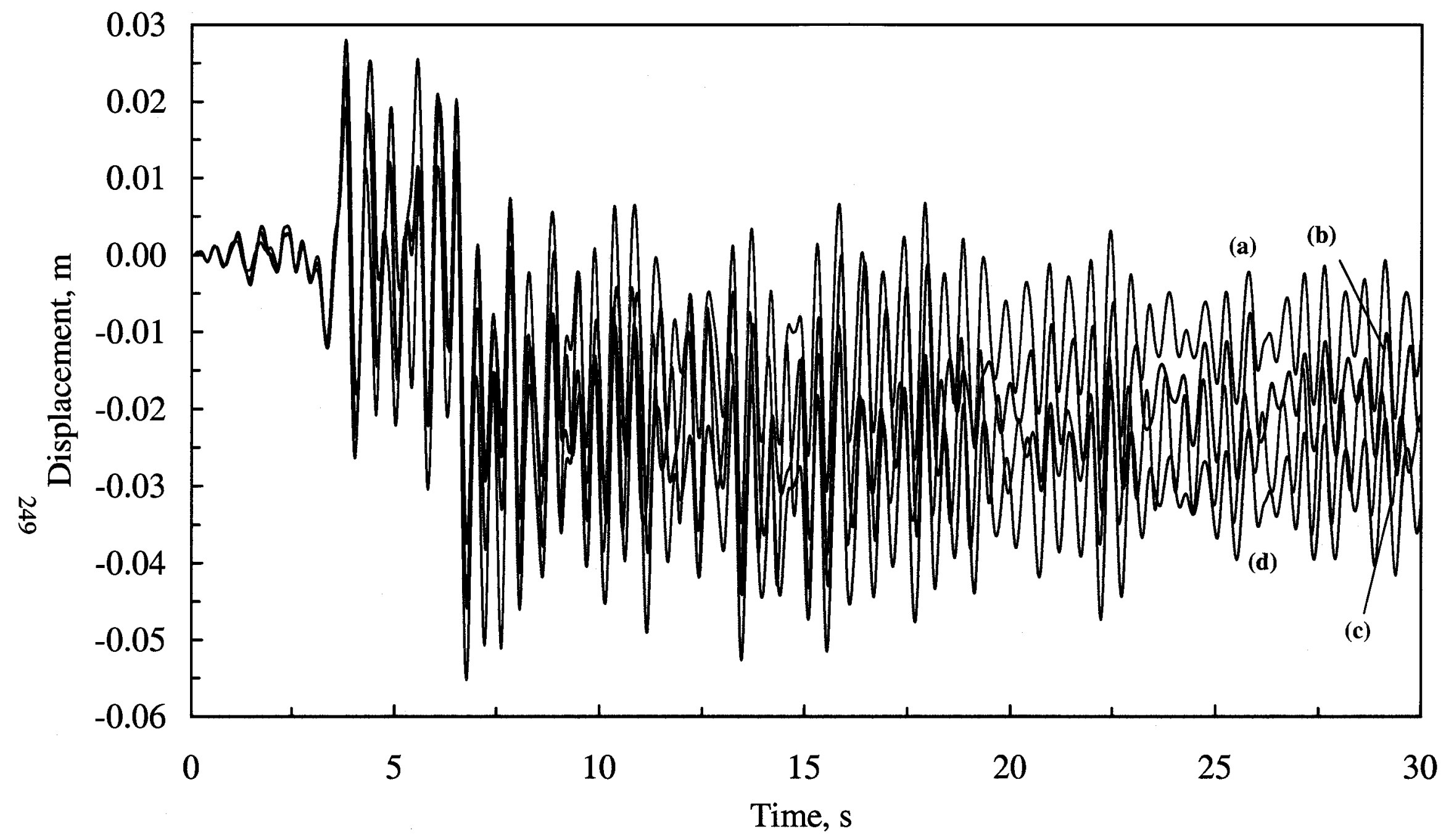

Fig. 5.27 History of lateral frame displacement caused by Kern County 1952 ground motion, (a) frame without P- $\Delta$ and $\alpha=10 \%$, (b) frame with P- $\Delta$ and $\alpha=10 \%$, (c) enhanced frame with P$\Delta$ and $\alpha=10 \%$ (Eq. 5.13), (d) enhanced frame with P- $\Delta$ and $\alpha=10 \%$ (Eq. 5.16) 


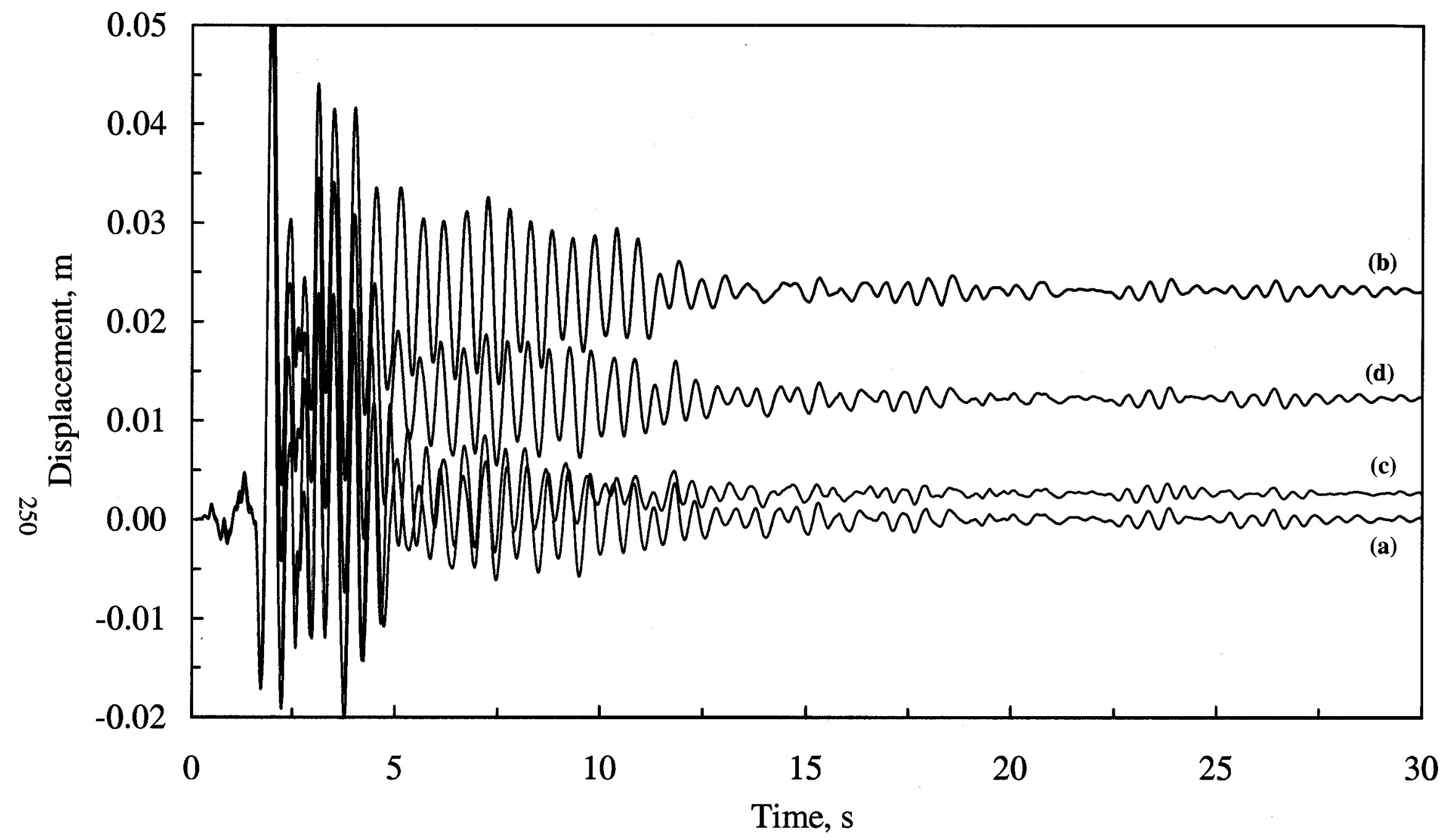

Fig. 5.28 History of lateral frame displacement caused by Montana 1935 ground motion, (a) frame without P- $\Delta$ and $\alpha=10 \%$, (b) frame with P- $\Delta$ and $\alpha=10 \%$, (c) enhanced frame with P$\Delta$ and $\alpha=10 \%$ (Eq. 5.13), (d) enhanced frame with P- $\Delta$ and $\alpha=10 \%$ (Eq. 5.16) 


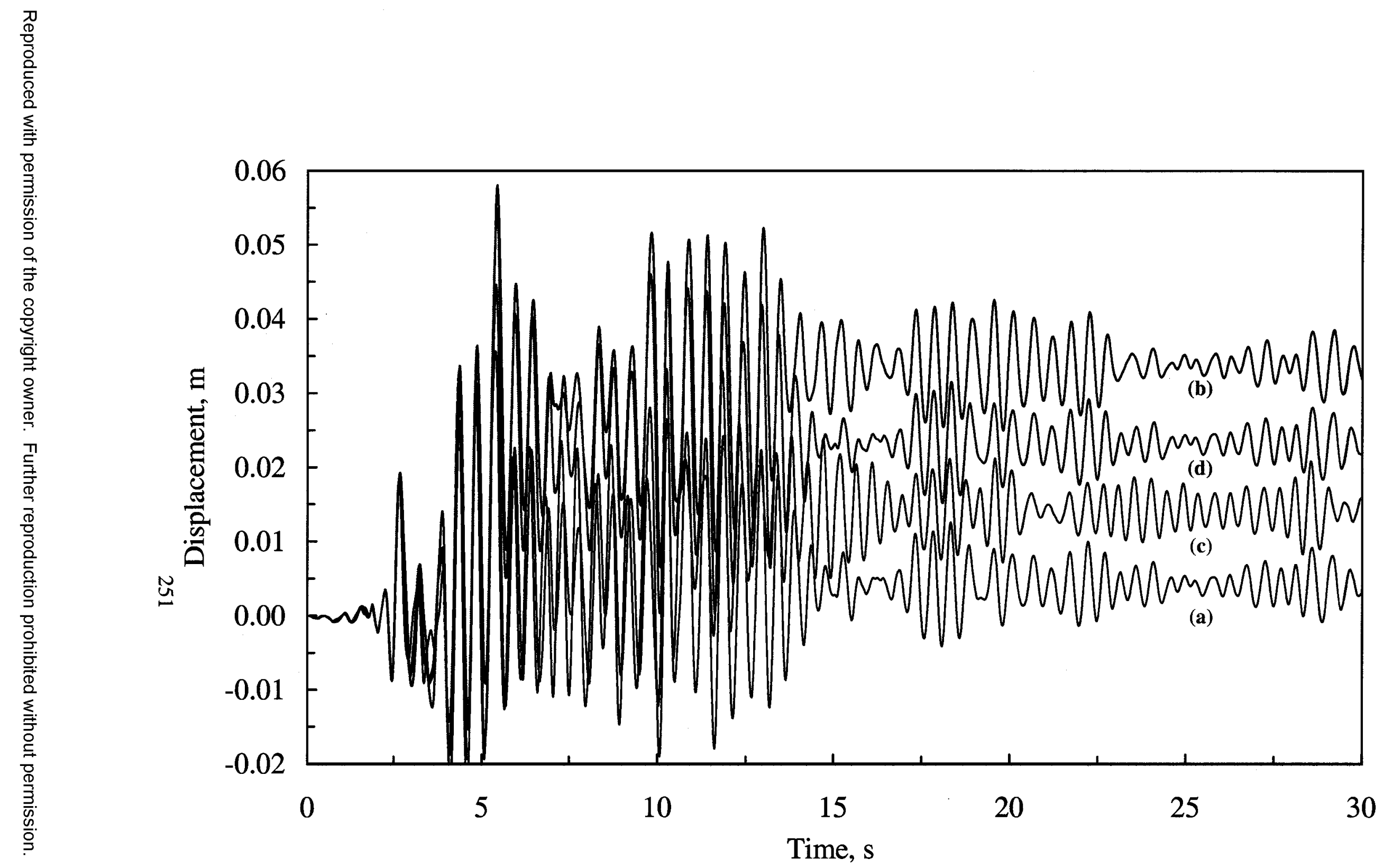

Fig. 5.29 History of lateral frame displacement caused by Monte Negro 1979 ground motion (a) frame without P- $\Delta$ and $\alpha=10 \%$, (b) frame with P- $\Delta$ and $\alpha=10 \%$, (c) enhanced frame with P$\Delta$ and $\alpha=10 \%$ (Eq. 5.13), (d) enhanced frame with P- $\Delta$ and $\alpha=10 \%$ (Eq. 5.16) 


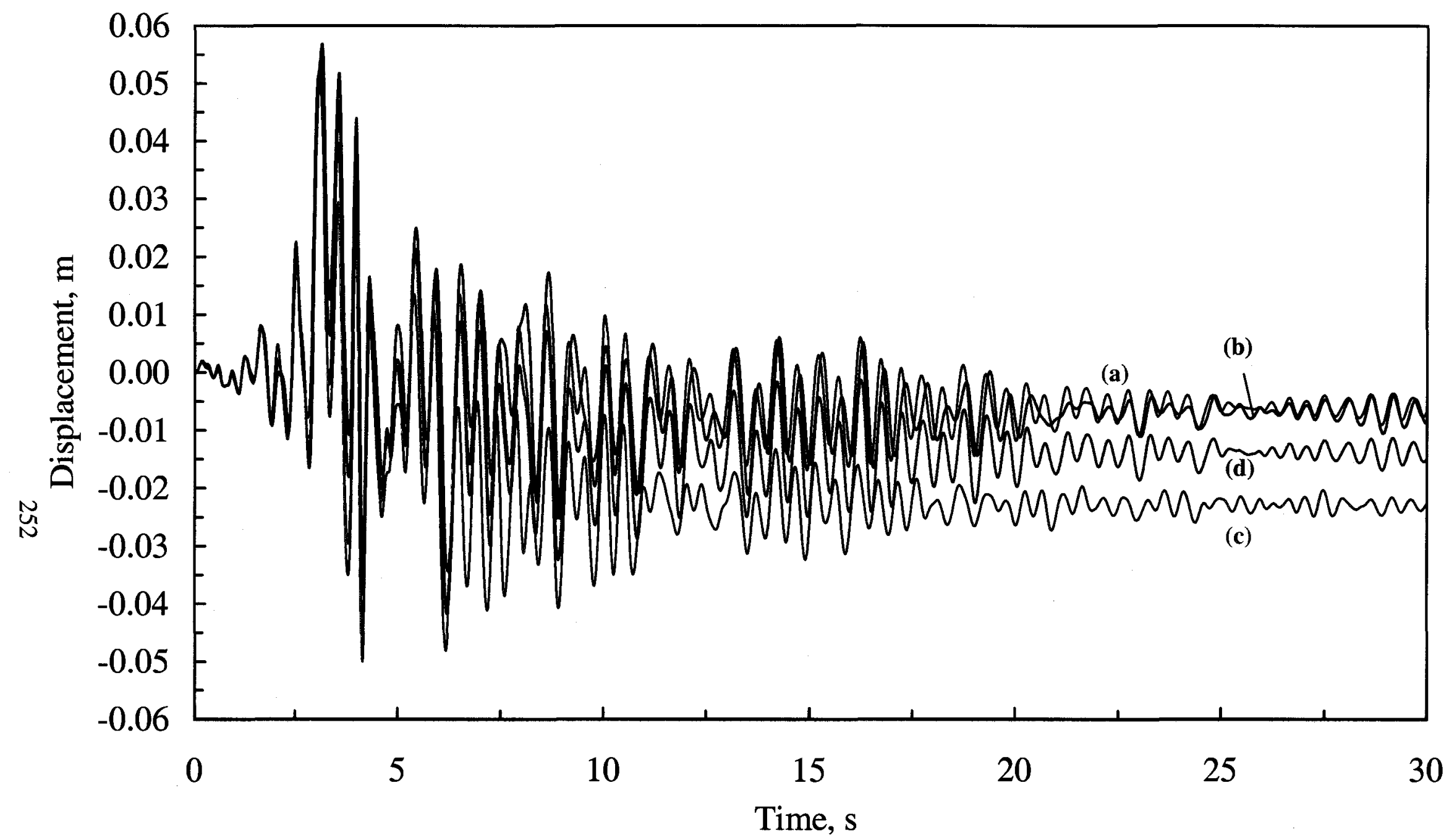

Fig. 5.30 History of lateral frame displacement caused by Parkfield 1966 ground motion, (a) frame without P- $\Delta$ and $\alpha=10 \%$, (b) frame with P- $\Delta$ and $\alpha=10 \%$, (c) enhanced frame with P$\Delta$ and $\alpha=10 \%$ (Eq. 5.13), (d) enhanced frame with P- $\Delta$ and $\alpha=10 \%$ (Eq. 5.16) 


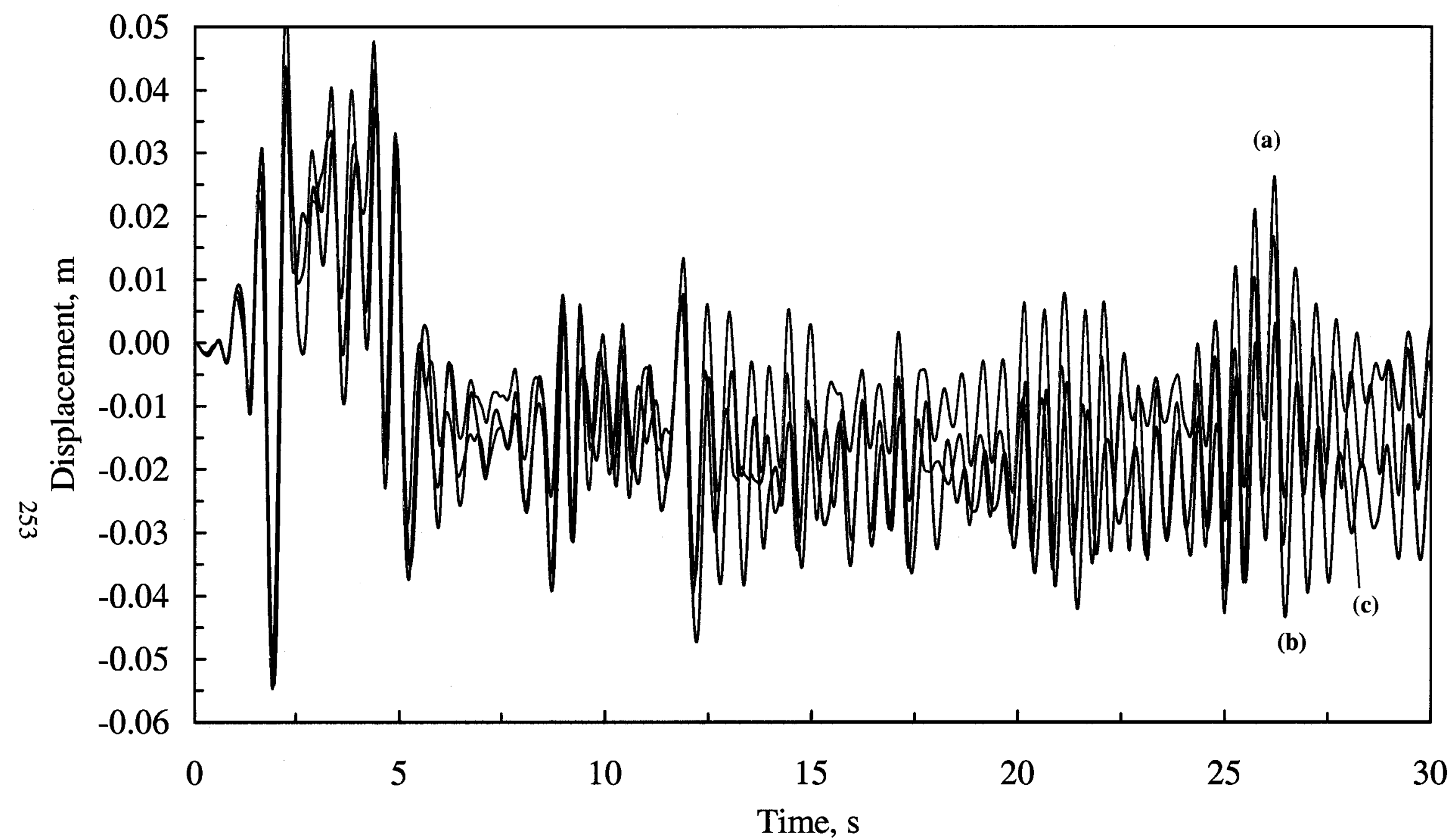

Fig. 5.31 History of lateral frame displacement caused by El-Centro 1940 ground motion, (a) frame without P- $\Delta$ and $\alpha=12 \%$, (b) frame with P- $\Delta$ and $\alpha=12 \%$, (c) enhanced frame with P- $\Delta$ and $\alpha=12 \%$ (Eq. 5.16), 


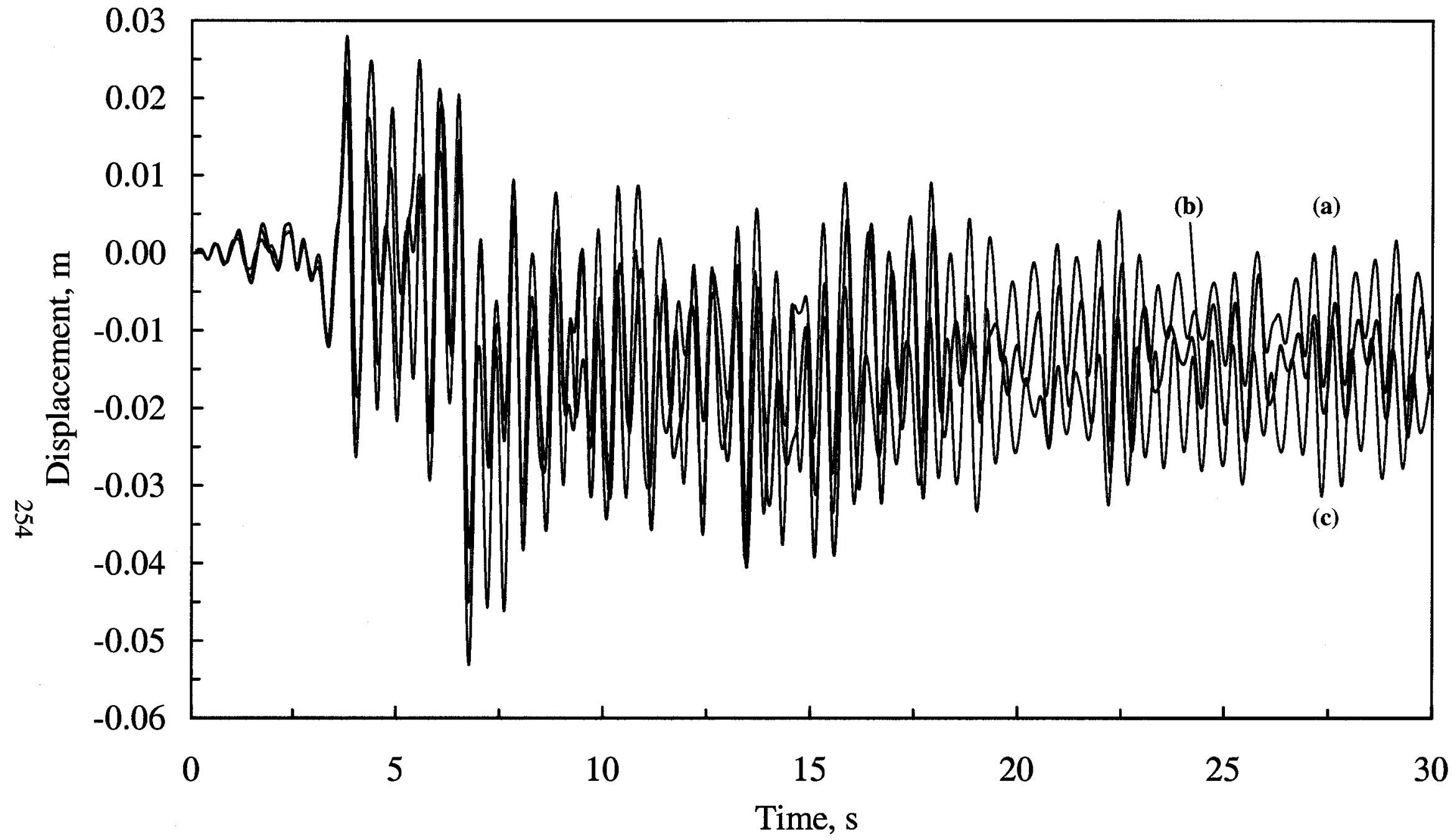

Fig. 5.32 History of lateral frame displacement caused by Kern County 1952 ground motion, (a) frame without P- $\Delta$ and $\alpha=12 \%$, (b) frame with P- $\Delta$ and $\alpha=12 \%$, (c) enhanced frame with P- $\Delta$ and $\alpha=12 \%$ (Eq. 5.16), 


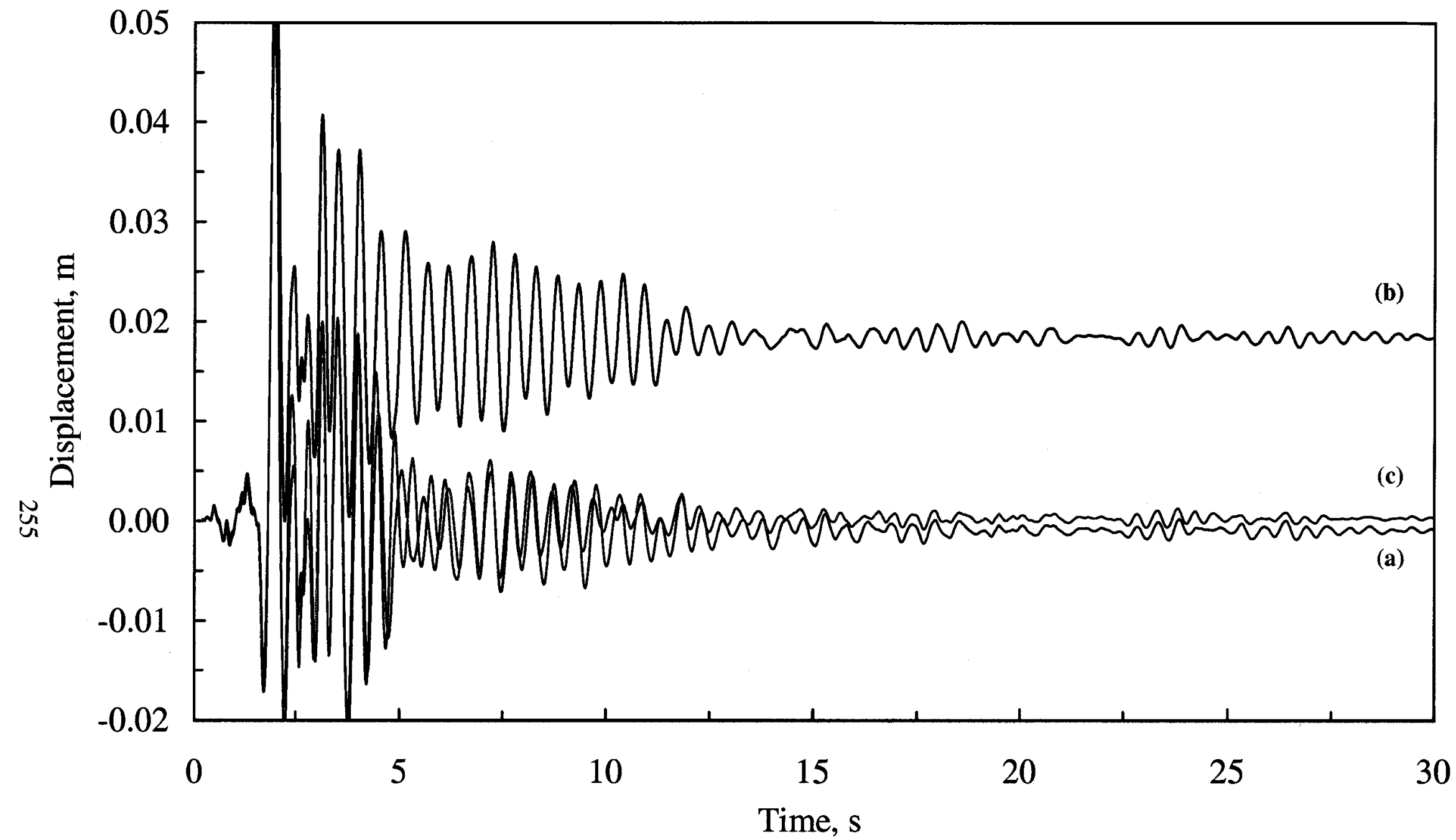

Fig. 5.33 History of lateral frame displacement caused by Montana 1935 ground motion,

(a) frame without P- $\Delta$ and $\alpha=12 \%$, (b) frame with P- $\Delta$ and $\alpha=12 \%$, (c) enhanced frame with

P- $\Delta$ and $\alpha=12 \%$ (Eq. 5.16), 


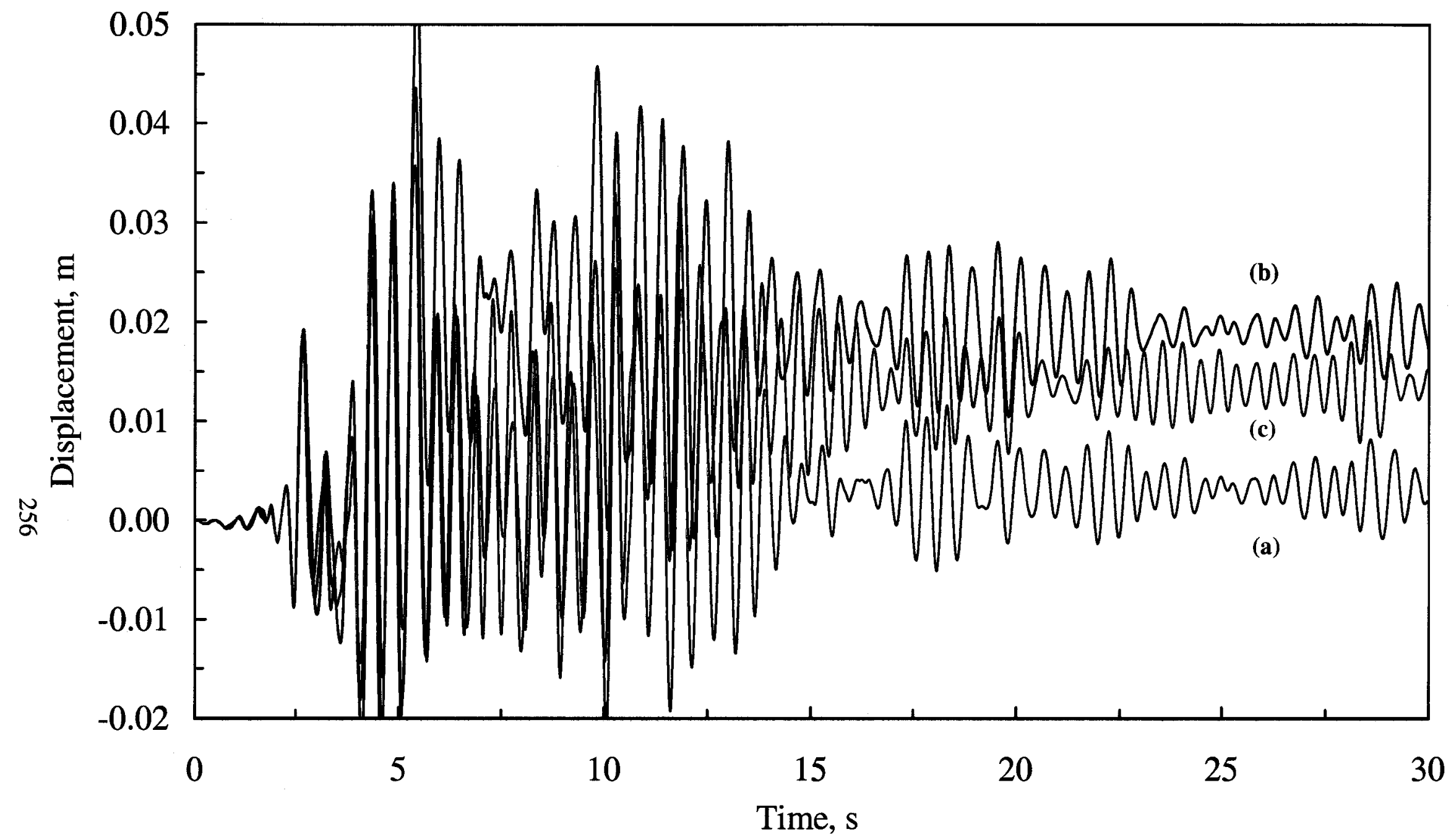

Fig. 5.34 History of lateral frame displacement caused by Monte Negro 1979 ground motion, (a) frame without P- $\Delta$ and $\alpha=12 \%$, (b) frame with P- $\Delta$ and $\alpha=12 \%$, (c) enhanced frame with P- $\Delta$ and $\alpha=12 \%$ (Eq. 5.16), 


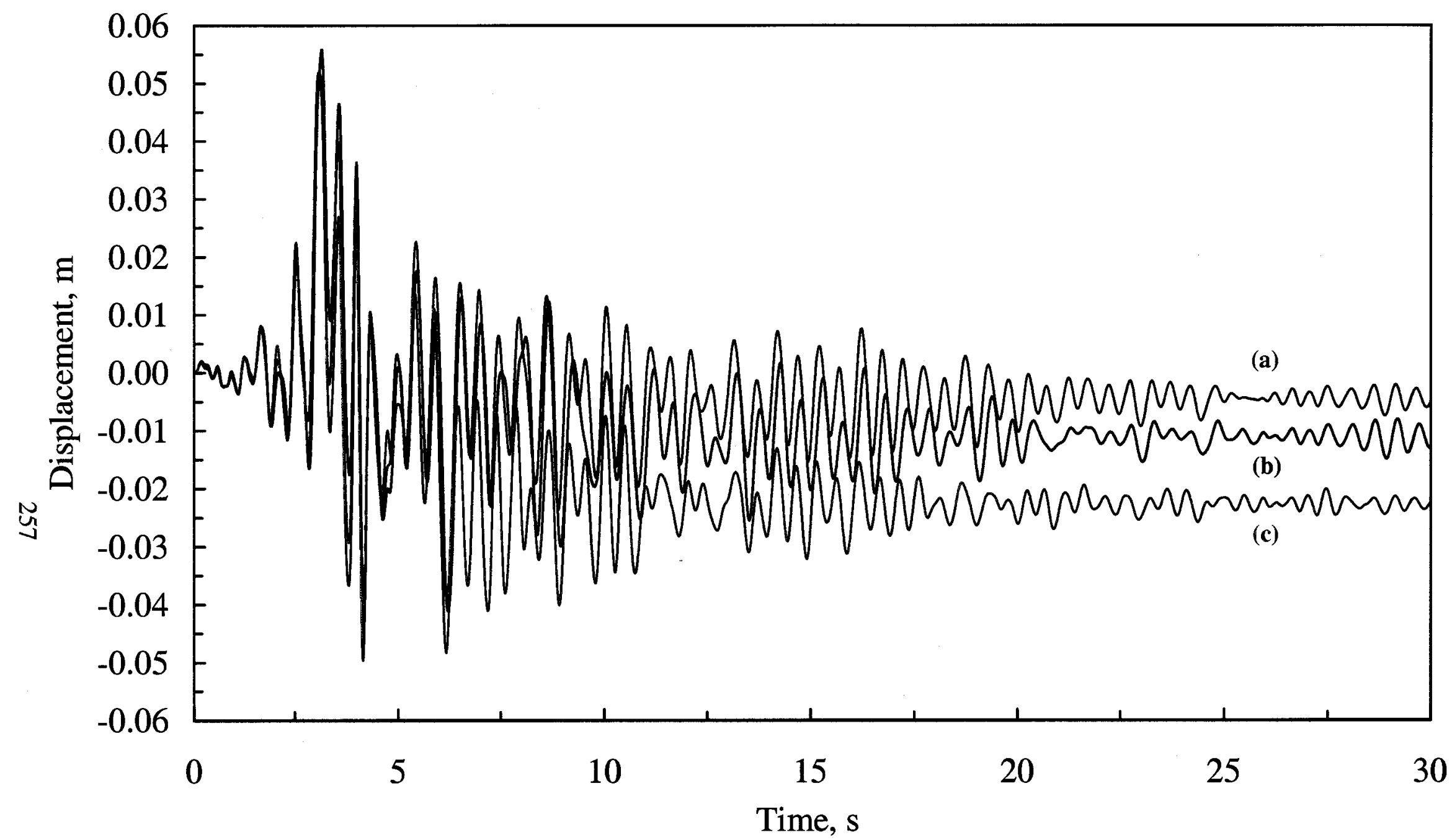

Fig. 5.35 History of lateral frame displacement caused by Parkfield 1966 ground motion,

(a) frame without P- $\Delta$ and $\alpha=12 \%$, (b) frame with P- $\Delta$ and $\alpha=12 \%$, (c) enhanced frame with

P- $\Delta$ and $\alpha=12 \%$ (Eq. 5.16), 

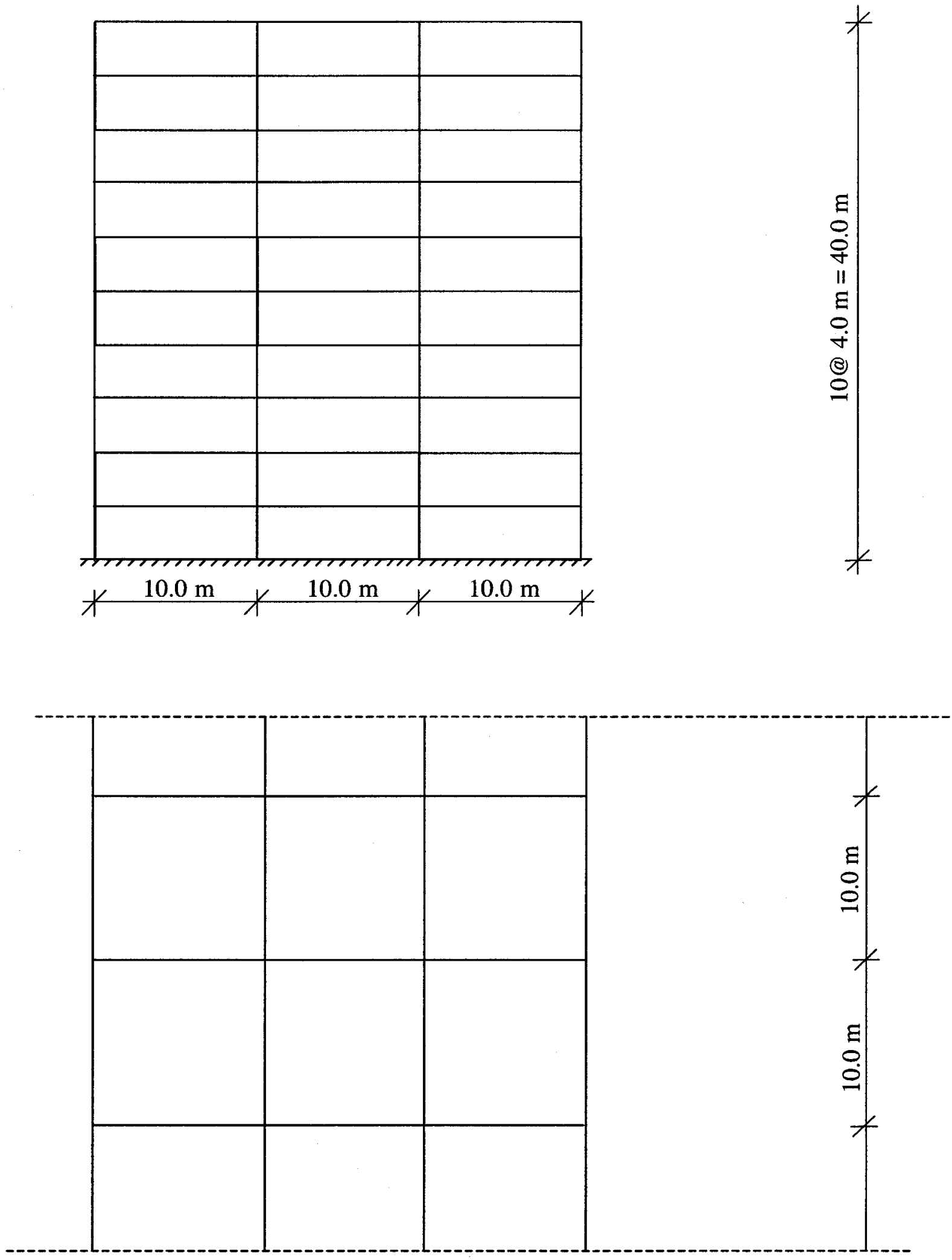

Fig. 5.36 An elevation and a plan for the 10-storey MRF model 258 


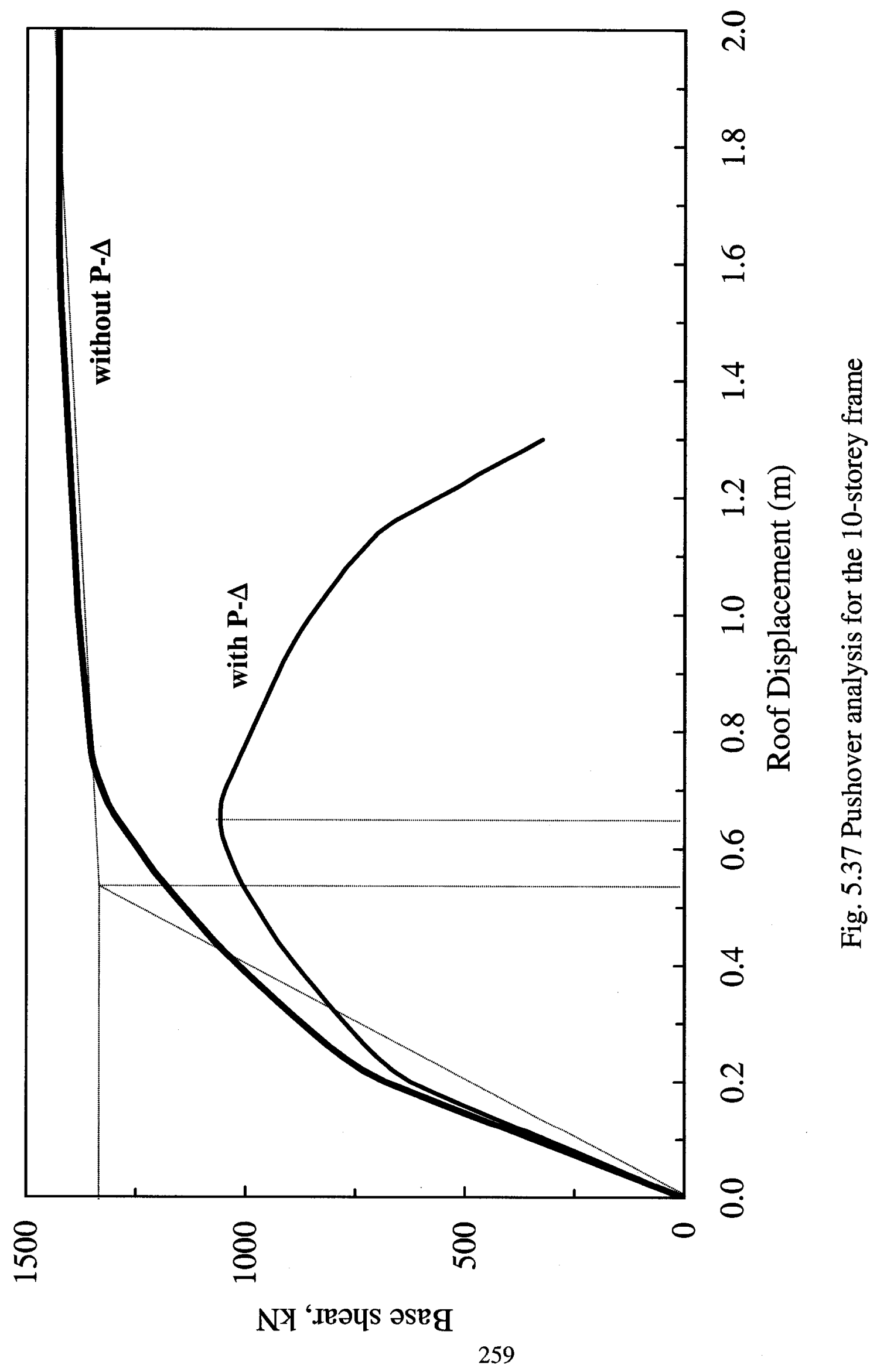

Reproduced with permission of the copyright owner. Further reproduction prohibited without permission. 


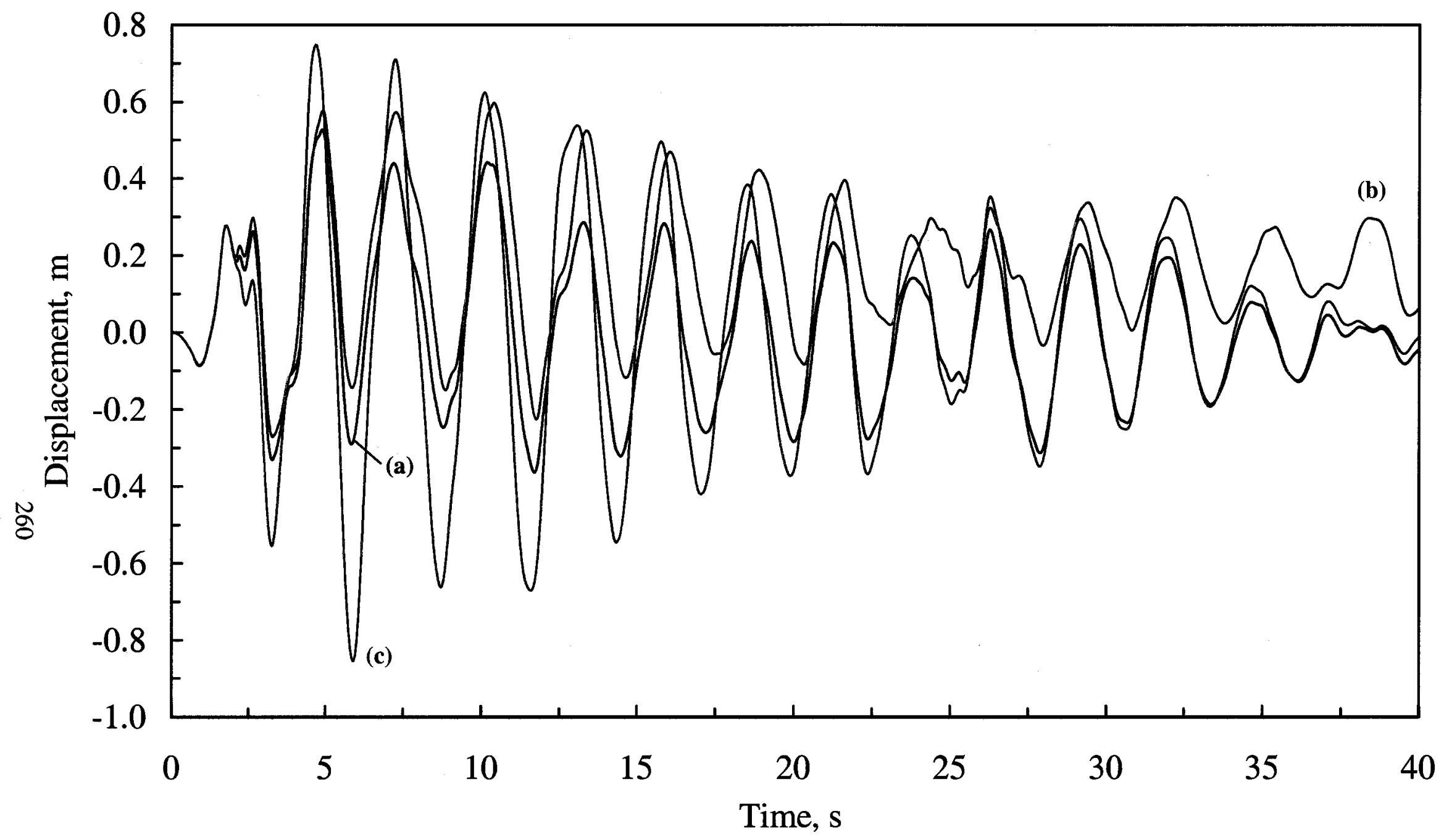

Fig. 5.38 History of lateral top frame displacement caused by El-Centro 1940 ground motion (scale factor $=2.291$ ), (a) MRF inelastic response without P- $\Delta$, (b) MRF inelastic response with $\mathrm{P}-\Delta$, (c) MRF elastic response without $\mathrm{P}-\Delta$ 


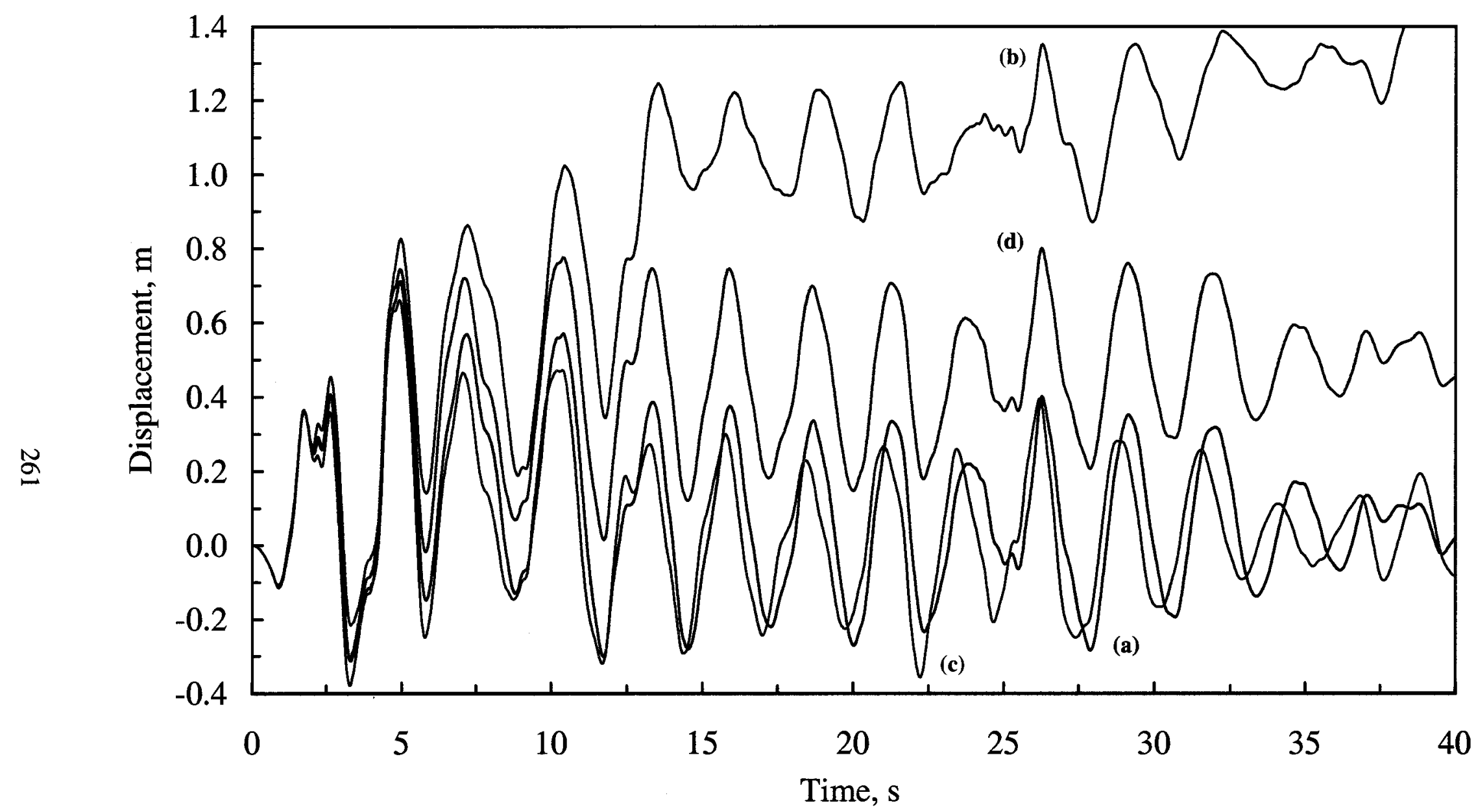

Fig. 5.39 History of inelastic lateral top frame displacement caused by El-Centro 1940 ground motion (scale factor $=3.00$ ), (a) MRF without $P-\Delta$, (b) MRF with $P-\Delta$, (c) enhanced MRF without $P-\Delta$, (d) enhanced MRF with P- $\Delta$ 


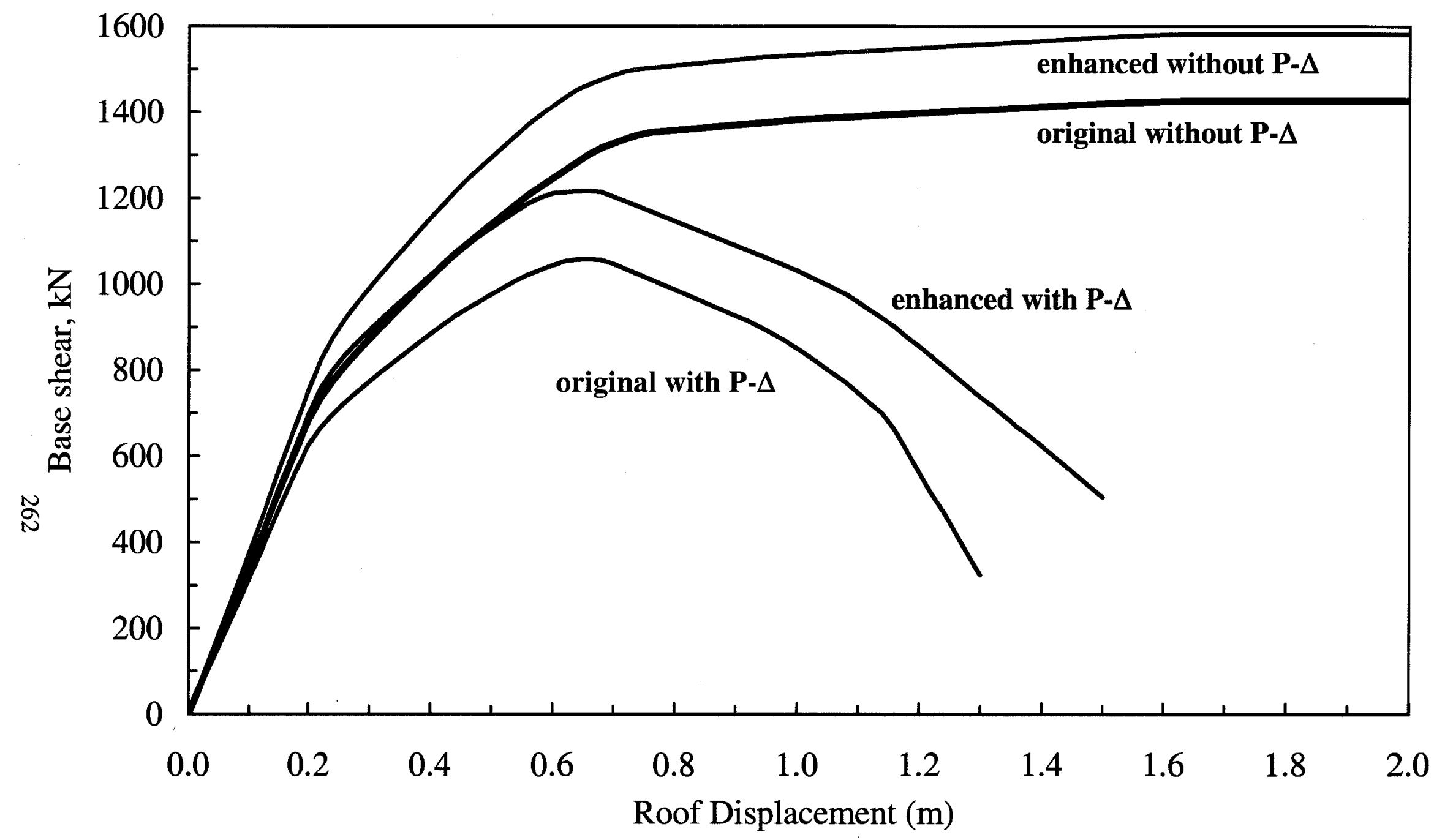

Fig. 5.40 Push-over analysis for the 10-storey original and enhanced frame 


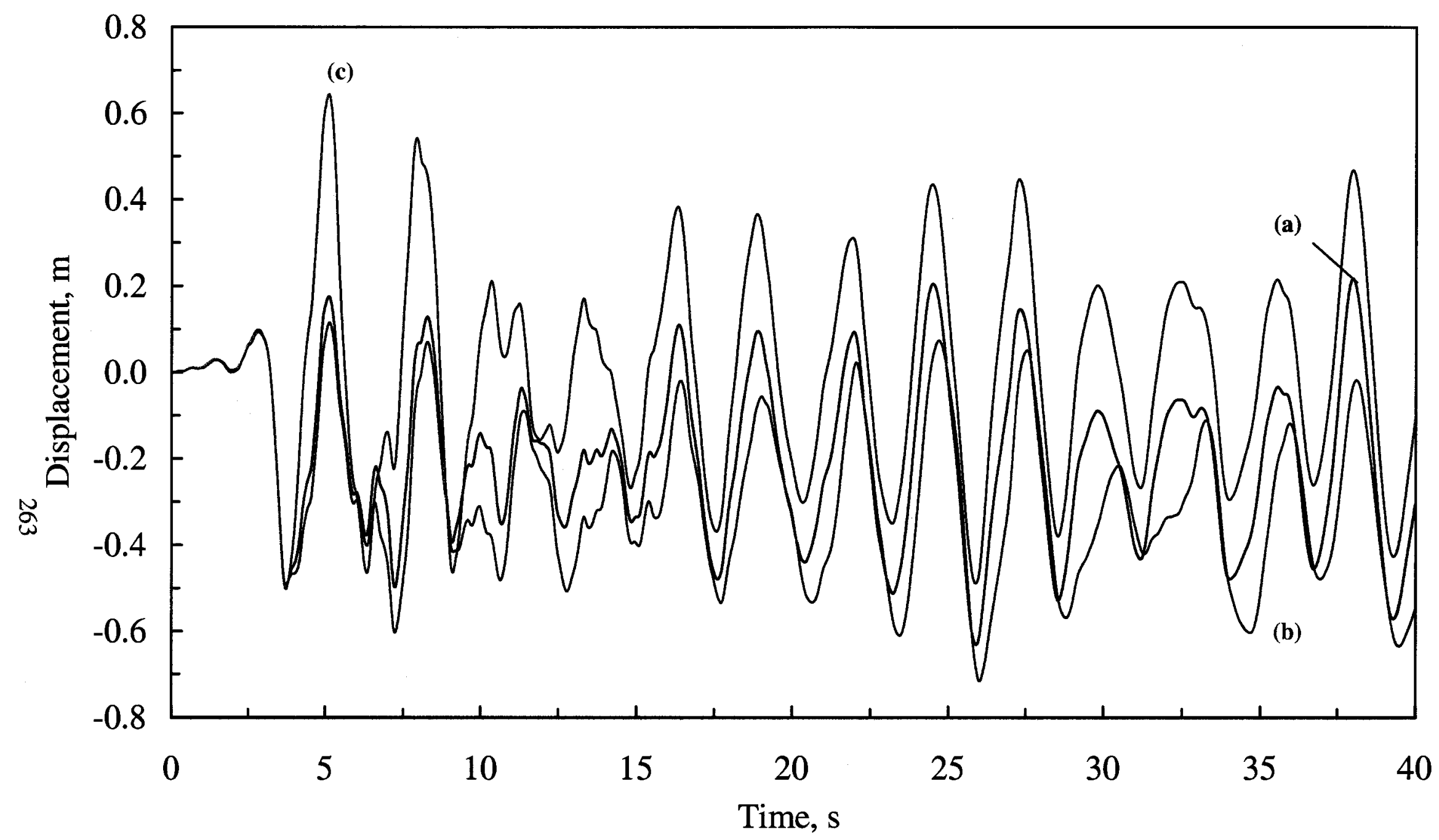

Fig. 5.41 History of lateral top frame displacement caused by Kern County 1952 ground motion (scale factor $=5.070$ ), (a) MRF inelastic response without P- $\Delta$, (b) MRF inelastic response with $\mathrm{P}-\Delta$, (c) MRF elastic response without $\mathrm{P}-\Delta$ 


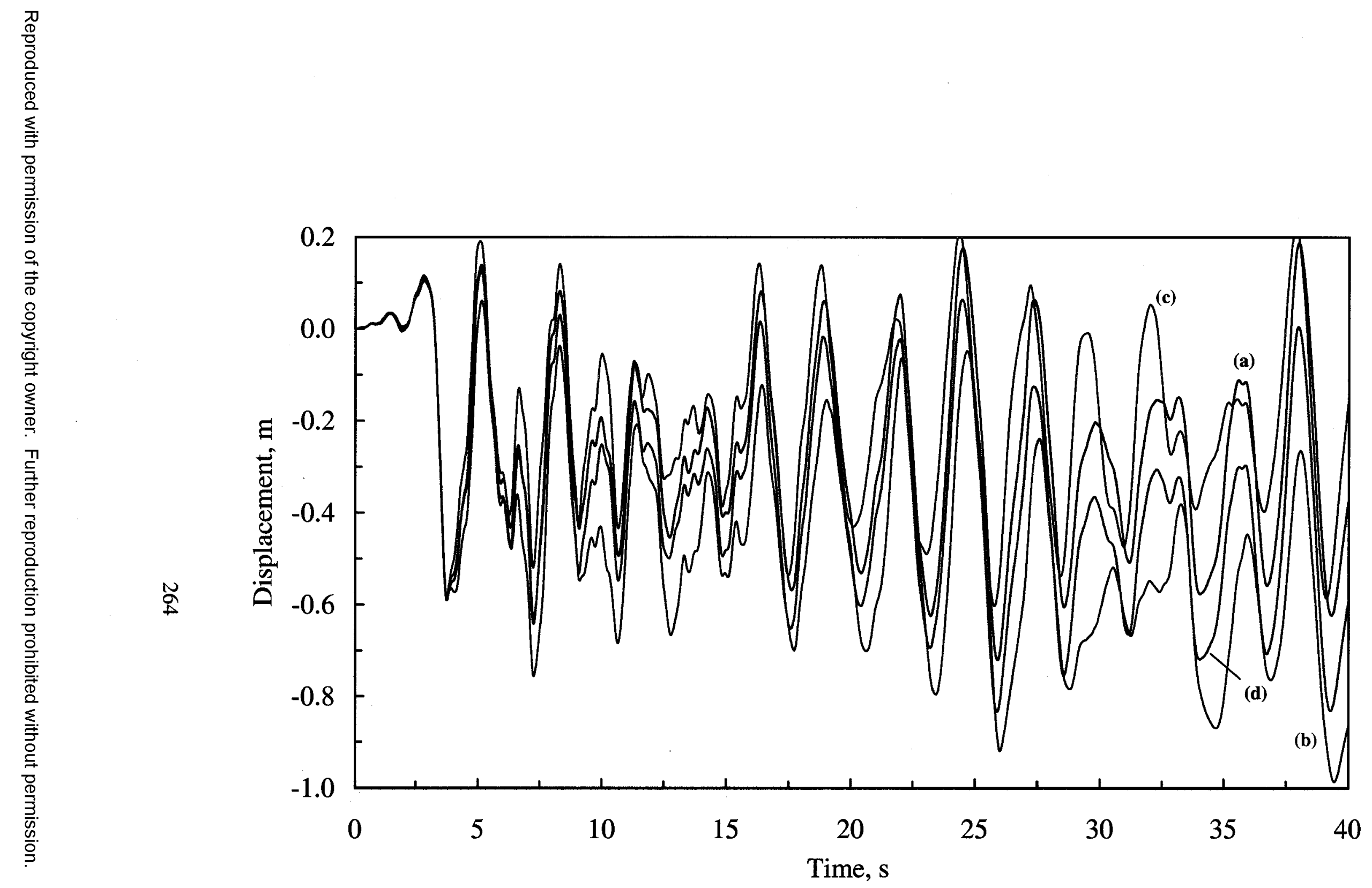

Fig. 5.42 History of lateral top frame displacement caused by Kern County 1952 ground motion (scale factor $=6.00$ ), (a) MRF without P- $\Delta$, (b) MRF with P- $\Delta$, (c) enhanced MRF without P- $\Delta$, (d) enhanced MRF with P- $\Delta$ 


\section{CHAPTER 6}

\section{SUMMARY AND CONCLUSIONS}

\subsection{INTRODUCTION}

The present work studies some important issues related to the design proposals developed for NBCC 2005. The current version of NBCC was issued in 1995. The level of seismic hazard in different regions of the country that formed the basis of 1995 NBCC was based on the catalogue of earthquakes until 1985. Since then many more earthquakes have been recorded. Also new relationships for calculating the attenuation of ground motion as it travels from the source to the site have been developed. These factors combined with improved knowledge of the tectonics of the country have led to a significant change in the manner in which the seismic hazard is represented, providing the main impetus for revisions to the seismic provisions of NBCC.

A number of issues related to the provisions in NBCC 2005 are discussed in the current study. The present work identifies the problems related to such issues, and attempts to develop solutions that are both rational and simple. The application of Uniform Hazard Spectra (UHS) in obtaining the seismic design forces is outlined in Chapters 1 and 2. Methods to account for higher mode effects on the base shear and development of adjustment 
factors for calculating the overturning moments are presented in Chapters 2 and 4. Code provisions for design against torsion are discussed in Chapter 3 . Impact of P- $\Delta$ effect is discussed in Chapter 5. The results presented in Chapters 2,3 and 4 have influenced the provisions of NBCC 2005 . The results related to $\mathrm{P}-\Delta$ effect should be helpful in designing to counter the P- $\Delta$ effect.

\subsubsection{Uniform Hazard Spectrum}

The seismic design provisions of the current NBCC 1995 require that buildings be designed to resist without collapse a base shear obtained from an idealized response spectrum for a single-degree-of-freedom. This idealized spectrum is derived from two ground motion parameters: the peak ground acceleration and the peak ground velocity for the seismic region in which the building is located. The spectral shape is obtained by applying suitable amplification factors to these ground motion bounds. It has been pointed out that this method of obtaining the design response spectra may involve significant errors, which can be as large as $300 \%$ (Atkinson, 1991). Methodologies have become available for deriving linear elastic spectra for a given site and for a given hazard level based on the knowledge of the seismicity of the area and ground motion attenuation relationships. Such spectra are called elastic Uniform Hazard Spectra (UHS). It may be noted that the standard spectrum provides the maximum spectral acceleration of a single-degree-of-freedom system with varying value of the period when excited by a single earthquake. On the other hand, a UHS represents the composite of spectral acceleration responses produced by several different earthquakes that contribute to the seismicity of the site and have varying magnitudes and source distances. It 
is apparent that UHS should be the preferred basis for seismic mapping when compared to the spectra derived indirectly from peak ground motion bounds, because the former provide response parameters that can be used directly in estimating the design earthquake forces. The revised picture of the seismicity of the country and the fact that it is best expressed in terms of UHS rather than peak ground motion values provide the main impetus for revisions being contemplated for the next version of NBCC.

\subsubsection{Higher Mode Effect}

The equivalent static procedures included in many seismic codes including NBCC 1995 specify that the elastic base shear be obtained from a design response spectrum using the first mode period of the structure under consideration. The elastic base shear is then reduced by a factor that reflects the capacity of the structure to undergo inelastic deformation without collapse. As stated earlier, a UHS provides the maximum spectral accelerations for a $5 \%$ damped single-degree-of-freedom system. Since the spectral acceleration values for different periods may be contributed by different earthquakes a UHS is not the same as the response spectrum of a single earthquake. Consequently when used in a modal analysis a UHS will provide somewhat conservative values of the response of a multi-degree-offreedom system. However, conservatism is not excessive and the results of such modal analysis can still be used for the purpose of design.

In an equivalent static procedure of design based on UHS the elastic base shear will be determined by finding the spectral acceleration corresponding to the first mode period of the structure. This processes ignores the effect of higher modes on response. Adjustment 
factors that must be applied to the base shear determined from the first mode period to obtain a better estimate are derived in the present study for several different structural types including moment-resisting frames, braced frames, flexural walls, coupled flexural walls and hybrid systems.

The corrected base shear can be distributed across the height according to the NBCC 1995 procedures. However, because the NBCC 1995 distribution is primarily in the form of the first mode, the resulting overturning moments generally overestimate the true moments which arise from a combination of various modes. Adjustment factors to be applied to the overturning moments determined from NBCC 1995 distribution are also derived in this study for the various structural types.

The following conclusions can be drawn from results presented in Chapter 2:

(1) The base shear adjustment factors $M_{v}$, and the overturning moment reduction factor $J$ are both dependent on the characteristics of the lateral force-resisting system. Factor $M_{\nu}$ is largest for a flexural wall system and smallest for a moment-resisting frame. On the other hand, $J$ is smallest for a flexural wall and largest for a momentresisting frame.

(2) Factors $M_{v}$ and $J$ also depend on the first mode period $T_{1}$. Thus $M_{v}$ increases with $T_{1}$ while $J$ decreases with $T_{1}$.

(3) Factors $M_{v}$ and $J$ strongly depend on the shape of the response spectrum. In comparison to the western regions of Canada, the UHS for the eastern regions drops more rapidly with periods. Thus the higher mode contribution is more predominant in 
east; as a consequence $M_{v}$ factors are larger and $J$ factors are lower for the eastern region.

(4) The distribution of shear across the height as specified in the current provision of NBCC 1995 is reasonable, but still underestimates the shear in the upper storeys while overestimating it in the lower storeys.

(5) The underestimation of shear in the upper storeys also leads to underestimation of the overturning moments. It is therefore proposed that the expression for $J_{x}$ be revised. A new formula for $J_{x}$ that is simpler than the current version is proposed.

(6) The dynamic behavior of a practical coupled flexural wall system is expected to be similar to that of a frame so that $M_{v}$ and $J$ factors for a moment-resisting frame can be applied to a coupled wall structure as well.

(7) The dynamic behavior of a practical hybrid system comprising a flexural wall and a moment-resisting frame is expected to be closer to that of a flexural wall so that factors $M_{v}$ and $J$ for a wall can be applied to the hybrid system too.

The higher mode factors presented in Chapter 2 are based on elastic response. To investigate the higher mode effect in MDOF structures, which are expected to be strained into the inelastic range, nonlinear dynamic time history analyses are carried out for two common structural types: moment-resisting frames and flexural walls. The UHS-2500 compatible records developed by Atkinson and Beresnev, (1998) for Vancouver and Montreal, representing the West and the East Canadian cities, are used in the analyses. Two different approaches are adopted in the iterative method of calculating the value of the 
strength modification factor: (a) modify the strength for all storeys; and (b) modify the strength for only the first storey.

The results of the nonlinear dynamic analyses of multistorey structures presented in Chapter 4 are qualitatively similar to the ones obtained from the linear dynamic analyses presented in Chapter 2. The following conclusions are obtained:

(1) The equivalent static procedures included in many seismic codes including NBCC 1995 do not fully account for the effect of higher modes on response. The results presented in this chapter show clearly that the ductility demands for MDOF systems differ significantly from those of associated SDOF systems. The implication is that the base shear strength capacities of MDOF systems must be modified from the inelastic strength demands of the equivalent SDOF systems, in order to limit the storey ductility demand to the desired target ductility. Adjustment factors that must be applied to the base shear determined from the first mode period are derived in this study to achieve the previous goal.

(2) Similar to the results of elastic analysis presented in Chapter 2, the strength modification factor is found to be dependent on the structure type and the type of ground motion. In addition, it also depends on the target ductility. It increases with an increase in the first mode period of the structure and the ductility ratio and is higher for eastern locations than western locations.

(3) Modifying the first storey strength alone often requires a higher strength modification factor compared to the other one when the strength for all storeys is modified. However, increasing only the strength of the first storey may be economically and practically more effective than increasing the strength of all storeys even though the amplification factor is 
higher.

(4) There is good agreement in the trend of $M_{v}$ factors obtained from the elastic dynamic and static analyses presented in Chapter 2 and the $M_{v m}$, and $M_{v o}$ factors obtained in Chapter 4 from the inelastic dynamic and static analyses. However, the latter factors are higher for both moment-resisting frame and flexural wall structural models and would be required to account for the impact of higher modes on the strength demands in inelastic multistorey buildings.

\subsubsection{Torsional Response}

This study presents the results obtained from the analyses conducted to study the elastic torsional response of a variety of asymmetric multistorey buildings of general class in which the ratios of torsional to translational stiffness vary significantly along the height of the building. Response spectrum dynamic analysis is carried out to obtain the exact response of the buildings. The results obtained from dynamic analysis are then compared to the results obtained according to design provisions proposed by Humar and Kumar (1998a). The dynamic analysis results are also compared to those of single storey buildings.

The main conclusions derived from this study are summarized as follows:

(1) The response values obtained from the analysis of corresponding single storey models do not match the response values obtained from the dynamic analysis of the multistorey buildings of general class.

(2) When the design eccentricity provisions proposed by Humar and Kumar (1998a) are applied, the response values obtained from the static analysis of the multistorey buildings of general class provide a conservative estimate of flexible edge interstorey 
displacements in multistorey buildings for all values of frequency ratio, $\Omega_{R}$ and eccentricity, $e / b$. For stiff edge, the values are again conservative except for $\Omega_{R}=1.00$ for which the proposed design provisions underestimate the response values obtained from the dynamic analysis of multistorey buildings.

(3) The alternative method of measuring torsional sensitivity, which is based on the ratio of maximum floor edge displacement to the average floor displacement, is a satisfactory procedure.

\subsubsection{P- $\Delta$ Effect}

Nonlinear static and dynamic analyses under earthquake ground motions have been carried out on single and multistorey frames to assess the effect of P- $\Delta$. A single storey and a 10-storey steel moment-resisting frames have been studied to evaluate the efficiency of proposed equations for calculating the amplification factors to account for $\mathrm{P}-\Delta$ effect. Five ground motions have been used in these analyses. The main findings of the study are summarized as follows:

(1) The P- $\Delta$ effect results in an increase in the lateral deformations of the structure and may lead to instability whenever it causes the second branch of the forcedisplacement relationship to have a negative slope. Instability is more likely if the response has gone far into the inelastic range and the duration of the ground motion is long.

(2) Several measures may mitigate the effect of P- $\Delta$. A decrease in the stability factor is helpful in improving the performance of building structures. A decrease in 
expected ductility demand obtained by increasing the strength may also be helpful in some cases.

(3) Increasing the strain hardening to be equal or higher than the stability factor would improve the response against P- $\Delta$ because the second branch will still have a positive slope and instability would be less likely. When the strain hardening is selected to be higher than the stability factor, there is no need to enhance the frame strength or stiffness to reduce the effect of P- $\Delta$. For an elasto-plastic force displacement relationship or when the strain hardening is less than the stability factor, enhancement of both strength and stiffness according to the proposed equations would help but does not guarantee against instability.

(4) The ground motion duration has a great effect on P- $\Delta$. The longer the ground motion duration the greater is the effect of $\mathrm{P}-\Delta$.

(5) The proposed P- $\Delta$ amplification factors are generally effective in enhancing the response and guarding against post-earthquake instability of single and multistorey moment-resisting frames. However, as stated earlier, when the strain hardening is sufficient to ensure a positive post-yield slope in the force-displacement relationship enhancement is not necessary.

(6) A conservative method is proposed to find out whether or not P- $\Delta$ effect will cause instability in a MDOF system, without performing an inelastic analysis. The procedure is to obtain the maximum displacement from an elastic spectrum of the earthquake corresponding to the first mode period, and to assume that the inelastic displacement will be similar. This equal displacement concept is known to be 
reasonable for long period structures. For short period structures, equal energy concept described in the literature may be used. However, P- $\Delta$ effect is more predominant in taller structures with long periods. A push over analysis is then performed to obtain the displacement corresponding to the limit beyond which instability would occur. If the inelastic displacement determined as outlined above is found to be smaller than the displacement at this limit, instability due to P- $\Delta$ effect is not likely, otherwise instability may occur and strengthening may be required.

\subsection{RECOMMENDATIONS FOR FUTURE WORK}

Earthquake resistant design of structures is a challenging task on account of the many uncertainties involved. The effect of many structural and loading parameters need to be further explored. The current study focuses only on a small part of the problem. Based on the analytical investigation conducted in this study, the following recommendations for further research are made:

(1) Development of an empirical relationship for producing inelastic SDOF response spectra would be useful. Such spectra could be developed from UHS compatible time histories developed by Atkinson and Beresnev (1998).

(2) Further studies are needed to investigate the applicability of the proposed design eccentricity provisions on torsionally unbalanced multistorey structures, such as buildings with setbacks and to develop modifications, if required.

(3) A study is required to develop an expression for height wise lateral load distribution that accounts for the effect of higher modes. 
(4) Further studies are needed on multistorey building structures to fully determine whether or not P- $\Delta$ amplification factor is required or is helpful in all cases. The future work should include wider selection of earthquake ground motions and other types of buildings. The applicability of the procedure based on the determination of a pushover curve and comparison of the maximum inelastic top displacement of the building with the limit of stability indicated on the pushover curve needs to be studied further through analyses of different structural systems of varying heights and for a range of earthquakes. 


\section{REFERENCES}

Adams, J., Weichert, D. H., and Halchuck, S. 2003. Fourth Generation Seismic Hazard Maps of Canada: Values for Over 650 Canadian Locations Intended for the 2005 National Building Code of Canada. Geological Survey of Canada Open file 4459.

Atkinson, G. M. 1991. Use of the Uniform Hazard Spectrum in Characterizing Expected Levels of Seismic Ground Shaking. $6^{\text {th }}$ Canadian Conference on Earthquake Engineering, Toronto, ON. pp. 469-476.

Atkinson, G. M., and Beresnev, I. A. 1998. Compatible Ground Motion Time-histories for New National Hazard Maps. Canadian Journal of Civil Engineering, April 1998.

Bernal, D. 1987. Amplification Factors for Inelastic Dynamic P- $\Delta$ Effects in Earthquake Analysis. Earthquake Engineering and Structural Dynamics, 15, 635-651.

Canadian Institute of Steel Construction. 2000. Handbook of Steel Construction. Seventh Edition.

Canadian Standards Association. 1994. A23.3-94 Design of Concrete Structures. Toronto, Ontario, Canada.

Chopra, A. K. 1995. Dynamics of Structures; Theory and Applications to Earthquake Engineering. Prentice Hall, New Jersey.

De La Llera, J. C. and Chopra, A. K. 1994a. Accidental and Natural Torsion in Earthquake Response and Design Buildings. Report No 94/07, Earthquake Engineering Research Centre, University of California, Berkeley, California.

De La Llera, J. C. and Chopra, A. K. 1994b. Evaluation of Code Accidental Torsion Provisions From Building Records. ASCE Journal of Structural Engineering. Vol. 120 No. 2, pp. 597-616.

Gupta, A. and Krawinkler, H. 2000. Dynamic P-Delta Effects for Flexible Inelastic Steel Structures. ASCE Journal of Structural Engineering, Vol. 126, No. 1, pp. 145-154. 
Humar, J. L. 2002. Dynamics of Structures, Second Edition. Swets and Zeitlinger, Netherlands, $970 \mathrm{pp}$.

Humar, J. L. and Kumar, P. 1998a. Torsional Motion of Buildings During Earthquakes. I. Elastic Response. Canadian Journal of Civil Engineering, 25, pp. 898-916.

Humar, J. L. and Kumar, P. 1998b. Torsional Motion of Buildings During Earthquakes. II. Inelastic Response. Canadian Journal of Civil Engineering, 25, pp. 917-934.

Humar, J. L. and Mahgoub, M. A. 2000. Accounting for Higher Mode Effects in UHS Based Design. Discussion paper, Canadian National Committee on Earthquake Engineering (CANCEE).

Humar, J. L. and Mahgoub, M. A. 2001. Seismic Design Provisions Based on Uniform Hazard Spectrum. International Conference on Structural Engineering, Mechanics and Computation, Cape Town, South Africa, pp. 1313-1320.

Humar, J. L. and Mahgoub, M. A. 2001. Future Directions of Seismic Design Provisions in NBCC. $29^{\text {th }}$ Annual Conference of the Canadian Society for Civil Engineering, Victoria, British Columbia.

Humar, J. L. and Mahgoub, M. A. 2003. Determination of Seismic Design Forces by Equivalent Static Load Method. Canadian Journal of Civil Engineering, Vol. 30, 2003, pp. 287-307.

Humar, J. L. and Rahgozar, M. A. 1996. Application of Inelastic Response Spectra Derived from Seismic Hazard Spectral Ordinates for Canada. Canadian Journal of Civil Engineering, 23, pp. 1051-1063.

Humar, J. L. and Rahgozar, M. A. 2000. Application of Uniform Hazard Spectra in Seismic Design of Multistorey Buildings. Canadian Journal of Civil Engineering, 27, pp. 1-18.

Kan, C. L., and Chopra, A. K. 1976. Coupled Lateral Torsional Response of Buildings to Ground Shaking. Earthquake Engineering Research Centre, University of California Berkeley, California., Report No. 76-13.

Kumar, P. 1998. Torsional Response of Buildings During Earthquake. PhD Thesis. Department of Civil and Environmental Engineering, Carleton University, Ottawa, Ontario, Canada.

Mahgoub, M. A. and Humar, J. L. 2001. Effect of Higher Mode in UHS-Based Design. Earthquake Engineering Research Institute, EERI, Annual Meeting. February 7-10, Monterey, California, USA.

Maison, B. F. and Neuss, C. F. 1983. SUPER-ETABS, An Enhanced Version of the ETABS Program. A report to the National Science Foundation, J. G. Bouwkamp Inc., Engineering Research Centre, University of California, Berkeley, California, USA. 
Montgomery, C. J. 1981. Influence of P- $\Delta$ Effects on Seismic Design. Canadian Journal of Civil Engineering, 8, pp. 31-43.

National Building Code of Canada, NBCC 1995. Canadian Commission on Building and Fire Codes, National Research Council of Canada, Ottawa, Ontario, Canada.

Nasser, A. A. and Krawinkler, H. 1991. Seismic Demand for SDOF and MDOF Systems. John A. Blume Earthquake Centre, Stanford University, Stanford, California, USA. Report No. CA94305-4020.

Naumoski, N., Tso, W. K., and Heidebrecht, A. C. 1988. A Selection of Representative Strong Motion Records Having Different a/v Ratios. EERG Report 88-01, McMaster University, Hamilton, Ontario, Canada.

NEHRP Recommended Provisions for Seismic Regulations for New Buildings and Other Structures 2000. Issued by FEMA in Furtherance of the Decade for Natural Disaster Reduction, USA.

New Zealand Standard. 1992. Code of Practice for General Structural Design and Design Loadings for Buildings, NZS4203. Standards Association of New Zealand. Wellington, New Zealand.

Paulay, T. 1978. A Consideration of P- $\Delta$ effects in Ductile Reinforced Concrete Frames. Bulletin of the New Zealand National Society for Earthquake Engineering, 11-3, pp. 151-160.

Paulay, T. 1998a. A Mechanism-based Design Strategy for torsional Seismic Response of Ductile Buildings. European Earthquake Engineering, 2, pp. 33-48.

Paulay, T. 1998b. Torsional Mechanisms in Ductile Building Systems. Earthquake Engineering and Structural Dynamics, 27, pp. 1011-1121.

Prakash, V. and Powell, G. H. 1993. DRAIN-2DX, Version 1.02, User Guide. Earthquake Engineering Research Centre, University of California, Berkeley, California, USA.

SAP2000. Version 6.1. 1997. Integrated Finite Element Analysis and Design of Structures. A Product of Computers and Structures, Inc. Berkeley, California, USA.

Tremblay, R., Cote, B. and Leger, P. 1999. An Evaluation of P- $\Delta$ Amplification Factors in Multistorey Steel Moment Resisting Frames. Canadian Journal of Civil Engineering, 26, pp. 535548.

Tso, W. K. and Asmis, K. G. 1971. Torsional Vibration of Symmetric Structures. Proceedings, First Canadian Conference on Earthquake Engineering, Vancouver, pp. 178-186. 
Tso, W. K. and Dempsey, K. M. 1980. Seismic Torsional Provisions for Dynamic Eccentricity. Earthquake Engineering and Structural Dynamics, 8, pp. 275-289.

Uniform Building Code 1997. International Conference of Building Officials, Pasadena, California, USA. 